\title{
Data Recovery Excavations at 41PR44, Fort Wolters, Parker County, Texas
}

\author{
Raymond P. Mauldin \\ Center for Archeological Research, University of Texas at San Antonio \\ Antonia L. Figueroa \\ Center for Archeological Research, University of Texas at San Antonio
}

Follow this and additional works at: https://scholarworks.sfasu.edu/ita

Part of the American Material Culture Commons, Archaeological Anthropology Commons, Environmental Studies Commons, Other American Studies Commons, Other Arts and Humanities Commons, Other History of Art, Architecture, and Archaeology Commons, and the United States History Commons

Tell us how this article helped you.

This Article is brought to you for free and open access by the Center for Regional Heritage Research at SFA ScholarWorks. It has been accepted for inclusion in Index of Texas Archaeology: Open Access Gray Literature from the Lone Star State by an authorized editor of SFA ScholarWorks. For more information, please contact cdsscholarworks@sfasu.edu. 


\section{Data Recovery Excavations at 41PR44, Fort Wolters, Parker County, Texas \\ Creative Commons License \\ (c) (1) (9)}

This work is licensed under a Creative Commons Attribution-NonCommercial 4.0 International License 


\section{Data Recovery Excavations at 41PR44, Fort Wolters, Parker County, Texas}

$B Y$

Raymond P. MAULdin AND Antonia L. Figueroa

WITH CONTRIBUTIONS BY

Russell D. Greaves and Barbara A. MeIssner

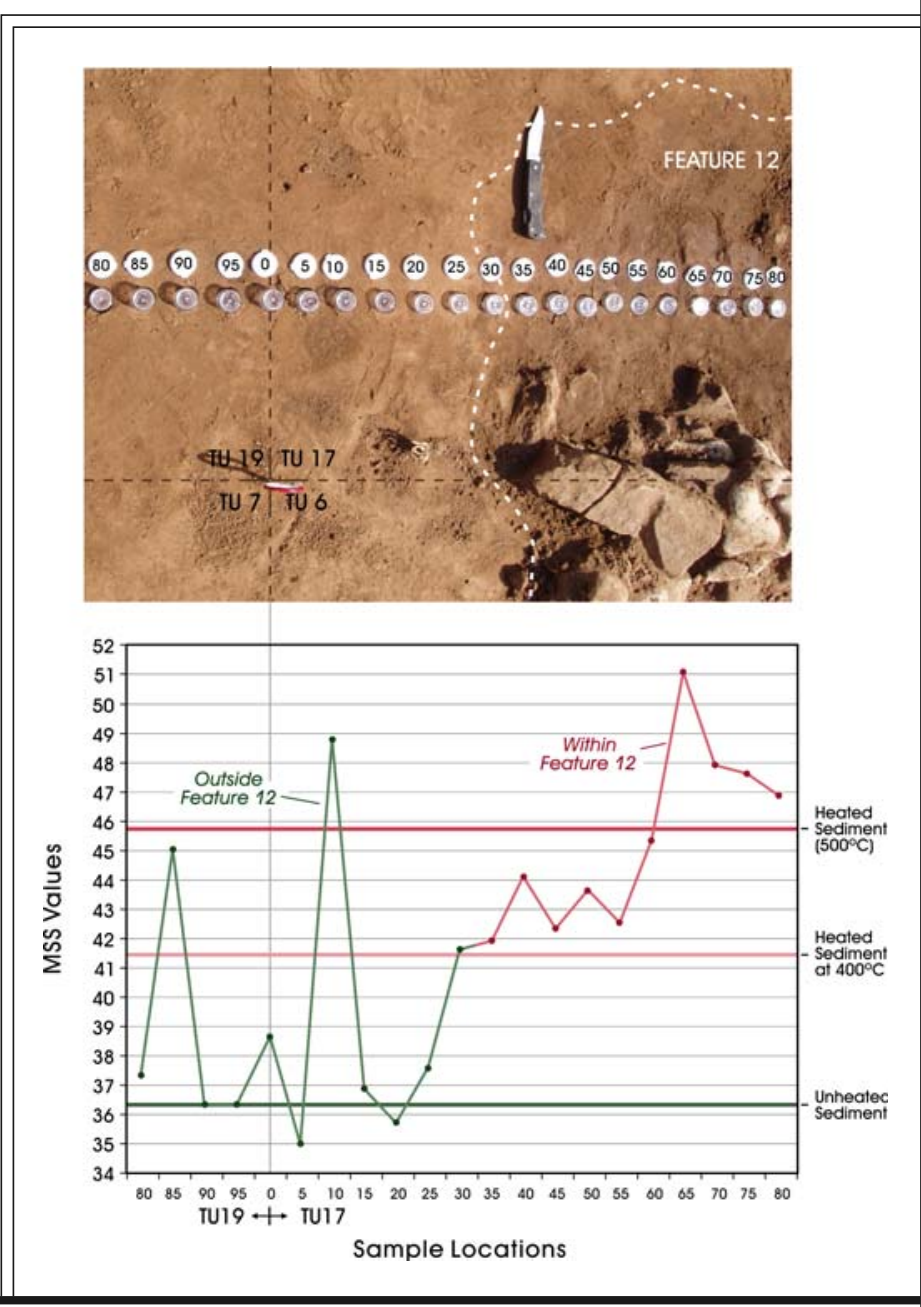

Archaeological Report, No. 369

Center for Archaeological Research

The University of Texas at San Antonio

हे C)2006 
$+1$

$1 \underline{ }$

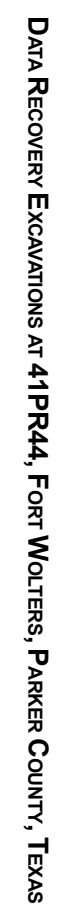

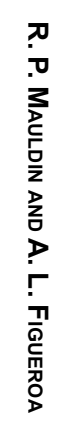

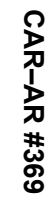

ธัธุำ

$\square$

$1 \bar{F}$ 


\title{
Data Recovery Excavations at 41PR44, Fort Wolters, Parker County, Texas
}

\author{
by \\ Raymond P. Mauldin and Antonia L. Figueroa \\ with contributions by \\ Russell D. Greaves and Barbara A. Meissner \\ Principal Investigator \\ Steve A. Tomka \\ prepared for \\ Adjutant General's Department \\ Texas Military Forces \\ Camp Mabry, Austin \\ under \\ Interagency Cooperation Agreement TX03=ENV-17 401-3-3736

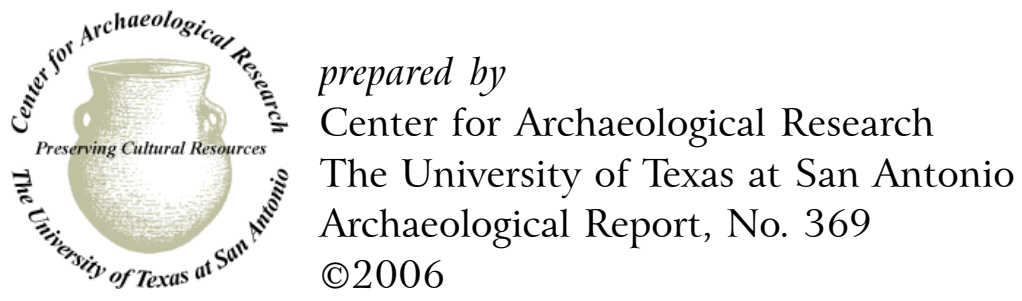


On the cover: Figure 10-5. Mass-specific magnetic soil susceptibility values through Feature 12. See discussion, Chapter 10: Burned Rock Features.

A list of publications offered by the Center for Archaeological Research is available. Call (210) 458-4378; write to the Center for Archaeological Research, The University of Texas at San Antonio, One UTSA Circle, San Antonio, Texas 78249-1644; e-mail to car@utsa.edu; or visit CAR's web site at http://car.utsa.edu. 


\section{Abstract}

During the spring of 2004, the Center for Archaeological Research (CAR) of The University of Texas at San Antonio conducted data recovery excavations at site 41PR44 on Fort Wolters. The site had been surveyed and tested by the Texas Archeological Research Laboratory (Brownlow 2001; Brownlow et al. 1999). The results of that testing suggested that the site contained a high density of burned rock features, chipped stone, and bone that dated to the Late Prehistoric period, with additional material possibly dating to the Late Archaic. Based on the testing, site 41PR44 was recommended as eligible for inclusion on the National Register of Historic Places under Criterion D. The site has been directly impacted by military traffic, and secondary erosion associated with a dirt road that cut through the center of the site has further damaged 41PR44. As continued use and maintenance of the road would result in continued erosion of the significant deposits, and as avoidance of this site area was not possible, CAR was contracted by the Adjutant General's Office of the Texas Military Forces to develop a data recovery plan that targeted critical data from the Late Prehistoric, and potentially earlier, occupations. That plan was produced in early 2004, and field work was undertaken in March and April. The work was conducted under a Memorandum of Agreement (MOA) between the Texas Military Forces and the Texas Historical Commission.

CAR personnel excavated 46 shovel and hand-auger tests, 24 1-x-1-m units, and cut four backhoe trenches. We defined 12 thermal features in the field, but subsequent analysis reduced this number to three. A variety of artifacts were collected, including large quantities of sandstone and limestone rock, a variety of lithic tools, 883 pieces of chipped stone debitage, sediment samples, and small quantities of bone, charcoal, and mussel shell. We identified several occupation periods at the site, including use of the location during the Late Prehistoric and Late Archaic periods, as well as earlier Archaic use. The distribution of projectile points, as well as the assessment of context by the project geoarchaeologists, demonstrated that several areas of the site were mixed. Nevertheless, we were able to isolate Late Prehistoric, Late Archaic, and Archaic age deposits that were used to explore a variety of research areas, including aspects of subsistence, chipped stone technology, and feature technology. While limited by less than ideal temporal resolution and low recovery rates, the analysis of the 41PR44 data provides a basic description of archaeological material for this understudied portion of Texas.

Following laboratory processing and analysis, and in consultation with both the Texas Military Forces and the Texas Historical Commission, selected samples and certain classes of materials collected from 41PR44 were discarded. This discard was in conformance with Texas Historical Commission guidelines. Material disposed of included all sandstone and limestone rock collected from non-feature contexts, as well as roughly $75 \%$ of all feature rock. All sediment samples not associated with features were discarded as were all metal items. All remaining archaeological samples collected by CAR, along with all associated documents, notes, and photographs, were prepared for permanent curation at the Texas Archaeological Research Laboratory in Austin. 


\section{Table of Contents}

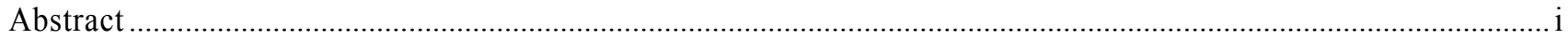

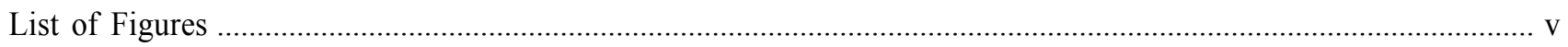

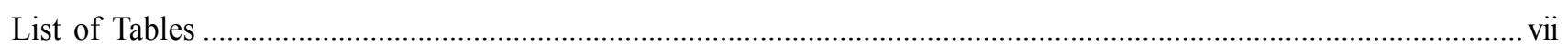

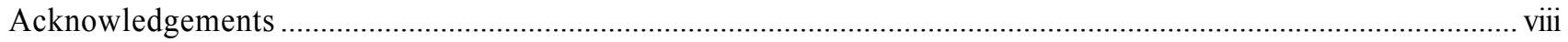

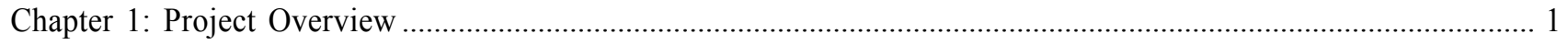

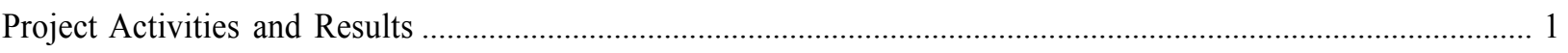

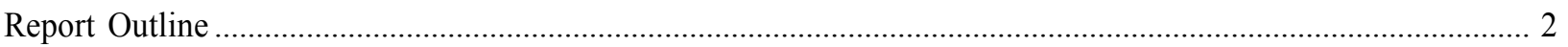

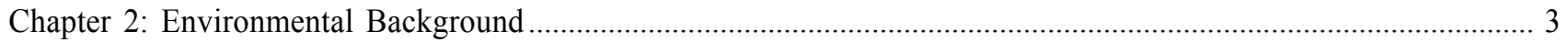

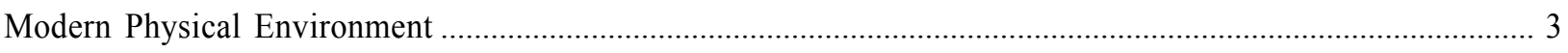

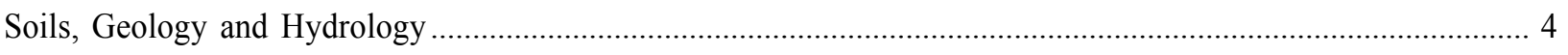

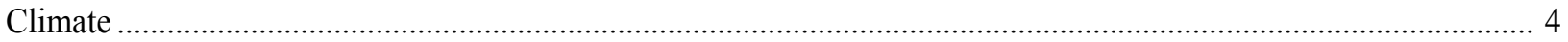

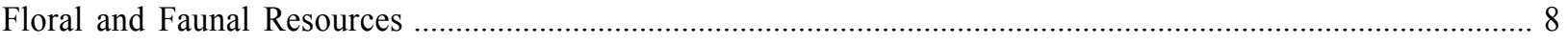

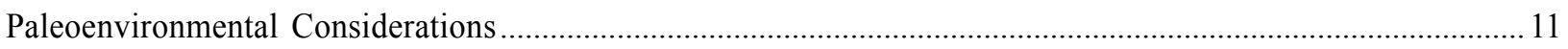

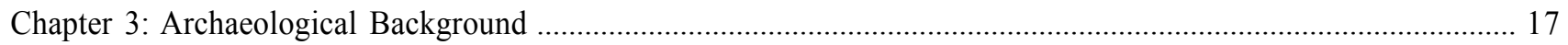

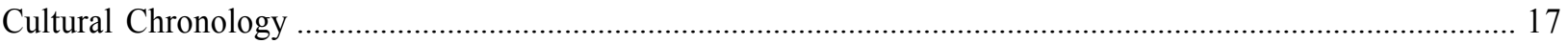

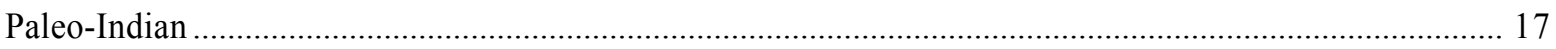

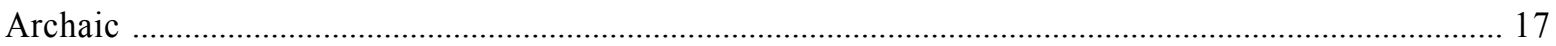

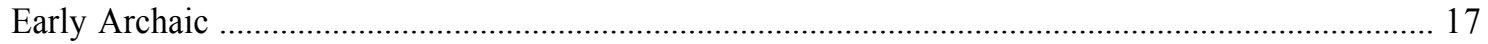

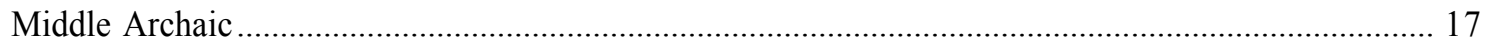

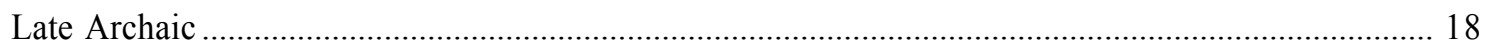

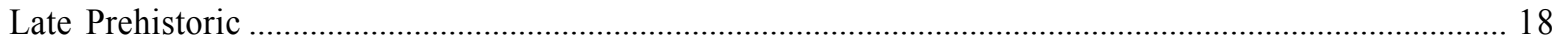

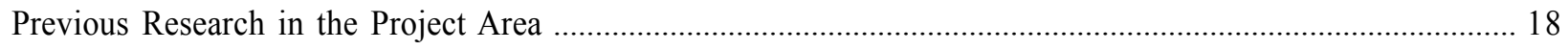

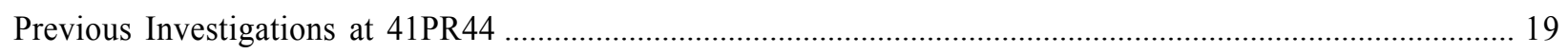

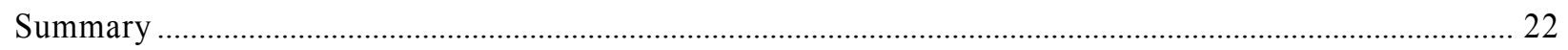

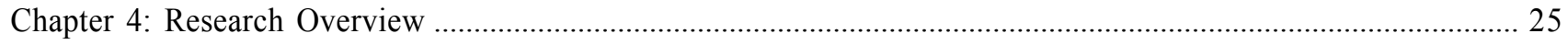

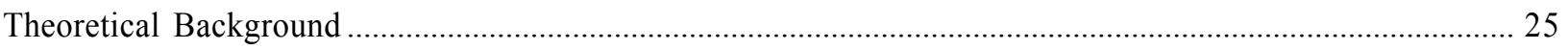

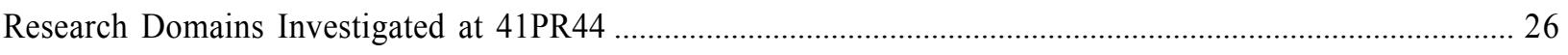

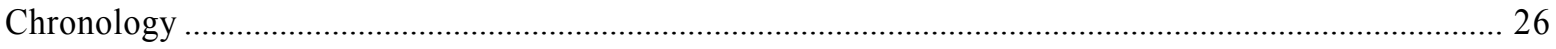

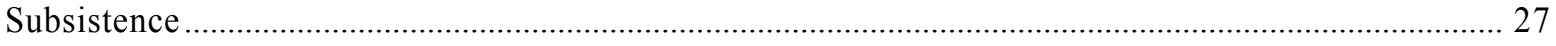

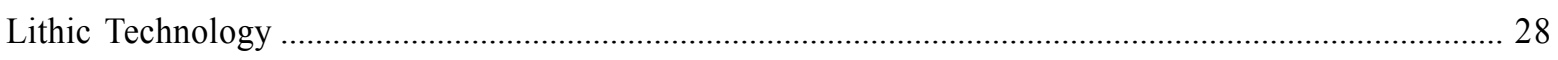

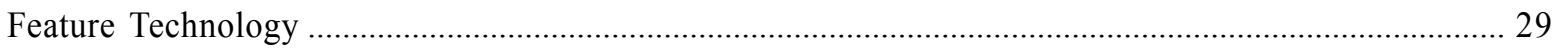

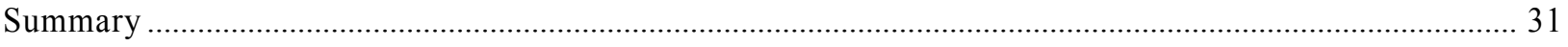

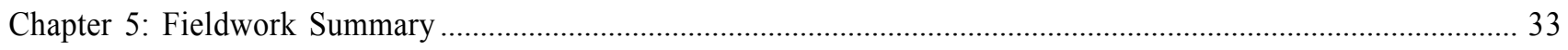

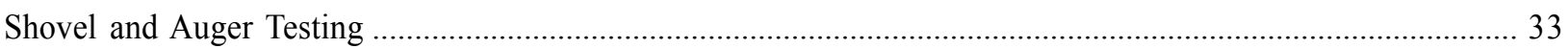




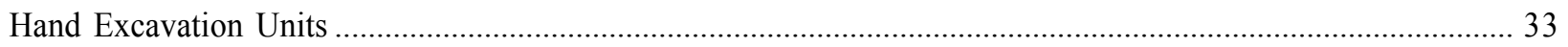

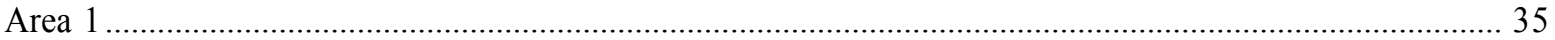

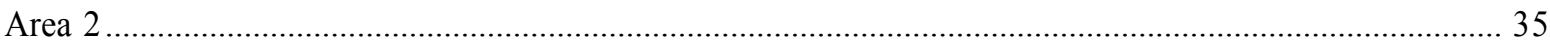

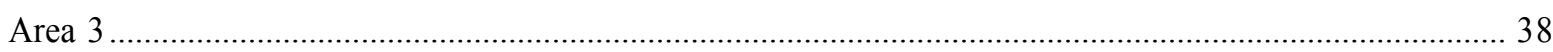

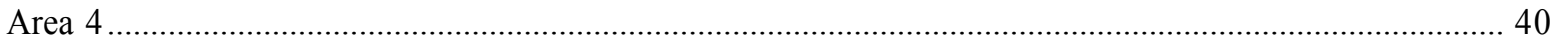

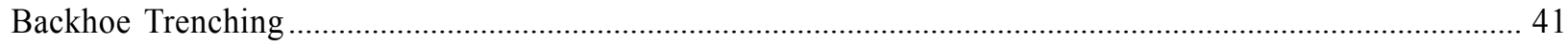

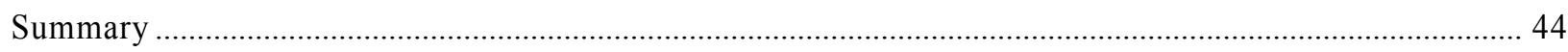

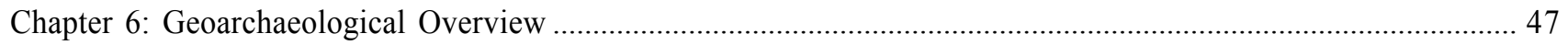

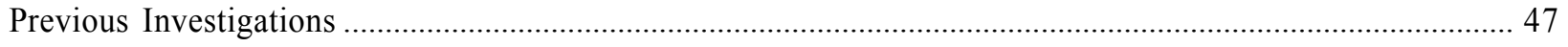

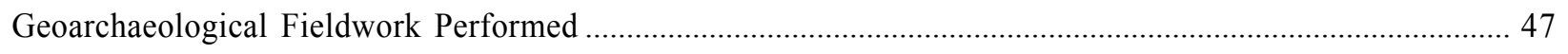

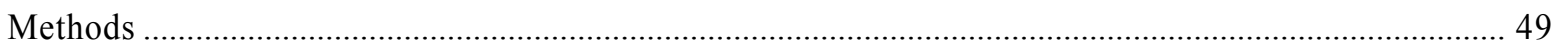

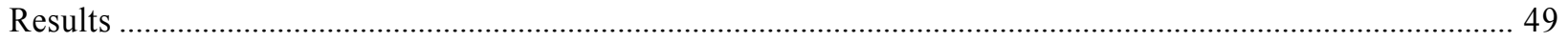

Examination of Previous Excavations ………….................................................................................. 49

Examination of CAR Excavations and Backhoe Trenches ..................................................................... 50

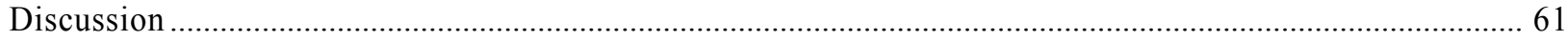

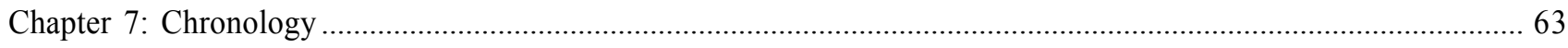

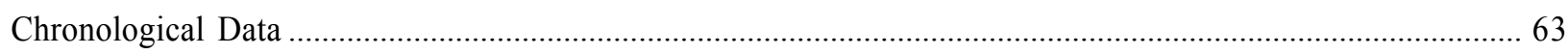

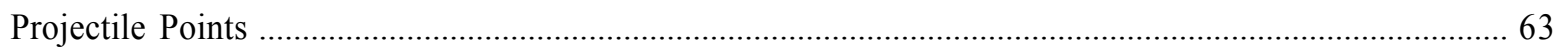

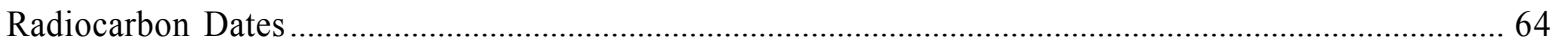

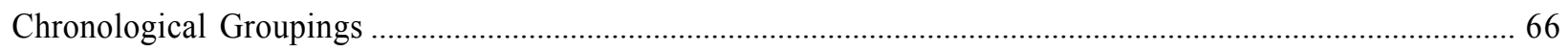

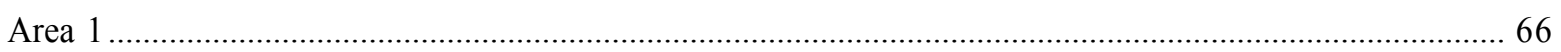

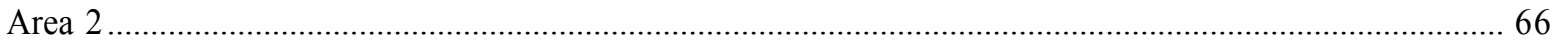

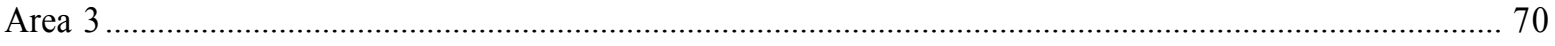

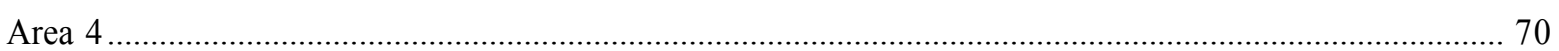

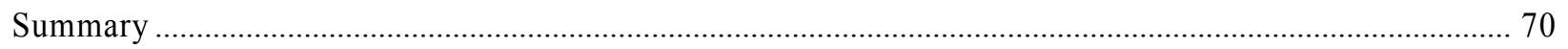

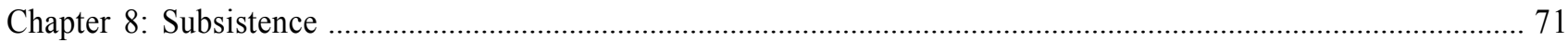

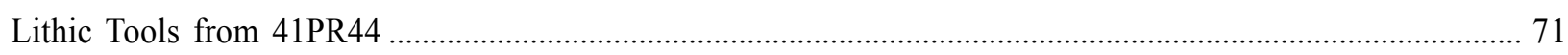

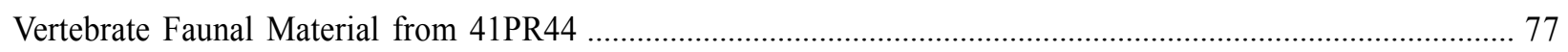

Site Level Descriptive Data ........................................................................................................... 78

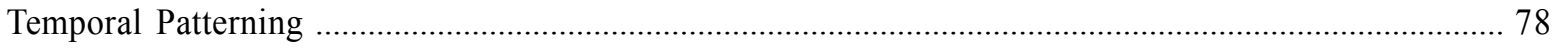

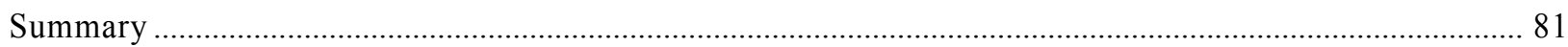

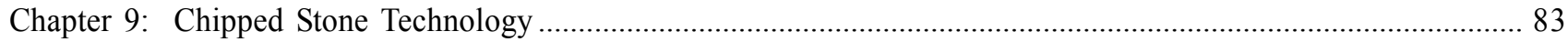

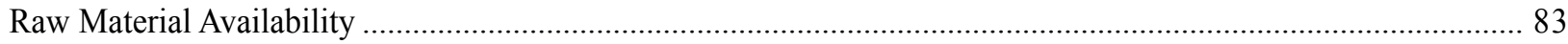

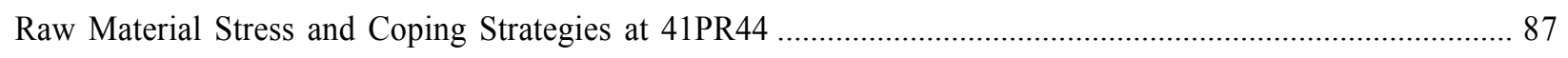

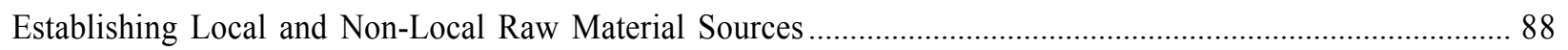

The Late Archaic and Early Late Prehistoric Patterns at 41PR44 .................................................................... 94 


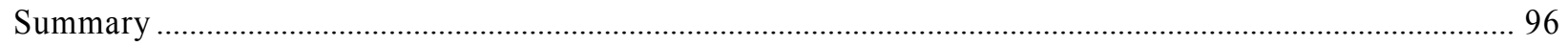

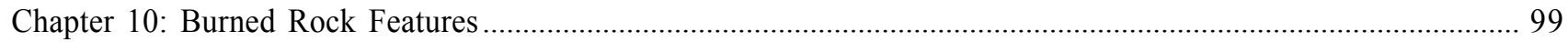

Identifying Burned Rock and Thermal Features with Magnetic Susceptibility ................................................. 99

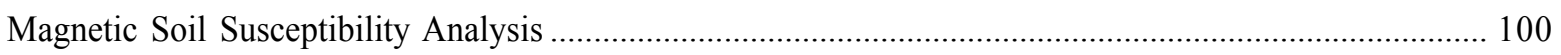

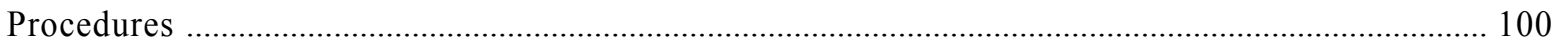

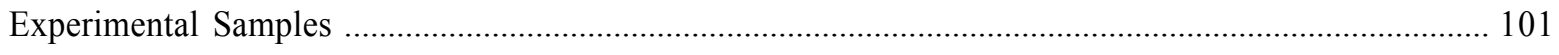

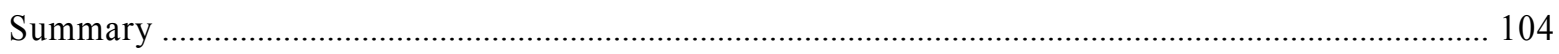

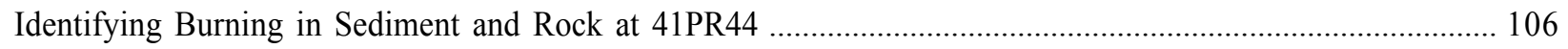

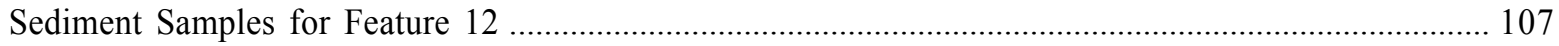

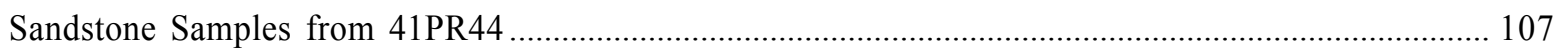

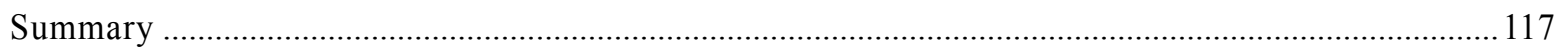

Attributes and Patterning in Burned Rock Features at 41PR44 ……............................................................... 117

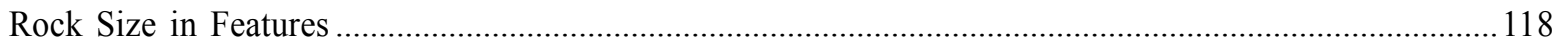

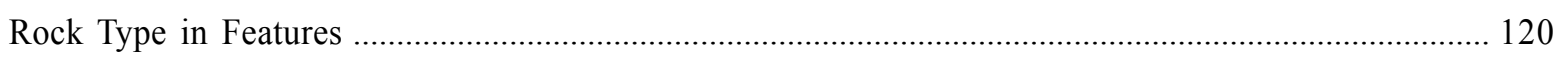

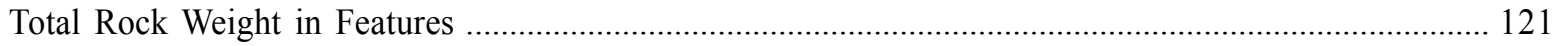

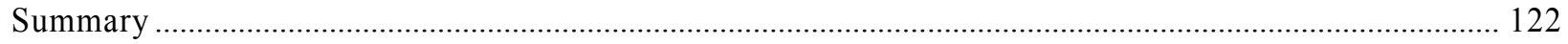

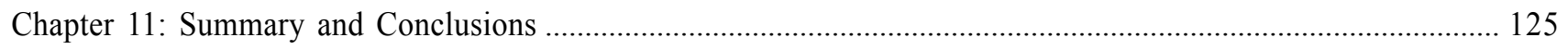

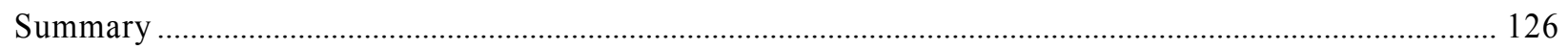

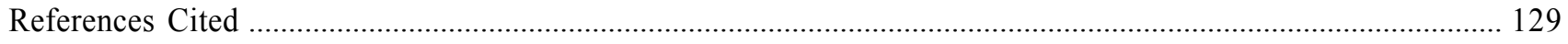

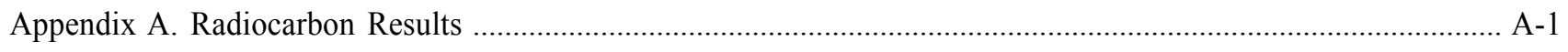

Appendix B. Vertebrate Faunal Remains ..................................................................................................... B-1

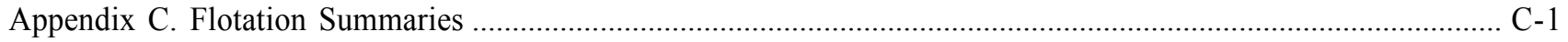

Appendix D. Memorandum of Agreement for Recovery of Significant Information from Archeological Site 41PR44, Ft. Wolters, Mineral Wells, Parker County, Texas .................................................................. D-1 


\section{List of Figures}

Figure 2-1. Fort Wolters Texas Army National Guard training area. ................................................................. 3

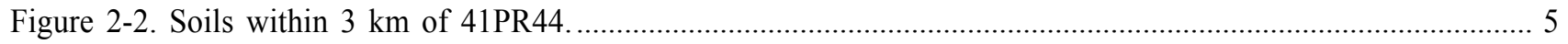

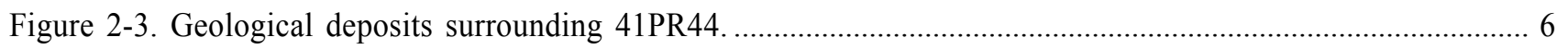

Figure 2-4. View of Rock Creek looking northeast adjacent to site 41PR44. Photograph taken spring 2004 ........ 7

Figure 2-5. Yearly average streamflow $\mathrm{ft}^{3} / \mathbf{s}$ for the Brazos River below Rock Creek (1969-2003). ....................... 7

Figure 2-6. Mineral Wells 30 year normal precipitation (1971-2000).................................................................... 9

Figure 2-7. Mineral Wells 30 year normal average monthly temperature (1971-2000). ......................................... 9

Figure 2-8. Natural regions of Texas showing the location of 41PR44 within the Cross Timbers area. ................. 10

Figure 2-9. Diversity of small, medium, and large mammals within Texas (Cross Timbers area identified in red

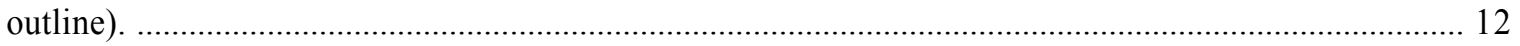

Figure 2-10. Possible core area of Bison bison in Texas (after Mauldin et al. 2006). ........................................... 13

Figure 2-11. Pedogenic carbon isotope data from the Aubrey Site (41DN479) plotted against estimated age........ 14

Figure 2-12. Poaceae pollen percentages from Boriack and Patschke Bogs. ........................................................... 15

Figure 3-1. View of 41PR44 looking toward the southwest. ............................................................................... 20

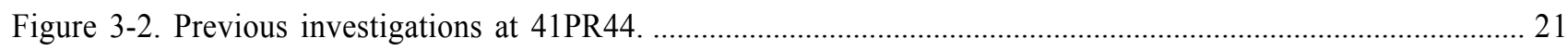

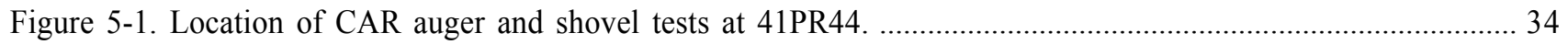

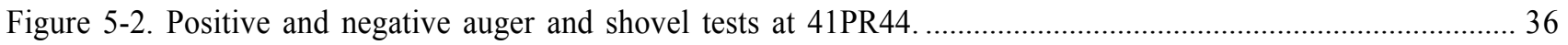

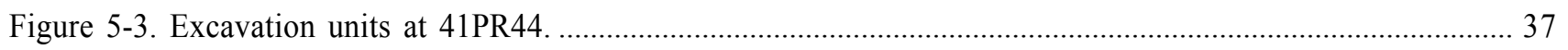

Figure 5-4. Area 2 after excavation, view toward the southeast............................................................................ 39

Figure 5-5. Test Unit 23 with TARL Backhoe Trench 12 outlined in white. .......................................................... 40

Figure 5-6. Feature 12 in Area 4 looking toward the west. .................................................................................. 42

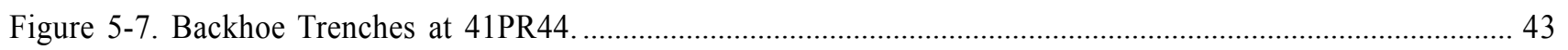

Figure 5-8. Feature 21: (a) South wall profile of Backhoe Trench 1; (b)Test Units 30 and 29. ........................... 45

Figure 6-1. Locations of excavation units and backhoe trenches at 41PR44 ....................................................... 48

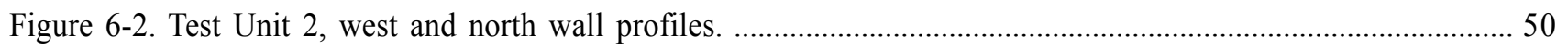

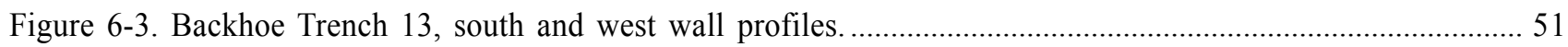

Figure 6-4. Test Units 16, 13, 24, 27, and 28, south wall profile ............................................................... 51

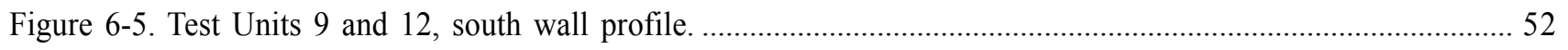

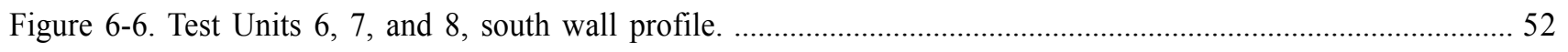

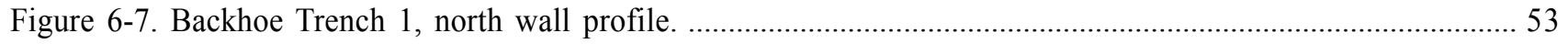

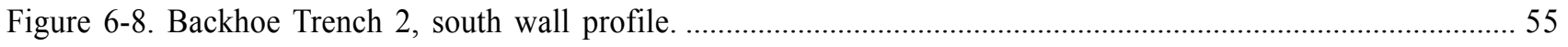

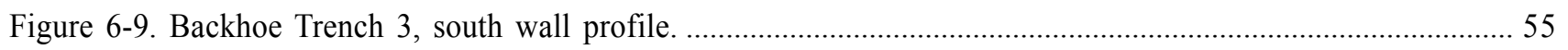

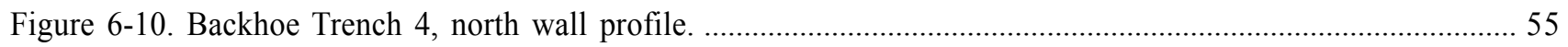

Figure 7-1. Late Prehistoric projectile points recovered from 41PR44: (a-c) Scallorn; (d-e) untyped arrow points; (f) untypable fragment. 
Figure 7-2. Dart points recovered from 41PR44: (a,b) consistent with Marshall; (c) Bulverde; (d) consistent with Dawson; (e) consistent with Hoxie; (f, g) untyped; (h) possible Wells; (i) possible Marshall; (j) Martindale.

Figure 7-3. Calibrated radiocarbon dates from 41PR44. Top calibration is from Area 3, TU 28, at 1.46 meters below datum. Bottom shows all associated dates. ............................................................................. 67

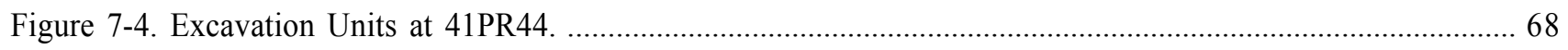

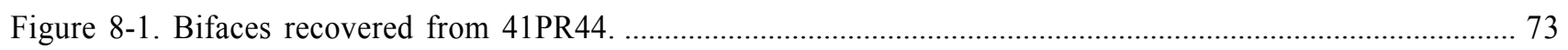

Figure 8-2. Edge-modified and unifacially retouched tools from 41PR44. ......................................................... 74

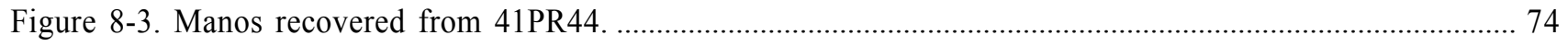

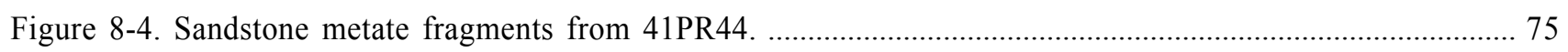

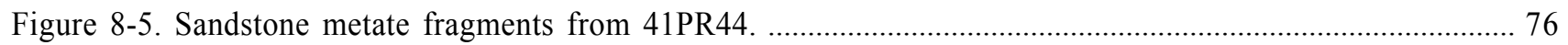

Figure 8-6. Comparsions of two ground stone indices from 26 sites (see Table 8-1). Triangles reflect sites

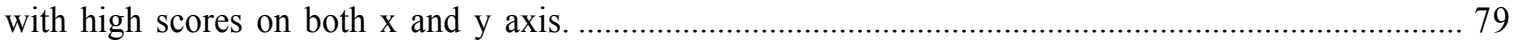

Figure 8-7. Body-size groups represented in Archaic (top) and Late Prehistoric (bottom) fauna from 41PR44 ... 80

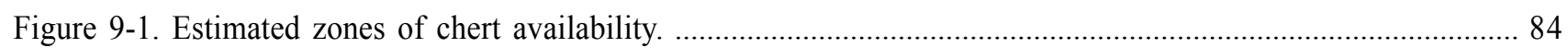

Figure 9-2. Histogram (upper) and box plots (lower) of tertiary flake percentages by raw material zone

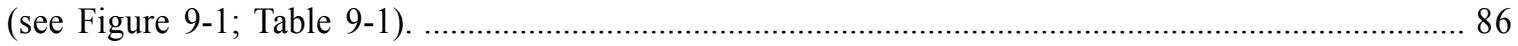

Figure 9-3. Examples of raw material groups identified on 41PR44................................................................ 89

Figure 9-4. Comparison of size variation and range for material groups at 41PR44 and 41TV163....................... 93

Figure 9-5. Raw material sources for Late Archaic (red) and Late Prehistoric (blue) assemblages at 41PR44. ... 96

Figure 10-1. Mass-specific magnetic soil susceptibility values from various sources. ........................................ 102

Figure 10-2. Mass-specific magnetic susceptibility values for sediment collected from near Feature 12, 41PR44.

Figure 10-3. Mass-specific magnetic susceptibility values of off-site sandstone samples at various temperatures.

Figure 10-4. Mass-specific magnetic susceptibility values of sandstone Sample 1, original (see Figure 10-3)

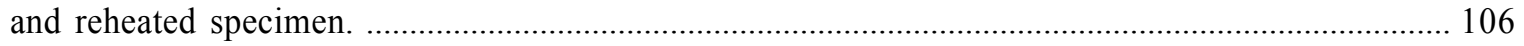

Figure 10-5. Mass-specific magnetic soil susceptibility values through Feature 12. .......................................... 108

Figure 10-6. Relative changes in mass-specific magnetic susceptibility values in sandstone rock after heating to $400^{\circ} \mathrm{C}$ (see Table 10-2). Three extreme values are not shown. .......................................................... 112

Figure 10-7. Feature 12 plan view and schematic cross-section.

Figure 10-8. Plan view of Area 3 showing Features 14, 16, 17, 18, 19, and 20 and rock distributions in Levels $8-10$.

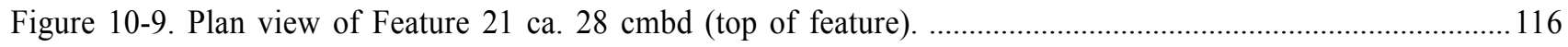

Figure 10-10. Percentage of rock in various weight classes for 41PR44 features (blue) and features previously classified as resulting from "stone boiling" (red). Note that the 0-100 g weight class is not shown.

Figure 10-11. Number of rocks and total weight for features at sites 41PR44 and 41MU55. Feature 21 (41PR44) is included in top plot and excluded in bottom plot. 


\section{List of Tables}

Table 5-1. Recovery Information by Level for Shovel Tests and Augers .............................................................. 35

Table 5-2. Material Recovered from Hand-Excavated Units by Level, Area 1 ....................................................... 38

Table 5-3. Material Recovered from Hand-Excavated Units by Level, Area 2 ...................................................... 39

Table 5-4. Material Recovered from Hand-Excavated Units by Level, Area 3 ........................................................ 41

Table 5-5. Material Recovered from Hand-Excavated Units by Level, Area 4 ........................................................ 42

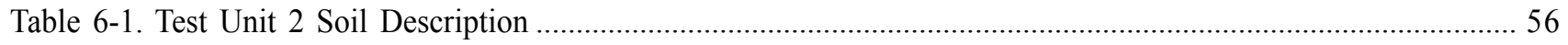

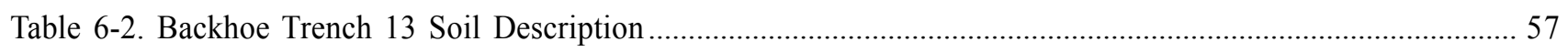

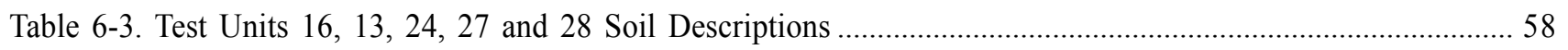

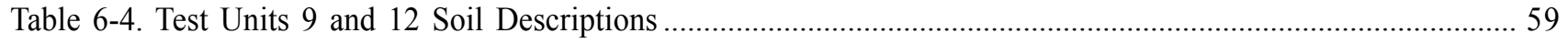

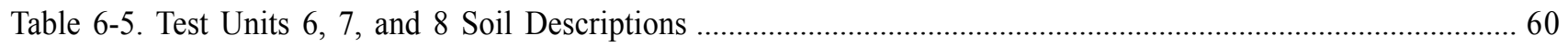

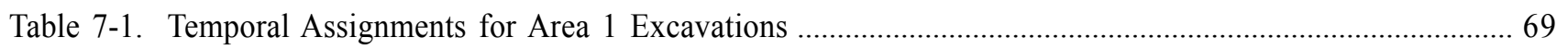

Table 8-1. Regional Ground Stone, Projectile Point, and other Stone Tool Data ...................................................... 77

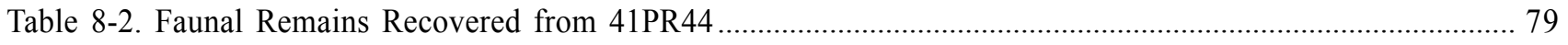

Table 9-1. Raw Material Availability, Cortical Data, and Reference Information for Selected Projects ................... 85

Table 9-2. Descriptions of Raw Material Types Observed in Debitage at 41PR44 ............................................. 91

Table 9-3. Maximum Size Data for Chipped Stone Raw Material Groups at 41PR44 .......................................... 92

Table 9-4. Observed Counts for Material Groups and Dorsal Cortex Coverage at 41PR44 ................................. 94

Table 9-5. Observed Counts of Local, Unknown, and Non-local Materials by Temporal Period ............................ 95

Table 10-1. Magnetic Sediment Susceptibility Data, Feature 12 (see Figure 10-5) ................................................ 109

Table 10-2. Magnetic Susceptibility Data on Crushed Sandstone from 41PR44 Before and After Heating ............ 111

Table 10-3. Feature Level Summary Data (see Table 10-2) .............................................................................. 113

Table 10-4. Selected Attributes of Thermal Features, 41PR44 .......................................................................... 118

Table 10-5. Counts and Weights by Rock Material Type, for Selected Non-feature Locations ...............................119

Table 10-6. Feature and Non-feature Rock Weight Data, 41PR44 .................................................................... 119

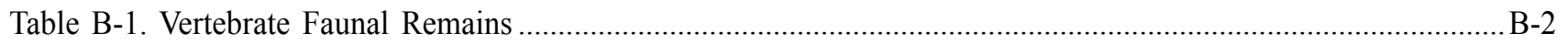

Table C-1. Light and Heavy Fraction Recovery from Water-Screening ................................................................. C-2 


\section{Acknowledgments}

As with any data recovery effort, a variety of people contributed to the completion of this project. Thanks go first to Ms. Shellie Sullo, who, at the time this work was initiated, was the archaeologist for the Texas Army National Guard (TXANG). Shellie has always been extremely supportive of research, and it was always a pleasure to work with her. I miss you Shellie- you never call. Thanks also to Shellie's replacement, Ms. Kristen Wenzel. Kristen came on board midway through this endeavor, and, for some reason that still escapes me, seemed to believe that we would produce a worthwhile report. I hope, after everything is read, that she is not too disappointed with the results. I also want to thank Michael Jordan, also at that time with TXANG, for initially showing me the site on a 14 hour road trip-it actually seemed longer now that I think about it- to someplace called Fort Wolters. Thanks are also in order for the professional staff at Fort Wolters. They arranged easy access to the facility, provided a backhoe and operator, and helped with advice on how to get from here to there. Oh, and I really am sorry that I drove our Suburban through that gate chain. I just did not see the thing.

The field and laboratory crews did a great job and were a pleasure to work with. At various points, they included Carl Welch, Kelsey Chase, Dawn Ramsey, Owen Ford, Jason Perez, Maggie Moore, and Jon Dowling. Bruce Moses and Jonathan White helped with the shovel testing, and Russell Greaves did the geoarchaeological overview. In the CAR laboratory, Cindy Munoz, Joseph Thompson, Bryant Saner, Cathy Stacy, Jon Dowling, Claudia Branton, and Marybeth Tomka helped with the analysis as well as with the curation preparation. Thanks to Sherrilyn Sunaz, Melanie Grabowske, and Monica Aguayo for making things run smoothly.

Bruce Moses and Rick Young produced the quality graphics in this report. Thanks Bruce for at least trying to control your eye rolls when I would show up at your desk and start a conversation with "Hey, you know what would look really cool?" Bruce also spent some time in the field mapping and climbing up tall trees to take great pictures. Antonia Figueroa wrote much of Chapters 2, 3, and 5 in this report, and provided indispensable help with research, references, and in tracking down assorted loose ends. Rusty Greaves wrote Chapter 6, and Barbara Meissner conducted the faunal analysis. Steve Tomka served as Principal Investigator, and helped with identifying the projectile points from the site. Finally, thanks to Cindy Munoz, Kristen Wenzel, and Debra Beene for helpful comments on the initial draft. 


\section{Chapter 1: Project Overview}

During the late spring of 2004, the Center for Archaeological Research of The University of Texas at San Antonio conducted data recovery excavations at site 41PR44, located in Parker County on Fort Wolters, a training facility for the Texas Army National Guard. The site had been previously surveyed and tested by archaeologists from the Texas Archeological Research Laboratory (TARL) at The University of Texas at Austin (Brownlow 2001; Brownlow et al. 1999). The results of that testing suggested that the site contained a high density of burned rock features, along with chipped stone and bone. A radiocarbon date from one feature, as well as the recovery of two arrow points, demonstrates that some of these deposits are clearly Late Prehistoric in age. Brownlow (2001:18) also suggested that a Late Archaic component is present, though the evidence for this component was minimal. Brownlow (2001:18) recommended that 41PR44 is eligible for inclusion on the National Register of Historic Places under Criterion D. The Texas Historical Commission and the Texas Army National Guard agreed with that recommendation. The site has been directly impacted by military traffic, and secondary erosion associated with a dirt road that cuts through the center of the site has further damaged 41PR44. Nevertheless, Brownlow (2001) suggested that intact cultural material was present in several areas of the site. Continued use and maintenance of the road would result in continued erosion of the significant archaeological deposits. As avoidance of this site area was not possible, CAR was contracted by the Adjutant General's Office of the Texas Army National Guard to develop and execute a data recovery plan that was designed to target critical data from the Late Prehistoric, and potentially earlier, occupations at 41PR44.

\section{Project Activities and Results}

The data recovery plan was produced in the early spring of 2004 (Mauldin 2004), and field work was undertaken in March and April of that year. The work was conducted under a memorandum of agreement between the Texas Army National Guard and the Texas Historical Commission. Steve Tomka of CAR served as Principal Investigator for the project, and Raymond Mauldin served as Project Archaeologist. Consistent with the work plan, CAR personnel initially excavated a series of shovel tests and hand-auger tests, spaced roughly $5 \mathrm{~m}$ apart, to document vertical and horizontal distributions of cultural material.
The results of these shovel tests, along with the results from the previous work at $41 \mathrm{PR} 44$, were used to plan the locations of hand-excavated units. CAR personnel excavated $241-\mathrm{x}-1-\mathrm{m}$ units, and screened roughly $18.8 \mathrm{~m}^{3}$ of sediment. Following the completion of the hand-excavated units, CAR excavated four backhoe trenches. All trenches, as well as the excavation blocks, were examined by the project geoarchaeologist, Dr. Russell Greaves, prior to backfilling.

The work conduced by CAR resulted in the definition of 12 burned rock features in the field, and a variety of data sets were collected and transported to CAR for subsequent analysis. These data sets included a large quantity (over 25,000 items) of what was thought to be burned sandstone and limestone rock, 46 lithic tools including 16 projectile points and several pieces of ground stone, close to 900 pieces of chipped stone debitage, sediment samples from the identified features, and small quantities of bone, charcoal, and mussel shell from a variety of contexts.

Based primarily on the projectile point types recovered, we identified several occupation periods at the site, including some use of the location during the Late Prehistoric and Late Archaic time frames. Occupation during the Early Archaic period is suggested by several dart point fragments that compare favorably with Early Archaic or Early/Middle Archaic forms. Unfortunately, the distribution of projectile points, as well as the assessment of context by the project geoarchaeologists, demonstrated that in several areas of the site, considerable mixing of deposits had occurred. In addition, Dr. Greaves suggested that the burned rock features identified by CAR, as well as those previously defined by TARL archaeologists, were unlikely to represent intact, cultural features. Rather, he argued that theses clusters were primarily the result of the natural deposition of sandstone, as well as the movement and deposition of cultural material. That is, he suggested that none of the features defined were in primary context.

Assessing the validity of the thermal features identified at 41PR44, as well as identifying material that could be used to investigate more general research areas, became an initial priority in our analysis of the 41PR44 data. We primarily used changes in the magnetic susceptibility of sediment and crushed sandstone, changes that occurred as a result of 
heating, to better identify which clusters of rock were, and were not, cultural. Ultimately, we identified three of the 12 features as having a high probability of being intact thermal features. In addition, we considered the distribution of projectile points and radiocarbon dates from our work, as well at the testing conducted previously on the site, to identify deposits that could be assigned to the early portion of the Late Prehistoric, deposits that could be assigned to the Late Archaic, and deposits that could be grouped only as Archaic in age. Various data sets contained in these deposits were then used to explore a variety of research areas, including considerations of subsistence, lithic technology, feature technology, and chronology. While limited by less than ideal temporal resolution and low recovery rates for some classes of material, the analysis of the 41PR44 data does provide a basic description of archaeological material for this understudied portion of Texas.

Following laboratory processing and analysis of the various materials collected from 41PR44, and in consultation with both the Texas Army National Guard and the Texas Historic Commission, selected samples and certain classes of materials collected from 41PR44 were discarded. This discard was in conformance with Texas Historical Commission guidelines. Material disposed of included all sandstone and limestone rock collected from non-feature contexts, as well as roughly $75 \%$ of all feature rock. All sediment samples not associated with features were discarded. In addition, all metal, consisting primarily of shell casings and bullet fragments, were discarded. All remaining archaeological samples collected by CAR, along with all associated documents, notes, and photographs, were prepared for permanent curation at the Texas Archaeological Research Laboratory in Austin.

\section{Report Outline}

This document presents the results of the data recovery effort at 41PR44. The initial six chapters provide background research relevant to the project. Chapter 2 provides an overview of the project setting. Included in that chapter are discussions of soils, geology, hydrology, climate conditions, and floral and faunal resources in the site area, as well as the larger project area. A short review of paleoenvironmental data are also presented in that chapter. Chapter 3 presents the archaeological background for the region. Included in that chapter is a review of the cultural chronology, previous research in the project area, and previous investigations at 41PR44. The fourth chapter provides an overview of the research issues explored with the data from 41PR44. These research areas included the establishment of site chronology, investigations of subsistence change as seen primarily through shifts in faunal material, exploration of the impact of raw material stress on the chipped stone assemblages, and the investigation of differences in thermal features at the site. Chapter 5 provides a summary of the field work undertaken by CAR at 41PR44. In Chapter 6, Dr. Greaves provides a geoarchaeological assessment of the site. As noted previously, that assessment concludes that the burned rock features identified in the previous testing, along with the rock features identified by CAR during the most recent work, are unlikely to be intact cultural features. Rather, he suggests that the accumulations of rock are the result of natural, colluvial deposition rather than reflecting discrete, cultural features.

Chapters 7 through 10 address specific research concerns. Chapter 7 considers chronology both at the site level, as well as within the site itself. Chapter 8 investigates subsistence, focusing primarily on faunal material. Chapter 9 provides an overview of aspects of chipped stone technology, with an emphasis on the impact of raw material availability on assemblages. Finally, Chapter 10 concerns thermal features at the site. Chapter 11 provides a short summary of the project.

Four appendices are included in this report. Appendix A provides information on the radiocarbon date obtained by CAR. Appendix B, by Barbara Meissner, presents details on the vertebrate faunal material collected. Appendix C presents information on the flotation samples processed from 41PR44 features. Finally, Appendix D is a copy of the Memorandum of Agreement between the Texas Army National Guard and the Texas Historical Commission that governed the data recovery excavations of $41 \mathrm{PR} 44$ at Fort Wolters. 


\section{Chapter 2: Environmental Background}

This chapter provides basic environmental data for the project area. Included are short summaries of aspects of soils, geology, hydrology, climate, and plant and animal resources in the general area. We also summarize what we currently know regarding the paleoenvironment of the region.

\section{Modern Physical Environment}

Located on the Whitt and Mineral Wells East USGS 7.5-minute quadrangle maps in Parker and Palo Pinto counties (Figure 2-1), Fort Wolters serves as a training facility for forces associated with the Texas Army National

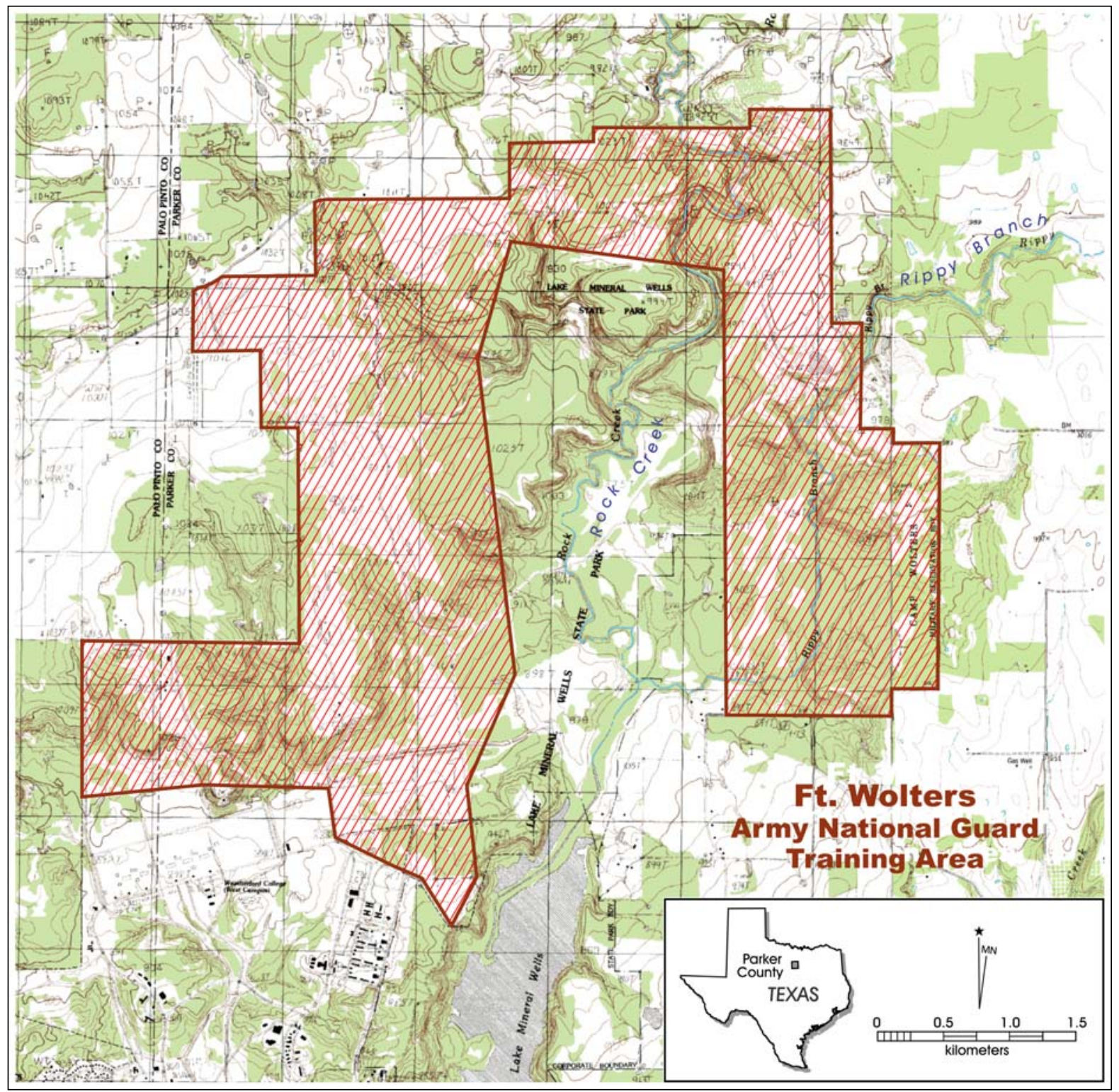

Figure 2-1. Fort Wolters Texas Army National Guard training area. 
Guard and the U.S. Air Force. The roughly 3,985-acre facility, near the cities of Mineral Wells and Weatherford in the gently rolling hills of north-central Texas, is used for a variety of small arms and machine gun training, training of tank and armored cavalry, and for aerial drop training by both the Texas Army National Guard and the U.S. Air Force (Texas Army National Guard 2002). The Fort Wolters facility is somewhat horseshoe-shaped, with the central portion of the horseshoe taken up by Mineral Wells State Park (Figure 2-1).

Fort Wolters is located on the southeastern edge of the Great Plains physiographic region (Fenneman 1938), within the Western Cross Timbers division of the Oak Woods and Prairies (Diamond et al. 1987; Dyksterhuis 1948; Gould et al. 1960). The Western Cross Timbers consists of a northeast to southwest trending overstory of oak with an understory dominated by sparse grasslands.

\section{Soils, Geology, and Hydrology}

Soils in the uplands within this section of Parker County are Bonti, Chaney, Owens, and Truce (SSURGO 2006). These soils are thin and generally develop over shale or sandstone. Lowland soils, primarily alluvial and colluvial in nature, are primarily sandy loams and include Yohola and Banyan soils, as well as clay loams of the Thurber series (Greenwade et al. 1977). Within the immediate project area, Figure 2-2 presents soils within $3 \mathrm{~km}$ of 41PR44 (SSURGO 2006). To the north of the site are a series of clays intermixed with sandy loams. The site area itself falls within the Shatruce-Bonti mapping unit. Shatruce soils make up $70 \%$ of this mapping unit, with Bonti soils comprising about $18 \%$. Shatruce soils are well drained with high runoff. Bonti soils are also well drained. Immediately to the east of the site are Bonti and Truce soils.

Figure 2-3 presents the major geological formations and deposits within $5 \mathrm{~km}$ of 41PR44 using data from Barnes (1972; 1988). Located primarily to the west of the site are Pennsylvanian age marine strata of shale and sandstone, limestone, and conglomerates grouped as the Mineral Wells Formation (Figure 2-3:IPmw). Several specific sandstone deposits of varying coarseness, including Lake Pinto Sandstone (Figure 2-3:IPIp), are present. Cherts are not noted in these deposits. Immediately to the east of the site area are Cretaceous age marine rocks of the Twin Mountains Formation (Figure 2-3:Ktm). These deposits are primarily composed of claystone and sandstone. While pebbles of chert are noted as present, no major chert deposits occur in this formation. Small occurrences of the Cretaceous Glen Rose Formation (Figure 2-3:Kgr), a limestone deposit that also lacks chert, occur to the north and east of 41PR44. Quaternary age sediments (Figure 2-3:Qal) are dominated by alluvium consisting primarily of gravel, sand, and silty clay, are encountered upstream from 41PR44, as well as to the south where the two major drainages within Fort Wolters (Rock Creek and Rippy Branch) converge and eventually flow into the Brazos River.

The primary channel of the Brazos is located roughly $12 \mathrm{mi}$. (ca. $19.3 \mathrm{~km}$ ) to the southwest of Fort Wolters. Rock Creek (Figure 2-4) flows across the north-central portion of Fort Wolters, and Rippy Branch drains the eastern edge of the facility (see Figure 2-1). We could not locate stream flow data for either Rock Creek or Rippy Branch. However, stream flow data are available for the Brazos River near Dennis, Texas (USGS 2006), roughly $18.5 \mathrm{mi}$. (ca. $30 \mathrm{~km}$ ) to the south of the project area below the confluence of Rock Creek and the Brazos. These stream flow data, collected from 1968 through 2003, provide some information on recent variation in yearly and monthly flow rates for the Brazos, variation that is probably similar in form, though certainly of a different magnitude, to that of Rock Creek. Figure 2-5 presents the yearly stream flow rates between 1969 and 2003 that demonstrate substantial variation. The lowest figure was recorded in 1984 when the yearly total was $1,418 \mathrm{ft}^{3} / \mathrm{s}$. In contrast, the highest total was in 1990 when yearly flow rates were at $35,718 \mathrm{ft}^{3} /$ $\mathrm{s}$, more than 25 times that in 1984. At a monthly scale, highest average flow rates during this time period occurred in the months of May $\left(1,737 \mathrm{ft}^{3} / \mathrm{s}\right)$ and June $\left(1,894 \mathrm{ft}^{3} / \mathrm{s}\right)$, with a smaller, secondary peak in October $\left(1,362 \mathrm{ft}^{3} / \mathrm{s}\right)$. The lowest monthly flow rates were recorded in January $\left(432 \mathrm{ft}^{3} / \mathrm{s}\right)$. Variation in these flow rates are probably related, in part, to variation in regional rainfall.

\section{Climate}

Characterized as subtropical humid, the climate of the project area is one of hot, humid summers and mild, dry winters. Figure 2-6 presents monthly average precipitation figures from Mineral Wells, just to the west of Fort Wolters, using data provided by the Southeastern Regional Climate Center (SRCC 2003a) from 1971 through 2000. Rainfall is clearly bimodal, with the wettest months generally being May (4.59 in; $11.66 \mathrm{~cm})$ and October (3.81 in; $9.68 \mathrm{~cm}$ ), and the driest months being December (1.74 in; $4.42 \mathrm{~cm})$ 


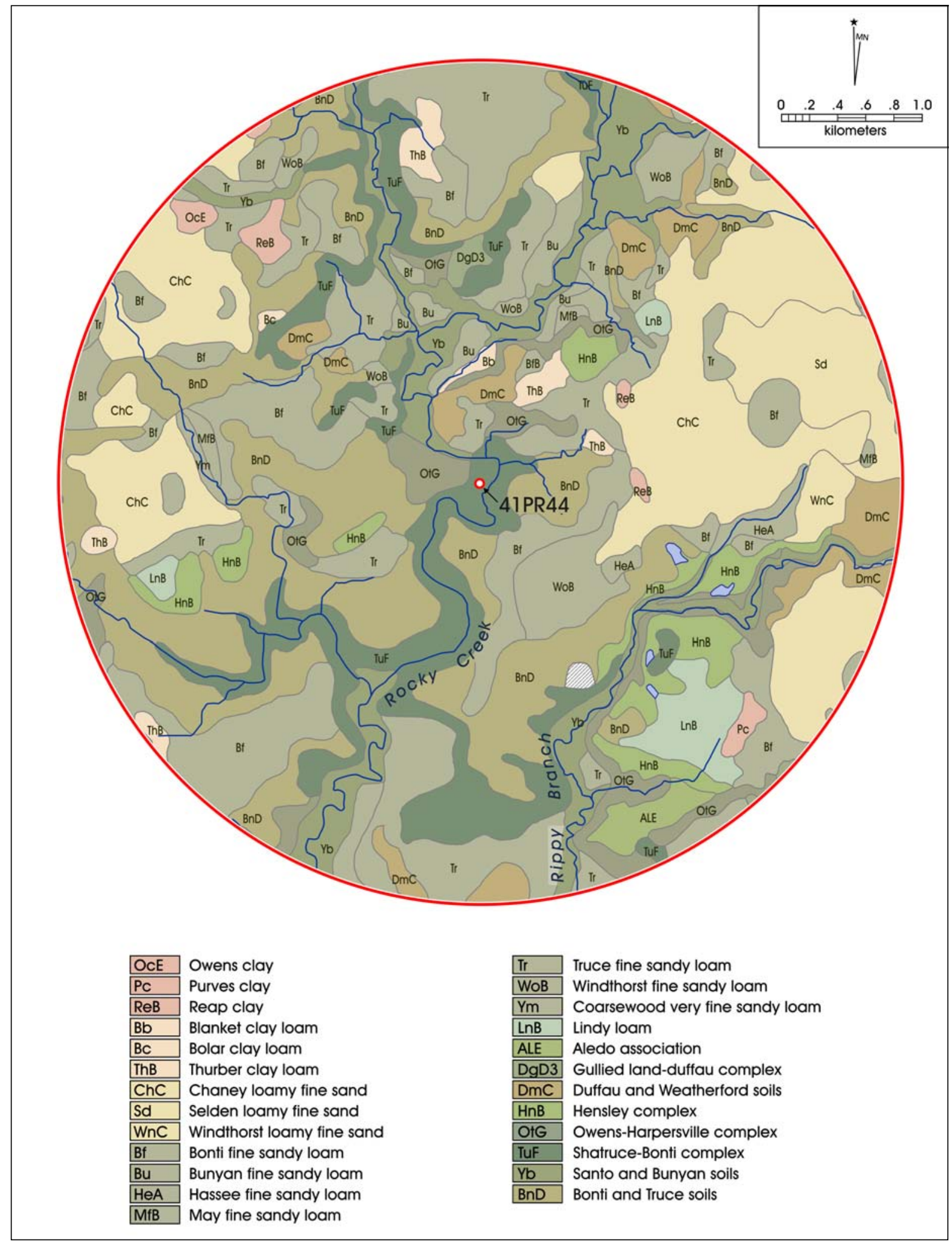

Figure 2-2. Soils within $3 \mathrm{~km}$ of $41 P R 44$. 


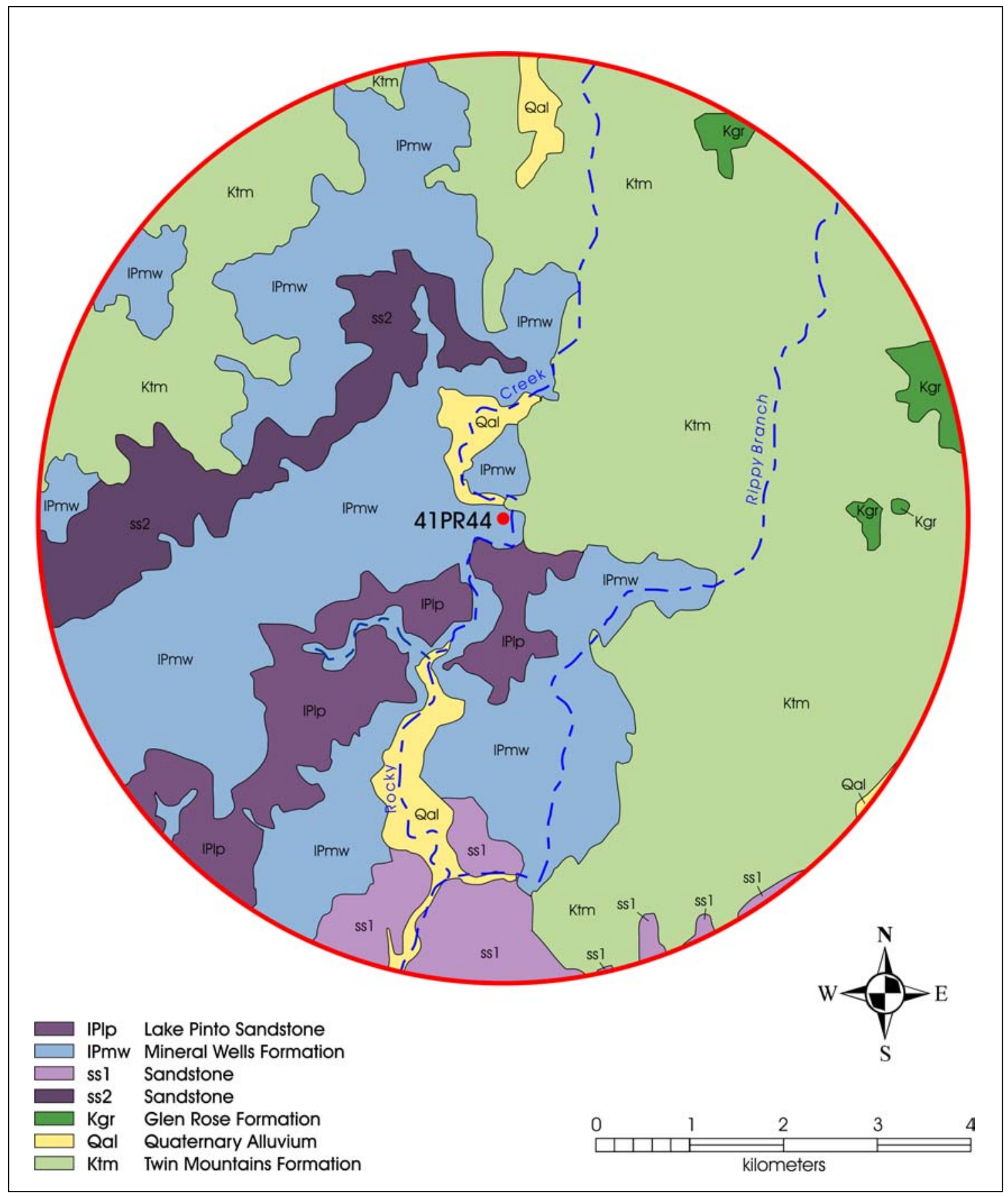

Figure 2-3. Geological deposits surrounding 41PR44. 


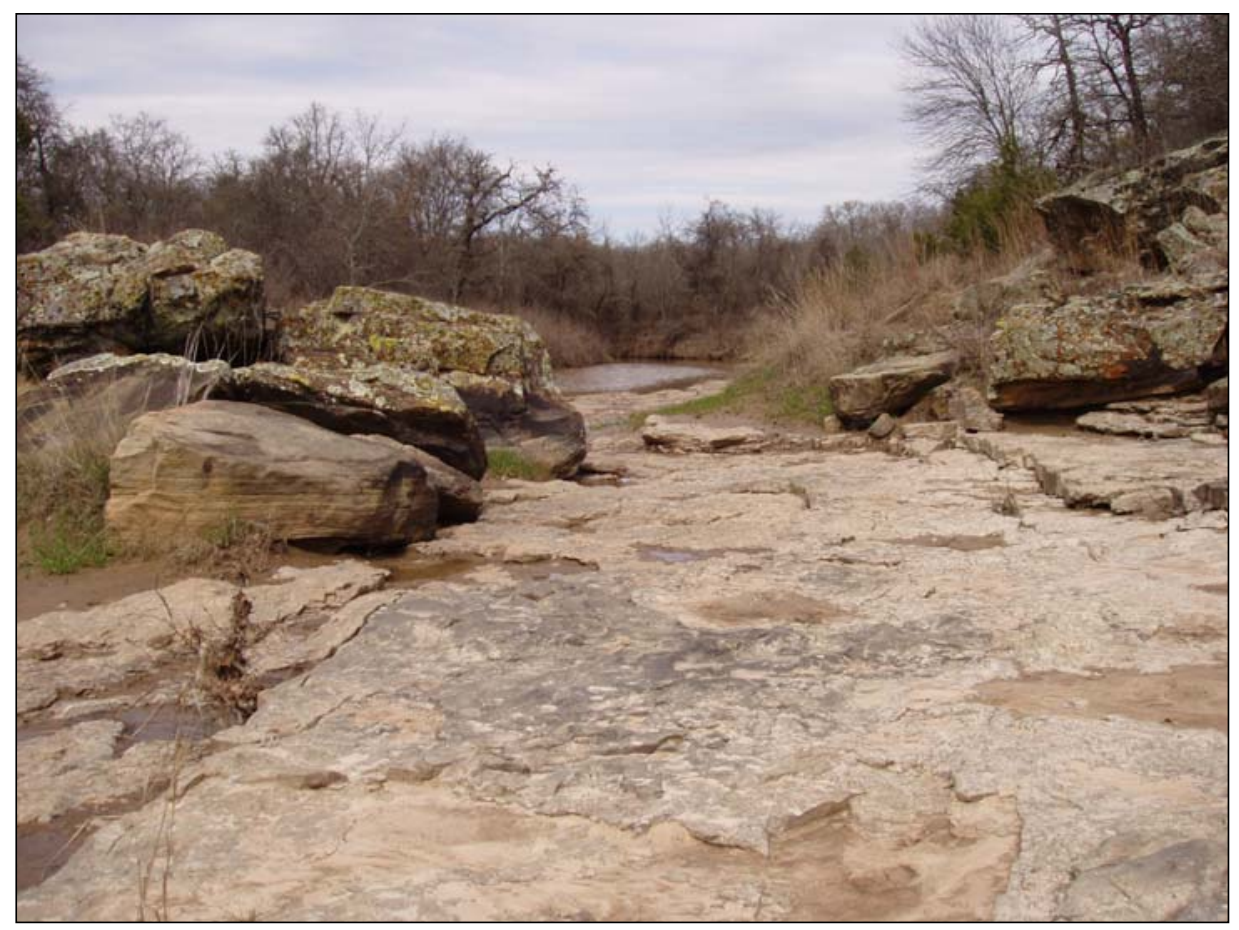

Figure 2-4. View of Rock Creek looking northeast adjacent to site 41PR44. Photograph taken spring 2004.

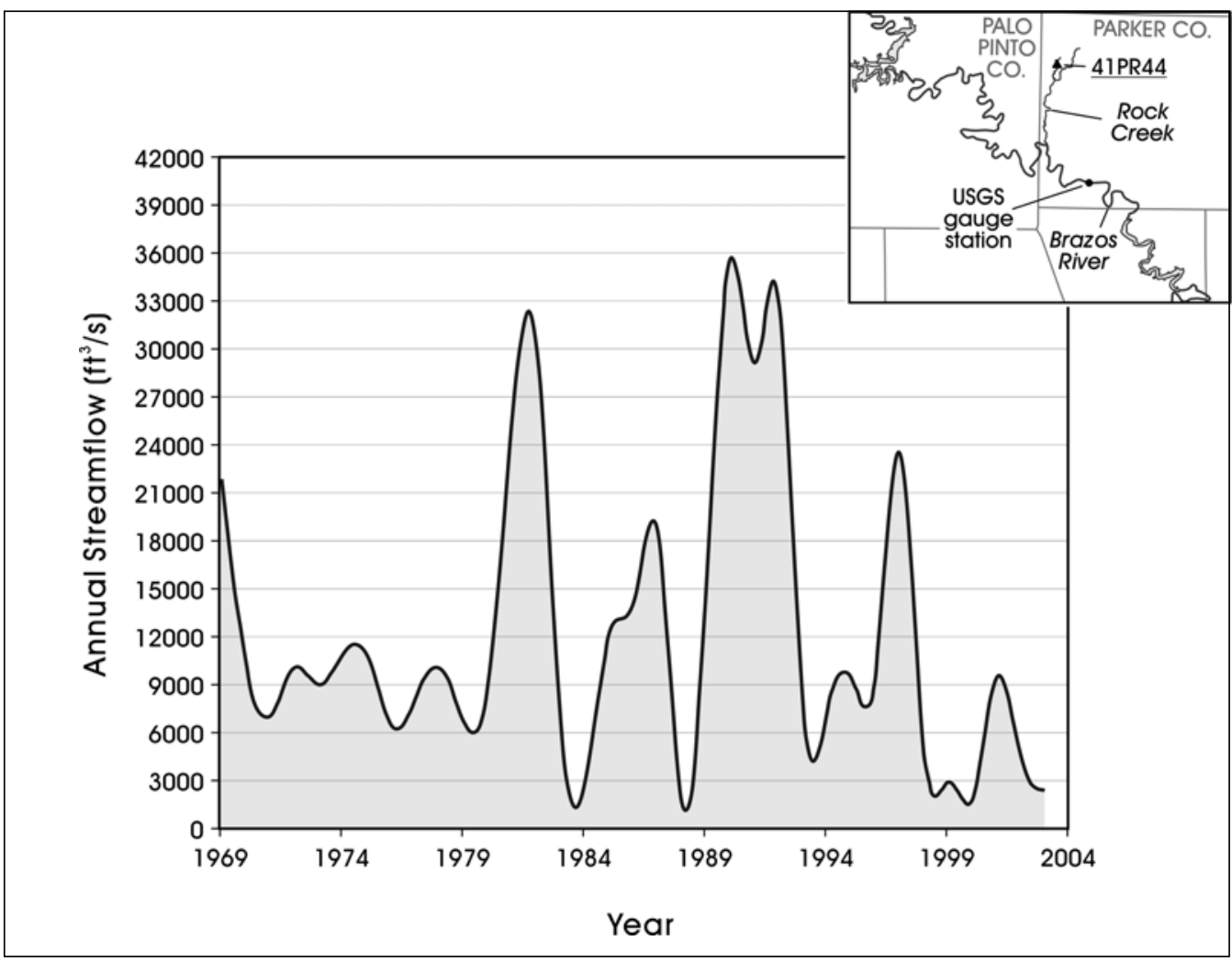

Figure 2-5. Yearly average streamflow fts for the Brazos River below Rock Creek (1969-2003). 
and January $(1.42 \mathrm{in} ; 3.61 \mathrm{~cm})$. The annual precipitation is approximately $31.79 \mathrm{in} .(80.75 \mathrm{~cm})$. There is considerable variability in yearly rainfall as shown in records from Weatherford, located just to the east of Fort Wolters. Between 1891 and 1989, the driest year at Weatherford was 1954, when 16.65 in. $(42.29 \mathrm{~cm})$ of precipitation was recorded. The wettest year on record was 1957, when 55.89 in. $(141.96 \mathrm{~cm})$ of precipitation was recorded (National Climate Data Center [NCDC] 2003).

Brownlow et al. (1999:4) report that the growing season averages about 225 days a year for the region. Figure 2-7 presents mean monthly temperatures from 1971 through 2000 at Mineral Wells (SRCC 2003b, c). The warmest months are July and August, with December and January being the coldest. Average yearly minimum temperature at Mineral Wells is $53.8^{\circ} \mathrm{F}\left(12.1^{\circ} \mathrm{C}\right)$, with average maximum temperature being $78.7^{\circ} \mathrm{F}\left(25.9^{\circ} \mathrm{C}\right)$. Bomar $(1999: 220,223)$ reports that the coldest recorded temperature at Mineral Wells was $-8^{\circ} \mathrm{F}\left(-22.2^{\circ} \mathrm{C}\right)$ in late December of 1989 , with the hottest temperature being $114^{\circ} \mathrm{F}\left(45.6^{\circ} \mathrm{C}\right)$, recorded several different times. On June 26,1980 , a record high temperature of $119^{\circ} \mathrm{F}\left(48.3^{\circ} \mathrm{C}\right)$ was recorded in Weatherford (Bomar 1999:223).

\section{Floral and Faunal Resources}

As noted previously, the project falls within the Cross Timbers area of Texas (Figure 2-8). Several summaries of resources for the Cross Timbers region are available. Dyksterhuis (1948) suggests that climax vegetation in the Cross Timbers area is primarily composed of grasses, including big bluestem (Andropogon gerardii Vitman), little bluestem (Schizachyrium scoparium), Indiangrass (Sorghastrum nutans), switchgrass (Panicum virgatum), Canada wildrye (Elymus canadensis), with small amounts of sideoats grama (Bouteloua curtipendula), blue grama (Bouteloua gracilis), hairy grama (Bouteloua hirsuta), Texas wintergrass (Stipa leucotricha), and buffalograss (Buchloe dactyloides). As described by Dyksterhuis (1948), the Western Cross Timbers has undergone a variety of vegetation changes as a result of grazing and farming activities. Based on an analysis of relic vegetation areas, Dyksterhuis (1948:347) notes that grass and forb coverage has been greatly reduced and oak coverage greatly increased since Europeans entered this region (Dyksterhuis 1948).

Brown (1989) provides a summary of resources in Hill County near Aquilla Lake which is located roughly
$130 \mathrm{~km}$ to the southeast of Fort Wolters. Brown (1989: 204-211) suggests that in terms of floral resources available to hunters and gatherers, a variety of grass species, as well as Oak and other nut producing species, are available in the region, with late fall being the principal period of availability. He suggests that acorns were the principal plant food. While a variety of faunal resources are available, Brown suggests that white-tail deer may have been the principal species available to hunters and gatherers. Thoms (1994:16-22) comes to roughly the same conclusion regarding the availability of nut resources and deer for the northern portion of the Cross Timbers area, near the Oklahoma border. These summaries, then, seem to suggest that the region has substantial resources available to hunters and gatherers, though the availability may be somewhat limited during certain seasons.

The notion that the Cross Timbers has substantial floral and faunal resources is, however, open to debate. The Cross Timbers area is one of 10 natural regions for the state as defined by several researchers (see Gould et al. 1960; Hatch et al. 1990). Hatch et al. (1990) provide a summary of over 4,000 plants within Texas by these natural regions. For the Cross Timbers, they list 1,148 species. For comparison, only two other regions, the Rolling Plains ( $\mathrm{n}=993)$ and the High Plains $(\mathrm{n}=718)$, have fewer plant species, and areas such as the Trans-Pecos $(n=1,952)$ and the Edwards Plateau $(\mathrm{n}=2,114)$ have much higher species numbers.

The vast majority of the 1,148 plant species listed by Hatch et al. (1990) for the Cross Timbers area are unlikely to have been used as food sources. Recently, Mauldin et al. (2006) compared each of the 4,287 unique native species listed by Hatch et al. (1990) for Texas to the Native American Ethnobotony database (Moerman 2005), a list of 4,029 different plant species used for a variety of purposes by 291 Native American groups from across North America. They identified all matches used for food or beverage at the species level. This comparison resulted in the identification of 394 different plant species that had a high probability of being used for food. In addition, for each species identified, they classified the part of the plant used into one of six groups: roots and tubers, seeds, nuts, greens, fruits, and other (e.g., sap, bark, stalks). In several cases, multiple elements of the same plant (e.g., seeds, greens) were listed in the Ethnobotony database. Consequently, 480 different components of the 394 different species used as food or beverage were considered for the 10 different natural regions of Texas shown in Figure 2-8. For the Cross Timbers region, 175 different components were listed as 


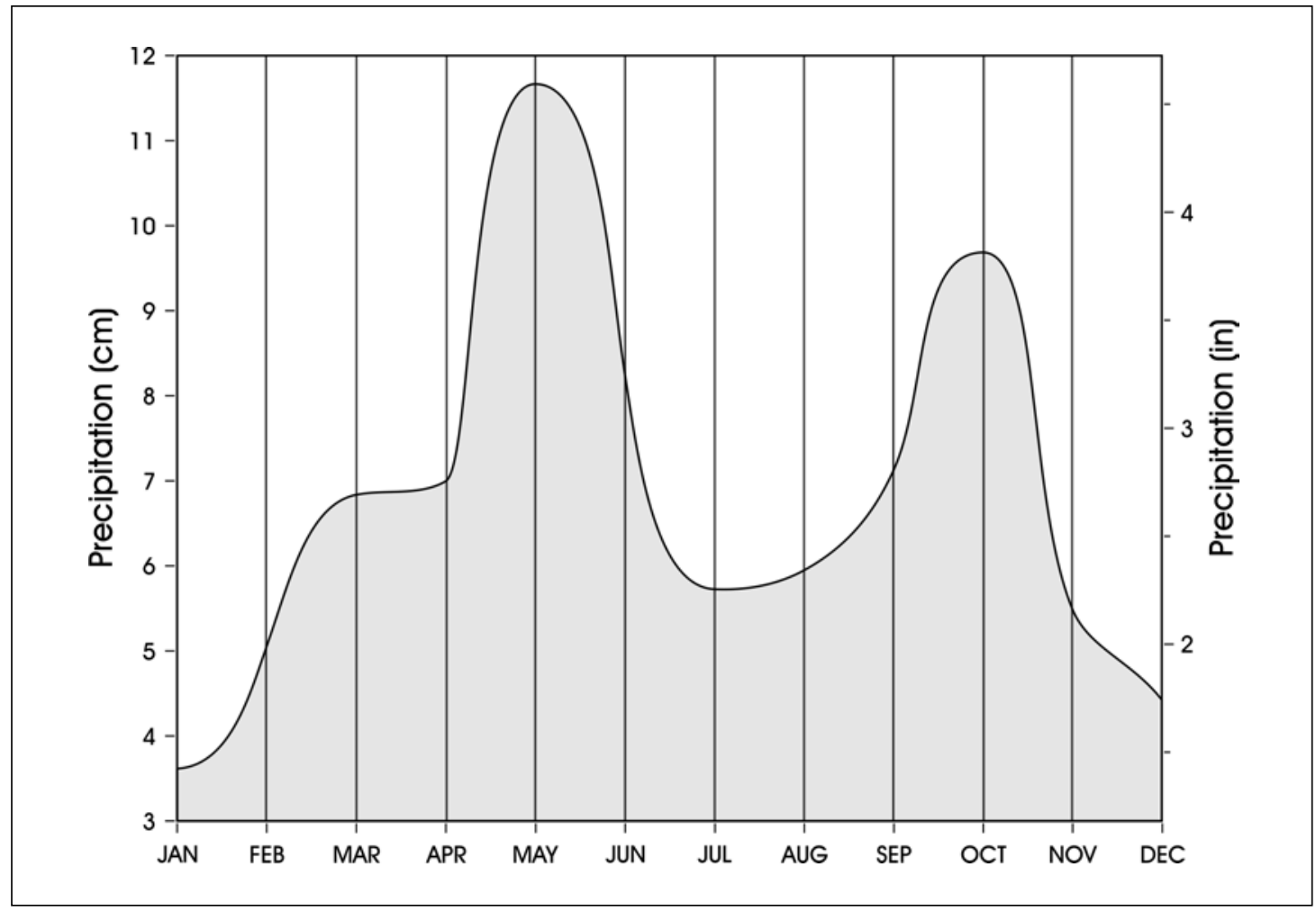

Figure 2-6. Mineral Wells 30 year normal precipitation (1971-2000).

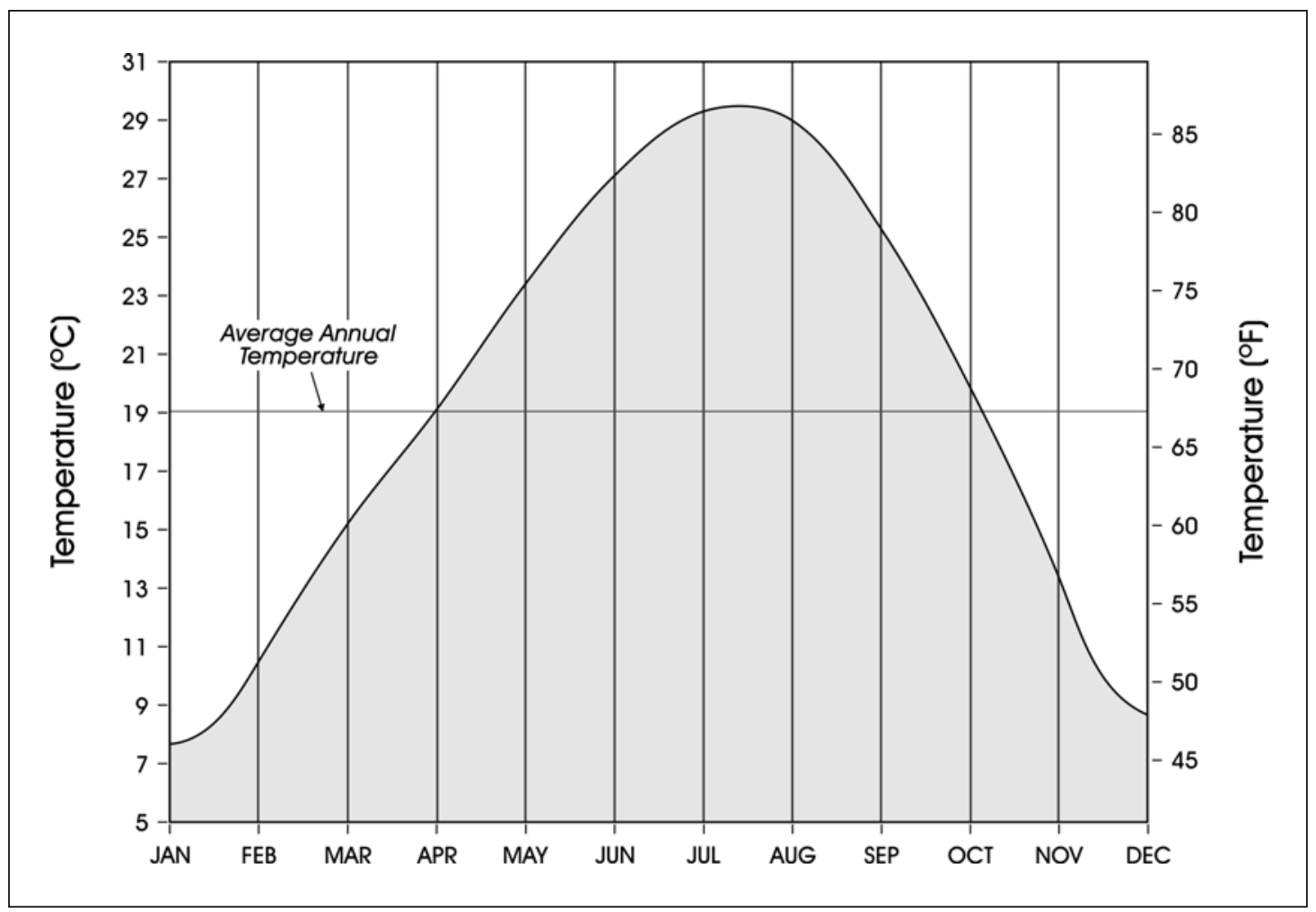

Figure 2-7. Mineral Wells 30 year normal average monthly temperature (1971-2000). 
likely subsistence items. Again, this is one of the lowest totals in the state, roughly equivalent to the Piney Woods $(n=172)$ and South Texas regions $(n=124)$.

The data summarized above is, of course, modern. As discussed in a subsequent section of this chapter, it is certainly the case that climate patterns, and associated vegetation in the Cross Timbers area, has undergone a number of changes since the close of the Pleistocene. These changes altered the species composition, as well as the density of individual plants. Nevertheless, these modern data, especially when used in comparison to modern data from other regions of the state, demonstrate the low diversity of vegetation within the Cross Timbers area, as well as the low diversity of plants that have a high probability of being used as food. The climax vegetation described for the Western Cross Timbers area by Dyksterhuis (1948) is dominated by grass (Poaceae) species. Recent vegetation inventories of Fort Wolters itself have recorded 359 different plant species on the facility, including 55 different grasses (Texas Army National Guard 2002). As evidenced by the observation that only 30 of the 421 different grass species (7\%) listed by Hatch et al. (1990) for Texas are identified as a food resources in the Native American Ethnobotony database (Moerman 2005), most members of the Poaceae family are unlikely to be a major human food source.

Not surprisingly, the relatively limited diversity of plant species in the Cross Timbers area is reflected in a reduced animal diversity, at least in the case of mammals. This can be seen by considering patterns developed by Mauldin et al. (2006) for 101 Texas mammals that have a moderate to high probability of being used for food. Using data from Davis and Schmidly (1997), Mauldin et al. (2006) defined four different mammal groups based on weight. Seventy three species were in the "small" mammal group with ranges

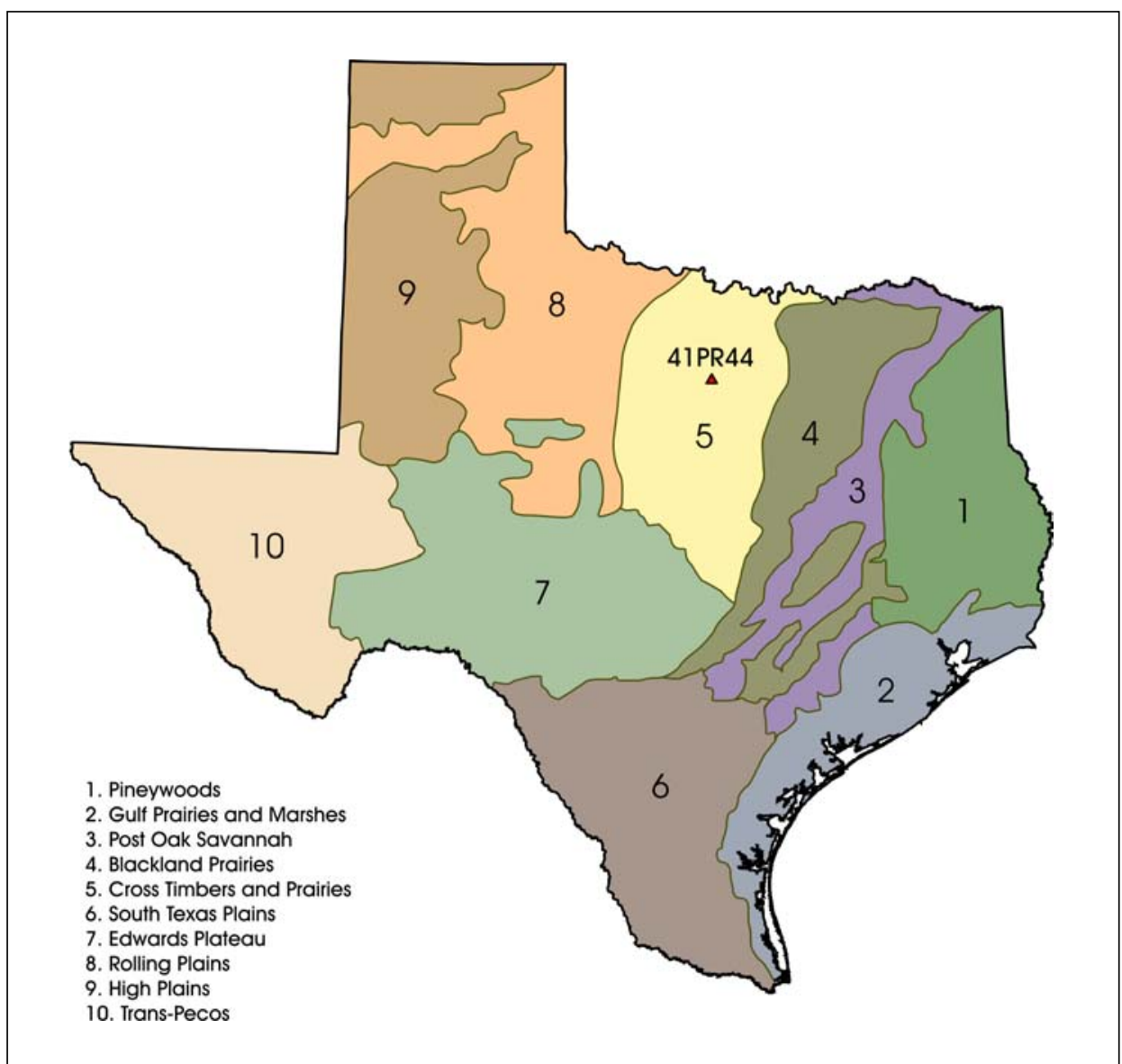

Figure 2-8. Natural regions of Texas showing the location of $41 P R 44$ within the Cross Timbers area. 
in weight from $.005 \mathrm{~kg}$ (least shrew) to $.95 \mathrm{~kg}$ (eastern fox squirrel, desert cottontail), and an average group weight of $.167 \mathrm{~kg}$. Twenty-one species were assigned to a "medium" mammal group that ranges in weights from $1.25 \mathrm{~kg}$ (ringtail) to $19.0 \mathrm{~kg}$ (collared peccary), with an average weight of $6.44 \mathrm{~kg}$. Seven species were in the "large" mammal group. The mean weight of this group was $124.6 \mathrm{~kg}$, with a range of $46.7 \mathrm{~kg}$ (pronghorn) to $275 \mathrm{~kg}$ (elk). Finally, bison, with an average weight of about $835.5 \mathrm{~kg}$, formed a "very large" mammal group. To map the spatial distribution of the three smaller animal groups, Mauldin et al. (2006) overlaid individual species distributional maps, presented primarily in Davis and Schmidly (1997), with 189 quadrates identified by Owen and Schmidly (1986; Owen 1988, 1990). Each quadrate is roughly $63.9 \mathrm{~km}$ square.

Figure 2-9 uses that data to create contour maps of the number of different types of mammals for the small, medium, and large groups, within each of the 189 quadrate. Also presented in the figure is the location of 41PR44 and the cross-timbers area. Examination of Figure 2-9 suggests that the highest diversity of both large and small mammals is in the Trans-Pecos area, with the number of different medium mammals having the highest occurrence in the Big Bend area and the southern portion of the Edwards Plateau. The lowest diversity for both large and medium mammals is in eastern portions of the state, while the number of different types of small animals is lowest along the upper coastal area. Within the Cross Timbers area, relatively low to moderate diversity is present in small, medium, and large mammals (Figure 2-9). Focusing on the area around 41PR44, all three mammal size groups have low to moderate diversity.

As noted previously, the Figure 2-9 data are focused primarily on modern, or historically well documented, mammalian species. Clearly, other faunal resources were available, and potentially important, to prehistoric occupants of the Cross Timbers region. Foremost among these may have been bison. Using data from a variety of sources, including presence/absence summaries of bison from archaeological sites (see Dillehay 1974; Huebner 1991; Mauldin and Kemp 2005), as well as ethnohistoric (Wade 1998) and ecological summaries (McDonald 1981), Figure 2-10 outlines the area within Texas that probably represents the primary area for bison. While bison densities fluctuated through time and across space within this core area, site 41PR44 clearly is located within the area where bison should have been available at various points in time. Finally, note that a variety of other non-mammal foods would have been available to hunters and gathers in this region. Both Brown (1989) and Thoms (1994) note that turtle, mussels, a variety of birds, including turkey, and fish were available. Modern inventories on Fort Wolters note the presence of several varieties of fish, birds, and reptiles (Texas Army National Guard 2002), many of which could have been used as food by the prehistoric inhabitants of 41PR44.

\section{Paleoenvironmental Considerations}

The above summaries of the Cross Timbers region in general, and Fort Wolters in particular, are based primarily on modern information supplemented, in a limited number of instances, by historic records. It is clear, however, that a variety of changes in the environment have occurred since the close of the Pleistocene. Unfortunately, for this portion of Texas we have a limited understanding of these changes. While there are several paleoenvironmental studies associated with work in Denton and Dallas counties to the northeast of 41PR44 (see Brown 1998; Humprey and Ferring 1994), much of what we think we know about past climates comes from studies conducted in other parts of Texas. Here, we primarily rely on patterns in two different data types, isotopic data from pedogenic carbon taken from a long sequence at the Aubrey Site (see Humprey and Ferring 1994; Ferring 2001), and pollen data taken from several studies conducted in Lee County (see Bousman 1998; Nickles and Mauldin 2001), well to the south of 41PR44. We use these data types to discuss broad aspects of the paloenvironment for north-central Texas over the last 12,000 years. Both data types are responding to shifts in vegetation. While the lag time between a major shift in vegetation and the appearance of that shift in either the pollen sequences or pedogenic carbon isotopic sequences is unknown and probably highly variable, being dependent, in part, on the nature and magnitude of the original vegetation change, both data sets should reflect broad changes, such as shift between grasslands and woodlands or between woodlands and forests (e.g., Bousman 1998).

Ferring (2001; see also Humphrey and Ferring 1994) has established a paleoclimatic record for the Aubrey Site (41DN479), in north-central Texas. The site is located roughly $120 \mathrm{~km}$ to the northeast of 41PR44. While Ferring (2001) uses a variety of different data sets, including oxygen isotopes, to reconstruct aspects of paleoclimate at the Aubrey Site, we focus here on their stable carbon isotope data. The pedogenic carbon isotope data used here are from a single profile (Trench 25) and are estimated to span much 


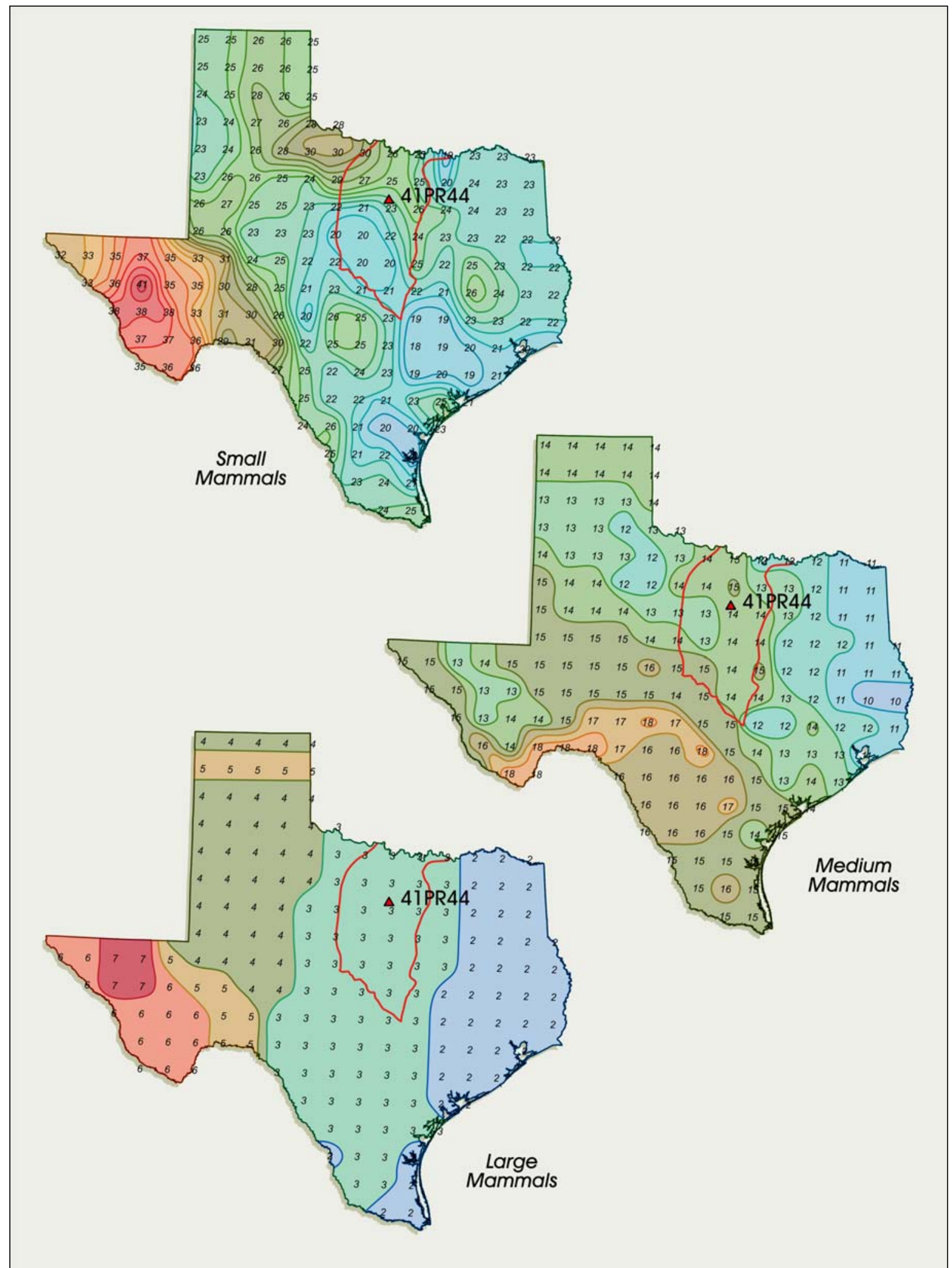

Figure 2-9. Diversity of small, medium, and large mammals within Texas (Cross Timbers area identified in red outline). 
of the Holocene, from 1730 BP through 10,800 BP (Humphrey and Ferring 2001:60). The temporal range is derived from interpolation based on nine radiocarbon dates from this trench (see Humphrey and Ferring 2001:58).

Nineteen samples were processed with carbonate ${ }^{13} \mathrm{C}$ ranging from -3.73 mill near the top of the profile to -8.69 mill near the bottom. Figure 2-11 present these carbon isotope data (see Humphrey and Ferring 2001:66-67). More negative values are indicative of increased contributions of plants that use $\mathrm{C}_{3}$ photosynthetic pathway, while more positive values are indicative of an increased importance of $\mathrm{C}_{4}$ species, primarily grasses in this portion of the state. Increasing $\mathrm{C}_{4}$ grasses are most likely to occur under conditions of increased overall temperatures, and possibly an increased proportion of summer rainfall (Epstein et al. 1997; Paruelo and
Lauenroth 1996; Teeri et al. 1978). Examination of the Figure 2-11 curve clearly shows two periods of increased $\mathrm{C}_{4}$ contribution, with one occurring between about 8000 and $4000 \mathrm{BP}$, and a second one occurring between about 2000 and $1700 \mathrm{BP}$. These periods probably reflect higher average temperatures, and possibly greater summer precipitation. Cooler, and potentially drier conditions, seem to have been occurring at the beginning of the sequence, as well as between around 3000 and $2000 \mathrm{BP}$.

Several of the alterations shown in Figure 2-11 are consistent with pollen data from Central Texas. Here we use pollen data compiled from two recent reviews, one of Boriack Bog (Bousman 1998) and one of Patschke Bog (Nickels and Mauldin 2001; see also Camper 1991). These bogs are located roughly $280 \mathrm{~km}$ to the southwest of 41PR44, in Lee

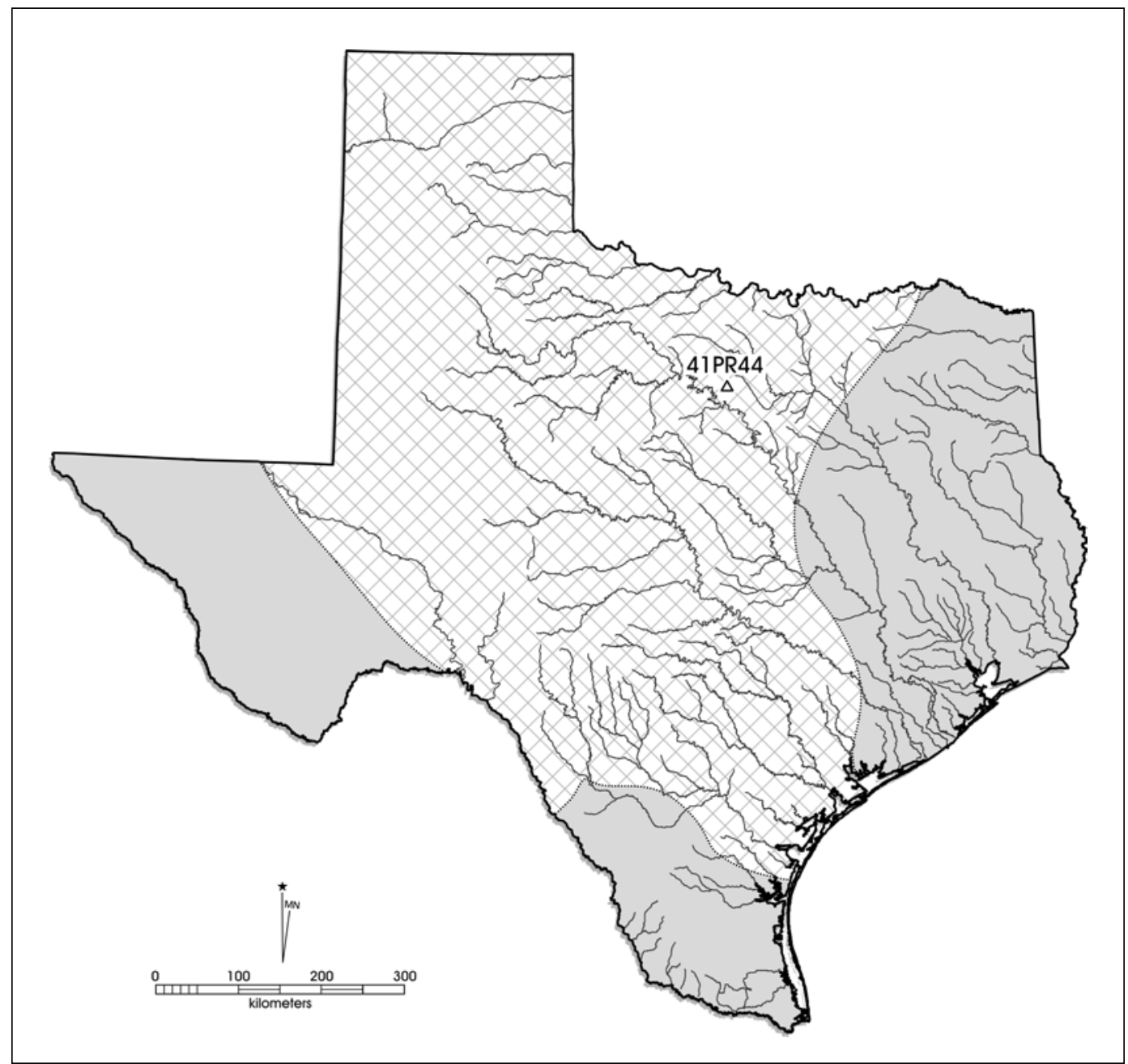

Figure 2-10. Possible core area of Bison bison in Texas (after Mauldin et al. 2006). 


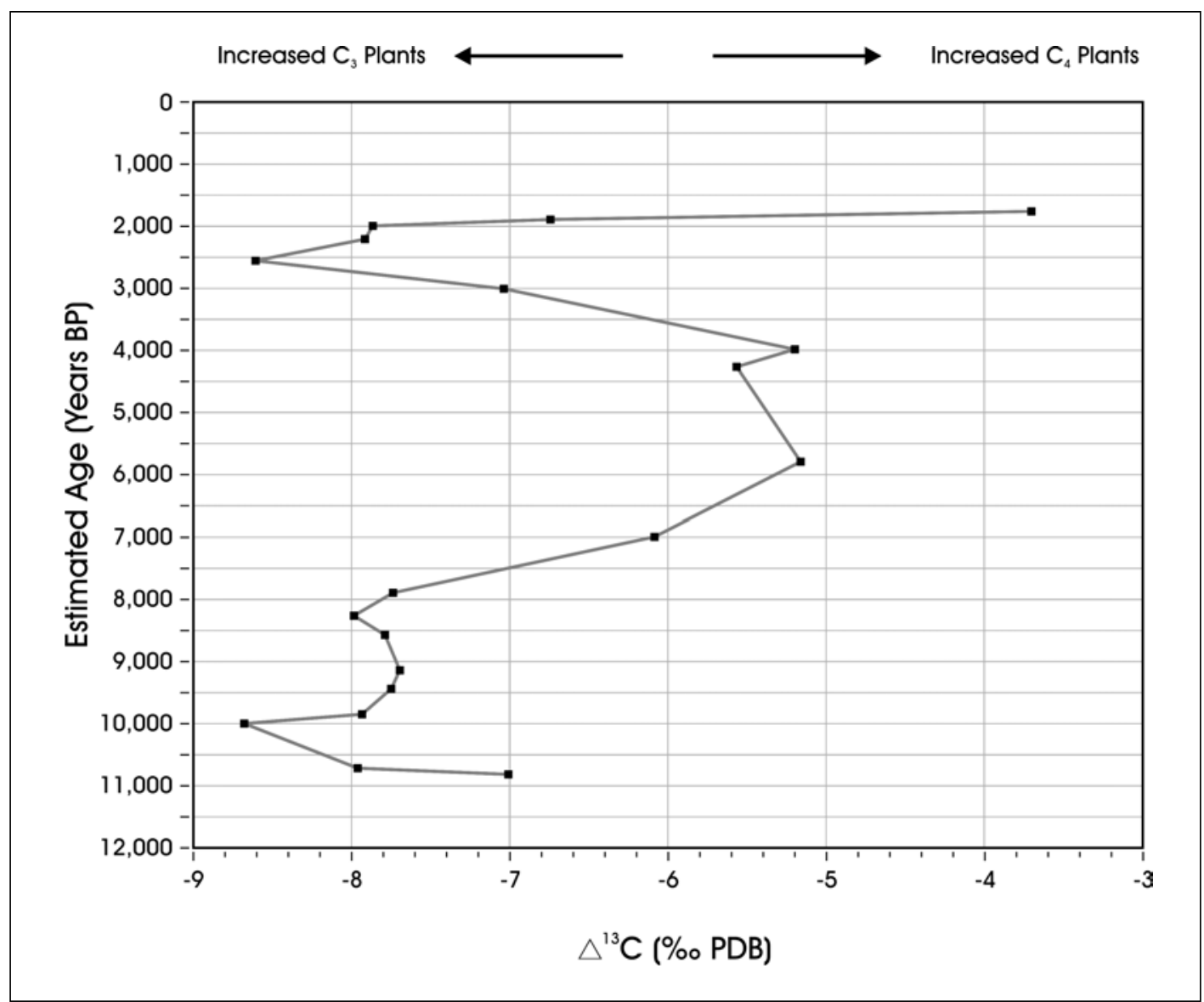

Figure 2-11. Pedogenic carbon isotope data from the Aubrey Site (41DN479) plotted against estimated age.

County. Bousman (1998) used secondary pollen counts from Boriack Bog, in which local taxa were eliminated, to focus on regional climatic conditions in that sequence. Unfortunately, the dating of the Boriack sequence is open to question, and the sequence seems to be missing the last 2,500 years. The Patschke sequence is better dated than the Boriack sequence, but, as Bousman (1998) notes, Camper's (1991) recent pollen counts from this bog include a significant amount of local marsh taxa. These taxa clearly obscure the regional signature of the Patschke data. However, Nickels and Mauldin (2001) have reviewed Camper's (1991) raw pollen counts and eliminated local marsh taxa from the Patschke sequence. Using these revised totals, the Patschke data allow consideration of regional changes.

Figure 2-12 present plots of grass (Poaceae) pollen from Boriack (blue) and Patschke (red) over the last 12,000 years. While there is a clear difference in the patterns shown between roughly 6,000 and 5,000 years ago, overall patterning in the two sequences is surprisingly close. Both show declines in the percentage of grass pollen between 12,000 and around 10,000 BP. Both show increasing grass pollen percentage throughout the Early Holocene and into the Middle Holocene. Finally, both show declining grass pollen early in the Late Holocene. As these two sequences are independent of one another, there is no reason that they should be similar unless they are, in fact, monitoring regional changes in pollen rain. Many of these same changes are reflected previously in the Figure 2-11 isotope data. After about 2000 BP, the Patschke pollen data clearly suggest declining grassland settings that eventually result in a domination of the sequence by arboreal (e.g., oak) pollen (see Nickels and Mauldin 2001).

The vegetation shifts implied by the data sets in Figures 2-11 and 2-12 are likely to be related, in part, to regional, 


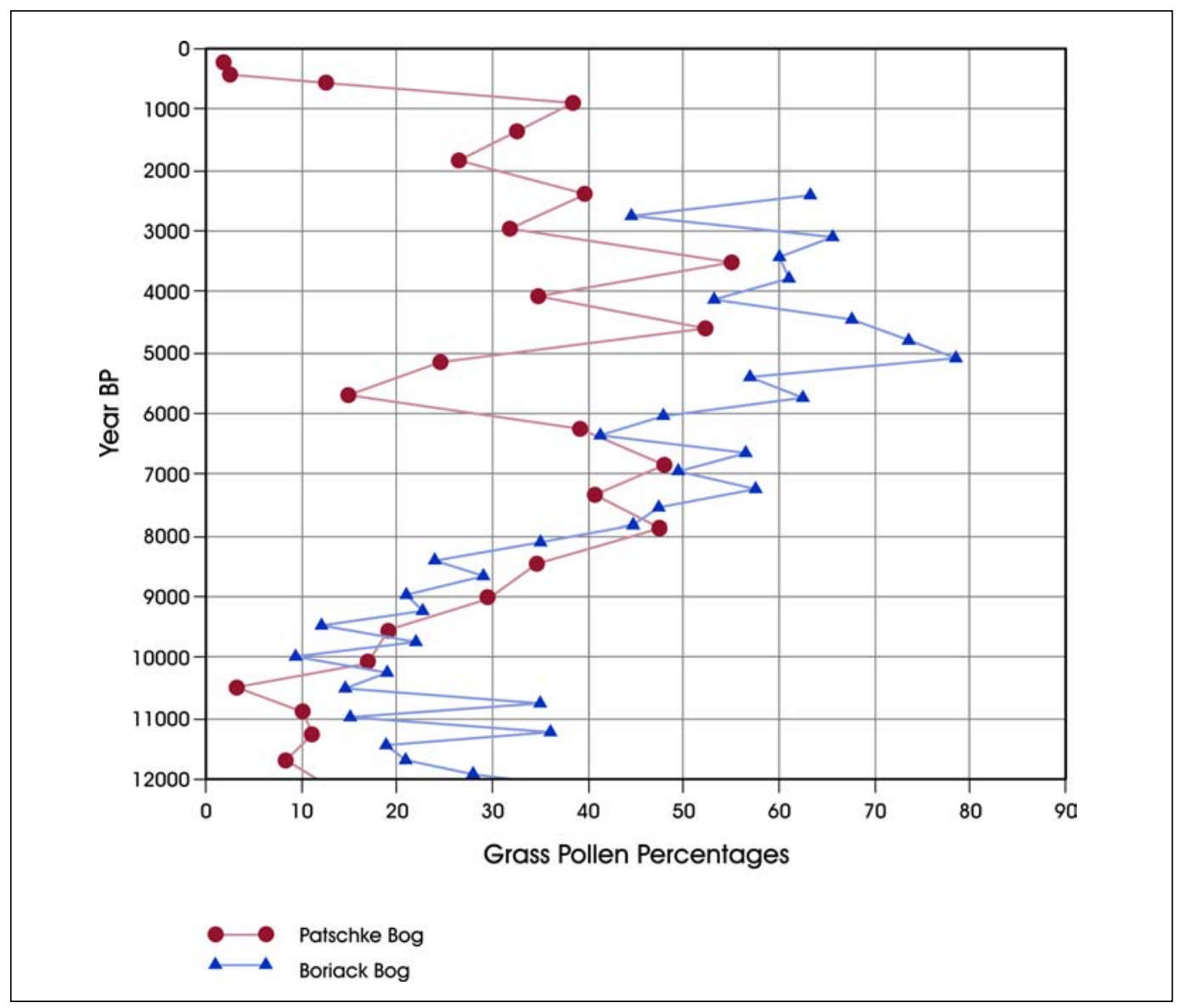

Figure 2-12. Poaceae pollen percentages from Boriack and Patschke Bogs.

long term changes in rainfall and temperature regimes initiated at the close of the Pleistocene. To the degree that these regional changes are manifested in the study area, we can anticipate similar shifts in vegetation. Throughout much of the Early and Middle Holocene, then, we can anticipate an expansion of grassland settings, with shrub/woodland cover, and the associate fauna, declining. At the close of the Middle Holocene and throughout much of the Late Holocene, these grassland settings would be slowly declining, with a more rapid decline in the last 2,000 years. We can anticipate that grassland settings would be more conducive to higher densities of several large mammals, including highly valued bison, as well as a variety of large (e.g., antelope), medium (e.g., rabbit) and small (e.g. rats, mice) mammals. Plant resources easily used by human hunters and gatherers, however, are likely to be more restricted in terms of diversity and density in a grassland setting. Conversely, increasing shrub/woodland settings should favor the expansion of deer, along with a different set of medium and small mammals. Expansion of shrub/ woodland settings could also result in greater availability of nut and tuber resources.

It is to this ebb and flow of vegetation communities and their associated fauna that hunters and gatherers attempted to successfully adapt. The following chapter summarizes what we surmise of the pattern of human adaptation in this portion of Texas, as well as how aspects of those adaptations were revealed by previous testing at 41PR44. 



\section{Chapter 3: Archaeological Background}

This chapter provides an introduction to the archaeology of the region. Included is a discussion of the poorly developed cultural chronology for this section of the state, and an overview of previous research in the area, including a summary of the testing activities conducted previously at 41PR44.

\section{Cultural Chronology}

Fort Wolters falls within the north-central portion of Texas. To date, few archaeological investigations have been conducted in the environs of the project area, and as a result the cultural chronology is not established. Better defined culture chronologies have been formed for adjacent regions (i.e., Red River, North East Texas, Deep East Texas, West Central Texas and Central Texas; see Perttula 2004:7) and aspects of the subsequent discussion rely primarily on these chronologies. The archaeological investigations that have been conducted in the area have generally used the chronology developed by Prikryl (1990) for the Upper Trinity River basin. Data on culture chronology continues to grow as data from other sites in the region are synthesized. For the purposes of this report, information on culture history was obtained from several sources, including Brownlow (2001), Ferring and Yates (1997, 1998), Perttula (2004), Prikryl (1990), and Thoms (1994). Cultural periods used for the project area are Paleo-Indian, Archaic, and Late Prehistoric. These periods mark particular cultural manifestations that are discernable by site setting, subsistence, and artifact sets (particularly projectile points). Note that while we lack any Paleo-Indian artifacts, site 41PR44 has projectile points that seem to date from throughout much of the long Archaic period, as well as points that can be placed in the early portion of the Late Prehistoric period.

\section{Paleo-Indian}

The Paleo-Indian period in this region of Texas dates prior to 8500 BP (Prikryl 1990). Typically, Paleo-Indian sites are marked by lanceolate projectile points such as Dalton, Plainview, Golondrina, Clovis, Folsom, Midland and Scottsbluff (Prikryl 1990:49). During this period, life-ways were characterized by highly mobile hunting groups that followed megafauna such as mammoth and bison. Though large game was presumed to be the main subsistence resource, small game were also used. Evidence of Paleo-Indian activity in the region consists of surface finds and a few in situ sites, such as the Aubrey Site in Denton County (Ferring 1989). Population levels are assumed to have been low, and group size thought to be small in number.

\section{Archaic}

The Archaic period, spanning roughly 9,000 years, is typically divided into three phases (Early, Middle and Late). These distinctions are made on the basis of changes in projectile points. Each phase is thought to reflect somewhat different adaptive patterns, with changes in subsistence and settlement frequently being related, in part, to major climate shifts such as those noted in the previous chapter.

\section{Early Archaic}

The Early Archaic spans the period from 8500-6000 BP (Prikryl 1990). Archaeological evidence in the region is restricted to surface finds of projectile points, such as Angostura, Gower, Martindale, Uvalde, and Early Split Stemmed. Subsistence data for this time period is scant (Ferring and Yates 1997:6). Prikryl (1990) suggests a lack of regional differences in adaptive patterns during this time period. Human populations are thought to have been less mobile during the Early Archaic relative to the Paleo-Indian period. Though data for this phase is sparse, data from Central Texas emphasizes subsistence shifts to smaller game, along with increased use of plant and aquatic resources (Collins 1995). Population size is thought to have increased relative to the earlier Paleo-Indian period.

\section{Middle Archaic}

This period ranges from 6000-3500 BP. Middle Archaic occupations in this portion of Texas are identified by the presence of particular projectile points, including Dawson, Wells, Carrollton, Morrill, and Basal Notched forms (Prikryl 1990; see also Collins 1995). It is during the Middle Archaic that several researchers argue that distinct regional cultural differences begin to become apparent. Similar to the Early Archaic period, there have been few investigations of 
Middle Archaic sites in the region. However, one site with a Middle Archaic component, 41DN102 (Calvert) has recently been investigated. The site is in the Trinity Valley just to the northeast of the project area (Ferring and Yates 1997). Ferring and Yates suggest that 41DN102 reveals evidence of adaptations to "a drier Middle Holocene landscape" (Ferring and Yates 1997:30) and repeated occupations of the site during the Middle Archaic suggest human populations in the region were quite mobile. A subsistence economy focused around smaller game and deer, suggested for the Early Archaic period, seems to have continued in the Middle Archaic.

\section{Late Archaic}

The Late Archaic in this region spans the period from 3500-1250 BP. According to Prikryl (1990) the frequency of Late Archaic sites in north-central Texas increased at least three times relative to the Middle Archaic period. Late Archaic sites exhibit Dallas, Edgewood, Elam, Ellis, Ensor, Gary, Marcos, Castroville and a variety of other projectile points, including Pedernales and Bulverde (Collins 1995). Many sites within the boundaries of Fort Wolters, including 41PR44, exhibit evidence of Late Archaic occupation. Deer and small game continue to be exploited along with plant food, the latter evidenced by an increase of tools thought to be related to plant processing (Brownlow et al. 1999). Though Late Archaic sites tend to be smaller there is evidence of repeated occupations, with higher artifact densities (Ferring and Yates 1997). Typically sites are encountered along flood plains of streams (Ferring and Yates 1997). Some researchers speculate that there is a decrease in long distance mobility and/or exchange, with a greater exploitation of local resources, including an increased reliance on local lithic material (Prikryl 1990). The Woodland phase began in the adjacent Lower Plains area of Oklahoma, with the emergence of ceramics, along with evidence of possible structures and storage pits (see Thoms 1994:30). Many of these changes are not seen in Texas until the Late Prehistoric period.

\section{Late Prehistoric}

Prikryl's (1990) culture chronology divides the Late Prehistoric into two phases: Late Prehistoric I and Late Prehistoric II. These two phases of the Late Prehistoric tend to coincide with Austin and Toyah phases for Central Texas. The Late Prehistoric I phase (1250-750 BP) is defined by the appearance of the bow and arrow in North-Central Texas (Ferring and Yates 1997:305), with smaller projectile points such as Alba, Catahoula and Scallorn types present (Prikryl 1990:58). During the Late Prehistoric I there is evidence from surrounding areas of early horticulture as Woodland sites continue to thrive in the Low Plains area and Caddo settlements are forming in East Texas (Perttulla 1995). As noted by Ferring and Yates (1997), there appears to be no evidence of Woodland sites or influence in the project area, with an absence of both ceramics and storage pit features. Evidence suggests that bison along with other fauna and flora continue to be a major subsistence resource in North-Central Texas. It also appears that occupations shift into rock shelters just southwest of the project area. Several other culture complexes are present in the Late Prehistoric in the Texas Panhandle area (see Perttula 2004).

In the Late Prehistoric II (750-250 BP) phase there is a steady increase in population with what appear to be sedentary groups just to the northwest and east of the project area. Projectile point assemblages for this period consist of Fresno, Harrell, Maud, Perdiz and Washita types (Prikryl 1990:80). Subsistence strategies continue to focus on deer, bison and small game with a continued exploitation of plants foods as well. In adjacent Palo Pinto County the Harrell Site (41YN1) exhibits evidence of interaction with groups such as the Toyah and Caddo (see Ferring and Yates 1997). Toyah affiliations have been suggested due to the presence of Perdiz points in the region. Though ceramics are associated with several regions of Texas and even parts of the North-Central Texas region, there is no evidence of them in the Fort Wolters area. Lacking from sites in North-Central Texas during this period are also burned rock midden features that are evident in South-Central and Central Texas, where sites of this type are ubiquitous (Black et al.1997; Nickels et al. 1997). Initially, burned rock middens were associated with Middle Archaic and Late Archaic periods though current research has concluded an abundant use of such features during the Late Prehistoric (see Black et al. 1997; Mauldin et al. 2003).

\section{Previous Research in the Project Area}

Focusing specifically on the project area, our review of archaeological literature for both Parker County and Fort Wolters produced limited results. Several small-scale surveys have been conducted in the region (e.g., Anthony and Brown 1991; Brown 1986; Hubbard 1994; Skinner 1981), though most have not recorded any prehistoric sites. This lack of information on the area is clearly evidenced 
by accessing the Texas Archeological Sites Atlas. In July 2003, the Sites Atlas contained information on only 57 prehistoric sites in Parker County, and these were primarily known only from survey. Most of these sites $(n=36)$ can be classified as lithic scatters as they consist of various densities of chipped stone without any evidence of features, scattered burned rock, or charcoal. Seventeen sites, classified as camps, have these elements in addition to lithic material. In the remaining cases, the site descriptions are unclear as to what material was observed or recovered from a location.

Not surprisingly, of the 57 prehistoric sites listed in the Sites Atlas for Parker County, 35 lack any temporal assignments and five can only be assigned to an unspecified Archaic age. The 17 remaining sites seem to reflect an emphasis on later occupations, with most assigned to a Late Prehistoric and Late Archaic temporal placement. There are six Late Prehistoric components, six Late Archaic components, two Middle Archaic sites, and three multi-component sites listed. While no single-component, Early Archaic or Paleoindian sites were recorded in the Sites Atlas, two Plainview points were recovered from 41PR26, a multi-component site located near Lake Worth on the eastern edge of the county. In addition, Brownlow et al. (1999:40) list two sites (41PR53 and 41PR54) as containing Early Archaic materials, although the Sites Atlas lists these sites as Late Archaic (41PR53) and Unknown Prehistoric (41PR54).

Much of what we do know about Parker County comes from work at Fort Wolters. Thirty-two of the 57 prehistoric sites recorded in the county are located on the facility. These sites were primarily discovered and recorded by archaeologists from TARL at The University of Texas at Austin who conducted a comprehensive archaeological survey of 3,500 acres within Fort Wolters (Brownlow et al. 1999). Forty-nine historic and prehistoric sites were recorded during that survey, including one site, 41PR57, which was assessed as eligible for inclusion in the National Register of Historic Places. In addition, Brownlow et al. (1999) recommended five sites (41PR44, 41PR49, 41PR77, 41PR88, and 41PR90) as potentially eligible, requiring additional testing. TARL conducted testing at four of these sites (41PR44, 41PR49, 41PR77, and 41PR90) in late 1999 (Brownlow 2001). They determined two of the prehistoric sites (41PR44 and 41PR90) were eligible for inclusion in the National Register of Historic Places.

\section{Previous Investigations at 41PR44}

As noted, site 41PR44 was originally recorded by TARL (Brownlow et al. 1999). The site is located on the northern portion of the facility, on the west side of Rock Creek, at an elevation of roughly $935 \mathrm{ft}$. (285 m). Brownlow (1999:6970) described the site as a Late Prehistoric and Late Archaic open camp, measuring roughly $35-x-75$ meters. He notes that the site was identified by the observation of chert debitage, a biface fragment, ground stone, and burned sandstone on the surface. Vegetation observed at the site during the current project included a variety of forbs and grasses, with oak forming the major overstory. Surface artifact density was low. The site is located on what appears to be a terrace below a north-south trending sandstone escarpment. Rock Creek is immediately to the southeast of the site. A frequently used dirt road, which serves as a lowwater crossing over Rock Creek, cuts through the center of 41PR44. The presence of this road, which is heavily used by military traffic, has resulted in erosion of the surrounding sediments (Figure 3-1).

Brownlow (1999:69) reports that nine shovel tests and two backhoe trenches were excavated in the initial work at 41PR44. Figure 3-2, adapted from Brownlow (1999:70; see also Brownlow 2001:14), shows details of both the site location, the initial work conducted at 41PR44, and subsequent testing. Three of the nine shovel tests placed during the survey were positive, with the three tests recovering five pieces of debitage. An examination of the chipped stone distribution (Brownlow 1999:98) seems to suggest two different clusters, with a group of four pieces of debitage recovered from $0-50 \mathrm{~cm}$ below surface $(\mathrm{cmbs})$, and a single flake recovered from $80-100 \mathrm{cmbs}$. Some quantities of fire-cracked rock were also present in the shovel tests, though counts or locations of occurrence could not be ascertained from the report. In addition, some lowdensity concentrations of fire-cracked rock and chipped stone were noted on the surface (see Figure 3-2).

Backhoe Trench (BHT) 12, located on the southern end of the site (Figure 3-2), yielded evidence of five distinct sediment zones down to $142 \mathrm{cmbs}$, the bottom depth of the trench. According to Brownlow (1999:69), two zones, Zone 1 (0-39 cmbs) and Zone 4 (82-104 cmbs), had strong potential to contain cultural material. This suggestion is based on the recovery of a flake and some fire-cracked rock in Shovel Test DP 6, located just to the north of the trench 


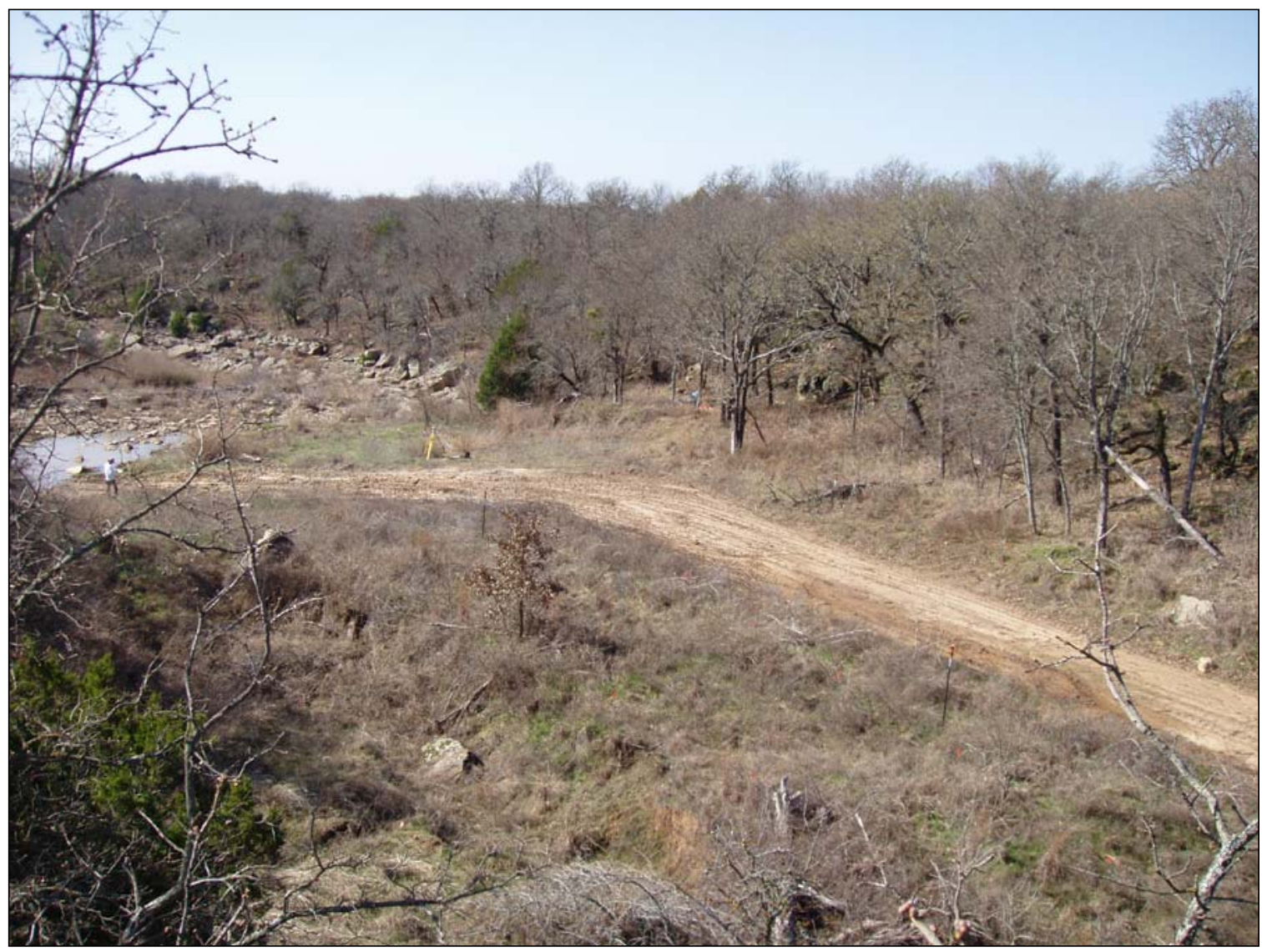

Figure 3-1. View of 41PR44 looking toward the southwest.

(Figure 3-2), from 0-20 cmbs, and a chert flake from this same shovel test from $80-100 \mathrm{cmbs}$. No evidence of cultural material was recovered in the trench, though three bone fragments, identified as coming from a juvenile bovid, were recovered from the trench backdirt. These bones probably represent bison. Sediment Zone 4 also contained evidence of a paleosol, which produced a radiocarbon date calibrating to a range of between 1425 and 1120 B.C.

The excavation of Backhoe Trench 13 by TARL, a trench located just off site (Figure 3-2), produced evidence of two large zones of sediment. The upper zone consisted of roughly $120 \mathrm{~cm}$ of a grayish brown sand, silt, and clay. The bottom zone consisted of a light reddish brown sandy clay loam that continued down to $200 \mathrm{cmbs}$, the bottom of the trench. The upper zone appeared to represent redeposited material. Neither zone produced any evidence of cultural material.

While no diagnostic artifacts were found during the initial work at the site, based on the above information, as well as the patterns identified by Dillehay (1974) for bison presence and absence, Brownlow (1999:69) suggests that two distinct occupations may be reflected at the site, with one probably being a Late Archaic occupation. Brownlow (1999:69-70) argued that additional testing of this location was warranted. Brownlow (2001) conducted this testing in late 1999. Two 1-x-1-m test units (TUs) were placed at the site (Figure 3-2), with TU 1 located at the center of the site, and TU 2 located on the southern end of the distribution.

TU 1 was excavated to a depth of $120 \mathrm{cmbs}$, producing evidence of three sediment zones, one feature, scattered fire-cracked rock, 33 flakes, two lithic tools, and 12 pieces of bone. Feature 1, a concentration of burned sandstone and limestone, occurred at the break between sediment Zones 2 and 1, at roughly $60 \mathrm{cmbs}$. Examination of the vertical distribution of other cultural material suggests two broad cultural zones may have been present in the unit, with the upper zone encompassing the feature. Of the 35 pieces of chipped stone recovered from the test unit, 24 


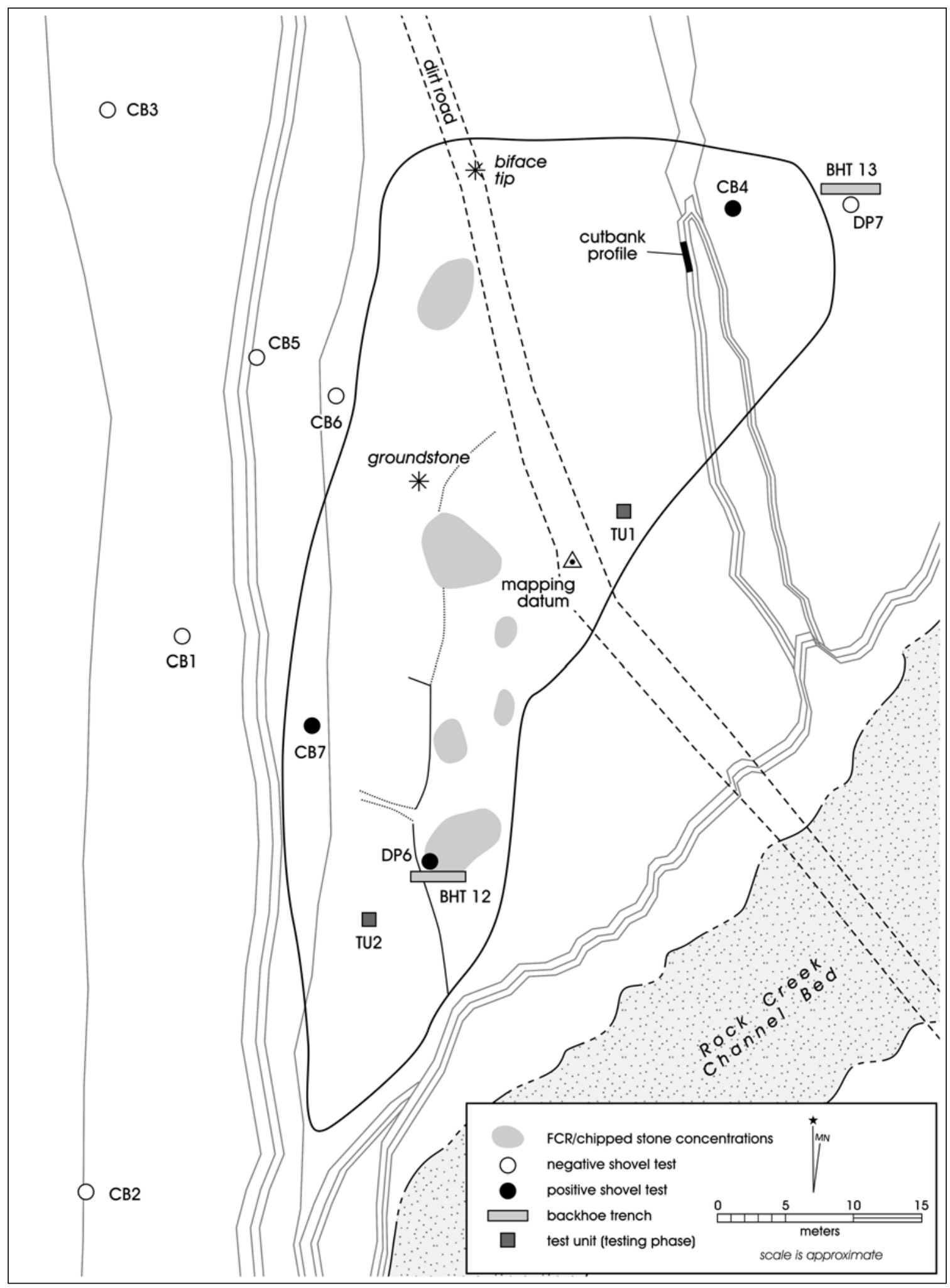

Figure 3-2. Previous investigations at 41PR44. 
(68.6\%) occurred between 10 and $70 \mathrm{cmbs}$, with 17 of these concentrated between 30 and $60 \mathrm{cmbs}$. This upper concentration also contained bone and burned rock, with the burned rock present between 30 and $70 \mathrm{cmbs}$. This broad upper zone of material was separated from the lower material by a relatively sterile level between 70 and $90 \mathrm{cmbs}$. While small amounts of bone were noted in both of these $10-\mathrm{cm}$ levels, the levels lacked any burned rock, and produced only three chipped stone items. Between 90 and $120 \mathrm{cmbs}$, a second occurrence of cultural material was present, with eight chipped stone items (22.9\%) recovered. In addition, fire-cracked rock was present in all three 10-cm levels between 90 and $120 \mathrm{cmbs}$ (Brownlow 2001).

TU 2 was excavated to a depth of $110 \mathrm{cmbs}$. This test unit revealed two sediment zones, and a variety of cultural materials, including 68 pieces of chipped stone debitage, five edge-modified flakes, two bifaces, two arrow points, charcoal, and a fire-cracked rock feature. Bone, along with both mussel and snail shell, was also present. Much of the cultural material, including the feature (Feature 2), occurred between 20 and $80 \mathrm{cmbs}$, and no material was recovered below $100 \mathrm{cmbs}$. Just over $95 \%$ of the chipped stone debitage $(n=68)$, all tools, and all charcoal were recovered from 20 to $80 \mathrm{cmbs}$. In addition, these levels were the only portion of the test unit with fire-cracked rock. Feature 2 appears to have been defined at roughly $60 \mathrm{cmbs}$, and consisted of a concentration of burned sandstone. A radiocarbon date from this feature produced a calibrated age range of between A.D. 870 and 1050, suggesting a Late Prehistoric use, an age consistent with the recovery of the arrow points. While a lower (90-100 cmbs) concentration of bone was noted in this test unit, it appears that the 20-80 cmbs area contained much of the cultural material, and reflected a Late Prehistoric use (Brownlow 2001).

Finally, Figure 3-2 identifies the location of a profile from along an erosional gully near the northeastern end of the site. The profile had evidence of burned sandstone at between about 50 and $80 \mathrm{cmbs}$, although no chipped stone artifacts were observed.

\section{Summary}

These summaries, then, suggest that most of the materials recovered from 41PR44 occurred within the upper 70 to 80 $\mathrm{cm}$ of the site, though a lower component (ca. 90 to 110 cmbs) was also present. Intact features, radiocarbon dates, and two diagnostic arrow points clearly indicate that the upper component represents a Late Prehistoric time period with good integrity. There is some possibility that the lower material represents Late Archaic material, and while bone, chipped stone, and fire-cracked rock are certainly present at these lower depths, no clearly defined features associated with these levels were identified. However, note that testing was limited at this site, and there is a high probability that features are present in these lower levels.

Using both the survey and testing results summarized above, Brownlow (2001:18) recommended that 41PR44 was eligible for inclusion in the National Register of Historic Places under Criterion D. While the site has been directly impacted by military traffic, and while secondary erosion associated with the dirt road has further damaged the site, he suggests that intact cultural material was present at several areas of the site. The testing, while limited, demonstrated the presence of intact burned rock features with the potential for good floral and faunal recovery from several different areas of 41PR44. A radiocarbon date from one feature, as well as the recovery of two arrow points, demonstrates that some of these deposits are clearly Late Prehistoric in age. Brownlow (2001:18) also suggests that a Late Archaic component is present. In our view, the evidence for a Late Archaic component is less clear, though the lower deposits near Shovel Test DP6 and Backhoe Trench 12, as well as the lower deposits in TU 1, may reflect such an occupation. In any event, it is the case that the Late Prehistoric occupation does have the potential to contribute to a variety of research areas.

As continued use and maintenance of the road will result in continued erosion of the significant deposits at the site, and as avoidance of the site area was not possible, CAR, under direction from the Texas Army National Guard, outlined a plan to recover significant data from 41PR44. That plan was submitted to the Texas Army National Guard and the Texas Historical Commission in January 2004 (Mauldin 2004). The plan was accepted in early March 2004 and fieldwork was initiated shortly thereafter.

Our review of both the cultural chronology for the region, as well as previous archaeological investigations in the area, produced surprisingly little information. While some survey data are available, few sites have been excavated. Much of what we think we know about the region is derived from surrounding areas. The cultural chronology is not well developed, and few independent dates exist for this region. Given the low level of testing on prehistoric occupations in 
the area, we have little concrete information on subsistence, and only minimal descriptive data on aspects of chipped stone or features. As such, the results of the data recovery work at 41PR44 can potentially make a significant contribution to our understanding of adaptations in this understudied portion of Texas. 



\section{Chapter 4: Research Overview}

As noted at the close of the previous chapter, our overview of cultural chronology and our review of previous investigations suggest that we know surprisingly little about the area surrounding 41PR44. Few sites have been tested, and with the exception of survey work on Fort Wolters, it does not appear that large, contiguous tracks of land have been systematically surveyed. In our review of Texas Sites Atlas records, summarized in the previous chapter, only 17 sites in Parker County had any detailed prehistoric temporal assignment. When this lack of information on prehistoric site distributions and temporal assignment is combined with our limited understanding of past environments discussed in Chapter 2, the potential importance of the data recovery work at 41PR44 becomes clear. In the current chapter, then, we provide a general overview of the theoretical position that will guide the analysis of material collected from data recovery work at 41PR44. In addition, we outline several research domains that will be subsequently investigated.

\section{Theoretical Background}

At a general level, our interpretive scheme comes from a theoretical position that can be broadly classified as cultural ecology. We view cultural systems as both adaptive and differentiated. By adaptive, we mean that cultural systems are continually responding to changes in their environment. Of particular concern in that response are the strategies and tactics, including technology, used to procure and process food, fuel, and raw materials from their environment. By differentiated, we mean that different activities are conducted at different times and locations depending on specific circumstances. As activities conducted by a group vary in space and through time, the material remains generated by those activities and the tools and facilities used to conduct those activities, will also vary. Consequently, individuals and groups operating within the same cultural system potentially will generate radically different material remains at various points on the landscape. Variations in material culture, both at the level of individual artifact forms and at an assemblage level, primarily reflect adaptive responses rather than cultural norms. This position contrasts with that frequently used in Texas archeology where variations in certain artifact forms (e.g., projectile points) and in assemblages (e.g., Austin Phase) are commonly interpreted as reflecting historical relationships or normative, cultural constraints, rather than adaptive responses.

From our perspective, changes in cultural systems, including changes in material culture, are principally the result of changing parameters in the physical and social environment in which systems operate and to which they must adapt, not a reflection of movement of groups with a shared culture, or influences diffused from other groups. This is not to suggest that diffusion or migration does not occur, but we are interested in why traits are adopted or why strategies and tactics change rather than tracing their supposed historical connections through similarities in artifact form. Currently, our understanding of the mechanisms of change, as well as our methodology for monitoring those mechanisms in the social realm, is not well developed. Clearly, social factors, such as territorial disputes and shifting alliances, can alter adaptive strategies, especially through altering access to resource areas. However, our current understanding of how to monitor these social factors with archeological data is all but non-existent. In addition, even the best archeological data probably has a temporal resolution of several decades, while social alliances commonly operated on a much shorter temporal scale. Consequently, we currently have no effective way to monitor many of these social factors in an archeological setting. We focus here, then, on interactions between aspects of cultural adaptation and the natural realm. At this level, we have better developed methods. Especially critical in that interaction are strategies and tactics, including the organization of technology and mobility, which are used to acquire resources. It is in this realm, where cultural systems interact with the natural environment, that extant adaptive strategies are molded and modified. In addition, at least some of these interactions operate on longer temporal scales that have the potential to manifest themselves in the archeological record.

Resources, including food, water, and raw material, are not uniformly distributed in space, nor are they of uniform quality or density through time. Among hunter-gathers, problems created by spatial variation in resources are commonly solved by mobility strategies that involve positioning and changes in group composition. Mobility strategies have several components that can vary, including the frequency of moves, the distance moved, and the degree 
to which different types of organization (e.g., logistically organized task groups, higher residential mobility) are used (see Kelly 1995). Temporal fluctuations in resources, including seasonal changes in resource availability and quality, year-to-year fluctuations in resource density, and longer-term changes in resource structure, are commonly solved by shifts in mobility strategies, fluctuations in group composition, technological alterations, and, potentially, resource storage strategies.

\section{Research Domains Investigated at $41 \mathrm{PR} 44$}

With the above overview as a background, we now turn to considering research domains that will be explored with the data collected from 41PR44. While, by definition, all archaeological sites have data present, and therefore have some potential research value, not all sites have data that can be used to investigate all research questions. If cultural deposits are significantly mixed by either cultural or physical processes, the potential of the assemblage to answer commonly asked questions is frequently seen as degraded. In part, this vision of the archaeological record reflects upon our underdeveloped ability to ask interesting questions, as well as on our level of methodological sophistication. And with sufficient temporal resolution, it is probably the case that all sites or assemblages are, to some degree, mixed by cultural and physical processes. That is, from a sufficiently detailed temporal perspective, there is no such thing as a "pristine" site. The integrity, and by extension the research value of an archaeological site, can only be considered with regards to a particular suite of questions. For some questions, sites located at the high end of the integrity continuum are critical, but for others, sites that traditionally are viewed as having low integrity, are critical. For example, if our research interests are centered on reconstructing the subsistence patterns during a particular temporal period, sites which have been repeatedly occupied by a variety of different groups over thousands of years have low research potential if these occupations can't be clearly separated. Conversely, single component sites, those traditionally viewed as having high integrity and high research potential, are of less use if our research questions center on understanding processes of reoccupation or processes of longterm change in the use characteristics of a given location. That is, we argue that the research potential of a location is highly dependent on the research questions being asked.

In addition, the research questions asked should be related to our current knowledge base. We argue that the research value of a site is not simply identifiable as the presence of certain kinds of deposits (e.g., features) or artifacts (e.g., projectile points). Rather, it is the recognition of what aspects of archaeology we can address in examination of any particular archaeological situation that should determine research value. The more we know about a particular area, the more sophisticated and focused our research questions should become. As questions become more focused, it is likely that fewer and fewer assemblages will be applicable to investigating those questions. Our review of current knowledge regarding prehistory in this portion of Texas, presented in the previous chapter, clearly suggests that there are many gaps in our current understanding.

Given our current state of ignorance regarding most aspects of adaptation in this portion of Texas, a variety of descriptive analysis may be best suited for the 41PR44 data. That is, we currently lack comparative data that can serve as a baseline for most investigations. A basic description of the 41PR44 data can begin to form that baseline. We will, then, explore four broad research areas with the 41PR44 data. These research interests include a description and exploration of subsistence activities at $41 \mathrm{PR} 44$ as manifested primarily through ground stone tools and vertebrate faunal remains, a description and exploration of aspects of chipped stone technology present at the site, and the description and exploration of burned rock feature technology. In addition, we explore basic chronological concerns present in the 41PR44 data. Each of these research domains are discussed subsequently.

\section{Chronology}

As noted previously, most researchers view the isolation of chronological units (e.g., Austin Phase) as a necessary first step in investigation. We have suggested that the isolation of discrete chronological units is necessary to address many commonly investigated research questions, but that for some questions, as well as for some regions where chronology is poorly developed, the isolation of discrete temporal units may be less important.

Previous research at 41PR44 (Brownlow et al. 1999; Brownlow 2001) has demonstrated the presence of a Late Prehistoric occupation, as well as a possible Late Archaic occupation. As will be discussed in Chapter 5, our research at the site produced a variety of projectile points that may reflect use of the site, at some level of intensity, from as early as the Early Archaic through the Early Late Prehistoric. 
While no clearly Early Archaic projectile points have been unambiguously typed, we have several specimens that compare favorably with Early Archaic or Early/Middle Archaic forms, such as Martindale, Hoxie, and Wells (see Turner and Hester 1999). No clearly Middle Archaic forms are present, but an early Late Archaic Bulverde point, as well as several specimens that are probably Late Archaic Marshall points, were recovered. Several Late Prehistoric Scallorn arrow points and one Edwards point were also recovered. In addition, we have a radiocarbon date on an isolated piece of charcoal that returned an early Late Archaic age of around $3550 \mathrm{cal}$ BP (Appendix A). The site seems to reflect, then, a long period of what appears to be low intensity occupations.

Our work at 41PR44 suggests that there is considerable mixing of deposits in some areas. However, we were able to isolate some deposits that have a high probability of dating between about A.D. 750 and A.D. 1250, as well as earlier deposits, some of which fall between about 50 B.C. and 1700 B.C. In addition, we can estimate ages, based on depth, for some additional deposits. While faunal and artifact samples for these periods are small in number, the groupings do provide material for more fine-grained consideration of subsistence activities.

\section{Subsistence}

As we noted at the beginning of this chapter, the acquisition of resources has significant implications for most other aspects of cultural systems, including how mobility and technology may be organized, as well as how aspects of these organizational components may change through time. Traditionally, several data sets, including faunal remains, floral remains, and aspects of processing technology (e.g., ground stone, burned rock features) are used to investigate subsistence.

In the case of 41PR44, our investigations produced a moderate to low frequency of vertebrate faunal material (see Appendix B), as well as several pieces of formal ground stone. However, much of these data are in questionable temporal contexts. In addition, while we designated 12 features in the field, many of these were determined not to represent thermal features with good context (see Chapters $6,10)$. Ultimately, only three thermal features were recorded. Flotation of matrix from these features failed to produce any significant quantities of carbonized material (see Appendix C). Consequently, while data with direct relevance to reconstructing subsistence activities at 41PR44 are primarily limited to aspects of ground stone and faunal remains from less than ideal temporal contexts, they are of interest given that we currently know little about subsistence activities in this portion of Texas. We investigate variations in ground stone, and provide a description of the faunal remains at the site level. These data can serve as a starting point for the development of a regional database.

In addition to the simple description of animals used at 41PR44, we can, as noted previously, isolate several broad temporal blocks that allow comparison of faunal assemblages, as well as the exploration of changes in those assemblages. While the samples sizes of fauna associated with these blocks are extremely small, rendering any conclusions tentative, the exploration of change through time in animals exploited is pursued with a cost/benefit framework developed by evolutionary ecologists (Charnov et al. 1976; Kaplan and Hill 1992; MacArther and Pianka 1966; Stephens and Krebs 1987; Winterhalder 1981). While many assumptions of these foraging models are clearly violated by human hunter-gatherers, and while parameters specified for analysis are often difficult to estimate in archeological situations, we find the models appealing as they provide an explicit cost/benefit framework for analysis. Foraging models of concern here (see Stephens and Krebs 1987) frequently quantify returns (benefits) as energy (kilocalories [kcal]) obtained from food (but see Jochim 1975; Speth and Spielmann 1983), and quantify costs as time expended on searching for, pursuing, capturing, and processing that food. They assume that foragers will attempt to maximize average return rates in the context of different cost/benefit ratios for different prey. Costs are usually broadly framed as search costs, the amount of time spent looking for game or resource patches, and handling costs, the amount of time required to pursue, capture, and process foods. For hunters and gatherers, we would also include in handling costs time associated with production of tools (e.g., raw material acquisition, tool shaping, maintenance), and time associated with processing elements such as preparation of hearths. While changes in technology can impact search costs (e.g., the use of dogs) and success rates, most of the impacts of technology are on handling costs.

A critical element of prey foraging models that we will use to structure our investigation of subsistence is associated with ranking of prey alternatives. Potential prey items are ranked in terms of handling costs and benefits. For animals, this ranking often reflects body size; larger-bodied animals (e.g., bison) are more profitable (higher returns relative to 
handling costs) than smaller-sized animals such as rabbit or rodents. Plants usually rank below animals, though there are exceptions (see Kelly 1995; Simms 1987). Search costs, though not taken into account in rankings, do play a critical role in determining the actual diet. In a classic prey foraging model, as more resource types are added to the diet, search costs decline because resources are encountered more frequently. However, these new resources, being lower ranked, have higher handling costs and/or lower caloric benefits (i.e., lower profitability). Foraging models predict a tradeoff, then, between handling cost, energy benefits, and search costs that will maximize the average return and produce an optimal diet. These models predict that foragers will continue to add lower-ranked resources to the diet, increasing the diet breadth, so long as the overall profitability of the diet, seen in terms of total costs and benefits, is increased. Furthermore, resource types should be dropped from the diet, reducing the diet breadth, when doing so would increase overall profitability.

Using this perspective, the faunal remains collected from 41PR44 that can be assigned to temporal periods will be grouped into body-size classes. These body-size classes should, at a broad scale, reflect profitability. That is, animals in the larger body-size groups should have a higher return relative to handling costs than those in the smaller body-size groups. As such, these higher return, larger bodied animals should be pursued when they are encountered. Conversely, animals in the smaller body-sized groups should be ignored, provided that the search costs of more profitable resources are not excessive. Of course, a variety of complications in any given setting must be acknowledged. Animal resources fluctuate in quality and density throughout the year. Hunter group size, landscape position, and available technology at the time of encounter will influence pursuit decisions. In addition, the post-encounter kill rates for various types of animals will vary significantly depending, in part, on encounter conditions. None of these complications, which operate at a short time scale, can be monitored in an archaeological situation. Nevertheless, similar cost/benefit frameworks has proven to be insightful elsewhere in the analysis of Texas archaeological material (see Figueroa and Mauldin 2005:88-92; Tomka and Mauldin 2003; Tomka et al. 2004). Using the NISP of body-size groups, we will explore shifts in the proportions of different body-size groups through time in the 41PR44 data set. These shifts may provide clues to broader patterns of resources stress and opportunity experienced by hunters and gatherers occupying 41PR44.

\section{Lithic Technology}

The third research domain concerns aspects of lithic technology. While, like subsistence, we provide a general description of the chipped stone and ground stone assemblage, and make limited comparisons between the temporal components that can be identified, much of our discussion concerning chipped stone involves an exploration of the impacts of raw material availability, size, and quality on various aspects of lithic technology. Site 41PR44 is located in a portion of the state that can be characterized as impoverished with regard to stone for chipped stone tools. Unlike much of the Edwards Plateau to the south where large nodules of high quality cherts are commonly exposed in Edwards limestone and correlated geological strata (see Frederick and Ringstaff 1994:133), prehistoric inhabitants of what is now Parker and Palo Pinto Counties did not have access to superior material. As discussed in Chapter 2 (see Figure 2-3), while sandstones, conglomerates, and shale are common, the limestone deposits in this section of the state lack high quality cherts. The 41PR44 chipped stone assemblage, then, provides an ideal case for investigating the impacts of raw material availability on lithic technology.

Note that such an examination is possible without any explicit reference to chronology. Raw material quality, size, and availability vary spatially. That variability provides a baseline against which we can investigate the responses of hunters and gatherers regardless of the time periods represented. Exploring this research domain with the 41PR44 chipped stone material can provide a better understanding of how raw material availability, quality, and size influence reduction strategies and aspects of lithic tool organization.

In raw material poor areas, such as 41PR44, we can envision two radically different coping strategies. In the first strategy, tool stone could be transported from areas of high availability into the region. These items would probably be in partially reduced forms such as bifaces or decorticated cores, though finished tools could also be present. These items could then be reduced, resharpened, or refurbished as needed. In the second strategy, hunters and gatherers would rely on lower quality/smaller sized chert resources, as well as non-chert materials, to meet their tool stone needs. While both strategies should result in smaller sized debitage, as well as a high frequency of exhausted and refurbished tools and cores, we can anticipate differences in cortical coverage for the two strategies, as well as differences in the frequency with which non-chert materials are used. That 
is, the transport strategy should produce debitage assemblages dominated by non-cortical debitage, whereas non-cortical flakes should be less common if local raw materials are used. This low frequency of non-cortical debitage when local materials are relied upon is an outgrowth of smaller nodule size. Patterns of debitage size and cortical cover, as well as the frequency of refurbishing and the frequency of exhausted cores and tools, should look dramatically different in raw material abundant regions of the state. While considerable variability in these measures may be evidenced in any particular situation as a function of specific adaptive responses, when a number of assemblages are considered, these patterns can be anticipated.

In many, if not most cases where tool stone is limited, a combination of both strategies probably occurred. Consequently, in most cases it is likely that cherts from a variety of non-local and local sources, as well as non-chert materials (e.g., quartzite), came into a location. Some of these cherts may have been reduced to bifaces or finished tools elsewhere and some may reflect smaller, lower quality sources. In order to document that such strategies are present at 41PR44, as well as to consider the relative contribution of each of the two coping strategies presented, we will monitor a series of attributes (e.g., attributes of debitage size, cortex percentages) for different raw material types. Raw material types will be defined by reference to stone color, the presence of inclusions, degree of transparency, and rock type (i.e., chert, quartzite). Once established, attributes of debitage size and cortex will be considered for each of these specific raw material types. This analysis will allow us to consider the impacts of raw material availability on reduction strategies at 41PR 44 , as well as begin to develop general expectations for other portions of the state.

\section{Feature Technology}

The final research domain investigated with the 41PR44 data involves the use of burned rock features. Based on the initial testing, burned rock features were anticipated to be common on 41PR44. Indeed, the possibility of excavating numerous features, with the potential to provide chronologically grounded information on technology and subsistence, was a primary research interest at the site (see Mauldin 2004). However, during our fieldwork it became apparent that while angular sandstone and, to a lesser degree, limestone rock was common in the site deposits, and while the rock often appeared in clusters, there were questions regarding both the degree to which these materials were burned as well as questions about their context. During our field work, we identified 12 burned rock features. The field assessment of the project geoarchaeologist, Dr. Russell Greaves, was that in all cases, the rock clusters identified as cultural features by CAR, as well as those identified previously by TARL, had a high probability of representing both natural accumulations of unburned rock as well as re-deposited burned rock and artifacts (see Chapter 6). In the field, we compared sandstone collected off site with examples collected from site and feature contexts. In many cases, the off site sandstone samples were angular and of a similar color range as those from site and feature contexts.

The initial dilemma we faced, then, in investigating feature technology at 41PR44 was devising methods that would allow us to unambiguously identify (1) what rocks were burned, and (2) which clusters of rock were the result of cultural rather than natural processes. As outlined in Chapter 10 , we were successful in devising methods that allowed us to identify heating in sandstone and sediment. The procedure relies on changes in magnetic susceptibility of crushed rock and sediment before and after heating. While the procedure is time consuming, and therefore could only be done on a small number of rocks, it proved successful in clearly eliminating eight of the original 12 clusters that we had identified as thermal features. At least some of the tested rocks in each of those clusters had not been previously heated. This is strong evidence that the cluster was not used as a hearth. In a second group of rock clusters $(n=4)$, all the rocks that we tested proved to have been previously heated and therefore we could not eliminate those clusters based on the presence of unheated stone. However, in one case the feature was identified in a context which, based on the vertical distribution of projectile points, the geomorphic context, and on the overall distribution of rock, was disturbed. That is, these clusters contained cultural material, but the clustering was probably a result of natural rather than cultural processes. We are left, then, with three features that are cultural in origin and appear to be in good context. In the single case where we had appropriate samples (Feature 12), we have strong evidence for in situ burning as shown by systematic changes in the magnetic susceptibility values of sediment.

Having developed procedures to identify thermal features on 41PR44, we ask more direct questions regarding what these features may represent. While a substantial investigation into the features at 41PR44 is now limited by the small sample size $(n=3)$, the research can begin to form a baseline that can be expanded by future investigations in this region. Below, we suggest three attributes of features 
(total rock weight, rock size within a feature, and the contribution of various types of stone) that may prove to be important in defining different groups of features and eventually in understanding thermal burned rock feature use.

Research into the use of rock in thermal features has, over the last decade, seen considerable development. Most of this research in Texas has focused on the thermal storage capacity of rock in the context of long-term cooking requirements of certain foods (see Black et al. 1998; Black 2003; Dering 1999; Ellis 1997). One of the more influential studies along these lines was done by Wandsnider (1997) who used a combination of chemical analysis and ethnographic sources to investigate the use of rock in features. Wandsnider (1997) found that many plant resources such as bulbs, roots, and nuts often contain compounds that are not immediately digestible by humans. As a result, these classes of plants require extended cooking times, frequently in excess of 10 hours and extending up to 60 hours, in order to convert the indigestible starch compounds to digestible sugars. Thermal features without rock are adequate in preparing foods that require short cooking times (e.g., meats) and/or are cooked in containers such as pots (i.e., stews). However, when lengthier cooking times are necessary, the use of rocks to increase heat storage and lengthen heat dissipation is commonly employed (see also Ellis 1997). That is, features with rock have the capacity to dissipate heat slowly over a long period of time. Given these results, we would expect that many, though not necessarily all plant resources, would be cooked in rock facilities, especially in the absence of ceramics. Conversely, the majority of meats would be prepared in hearths with little or no rock. Wandsnider's (1997) search of the ethnographic literature revealed a series of case studies that seem to support aspects of this general relationship. Seventy-six percent (55 of 72) of the facilities used to cook plants contain heated rocks, while in the majority of cases (75\%) facilities used to prepare animal tissue lacked rocks as a heating element.

As Black (2003) has recently argued, one of the critical variables in developing an understanding of rock features is likely to be the total weight of rocks that make up an individual feature. This is because there is a relationship between the total weight of a feature and the capacity of that feature to store and transmit heat. We anticipate that different feature weights may be used by prehistoric hunters and gatherers to generate different thermal properties in order to process different types of plants (e.g., sotol vs. acorns), as well as different quantities of plants (see Black 2003; Ellis 1997). Different quantities of rock, as measured by total weight at a feature level, might well be one way to empirically define different feature types, and begin to develop an understanding of the thermal capacities of various feature types, as well as the range of resources that were processed in those features.

The focus on total rock weight, suggested above, assumes that all rock features are used, at a general level, for cooking at the locus of the feature. While this is probably the case for most rock features, several researchers have suggested that concentrations of burned rock may also result from dumps associated with indirect cooking methods, such as stone boiling (see Quigg 1997; Quigg et al. 2002). Refuse associated with stone boiling, in which heated stones are dropped into containers of liquid in order to cook the contents (see Driver and Massy 1957; Ellis 1997), should be dominated by relatively small accumulations of small, badly fractured rock, all of which are within the same general size range. Conversely, if accumulations of features represent primary cooking locations, we might expect larger rocks to dominate the features, though smaller rocks should certainly be present as a result of thermal shattering during feature use. Using individual rock weight as a proxy for rock size, we will consider the distribution of weights within a given feature on 41PR44. If features are the result of stone boiling, the distribution should be dominated by small rock, and the overall variation in rock weight should be minimal.

Finally, we focus on the relative contributions of different types of rock in the features at 41PR44. Though, as demonstrated in Chapter 2, sandstone dominates the immediate site environment, limestone is present, being exposed in Rock Creek. Limestone and sandstone probably have different characteristics when it comes to heating, heat dissipation, and resistance to thermal fatigue and thermal shock. Studies of Edwards Limestone suggest that from four to eight cycles of heating and cooling will result in disintegration of the stone (see Lucas and Frederick 1998). While we know of no comparable studies on materials in the Parker County area, the limestone located near the site is certainly a much denser material than the available sandstone, and it may well be the case that limestone frequencies in features may vary as a function of different heating requirements. We will monitor the composition of sandstone and limestone in features, both by number of specimens and by weight, in order to investigate this possibility. 
The analysis of total rock weight by features, the distribution of rock size within features, and the composition of features at 41PR44 is designed, then, to provide clues to different types of features that were used by the prehistoric inhabitants of the region. While conclusions are limited by the small number of rock features available for consideration, the 41PR44 feature data can serve as a starting point for an investigation of feature technology in north-central Texas.

\section{Summary}

The data available from our work at 41PR44 for consideration of research issues related to subsistence, lithic technology, feature technology, and chronology are limited. Nevertheless, the analysis of the 41PR44 data can minimally provide basic descriptions that can begin to form a baseline for future research. Given that there are significant gaps in what we currently know about this portion of Texas, basic descriptive data is a necessary step in eventually documenting, and developing an understanding of adaptations in this region. Beyond the basic description, however, the analysis outlined here can make a significant contribution to several areas, including increasing our understanding of subsistence change, the impacts of raw material availability on chipped stone assemblages, and the identification of burned rock features. 



\section{Chapter 5: Fieldwork Summary}

Consistent with the data recovery plan (Mauldin 2004), a variety of field methods were used during CAR's excavations at 41PR44. These field methods included shovel and hand auger testing, excavation of 1-x-1-m units, and backhoe trenching. In all, 26 shovel tests, 26 auger tests, and 24 1-x-1-m units were excavated. In addition, four backhoe trenches were excavated. Details on each of these methods are provided below.

\section{Shovel and Auger Testing}

Shovel and auger testing were used to identify areas of the site that had potential either for buried features or artifact accumulations. Twenty-six shovel tests and 26 auger tests were excavated by CAR in the area of 41PR44. Tests were spaced on a 5-m grid. The grid testing was designed to explore the distribution of material across 41PR44 (Figure 5-1). Consistent with the scope of work, all shovel tests were roughly $30 \mathrm{~cm}$ in diameter, excavated in $10-\mathrm{cm}$ levels, and screened through $1 / 4-$ in. mesh. Hand-auger tests were done with a $10-\mathrm{cm}$ diameter bucket, excavated in $10-\mathrm{cm}$ levels, and screened through $1 / 4-i n$. mesh. For a given $10-\mathrm{cm}$ level, nine times as much sediment was screened for a shovel test as for an auger test. Two hundred and ninety-two $10-\mathrm{cm}$ levels were excavated during auger tests, resulting in the screening of about $0.23 \mathrm{~m}^{3}$ of sediment. One hundred and eighty-two levels were excavated during shovel testing, encompassing a screened volume of roughly $1.27 \mathrm{~m}^{3}$ of sediment. The augers, however, were able to sample deeper deposits at the site. Shovel tests had an average depth of $69.5 \mathrm{cmbs}$, with most tests $(\mathrm{n}=18)$ terminating at a target depth of $70 \mathrm{cmbs}$. In three cases, the terminal depth of shovel tests exceeded $70 \mathrm{~cm}$. Augers had an average depth of $112.6 \mathrm{cmbs}$, with 11 terminating at the target depth of $140 \mathrm{cmbs}$ and a single test terminating at $150 \mathrm{cmbs}$. For shovel and auger tests, the average termination depth on the western side of the site was higher as both methods encountered high densities of rock. On the eastern side of the site, both augers and shovel tests frequently reached their respective target depths. This was primarily a function of the presence of sandstone associated with the colluvial deposits and the alluvial fan associated with the north-south trending ridge on the western edge of the site.
Table 5-1 lists the number of rock, the number of chipped stone items, and the presence of other materials (i.e., charcoal, bone, shell) recovered in shovel tests and auger tests by level, along with the number of levels excavated. While neither method produced a significant number of items, shovel tests recovered a substantially higher number of rocks and chipped stone. This greater recovery is not surprising given the differences in screened volumes noted above. For the upper $70 \mathrm{~cm}, 171$ auger levels were excavated and five pieces of chipped stone were recovered (Table 5-1) in a screened volume of roughly $.134 \mathrm{~m}^{3}$ of sediment (37.3 items per cubic meter). One hundred and seventy-nine shovel test levels were excavated and 26 items (Table 5-1) recovered in $1.265 \mathrm{~m}^{3}$ of sediment screened (20.6 items per cubic meter). For comparable levels (i.e., Levels 1 through 7), volumetrically adjusted auger recovery rates are higher than the recovery rates for shovel tests. While this difference is probably a statistical fluke related to the low overall recovery rates, the data suggest that augers may be a viable alternative to shovel tests in certain situations.

Figure 5-2 presents the pattern of positive shovel tests, identified by a circle, and auger tests, identified by a star symbol. Locations positive for burned rock are in red. Locations positive for other materials, including chipped stone, charcoal, bone, and shell, are in blue. Overall, $63.5 \%$ of the 52 tests were positive. The distribution of tests positive for burned rock in Figure 5-2 is difficult to interpret given that sandstone is common in the immediate site area. On the basis of the positive shovel and auger tests shown in Figure 5-2, the boundary of 41PR44 is expanded slightly to the southeast. Note also that the far northeastern portion of the site (Tests 42, 47, 48, 49, 52, and 53) had no recovery. While TARL reported a positive shovel test (CB 4) in this area, represented by a single flake in the upper $20 \mathrm{~cm}$ of the test, the low frequency of recovery effectively eliminates this section of the site from further consideration.

\section{Hand Excavation Units}

Based on the auger and shovel test results, and the previous work at 41PR44, CAR excavated $221-x-1-m$ units, with roughly $18.19 \mathrm{~m}^{3}$ of sediment screened through $1 / 4$-inch 


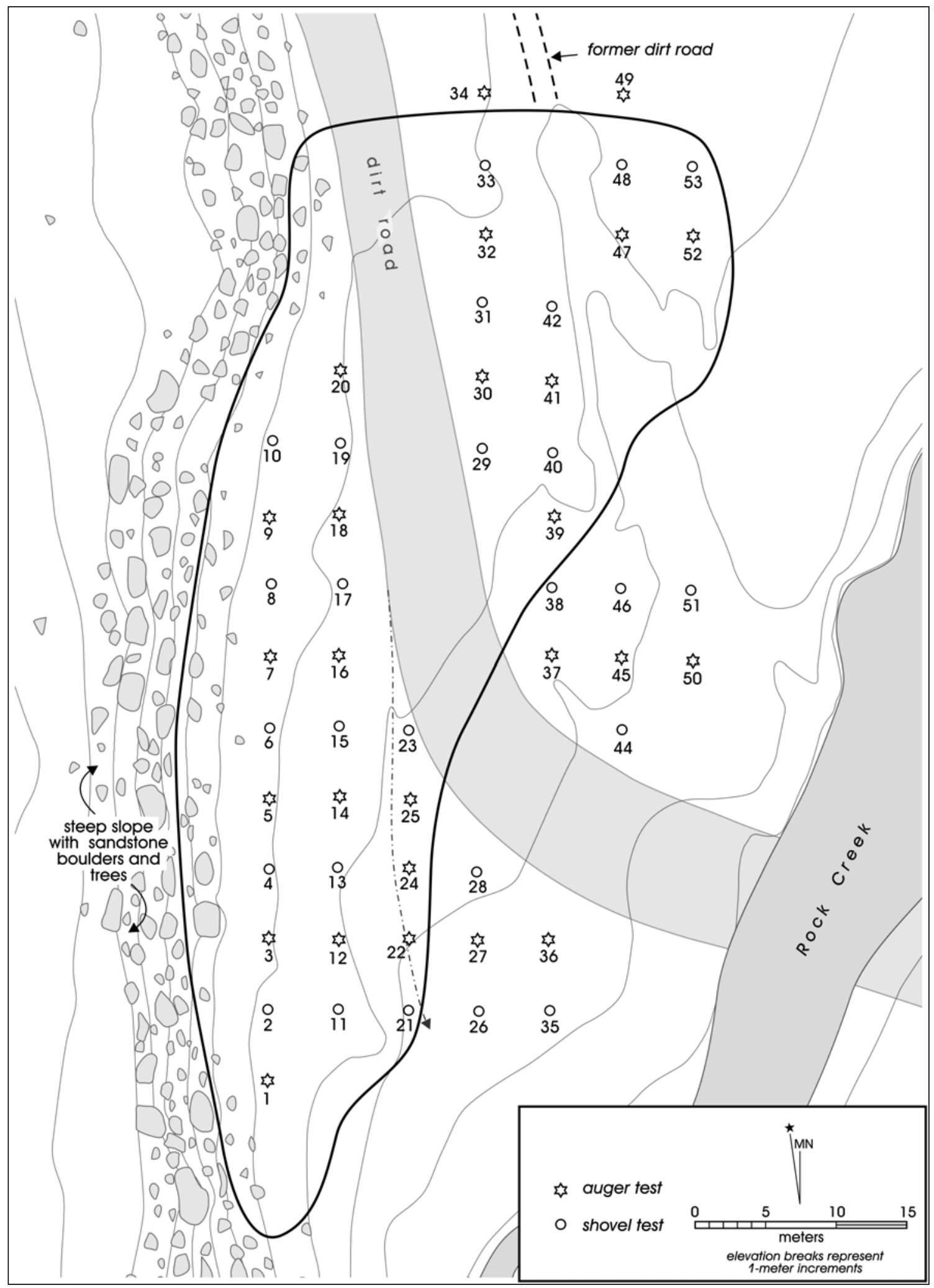

Figure 5-1. Location of CAR auger and shovel tests at 41PR44. 
Table 5-1. Recovery Information by Level for Shovel Tests and Augers

\begin{tabular}{|c|c|c|c|c|c|c|c|c|}
\hline \multirow[b]{2}{*}{ Level } & \multicolumn{3}{|c|}{ Shovel Test } & \multirow[b]{2}{*}{$\begin{array}{l}\text { Number } \\
\text { of Levels }\end{array}$} & \multicolumn{3}{|c|}{ Auger Test } & \multirow[b]{2}{*}{$\begin{array}{l}\text { Number } \\
\text { of Levels }\end{array}$} \\
\hline & Rock & $\begin{array}{c}\text { Chipped } \\
\text { Stone }\end{array}$ & Other & & Rock & $\begin{array}{c}\text { Chipped } \\
\text { Stone }\end{array}$ & Other & \\
\hline 1 & 19 & 3 & & 26 & 3 & 1 & & 26 \\
\hline 2 & 12 & 6 & & 26 & 22 & 1 & & 26 \\
\hline 3 & 16 & 2 & & 26 & 12 & 0 & & 26 \\
\hline 4 & 25 & 6 & + & 26 & 9 & 2 & + & 26 \\
\hline 5 & 38 & 4 & + & 25 & 0 & 0 & + & 24 \\
\hline 6 & 50 & 2 & + & 25 & 1 & 1 & & 23 \\
\hline 7 & 27 & 3 & & 25 & 0 & 0 & & 23 \\
\hline 8 & 11 & 0 & & 3 & 77 & 1 & + & 20 \\
\hline 9 & $\mathrm{n} / \mathrm{a}$ & $\mathrm{n} / \mathrm{a}$ & & 0 & 8 & 6 & & 19 \\
\hline 10 & $\mathrm{n} / \mathrm{a}$ & $\mathrm{n} / \mathrm{a}$ & & 0 & 1 & 0 & & 19 \\
\hline 11 & $\mathrm{n} / \mathrm{a}$ & $\mathrm{n} / \mathrm{a}$ & & 0 & 4 & 0 & & 18 \\
\hline 12 & $\mathrm{n} / \mathrm{a}$ & $\mathrm{n} / \mathrm{a}$ & & 0 & 1 & 0 & + & 16 \\
\hline 13 & $\mathrm{n} / \mathrm{a}$ & $\mathrm{n} / \mathrm{a}$ & & 0 & 1 & 0 & & 14 \\
\hline 14 & $\mathrm{n} / \mathrm{a}$ & $\mathrm{n} / \mathrm{a}$ & & 0 & 0 & 0 & & 12 \\
\hline Total & 198 & 26 & & 182 & 139 & 12 & & 292 \\
\hline
\end{tabular}

mesh. Two additional units (designated TU 29 and TU 30), totaling $0.62 \mathrm{~m}^{3}$ of screened sediment, were excavated in association with the backhoe trenching. Finally, two 1-x-1-m units, designated TUs 1 and 2, were previously dug by TARL (Brownlow 2001). Figure 5-3 shows all 26 units excavated at 41PR44. CAR's excavation at the site focused on four areas, designated Areas 1 through 4 (Figure 5-3). Additional information on these excavation areas, including detailed discussion of the sediments and geomorphic setting, can be found in Chapter 6 .

\section{Area 1}

Area 1 was located on the southern end of the site (Figure 5-3), and was placed to explore Feature 2, a rock feature initially identified and dated to the Late Prehistoric during testing (Brownlow 2001). A portion of Feature 2 remained in the north wall of TU 2 (Brownlow 2001). Three additional units (TUs 3, 4, and 5) were excavated bordering TU 2. These three units had a total screened sediment volume of $3.16 \mathrm{~m}^{3}$. Sediments from TU 3 were removed in 10 levels down to a terminal depth of $120 \mathrm{~cm}$ below datum (cmbd), or roughly $1 \mathrm{~m}$ below surface. In all, $0.99 \mathrm{~m}^{3}$ of sediment were screened from this test unit. In TU 4, 11 levels were excavated down to a depth of $125 \mathrm{cmbd}$, or roughly $1.07 \mathrm{~m}$ below surface. Sediments from TU 5 were removed down to $110 \mathrm{~cm}$ below surface in 11 levels. Overall, the three units in Area 1 yielded low quantities of chipped stone debitage, small quantities of scattered charcoal, and small fragments of bone. Several lithic tools were recovered from this area. Table 5-2 lists the artifacts recovered by level for these three units.

No additional information or evidence of Feature 2 was uncovered in our excavation. As suggested in subsequent chapters, it is unlikely that this particular rock feature represents a cultural accumulation. The original feature drawing referenced in Brownlow (2001) shows a sloping accumulation of small rock as Feature 2. The slope matches that of the current ground surface. While both charcoal and artifacts are associated with the rock accumulation, the clustering of rock, as such, probably represent alluvial and colluvial deposition rather than a cultural accumulation.

\section{Area 2}

Area 2 was located just to the northeast of Area 1 (Figure 5-3). This area was selected for investigation based on the documentation in BHT 12, excavated by TARL, of a buried soil with a calibrated radiocarbon date of between 1425 and 1120 B.C. (Brownlow et al 1999:46), as well as the results of Auger Test 22 excavated by CAR on the current project. That test recovered several pieces of chipped stone and what appeared to be a buried soil between 80 and 


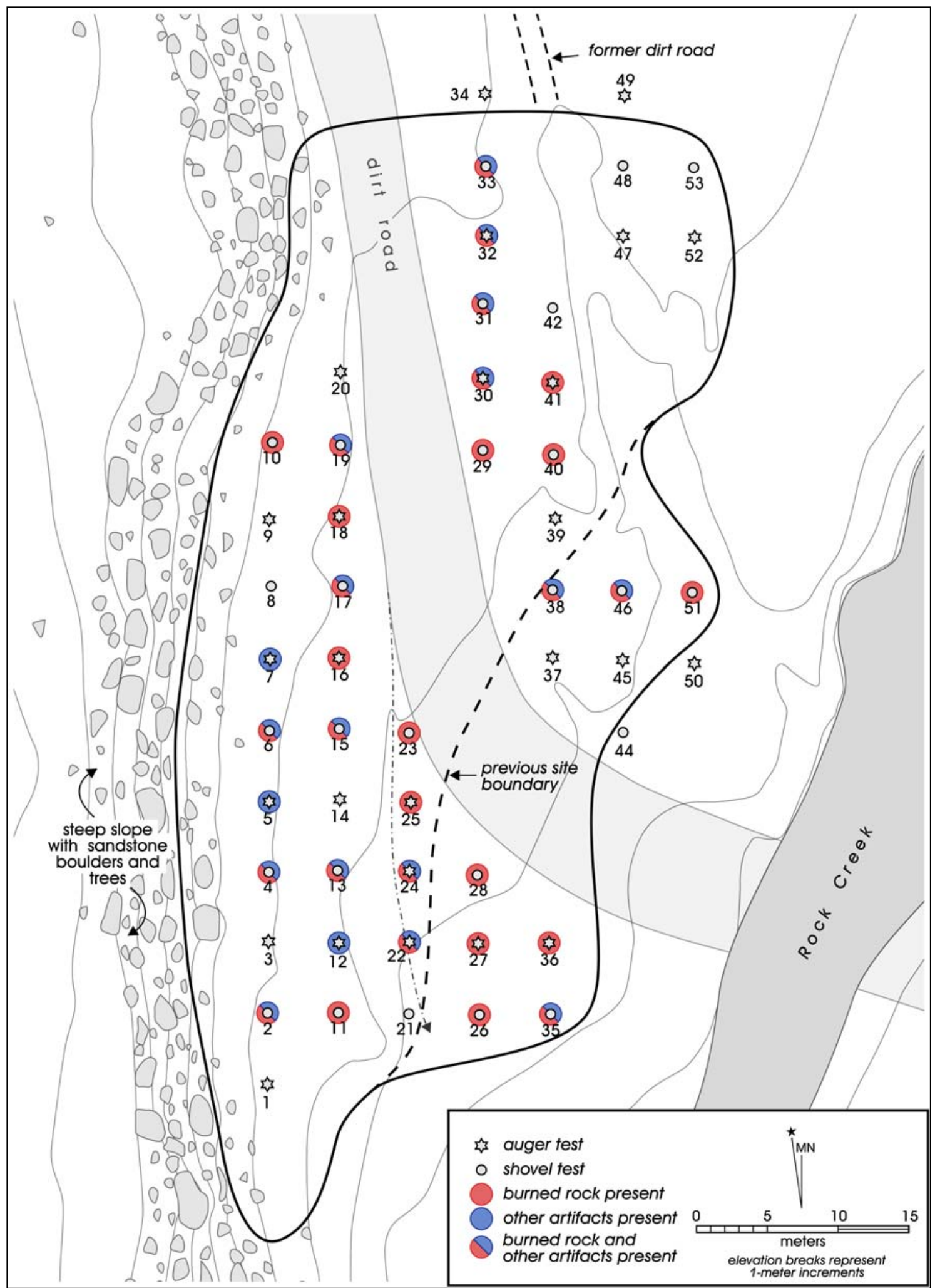

Figure 5-2. Positive and negative auger and shovel tests at 41PR44. 


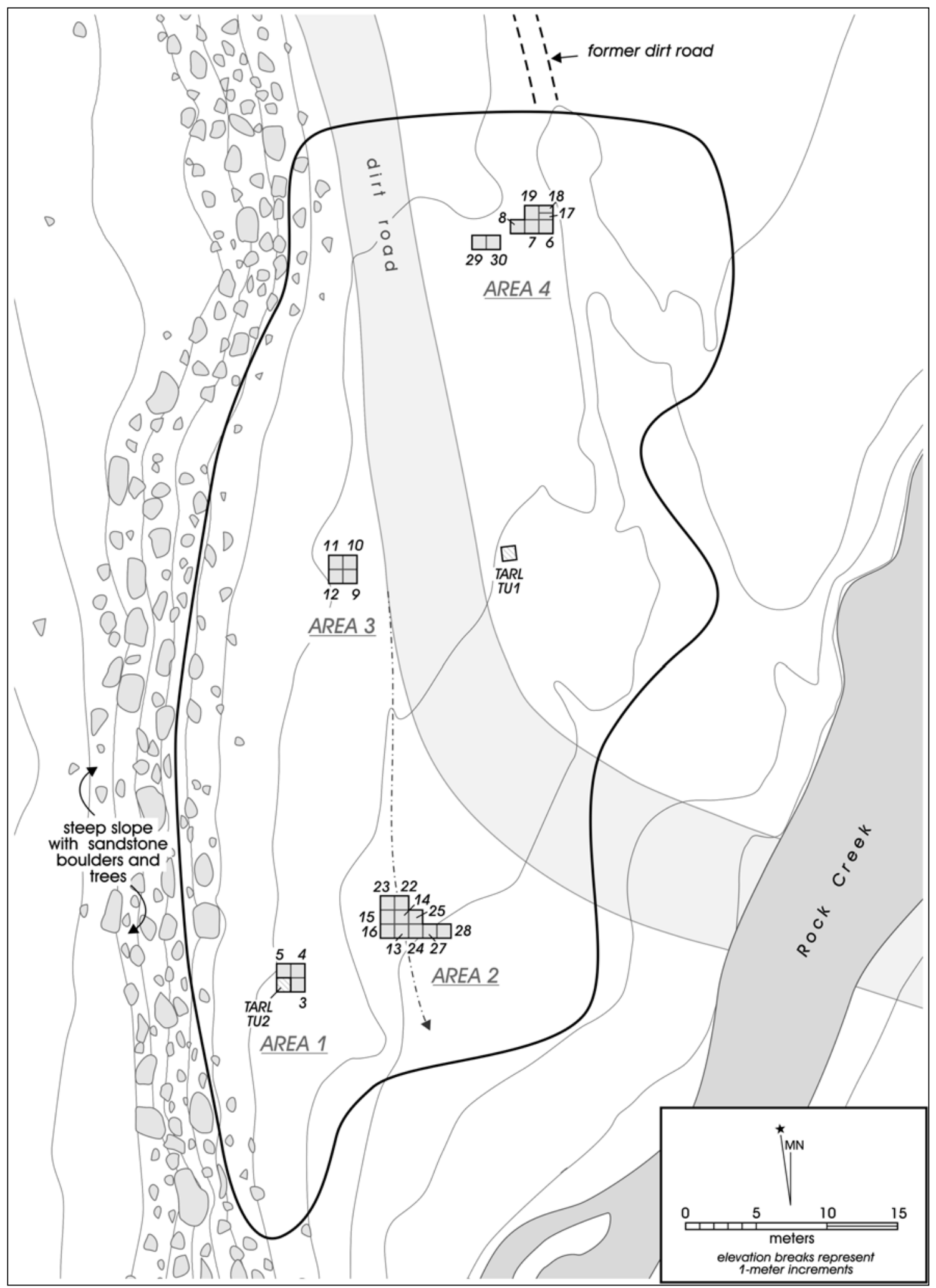

Figure 5-3. Excavation units at 41PR44. 
Table 5-2. Material Recovered from Hand-Excavated Units by Level, Area 1

\begin{tabular}{|c|c|c|c|c|c|c|}
\hline Level & $\begin{array}{c}\text { Burned } \\
\text { Rock }\end{array}$ & $\begin{array}{c}\text { Chipped Stone } \\
\text { Debitage }\end{array}$ & $\begin{array}{c}\text { Lithic } \\
\text { Tools }\end{array}$ & $\begin{array}{c}\text { Bone } \\
\text { Weight }(\mathbf{g})\end{array}$ & $\begin{array}{c}\text { Charcoal } \\
(+/-)\end{array}$ & $\begin{array}{c}\text { Volume Screened } \\
\left(\mathbf{m}^{\mathbf{3}} \text { of Sediment) }\right.\end{array}$ \\
\hline 2 & 16 & 0 & 0 & 0 & + & 0.14 \\
\hline 3 & 86 & 12 & 0 & 1.6 & + & 0.29 \\
\hline 4 & 77 & 25 & 0 & 33.7 & + & 0.29 \\
\hline 5 & 224 & 46 & 3 & 26.9 & + & 0.32 \\
\hline 6 & 324 & 30 & 2 & 0.9 & + & 0.32 \\
\hline 7 & 322 & 22 & 2 & 6 & + & 0.31 \\
\hline 8 & 224 & 9 & 1 & 0.2 & + & 0.25 \\
\hline 9 & 255 & 4 & 1 & 3.7 & + & 0.31 \\
\hline 10 & 242 & 5 & 0 & 2.3 & + & 0.31 \\
\hline 11 & 153 & 4 & 2 & 30.8 & + & 0.32 \\
\hline 12 & 160 & 2 & 0 & 0 & + & 0.3 \\
\hline Total & $\mathbf{2 0 8 3}$ & $\mathbf{1 5 9}$ & $\mathbf{1 1}$ & $\mathbf{1 0 6 . 1}$ & & $\mathbf{3 . 1 6}$ \\
\hline
\end{tabular}

$90 \mathrm{~cm}$ below the surface. In all, $101-\mathrm{x}-1-\mathrm{m}$ units were excavated in this area (Figure 5-4) with roughly $7.46 \mathrm{~m}^{3}$ of sediment being systematically screened.

Initially, a 2-x-2-m block (TUs 13, 14, 15, and 16) was laid out with Auger Test 22 forming the southeast corner of TU 13, as well as the southeast corner of the larger 2-x-2-m block (see Figure 5-3). The surface of the 2-x-2-m block sloped dramatically from northwest to southeast, with the southeast corner of the block being roughly $34 \mathrm{~cm}$ lower than the northwest corner. TU 13 was excavated in 15 levels to a depth of $130 \mathrm{cmbs}$, and all sediments, reflecting roughly $1.20 \mathrm{~m}^{3}$, were screened. TU 14 was excavated to $131 \mathrm{cmbs}$ in 14 levels, with a screened volume of $1.22 \mathrm{~m}^{3}$. TU 15 was excavated to $126 \mathrm{cmbs}$ in 14 levels, with a screened volume of $1.19 \mathrm{~m}^{3}$. Finally, TU 16 was excavated to $125 \mathrm{cmbs}$ in 13 levels. The total volume removed and screened from this unit was roughly $1.25 \mathrm{~m}^{3}$.

As shown in Table 5-3, chipped stone debitage, small quantities of bone, and what appeared to be burned sandstone was consistently present in the upper four levels in this 2-x-2-m block (Levels 3 through 6). A single rock feature with associated staining, designated Feature 10, was discovered primarily in TU 16 in Level 5. As discussed below and in subsequent chapters, this feature probably does not represent an in situ hearth. Levels 7 through 11 evidenced little or no recovery of chipped stone, with Levels 8 though 10 in all four units having no chipped stone recovered. Level 12 through the termination of the excavations (Levels 15 and 16) had a significant increase in debitage in all four units, with counts of over 20 items noted in several of the levels in this lower portion of the excavation.

Given these strong patterns in the distribution of debitage noted above, a pattern mirrored by bone and rock, the presence of a consistently sterile zone in all four $1-\mathrm{x}-1-\mathrm{m}$ units, and the time constraints on the project, the excavation strategy used for additional 1-x-1-m units in Area 2 was altered. For TU 22, the upper and lower portions of the 1 - $\mathrm{x}-1-\mathrm{m}$ unit were screened $\left(0.95 \mathrm{~m}^{3}\right)$. The middle levels (Levels 9-11) were not screened. For TUs 24, 25, 27, and 28 , only the lower levels were screened for a total volume of $1.65 \mathrm{~m}^{3}$. Finally, TU 23 was dominated by the southeastern end of BHT 12 excavated by TARL (see Figure 5-5). None of the TU 23 deposits were screened. In all, this additional work resulted in $2.6 \mathrm{~m}^{3}$ of screened sediment being removed.

\section{Area 3}

Area 3 was located roughly $25 \mathrm{~m}$ to the north of Area 2 (see Figure 5-3). The area was selected for excavation on the basis of the shovel testing data, as Shovel Test 17 produced evidence of a possible feature, including burned bone, artifacts, sandstone, and charcoal between 40 and 60 cmbs. A 2-x-2-m excavation block, consisting of TUs 9, 10, 11, and 12, was laid out, with Shovel Test 17 located midway along the southern wall of the block. As with the Area 2 excavation, the surface of Area 3 sloped dramatically 


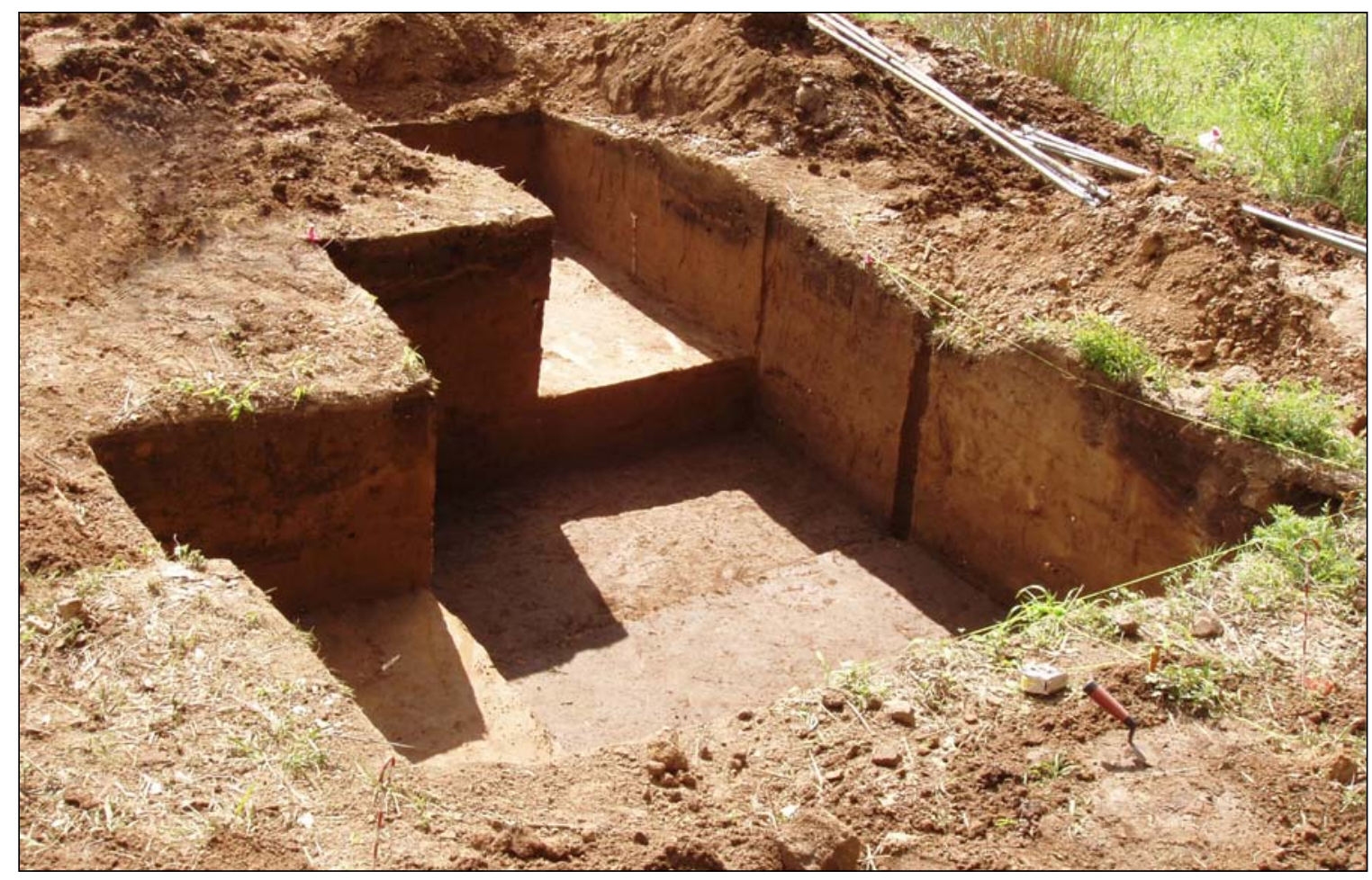

Figure 5-4. Area 2 after excavation, view toward the southeast.

Table 5-3. Material Recovered from Hand-Excavated Units by Level, Area 2

\begin{tabular}{|c|c|c|c|c|c|c|}
\hline Level & $\begin{array}{c}\text { Burned } \\
\text { Rock }\end{array}$ & $\begin{array}{c}\text { Chipped Stone } \\
\text { Debitage }\end{array}$ & $\begin{array}{c}\text { Lithic } \\
\text { Tools }\end{array}$ & $\begin{array}{c}\text { Bone } \\
\text { Weight }(\mathbf{g})\end{array}$ & $\begin{array}{c}\text { Charcoal } \\
(+/-)\end{array}$ & $\begin{array}{c}\text { Volume Screened } \\
\left(\mathbf{m}^{3} \text { of Sediment) }\right.\end{array}$ \\
\hline 2 & 3 & 0 & 0 & 0 & - & 0.01 \\
\hline 3 & 86 & 2 & 0 & 0.6 & + & 0.21 \\
\hline 4 & 165 & 7 & 0 & 0 & - & 0.39 \\
\hline 5 & 256 & 6 & 0 & 0 & + & 0.47 \\
\hline 6 & 59 & 3 & 0 & 0 & + & 0.51 \\
\hline 7 & 43 & 1 & 0 & 0 & + & 0.48 \\
\hline 8 & 27 & 0 & 0 & 141.8 & + & 0.51 \\
\hline 9 & 6 & 0 & 0 & 0 & - & 0.4 \\
\hline 10 & 15 & 0 & 0 & 0 & - & 0.4 \\
\hline 11 & 41 & 3 & 0 & 0 & - & 0.6 \\
\hline 12 & 15 & 1 & 0 & 0 & - & 0.92 \\
\hline 13 & 16 & 78 & 1 & 0 & + & 0.93 \\
\hline 14 & 116 & 162 & 1 & 34.1 & - & 0.94 \\
\hline 15 & 76 & 8 & 0 & 0 & - & 0.63 \\
\hline 16 & 7 & 2 & 0 & 0 & - & 0.06 \\
\hline Total & $\mathbf{9 3 1}$ & $\mathbf{2 7 3}$ & $\mathbf{2}$ & $\mathbf{1 7 6 . 5 0}$ & & $\mathbf{7 . 4 6}$ \\
\hline
\end{tabular}




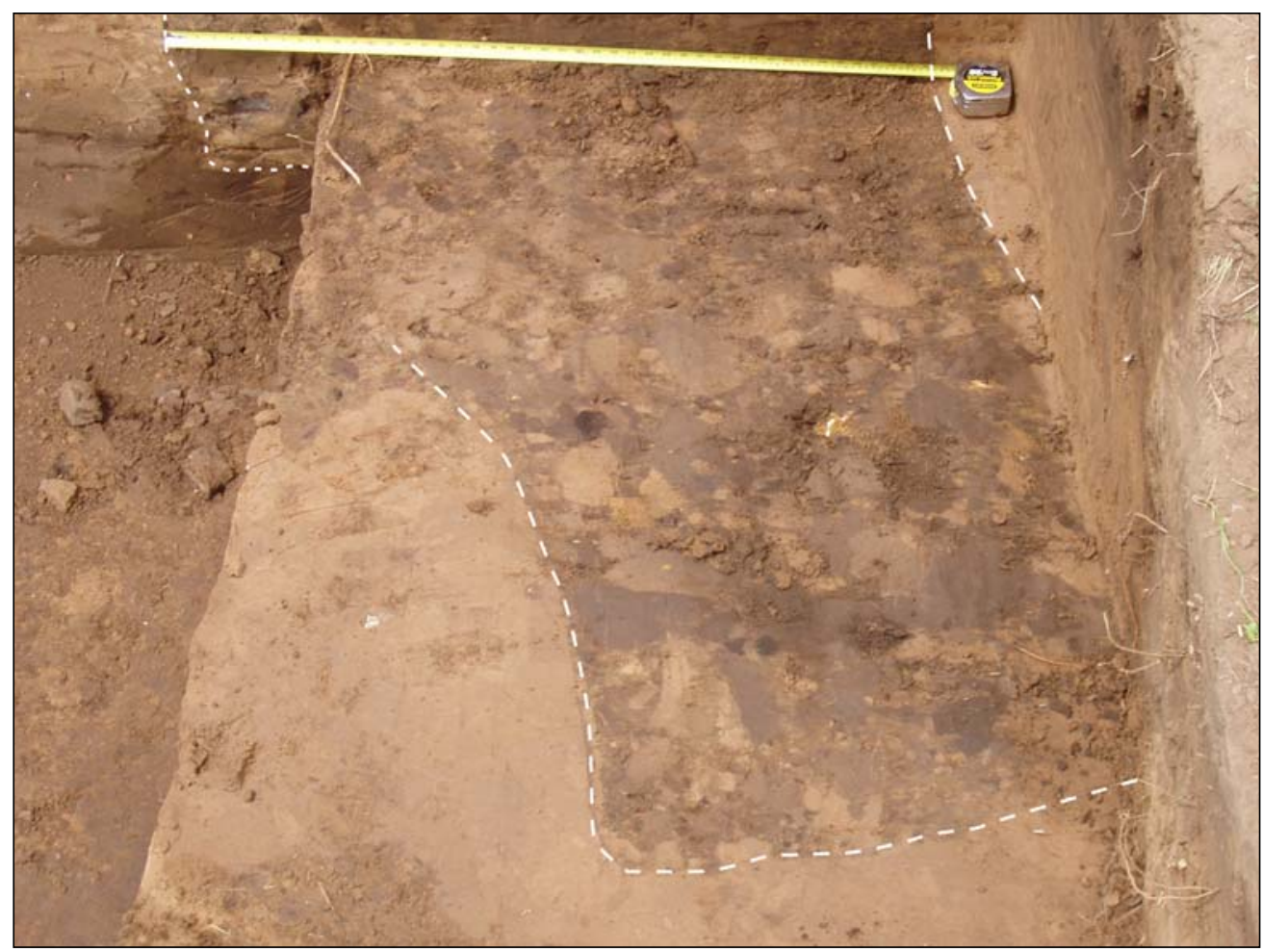

Figure 5-5. Test Unit 23 with TARL Backhoe Trench 12 outlined in white.

from west to east, with a difference of roughly $40 \mathrm{~cm}$ in surface elevations. In all, $3.40 \mathrm{~m}^{3}$ of sediment were removed and screened in Area 3. TU 9 was excavated to roughly $93 \mathrm{~cm}$ below surface, with approximately $0.93 \mathrm{~m}^{3}$ of sediment being removed in 10 levels. TU 10 was excavated to about $76 \mathrm{~cm}$ below surface, with $0.76 \mathrm{~m}^{3}$ of sediment being removed in nine levels. In TU $11,0.81 \mathrm{~m}^{3}$ of sediment were removed in nine levels. That unit terminated at about $81 \mathrm{cmbs}$. Finally, TU 12, which terminated at $90 \mathrm{cmbs}$, was excavated in 10 levels.

As shown in Table 5-4, materials recovered from these units included large quantities of sandstone, and small quantities of bone and scattered charcoal, and moderate numbers of chipped stone debitage and tools. Recovery from the units in this area was dominated by sandstone and small quantities of limestone. It was extremely difficult to differentiate clusters of natural rock associated with the slope deposit from the adjacent ridge from clusters that may have reflected cultural features. While cultural material was clearly mixed with the rock, and while in many cases the sandstone and small quantities of limestone certainly appeared burned, it was unclear which, if any, concentrations reflected intact hearths, and which represented redeposited cultural material or natural accumulations. As there was no way to clearly differentiate this in the field, we decided to designate all clusters as features. As a result, nine different rock features, assigned numbers $11,13,14,15,16,17,18,19$, and 20, were designated in this area. As we will argue subsequently, based on patterns in rock distribution and in magnetic susceptibility in sandstone samples, all of these features, with the exception of Feature 20, probably represent clusters of unburned and redeposited rock intermixed with redeposited artifacts and bone (see Chapters 6 and 10).

\section{Area 4}

Area 4 was located roughly $28 \mathrm{~m}$ to the northeast of Area 2 (Figure 5-3). The area was selected for excavation on the basis of a cluster of what appeared to be burned sandstone and limestone, exposed roughly 50 to $70 \mathrm{cmbs}$ in the western wall of a north-south trending small arroyo cut. In addition to this exposed feature, designated Feature 12, Auger Test 32 , located about $5 \mathrm{~m}$ to the west of the feature, had encountered what was thought to be burned sandstone at 
70 to $90 \mathrm{cmbs}$, suggesting the possibility that several features were in this area. Area 4 was initially investigated by laying out three contiguous $1-\mathrm{x}-1-\mathrm{m}$ units (TUs 6, 7, and 8) oriented east-west (see Figure 5-3), with TU 6 being located such that it would bisect Feature 12. As with many portions of $41 \mathrm{PR} 44$, the surface of Area 4 sloped substantially from east to west, with a drop in the surface elevation of roughly $48 \mathrm{~cm}$ over the three units. In addition, note that TU 6 was not a complete $1-\mathrm{x}-1-\mathrm{m}$ unit, as a portion of the eastern edge of the unit had been removed by the arroyo cut. Roughly $0.88 \mathrm{~m}^{3}$ of sediment were removed from TU 6 in 12 levels down to roughly $110 \mathrm{cmbs}$.

Density of chipped stone was low, with no chipped stone material present for the first $50 \mathrm{~cm}$ of excavation (see Table 5-5). Feature 12, a cluster of limestone and sandstone rock, was defined at between 86 and $91 \mathrm{cmbs}$ in this unit. Sediments in TU 7 were removed in 13 levels down to 104 cmbs, and TU 8 was excavated down to $94 \mathrm{cmbs}$ in 11 levels. As with TU 6, these two units contained very low numbers of chipped stone, with the upper portions of the deposits containing almost no material. Chipped stone densities were higher at depth, though the overall numbers remained low. The excavation of these three units removed roughly $2.86 \mathrm{~m}^{3}$ of sediment, all of which was screened.

During the course of excavating these three units, three additional units were added in this area. TU 17 was originally excavated as a $50-\mathrm{cm}-\mathrm{x}-1-\mathrm{m}$ unit just to the north of TU 6 , though a portion of this unit had been removed by erosion (see Figure 5-3). This unit was designed to uncover the remaining portions of Feature 12. Given the low recovery present in the upper levels of the 1-x-3-m block (TUs 6, 7, and 8), the upper $40 \mathrm{~cm}$ of TU 17 were removed without screening. Three levels were excavated down to $68 \mathrm{~cm}$ below the original ground surface. At this point, much of the remaining outline of Feature 12 was visible, as can be seen in Figure 5-6. TU 18 was located just to the north of TU 17, and also consisted of a 50-cm-x-1-m unit, though some of that area had been removed by erosion. Like TU 17, the upper levels (ca. $20 \mathrm{~cm}$ ) of TU 18 were removed without screening. TU 18 was excavated in five levels to the same elevation as Feature 12. Subsequently, the two $50-\mathrm{cm}-\mathrm{x}-1-\mathrm{m}$ units were combined into a single 1-x-1-m unit and an additional $30 \mathrm{~cm}$ of deposits were removed. Finally, TU 19, a 1-x-1-m unit, was excavated just to the west of TU 17/18 (Figure 5-3). The upper $30 \mathrm{~cm}$ of this unit was removed without screening, and subsequently nine levels were excavated. In all, about $1.31 \mathrm{~m}^{3}$ of sediment was removed and screened from these three additional units. Note that two more units, designated 29 and 30, were excavated in this area (Figure 5-3). These were associated with Backhoe Trench 1, and consequently will be discussed below. No projectile points were recovered from the initial excavations in this area, though what appears to be a reworked Marshall form was collected from TU 29 in direct association with Feature 21.

\section{Backhoe Trenching}

Four new backhoe trenches, designated BHT 1 through BHT 4, were excavated by CAR at 41PR44. Figure 5-7 presents these locations, along with the locations of Backhoe Trenches 12 and 13 excavated previously by TARL in 1999

Table 5-4. Material Recovered from Hand-Excavated Units by Level, Area 3

\begin{tabular}{|c|c|c|c|c|c|c|}
\hline Level & $\begin{array}{c}\text { Burned } \\
\text { Rock }\end{array}$ & $\begin{array}{c}\text { Chipped Stone } \\
\text { Debitage }\end{array}$ & $\begin{array}{c}\text { Lithic } \\
\text { Tools }\end{array}$ & $\begin{array}{c}\text { Bone } \\
\text { Weight (g) }\end{array}$ & $\begin{array}{c}\text { Charcoal } \\
(+/-)\end{array}$ & $\begin{array}{c}\text { Volume Screened } \\
\left(\mathbf{m}^{\mathbf{3}} \text { of Sediment) }\right.\end{array}$ \\
\hline 1 & 1 & 0 & 0 & 0 & - & 0.04 \\
\hline 2 & 18 & 2 & 0 & 0 & + & 0.14 \\
\hline 3 & 117 & 15 & 1 & 8.9 & + & 0.32 \\
\hline 4 & 329 & 28 & 5 & 11.75 & + & 0.4 \\
\hline 5 & 414 & 25 & 1 & 15.75 & + & 0.4 \\
\hline 6 & 326 & 35 & 4 & 14.5 & - & 0.4 \\
\hline 7 & 323 & 46 & 2 & 9.4 & - & 0.4 \\
\hline 8 & 462 & 47 & 0 & 20.6 & + & 0.4 \\
\hline 9 & 418 & 67 & 2 & 26.9 & + & 0.4 \\
\hline 10 & 429 & 49 & 2 & 9.7 & - & 0.4 \\
\hline 11 & 149 & 14 & 1 & 1.2 & - & 0.1 \\
\hline Total & $\mathbf{2 9 8 6}$ & $\mathbf{3 2 8}$ & $\mathbf{1 8}$ & $\mathbf{1 1 8 . 7}$ & & $\mathbf{3 . 4}$ \\
\hline
\end{tabular}


Table 5-5. Material Recovered from Hand-Excavated Units by Level, Area 4

\begin{tabular}{|c|c|c|c|c|c|c|}
\hline Level & $\begin{array}{c}\text { Burned } \\
\text { Rock* }\end{array}$ & $\begin{array}{c}\text { Chipped Stone } \\
\text { Debitage }\end{array}$ & $\begin{array}{c}\text { Lithic } \\
\text { Tools }\end{array}$ & $\begin{array}{c}\text { Bone } \\
\text { Weight }(\mathbf{g})\end{array}$ & $\begin{array}{c}\text { Charcoal } \\
(+/-)\end{array}$ & $\begin{array}{c}\text { Volume Screened } \\
\left(\mathbf{m}^{3} \text { of Sediment }\right)\end{array}$ \\
\hline 2 & 0 & 0 & 0 & 0 & - & 0.02 \\
\hline 3 & 0 & 0 & 0 & 0 & - & 0.09 \\
\hline 4 & 0 & 1 & 0 & 0 & - & 0.18 \\
\hline 5 & 0 & 1 & 0 & 0 & - & 0.24 \\
\hline 6 & 49 & 3 & 0 & 0 & - & 0.31 \\
\hline 7 & 96 & 4 & 0 & 6.2 & - & 0.38 \\
\hline 8 & 93 & 1 & 0 & 0.7 & - & 0.441 \\
\hline 9 & 120 & 6 & 0 & 0 & - & 0.421 \\
\hline 10 & 144 & 12 & 1 & 1.2 & - & 0.475 \\
\hline 11 & 255 & 9 & 0 & 0 & - & 0.465 \\
\hline 12 & 323 & 16 & 0 & 0 & - & 0.372 \\
\hline $12 \mathrm{a}$ & 86 & 3 & 0 & 11.1 & - & 0.067 \\
\hline 13 & 211 & 7 & 0 & 0 & - & 0.365 \\
\hline 14 & 158 & 2 & 0 & 0.3 & - & 0.308 \\
\hline 15 & 5 & 0 & 0 & 0 & - & 0.037 \\
\hline Total & $\mathbf{1 5 4 0}$ & $\mathbf{6 5}$ & $\mathbf{1}$ & $\mathbf{1 9 . 5}$ & - & $\mathbf{4 . 1 7 1}$ \\
\hline
\end{tabular}

* Only $>=1 / 2$ inch

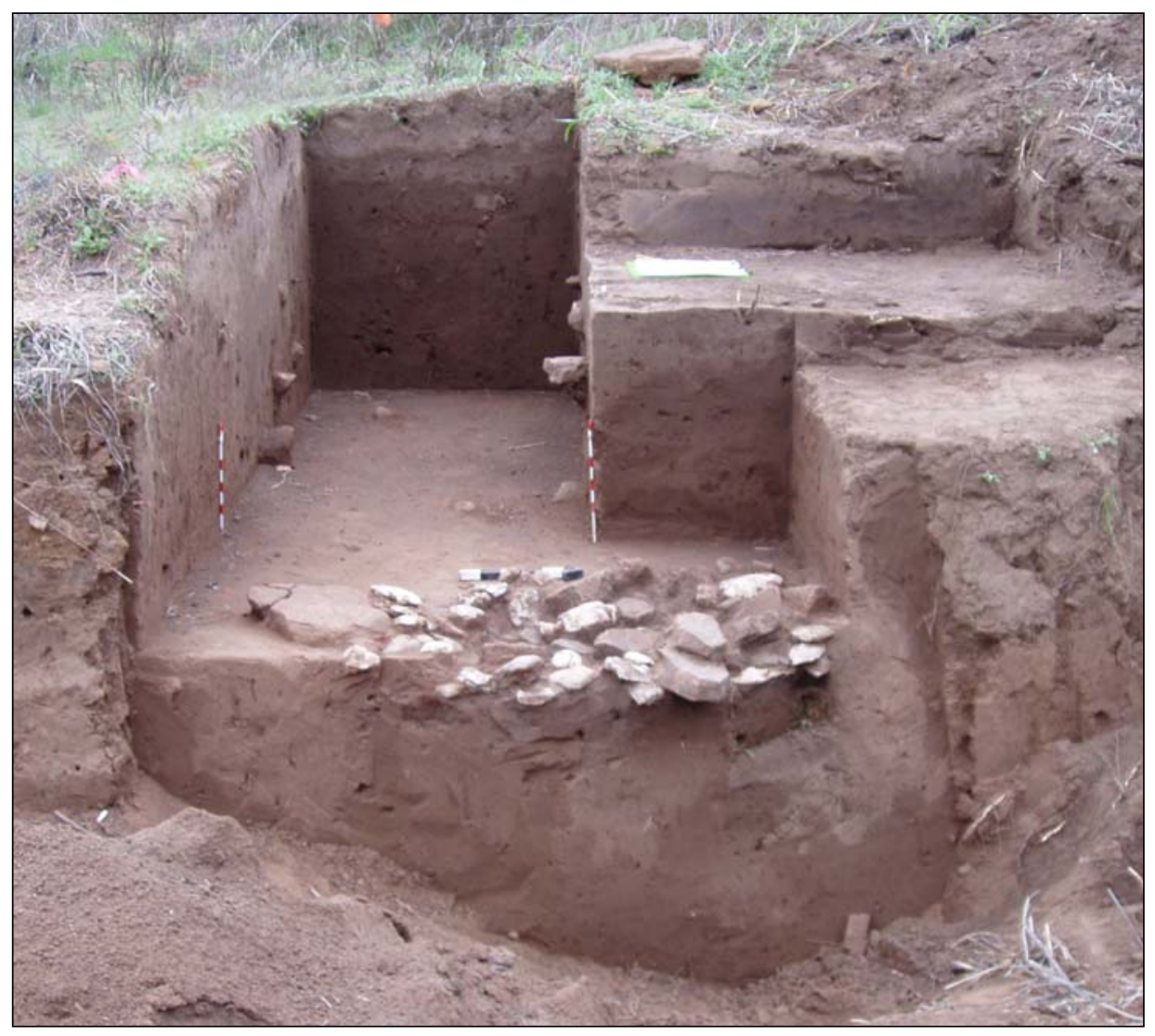

Figure 5-6. Feature 12 in Area 4 looking toward the west. 


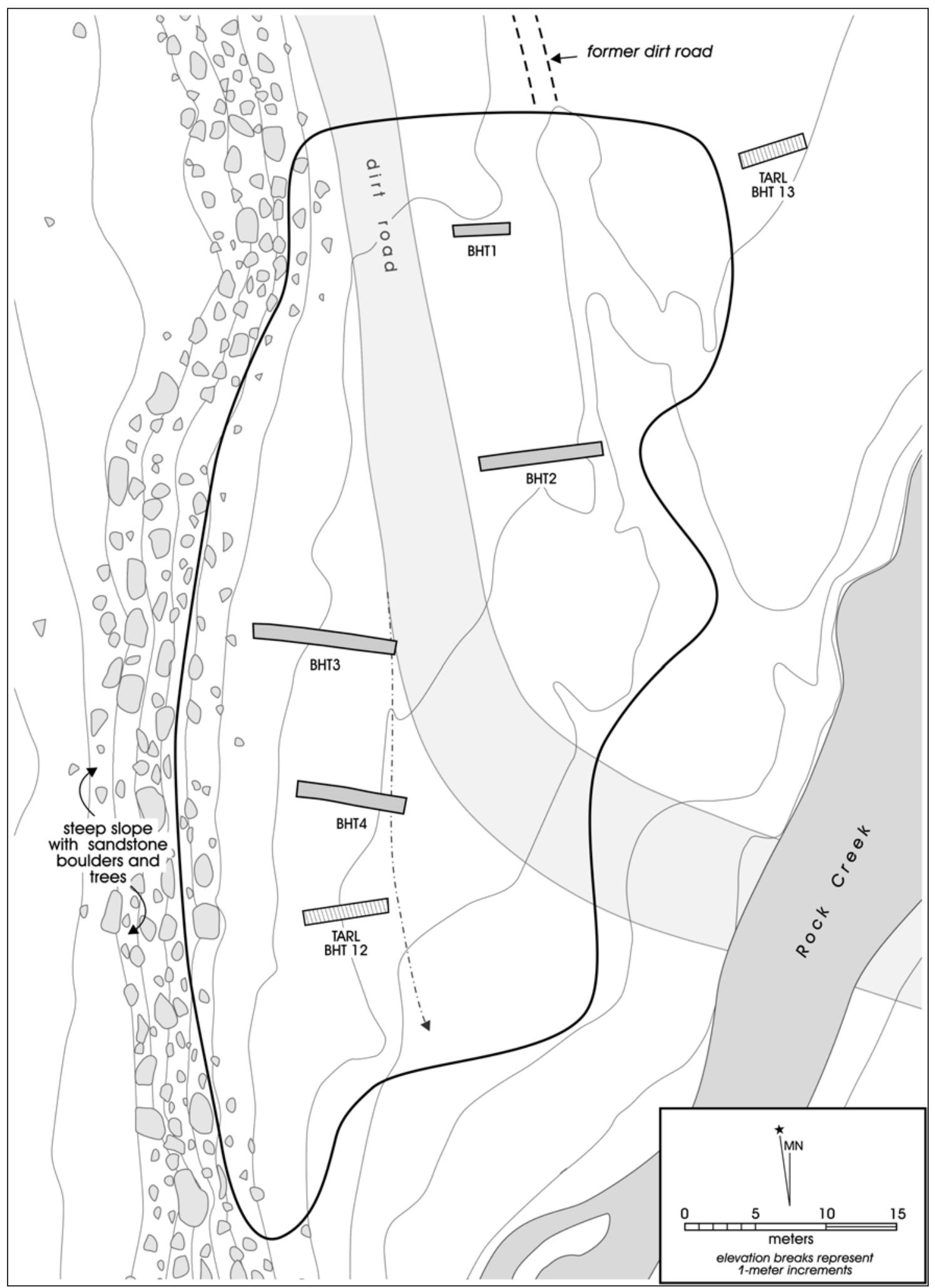

Figure 5-7. Backhoe Trenches at 4IPR44. 
(Brownlow et al. 1999). All CAR trenches, along with TARL BHT 13, were examined by Dr. Russell Greaves, formerly of CAR. His descriptions of sediments, soils, and geomorphic setting are presented in Chapter 6.

Backhoe Trench 1 was roughly $4 \mathrm{~m}$ in length, about $75 \mathrm{~cm}$ in width, and excavated to $1.60 \mathrm{~m}$ below the ground surface (Figure 5-7). The trench was located off the Area 4 excavation, and was designed to both explore the possible colluvial nature of the deposits identified as Feature 12, as well to investigate the possible feature identified in Auger Test 32. During excavation of the trench, a dense concentration of what appeared to be burned sandstone, mixed with a small quantity of limestone, was present in both the northern and southern walls of the trench (Figure 5-8[a]). This discrete concentration was designated Feature 21 , and explored with the excavation of two 1-x-1-m units, designated TUs 29 and 30 . Note that roughly $30 \mathrm{~cm}$ of deposits above the feature were removed with the backhoe prior to the start of excavation. In all, $0.41 \mathrm{~m}^{3}$ of sediment was removed in five levels in TU 29, while $0.21 \mathrm{~m}^{3}$ of sediment was removed in three levels in TU 30. TU 29 cut through the feature, while TU 30 was excavated down to the top of the rock accumulation (Figure 5-8[b]). Burned sandstone and limestone, chipped stone debitage $(n=23)$, and a single projectile point were recovered from these two units.

Three additional trenches were excavated at $41 \mathrm{PR} 44$ by CAR. Backhoe Trench 2 was located roughly $16 \mathrm{~m}$ south of BHT 1 (see Figure 5-7). It was about $8.5 \mathrm{~m}$ in length and excavated to a maximum depth of $1.60 \mathrm{~m}$ below the surface. No cultural material was observed in this trench. BHT 3 was roughly $15 \mathrm{~m}$ to the southwest of BHT 2 (see Figure 5-7) and roughly $4 \mathrm{~m}$ due south of the Area 3 excavations. The trench, which was $9.75 \mathrm{~m}$ in length and excavated to a maximum depth of $1.5 \mathrm{~m}$ below the surface, cut into the colluvial deposit that dominates the western side of the site. While providing clear documentation on the nature of this colluvial deposit, BHT 3 contained no clearly identifiable cultural features. Finally, a fourth trench was excavated about $11 \mathrm{~m}$ south of BHT 3 , and roughly $9 \mathrm{~m}$ north of TARL BHT 12 (see Figure 5-7) and the Area 2 excavations. This trench was $7.5 \mathrm{~m}$ in length and excavated to a maximum depth of $1.30 \mathrm{~m}$ below surface. Like BHT 3, BHT 4 lacked any clear evidence of cultural features.

The four trenches excavated by CAR totaled $29.75 \mathrm{~m}$ in length. While the original data recovery plan (Mauldin 2004) called for a more extensive use of backhoe trenches in order to locate features, that effort was curtailed given the results of both the hand excavations and the trenching that was conducted. The trenching and excavation demonstrated that much of the western portion of the site contains a mixture of natural sandstone-dominated colluvium and some possible burned sandstone and limestone, along with artifacts that had a high probability of being redeposited (see Chapter 6). This area was eliminated from further backhoe trenching. Note also that the northeastern section of the site had no recovery during the current testing in either the shovel or auger tests. Backhoe trenches planned for this area were also eliminated. Finally, between the time that the testing by TARL occurred and the current project was conducted, the road through the site had been widened, further removing portions of the site from consideration. The MOA (Appendix D) and subsequent work on 41PR44 was initiated as a result of that road maintenance.

\section{Summary}

CAR's work at site 41PR44 employed a variety of field methods during data recovery efforts. These included shovel testing, auger testing, hand excavation of 1-x-1-m units, and the excavation of four backhoe trenches. The only deviation from the data recovery plan for the project (see Mauldin 2004) was that the number of backhoe trenches was reduced. The decision to reduce the number of trenches was based on several factors, including the results of the hand-excavation units and the shovel and auger testing. Twelve burned rock features were identified, though, as we will argue subsequently, many of these probably are not cultural in origin or are in secondary contexts. A variety of artifacts were recovered, including large quantity of what was thought to be burned rock, 16 projectile points, close to 900 pieces of chipped stone debitage, several metate fragments, two complete manos, and small quantities of bone, charcoal, and mussel shell. 


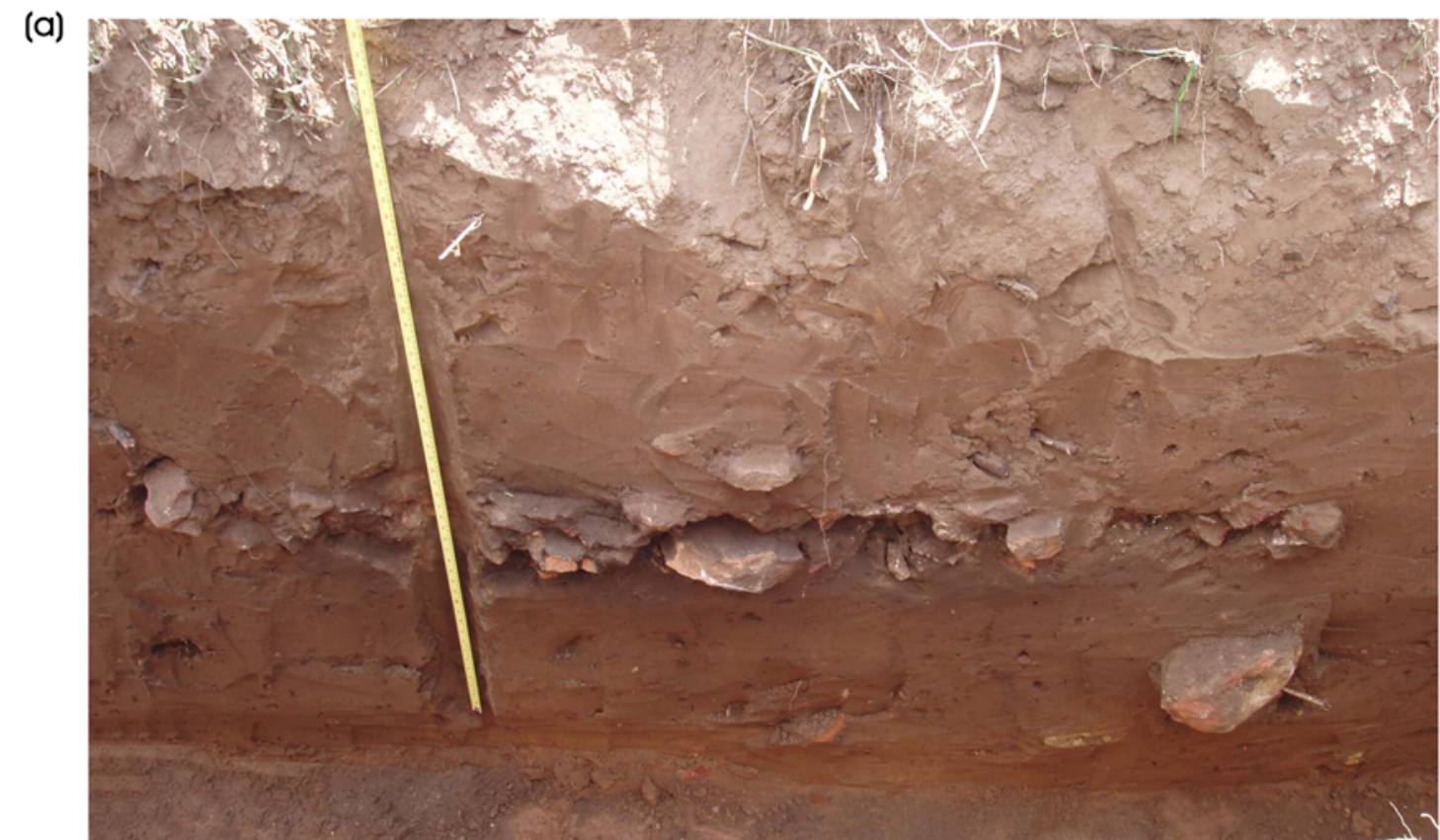

(b)

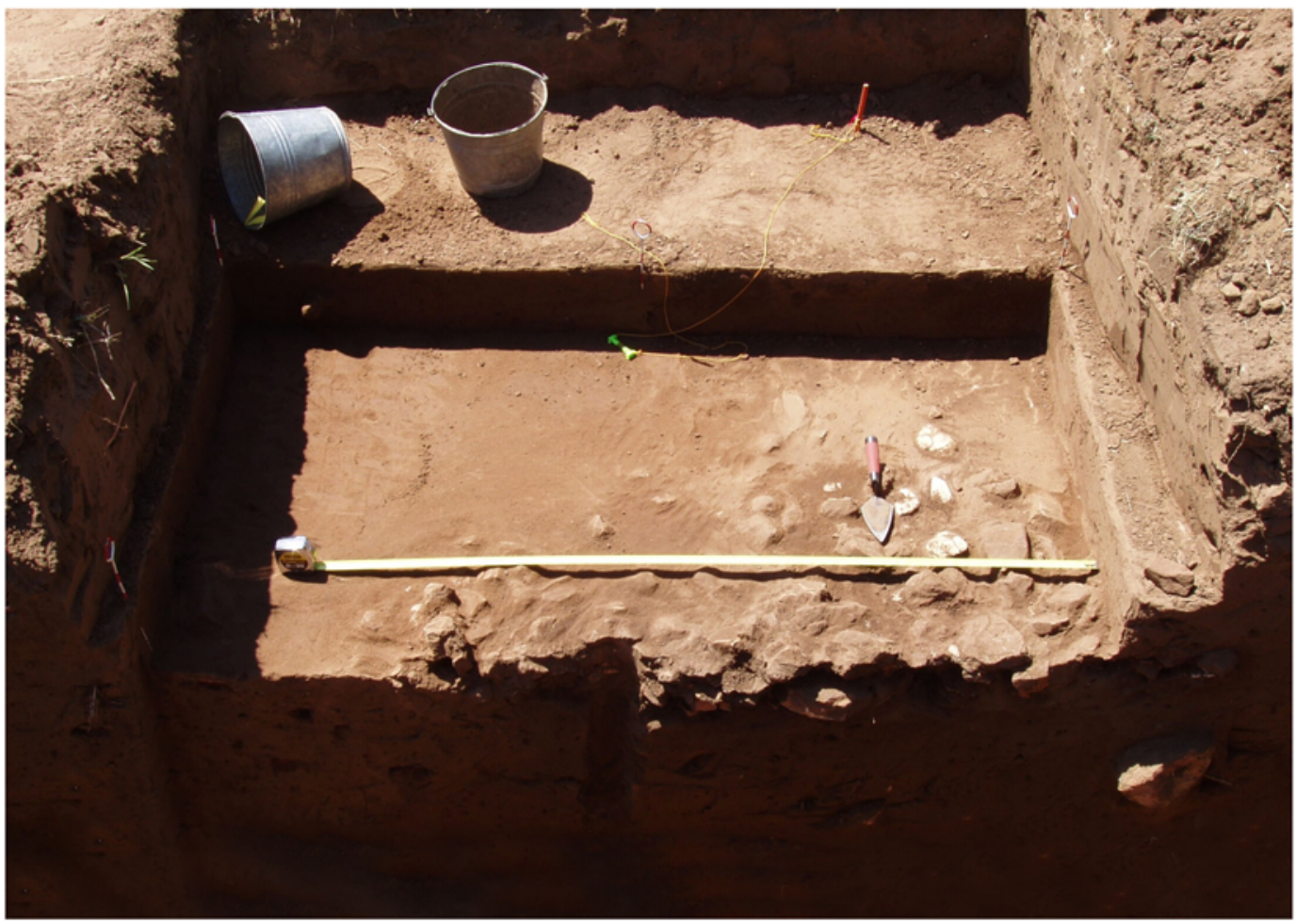

Figure 5-8. Feature 21: (a) South wall profile of Backhoe Trench 1; (b) Test Units 30 and 29. 



\section{Chapter 6: Geoarchaeological Overview}

\section{By Russell D. Greaves}

During excavations of 41PR44 by CAR, geoarchaeological investigations examined two previously excavated soil profiles, recorded three profiles associated with CAR's controlled block excavations, and examined four backhoe trench exposures. The primary geoarchaeological features of interest were discrete layers of rock accumulation variously associated with $\mathrm{B}$ and $\mathrm{C}$ horizons, depending on the portion of the site. Data recovery excavation was designed, in part, to sample the inferred distribution of several thermal rock features identified from the test excavations at this site (Brownlow 2001). Several portions of the site have been subject to significant disturbance from road construction and maintenance activities. Additionally, the site is located at the base of a sandstone outcrop and has been subject to repeated episodes of colluvial deposition. Alluvial deposition from Rock Creek is most pronounced in the southern and eastern portions of the site away from the sandstone ridge along the western margin of the site. Geoarchaeological investigations indicate a low probability that the concentrations of sandstone, previously identified as thermally fractured rock and features, represent anything other than natural colluvial deposits. There may be features present on this site, but the geomorphological data suggest that 41PR44 is dominated by natural rock accumulations. In the absence of compelling associations of charcoal, artifacts, thermally altered soil, or other clear indications of cultural features, none of the exposed rock layers or concentrations suggests that this site contains unambiguous evidence of hearths or other thermal uses of the natural rock. Except for paleosol deposits identified in the southern excavation block (Area 2, TUs 13-16, 22-25, 27-28), the geoarchaeological investigation concludes that 41PR44 has a poor potential to contain intact archaeological occupation debris to the depths examined.

\section{Previous Investigations}

Investigations by TARL determined that 41PR44 had the potential to contain intact, well-preserved archaeological remains and was eligible for the National Register of Historic Places (Brownlow 2001:18). Much of the inferred research potential of this site was based on the interpretation of abundant clasts with relatively discrete vertical distributions as intact cultural thermal features. Despite the adjacent outcrop of sandstone and alluvial fan morphology of much of the site deposits, the probability of colluvial origin for this rock was not considered in the initial interpretations (Brownlow 2001). The identification of much of the rock having been subject to thermal modification was based on its rubified appearance. Natural exposures of sandstone at the site and adjacent locations indicate this material naturally weathers with an oxidized reddish color even in the absence of thermal events.

Site 41PR44 is located on the northwestern bank of Rock Creek between the modern channel and an exposure of sandstone bedrock (Figure 6-1). Much of the site is adjacent to a north-south trending ridge of sandstone that is eroding on its eastern exposure. Sandstone is exposed all along the western margin of 41PR44. A limestone unit (or calcareous mudstone) underneath the sandstone is exposed on the eastern side of Rock Creek and in the riverbed. An unpaved military road runs through the middle of the site. This feature is apparently associated with excavation and fill of a roadbed to an unknown depth. Periodic maintenance is apparent in blading push piles all along the western margin of the road effecting most of the level area below the steeper alluvial fan deposits of the sandstone ridge. An abandoned roadway is apparent to the east of the current road. This old road has been heavily eroded, in places slightly over a meter in depth. Relatively intact alluvial floodplain deposits from Rock Creek are present only on the northeastern portion of the site in the vicinity of BHT 13 . BHT 1, the associated block excavation areas, and BHT 2 are situated in areas dominated by floodplain sediments, although the upper portion has been disturbed by road construction, maintenance, and subsequent natural erosion. The southernmost block excavation area also exposed primarily alluvial deposits. The upper sediments and soils in this area have been removed by military roadwork. All of the other excavation areas investigated by CAR are dominated by colluvial sediment of alluvial fan material from the sandstone ridge at the western margin of the site.

\section{Geoarchaeological Fieldwork Performed}

Geoarchaeological investigations at 41PR44 within the Fort Wolters military facility consisted of preliminary 


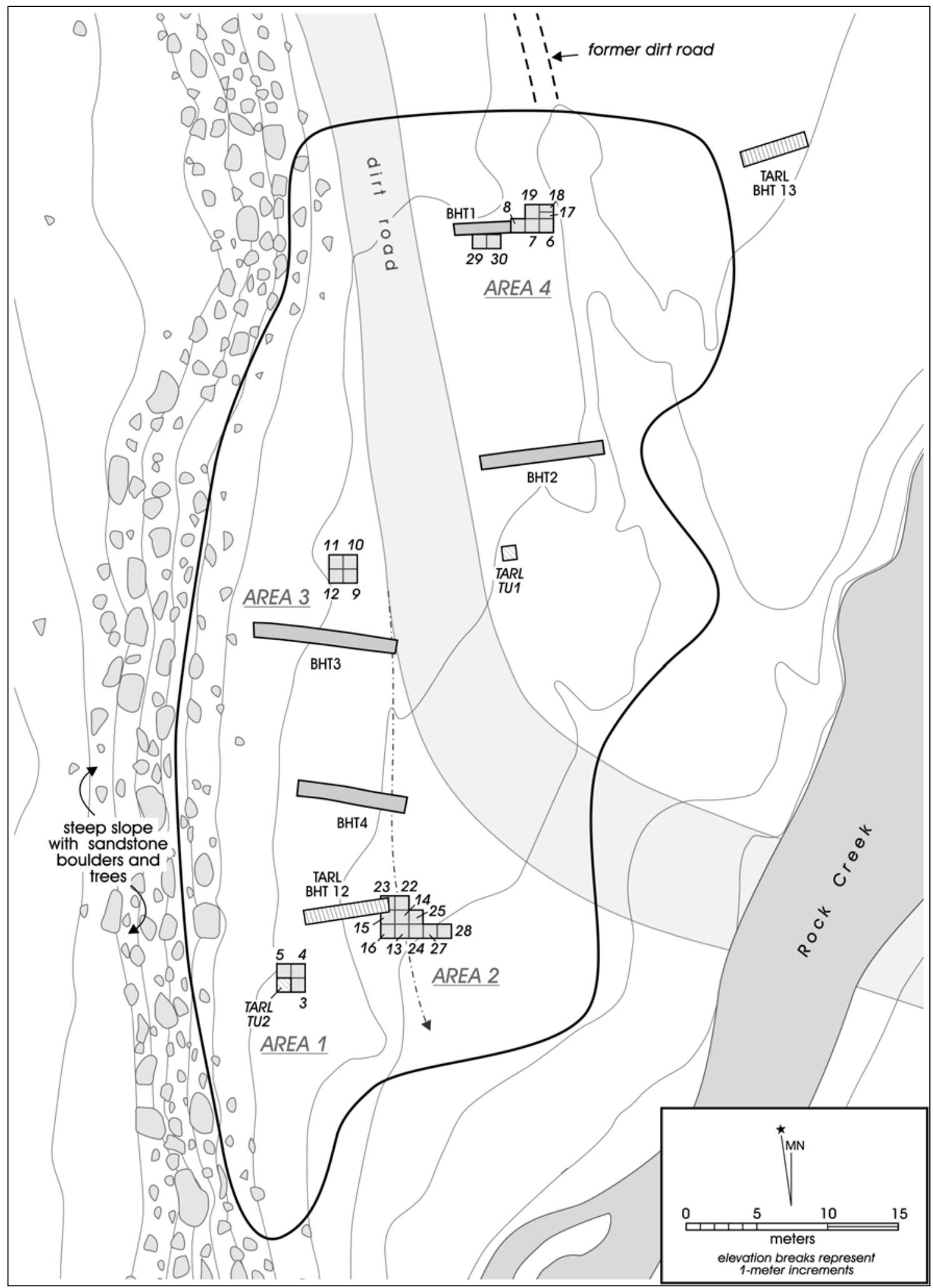

Figure 6-1. Locations of excavation units and backhoe trenches at 4IPR44. 
examination of previous excavations and recording of CAR's excavation units and backhoe trenches. Figure 6-1 shows the site setting and location of previous TARL investigations and CAR's excavations of 41PR44. Initial re-examination of the stratigraphic exposures of two previous excavations was performed in March 2004. This work recorded profiles from TARL's TU 2 and BHT 13. These two units were selected because their positions were readily relocated and they provided information about two different regions of the site. The northern and western walls of TU 2 were recorded and the southern and western walls of the western portion of BHT 13 were profiled (Figures 6-2 and 6-3). Complete soil descriptions were performed for both of these profiles. Subsequent to completion of the majority of CAR's mitigation excavations, geoarchaeological recording was performed on the profiles of three excavation blocks and four backhoe trenches. The southern wall of the southernmost block excavation (Area 2) recorded the exposures of a relatively deeply buried paleosol in TUs 16, 13, 24, 27, and 28 (Figure 6-4). These represent a contiguous 5-m exposure of the deepest deposits examined during this mitigation. A complete soil description was performed on this profile. The southern walls of TUs 12 and 9 (Area 3) were recorded within this 2-x-2-m block excavation in the middle of the western portion of 41PR44 (Figure 6-5). The southern wall of TUs 6, 7, and 8 were recorded in the northernmost excavation block (Area 4) adjacent to possible burned rock features (Figure 6-6).

\section{Methods}

Profile walls were trowelled and examined for evidence of any potential archaeological artifacts, features, or significant indicators of formation events. All walls of the excavation units and one wall of each backhoe trench was profiled and drawn (Figures 6-2 through 6-10). No archaeological artifacts or charcoal samples were identified during profiling. Full soil descriptions were performed on the profile of TU 2 and BHT 13 from the previous test excavations. Profile descriptions were recorded for each of CAR's three block excavations but not for any of the backhoe trenches. Soils were considered similar to those described from controlled excavations. Abbreviated observations about the deposits in these backhoe trenches were recorded. Complete field soil observations included soil texture, consistency, presence and morphology of clay films, grain coatings, structure, abundance and size of roots, abundance and size of pores, horizon boundaries, and Munsell colors. Soil descriptions are provided in Tables 6-1 through 6-5. These attributes permit designation of the soil and sedimentary horizons in standard soil nomenclature (Birkeland 1984:353-360; Soil Survey Staff 1993:117-135).

\section{Results}

\section{Examination of Previous Excavations}

Test Unit 2 was the closest excavation unit to the sandstone bedrock outcrop (Figure 6-1) and provided initial control of the colluivial deposits at 41PR44. This test unit was re-excavated to examine the profile interpreted to show the presence and stratigraphic position of a relatively intact cultural feature, Feature 2 (Brownlow 2001:Figure 4c). No additional excavation was performed prior to profiling. All walls of this unit were carefully examined but only the northern and western walls were drawn (Figure 6-2) and described (Table 6-1). A maximum of $112 \mathrm{~cm}$ of the soil profile was exposed in this excavation. Weathered bedrock was apparent all across the base of the excavation of TU 2 .

The distribution of rock identified as a cultural feature by Brownlow (2001:16-18) appears to represent a natural deposit of colluvial clasts. From Brownlow's (2001:Figure $4 c)$ original profile, the sloping angle of this line of clasts appeared problematic to interpretation that this represented a cultural thermal feature. The higher rocks are situated upslope (west) and they dip toward the downslope side (east). While a cultural feature situated on an ancient land surface might show this orientation, there must be some compelling reason to infer that this is a cultural deposit rather than colluvium. No such evidence is apparent. The rock within this distribution is weathered sandstone from the ridge above TU 2. One piece of limestone was present at the extreme eastern portion of this profile (Figure 6-2). The rock cluster was associated with the boundary between the B1 and B2 horizons. There was no charcoal or apparent organic enrichment associated with this rock cluster. Subsequent enlargement of this area through excavation of three additional 1-x-1-m units (Figure 6-1, TUs 3-5) showed that the same approximate portion of the profile contained a relatively discrete vertical rock concentration. No evidence of charcoal, organic enrichment or artifact concentration from these excavations and exposed profiles support the position that this rock was a cultural accumulation.

Backhoe Trench 13 was previously examined by TARL and was not associated with any identified cultural materials. Geoarchaeological examination was performed at this location because it provided a minimally disturbed location 
to examine alluvial sediments at 41PR44. BHT 13 was located just outside of the previously determined site boundary (Figure 6-1). The southwestern corner and approximately $45-190 \mathrm{~cm}$ of the southern wall of BHT 13 was exposed through re-excavation. Approximately $87-108 \mathrm{~cm}$ of the western wall of BHT 13 was re-exposed for this examination. The trench was cleaned down to $130-135 \mathrm{cmbs}$. Both walls were carefully trowelled and examined for the presence of artifacts or charcoal. No evidence of any cultural materials or charcoal was found during this investigation. Both profile walls were drawn (Figure 6-3) and described (Table 6-2).

The uppermost $10-25 \mathrm{~cm}$ of the profile were disturbed and showed a clear erosional unconformity with the underlying soils. This is likely evidence of the previous effects of excavation of BHT 13 during the previous investigations. No clasts were present in these profiles and it demonstrated a dominance of alluvial floodplain deposits in this area of the site. Lamellae present in the $\mathrm{C} 1$ horizon suggest that sedimentary episodes were represented at least in the lowest portion of the profile. Unlike sediments in excavations to the west of this location where clasts were present, all of the soil horizons were flat laying and showed no depositional influences from the sandstone ridge. There was no evidence of any cultural deposits or paleosol that were likely to provide archaeological remains in this location.

\section{Examination of CAR Excavations and Backhoe Trenches}

A contiguous exposure of $5 \mathrm{~m}$ along the southern margin of Area 2 (Figure 6-1) was examined, drawn (Figure 6-4) and described (Table 6-3). This location provided information about a buried paleosol identified during initial augering of 41PR44. A very dark soil associated with a relatively high density of artifacts was encountered in auger testing of this location. This is the lowest elevation portion of the site and, as such, provided information on sediments that are much more deeply buried than could be readily examined in other portions of the site. This may be the soil unit that was previously dated to cal BP $3050 \pm 60$ (Brownlow 2001:12).

The uppermost $10-37 \mathrm{~cm}$ of this profile exposure was recently disturbed by road construction and maintenance activities. All of the solum had been removed from this location except for a few isolated examples of localized, recent, weakly developed soils. The $\mathrm{C} 1$ and $\mathrm{C} 2$ horizons

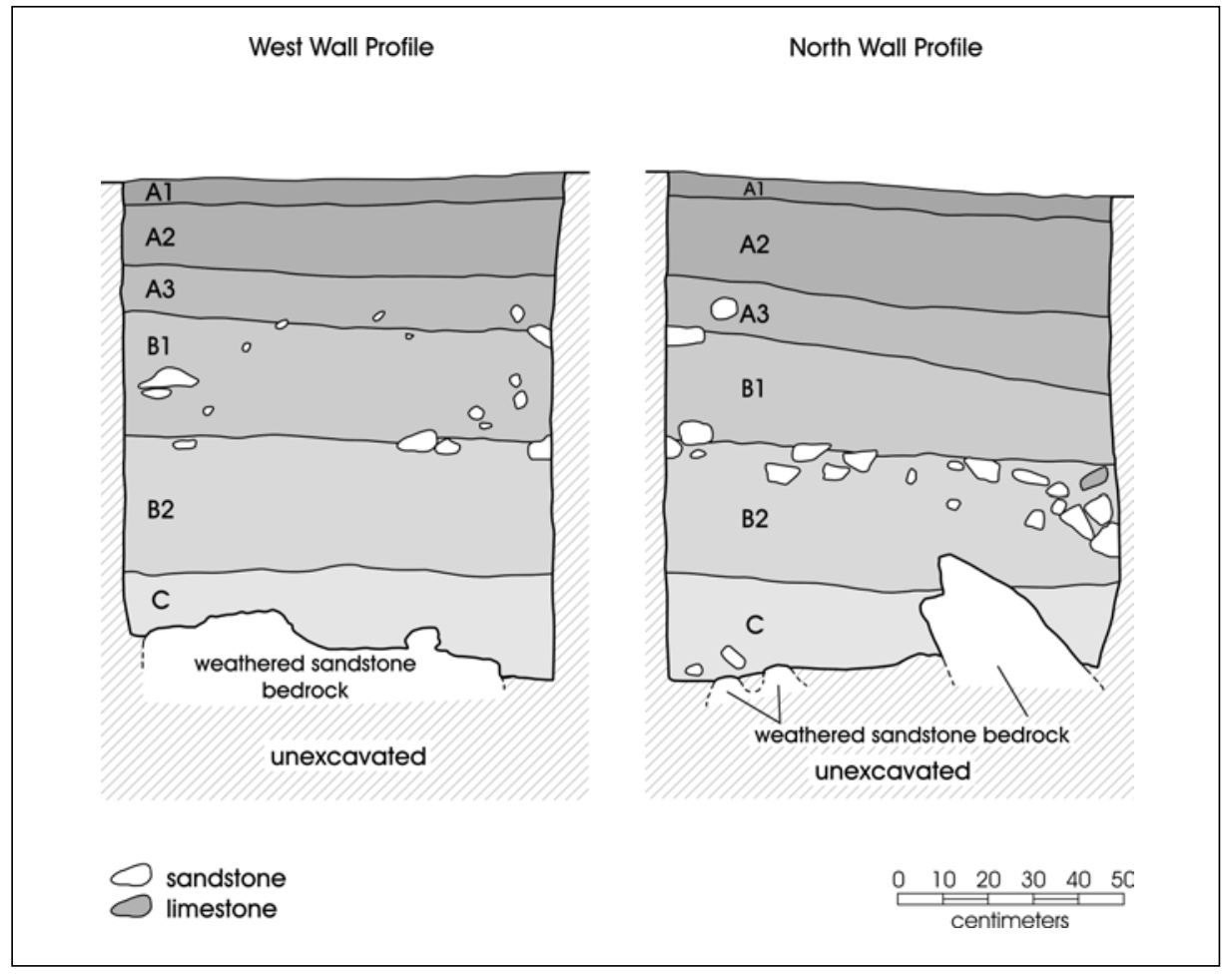

Figure 6-2. Test Unit 2, west and north wall profiles. 


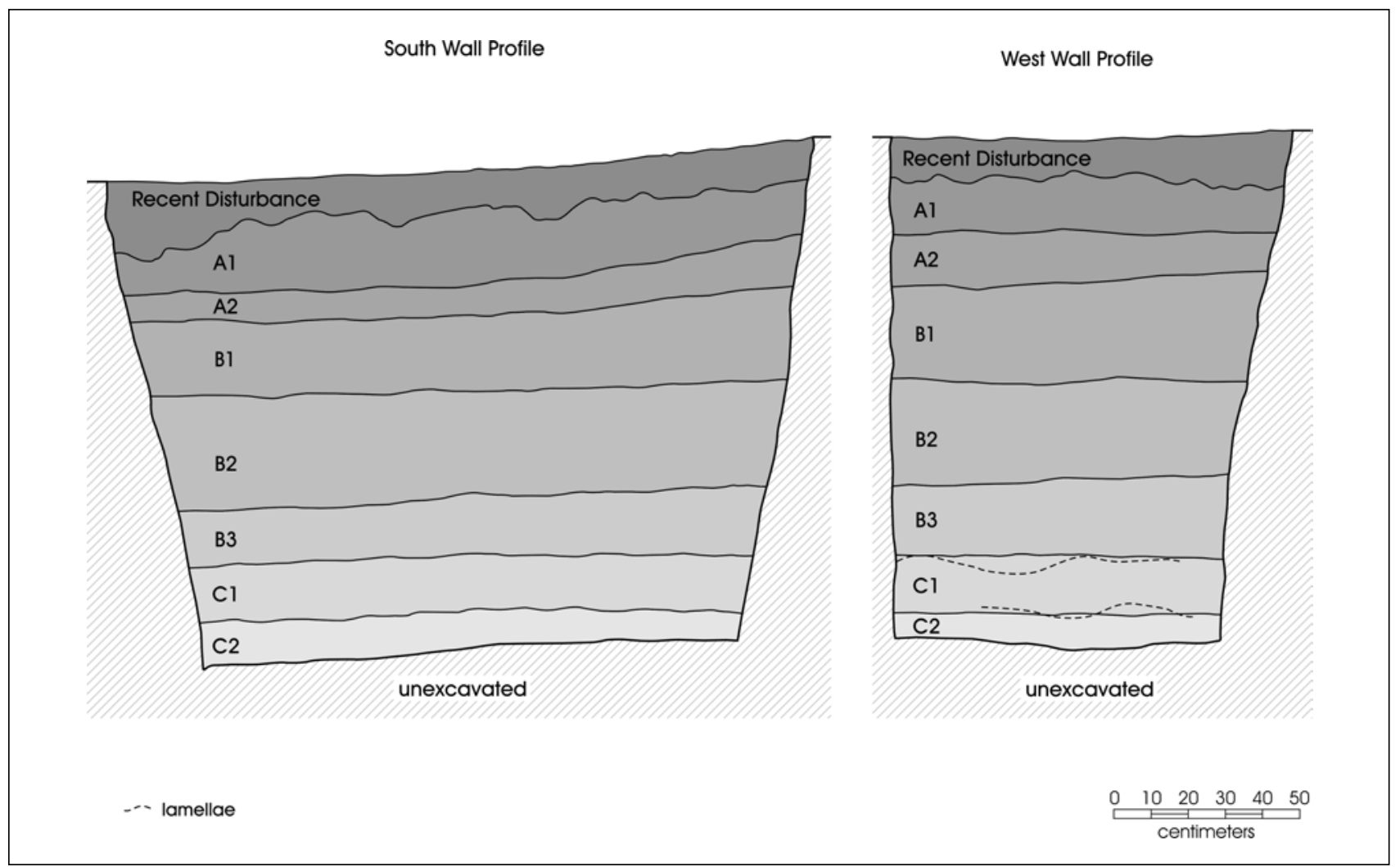

Figure 6-3. Backhoe Trench 13, south and west wall profiles.

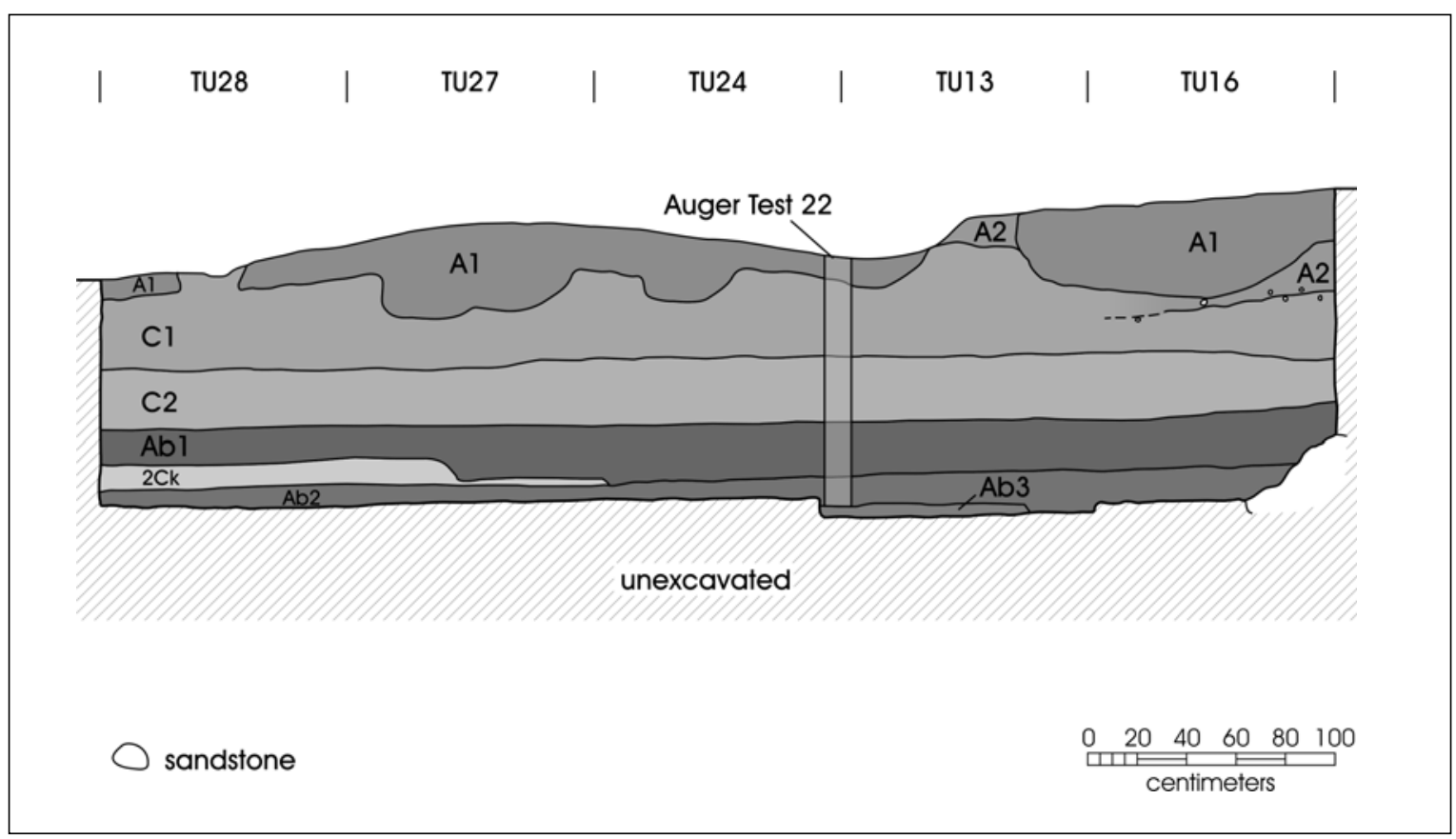

Figure 6-4. Test Units 16, 13, 24, 27, and 28, south wall profile. 


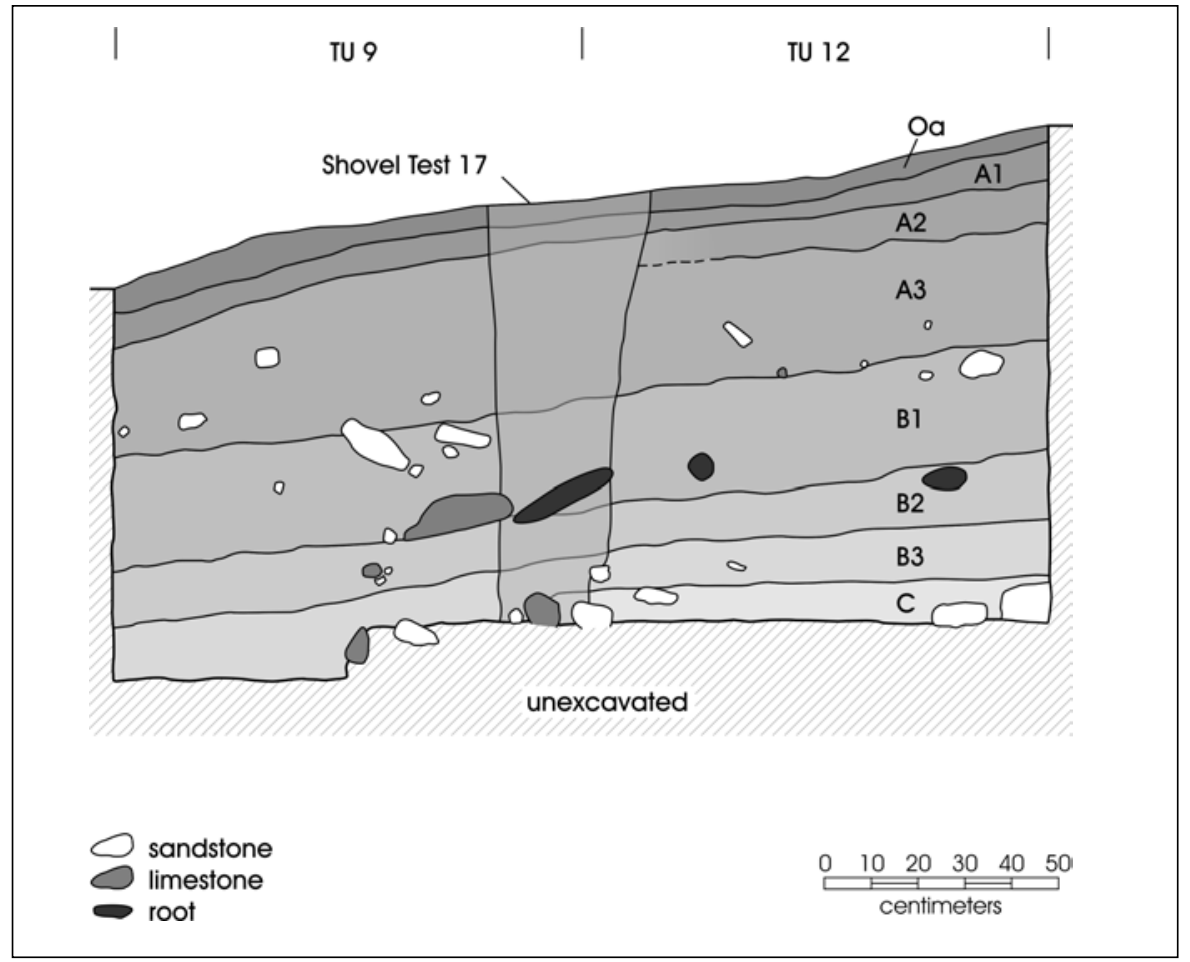

Figure 6-5. Test Units 9 and 12, south wall profile.

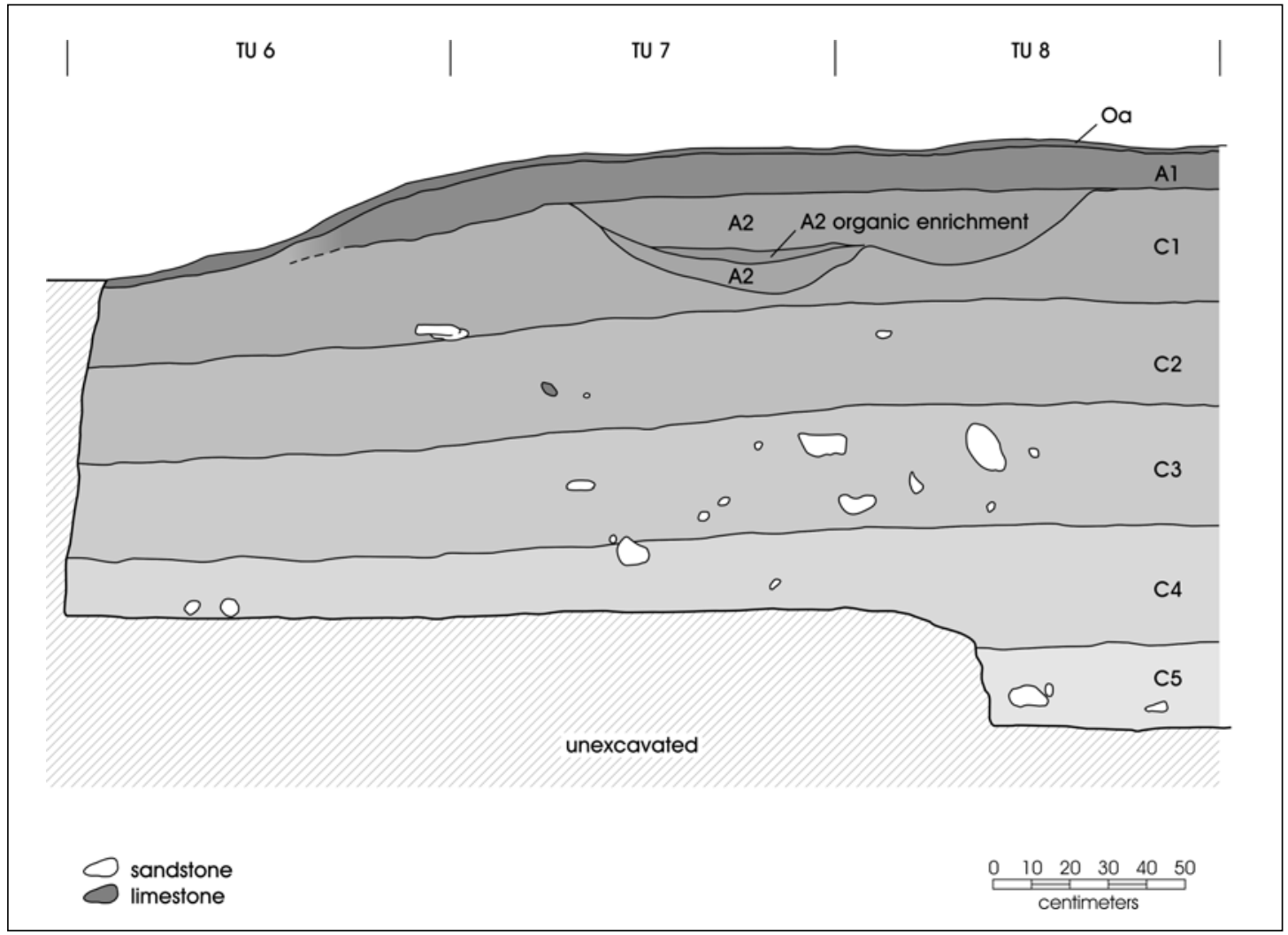

Figure 6-6. Test Units 6, 7, and 8, south wall profile. 


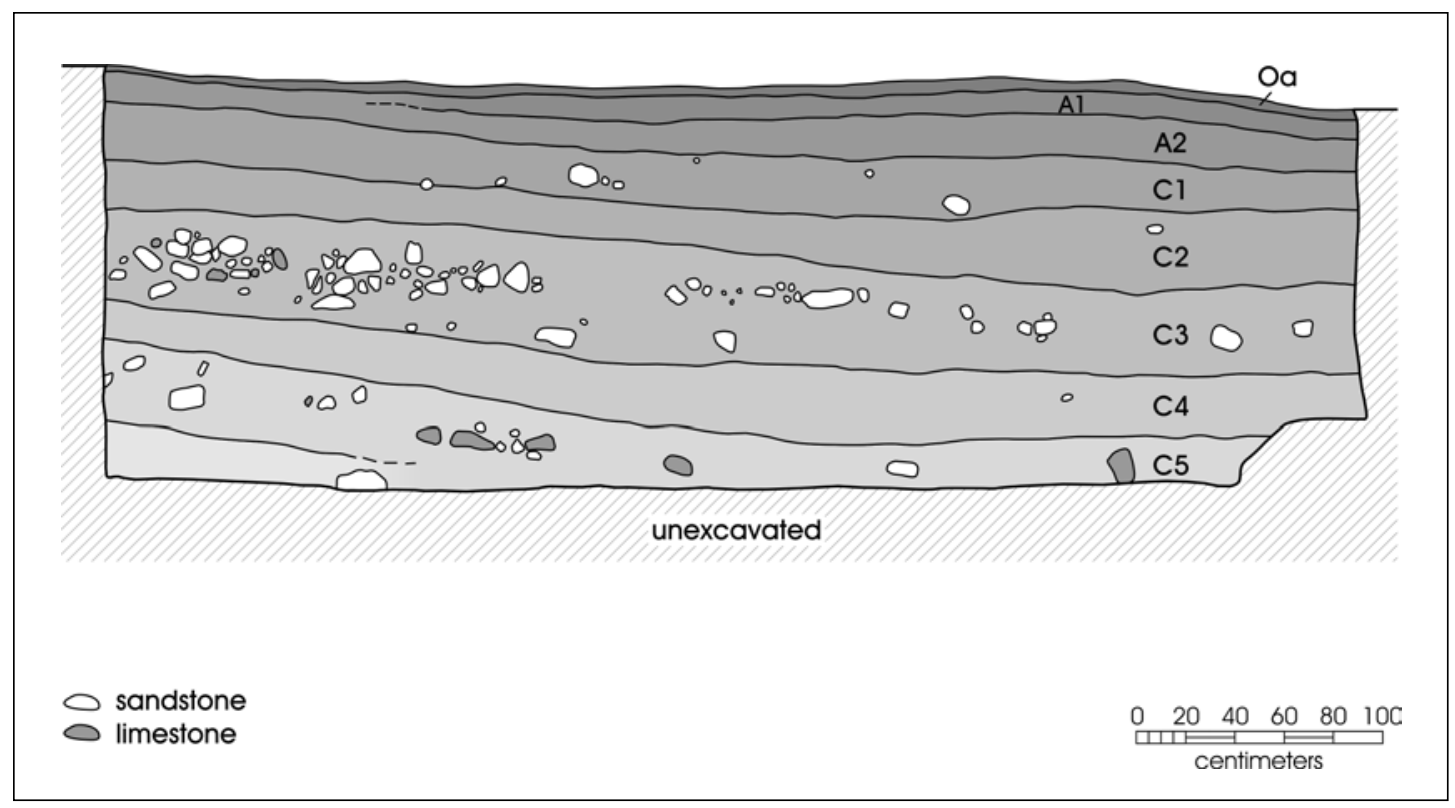

Figure 6-7. Backhoe Trench 1, north wall profile.

extended approximately $66-80 \mathrm{~cm}$ below the irregular modern ground surface. Below the $\mathrm{C} 2$, a sequence of three paleosols was identified. Ab1 extended across the entire profile. Below this buried A horizon, a $4-10 \mathrm{~cm}$ thick $2 \mathrm{Ck}$ sediment was visible to $106 \mathrm{~cm}$ west of the southeastern corner of TU 28. This sediment thinned to the east and was not visible in the other portions of the profile. Underlying the $2 \mathrm{Ck}$ and the $\mathrm{Ab} 1$ was $\mathrm{Ab} 2$ that also extended across the entire profile. A very small portion of Ab3 was exposed only in the eastern $78 \mathrm{~cm}$ of excavation in TU 13. This paleosol had few soft $\mathrm{CaCO}_{3}$ masses that were less than or equal to $3 \mathrm{~mm}$ in maximum dimension. The morphology of these three paleosols and the $2 \mathrm{Ck}$ sediment between the eastern portions of $\mathrm{Ab} 1$ and $\mathrm{Ab} 2$ indicate they were formed in alluvial floodplain sediments that were being input from the east where the modern channel of Rock Creek is situated. The organic enrichment of these buried A horizons contrasts dramatically with the $\mathrm{C}$ horizon sediments of most of this profile. Two relatively large pieces of charcoal $(6-10 \mathrm{~mm})$ were recovered from the floor exposure of $\mathrm{Ab} 2$ in TU 28. It is uncertain whether these are cultural in origin. These three soils represent a period of ground surface stability that was followed by significant amounts of steadily aggrading deposition that are not interrupted by surface stability and soil formation.

The southern wall of the central excavation block (Area 3, TUs 9-12) was examined and profiled. The southern walls of TUs 9 and 12 were drawn (Figure 6-5) and fully described (Table 6-4). This area was considered to contain good evidence of possible thermal features during excavation. These two units were centered on Shovel Test 17, which was still apparent in the southern wall profile. No artifacts or charcoal were encountered during these geoarchaeological investigations.

Soils and sediments showed the west-east dip that indicates a dominance of colluvial deposition in this location. An Oa, A1, A2, A3, B1, B2, B3, C sequence was exposed in this profile. All soil units showed pronounced dips to the east, following the modern ground contour. Clasts were relatively common in the $\mathrm{B} 1$ soil while only a few were present in the $\mathrm{A} 3, \mathrm{~B} 2$, and $\mathrm{B} 3$ horizons. A single piece of limestone was present at the base of the $\mathrm{B} 1$ unit. Clasts were abundant in the $\mathrm{C}$ horizon at the base of the excavations. One piece of limestone was present within the B2 and two were exposed in the lower portion of the B3 soil. This restricted distribution of rocks was similar to that seen across most of the site. The distribution and morphology of the clast-rich deposits in these excavation units strongly suggests colluvial deposition and does not unambiguously indicate any likelihood that culturally constructed rock features are present in this location. No artifacts or charcoal were identified within the profiles that would provide secure identification of cultural features among naturally deposited rocks. Although some roughly 
circular horizontal distributions were identified at the time of excavation, profiling was unable to confirm that cultural features were present.

The southern wall of TUs 6, 7, and 8, Area 4, were profiled (Figure 6-6) and described (Table 6-5). These units were adjacent to excavations of a rock concentration within TUs 17-19 that may represent a cultural feature. This block excavation was directly east of the BHT 1 excavation. At the time of the geoarchaeological recording, a rock concentration apparent in the southern wall of BHT 1 was being excavated in TUs 29-30. A profile was drawn of the northern wall of BHT 1 (Figure 6-7) that represents the contiguous western deposits of TUs 6-8. BHT 1 extended approximately $5 \mathrm{~m}$ west of TU 8 . This trench was maximally $160 \mathrm{~cm}$ deep. The rock concentration examined in TUs 29-30 also was apparent in the north wall profile of BHT 1.

The $\mathrm{Oa}, \mathrm{A} 1$, and $\mathrm{A} 2$ soils at this location represented very recent soils that were unconformable with the C1-C5 horizons below them. Recent human activities (Texas Army National Guard use) and some natural erosion appear to have removed the intact older solum from this location. A distinct erosional unconformity was present between the $\mathrm{A} 2$ and $\mathrm{C} 1$ horizons. The $\mathrm{Oa}, \mathrm{A} 1$, and $\mathrm{A} 2$ appeared to represent very weakly developed recent soils formed in sediments that postdate surface modifications at this location associated with road construction. The lack of any B horizon also was apparent in the profile of the adjacent northern wall of BHT 1. The Oa, A1, and A2 soils mantled the truncated upper margin of the $\mathrm{C} 1$ unit. In TUs 6,7 , and 8 they did not follow the general landscape contour and contrast with the C1-C5 horizons that all dipped from west to east. In the profile of the northern wall of BHT 1, this same contrast was apparent, especially in the $\mathrm{Oa}$ and $\mathrm{A} 1$ soils.

The profile of the southern wall of TUs 6, 7, and 8 showed a relatively low density of sandstone clasts (Figure 6-6). They were most common in the $\mathrm{C} 3$ and $\mathrm{C} 5$ units, but were present from throughout the C1-C5 sediments. The clustering of rock was more apparent upslope in the profile of the northern wall of BHT 1 (Figure 6-7). A dense concentration of sandstone was present in the middle of the $\mathrm{C} 3$ horizon from approximately $0-180 \mathrm{~cm}$ east of the western end of the trench. Two pieces of limestone also were present in this cluster. This profile indicates that $\mathrm{C} 5$ contained a moderate density of clasts. Four pieces of limestone and a low quality piece of chert also were present in association with the sandstone present in C5.
No archaeological artifacts or charcoal were identified during the profiling of BHT 1 or TUs 6-8. Although controlled excavations suggested that there are prehistoric cultural deposits in this area, profiling did not identify any discrete or robust archaeological deposits. It is unclear whether the zones of maximal clast density represent stable surfaces that accumulated periodic input of colluvial rock or if they are evidence of pulses of alluvial fan deposition. The exposed profile indicated that colluvial sedimentation represents the dominant formation events, but they may interfinger with alluvial terrace deposits (as recorded in the profile of BHT 13).

Profile drawings were made of BHTs 2, 3, and 4 (Figures 6-8 through 6-10) but no detailed soil descriptions were made for them. Brief notes were recorded about each of these trenches. BHT 2 was similar to BHT 1, showing a mix of colluvial deposits and alluvial floodplain sedimentation. BHT 3 was similar to the recorded profile of TUs 9 and 12 (Table 6-4) just north of this trench. BHT 4 showed similar deposits to those in BHT 2 and in the profiles of TU 2. Brief descriptions of BHTs 2, 3, and 4 are presented in relation to their profiles and implications for understanding site formation at 41PR44.

BHT 2 was placed south of BHT 1 on the eastern side of the existing roadway (Figure 6-1). Both walls were examined and the southern wall was drawn (Figure 6-8). The surface of this area had been significantly affected by roadwork and natural erosion. The upper portion of the profile did not appear to be as disturbed as the BHT 1 setting and potentially intact $\mathrm{A}$ and $\mathrm{B}$ horizons were present in this profile. It is apparent from both the setting and the profile that this location is dominated by alluvial terrace sediments. Clasts from the sandstone outcrop were apparent in the western $120 \mathrm{~cm}$ of this profile, but were less common in the other portions of this profile. The $\mathrm{Oa}$ and $\mathrm{A} 1$ horizons were recent. They were thin (less than or equal to $10 \mathrm{~cm}$ ) and conform to the modern ground surface morphology. A deposit mantling the eastern end of the trench was from a very recent set of sedimentary events at the margin of the ephemeral drainage that is associated with road construction and use. An apparently recent concentration of charcoal was present within the $\mathrm{A} 2$ horizon at the western end of the trench. No archaeological artifacts, cultural features, or possibly ancient charcoal were identified in this profile. The utility of this exposure was to identify the predominance of floodplain deposits in this portion of the site as also apparent in most of BHT 1 and in BHT 13. 


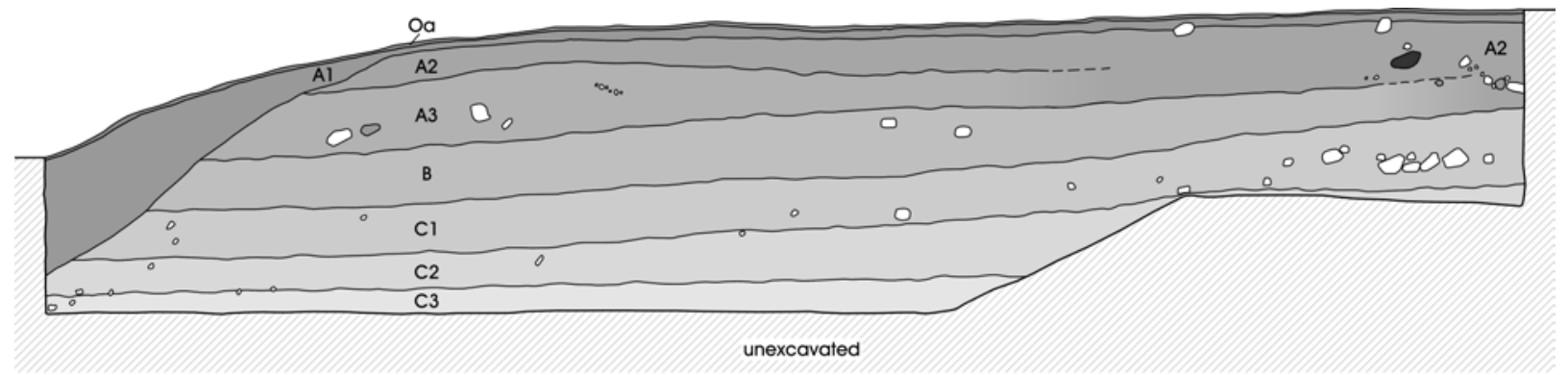

sandstone

limestone

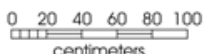
centimeters

Figure 6-8. Backhoe Trench 2, south wall profile.

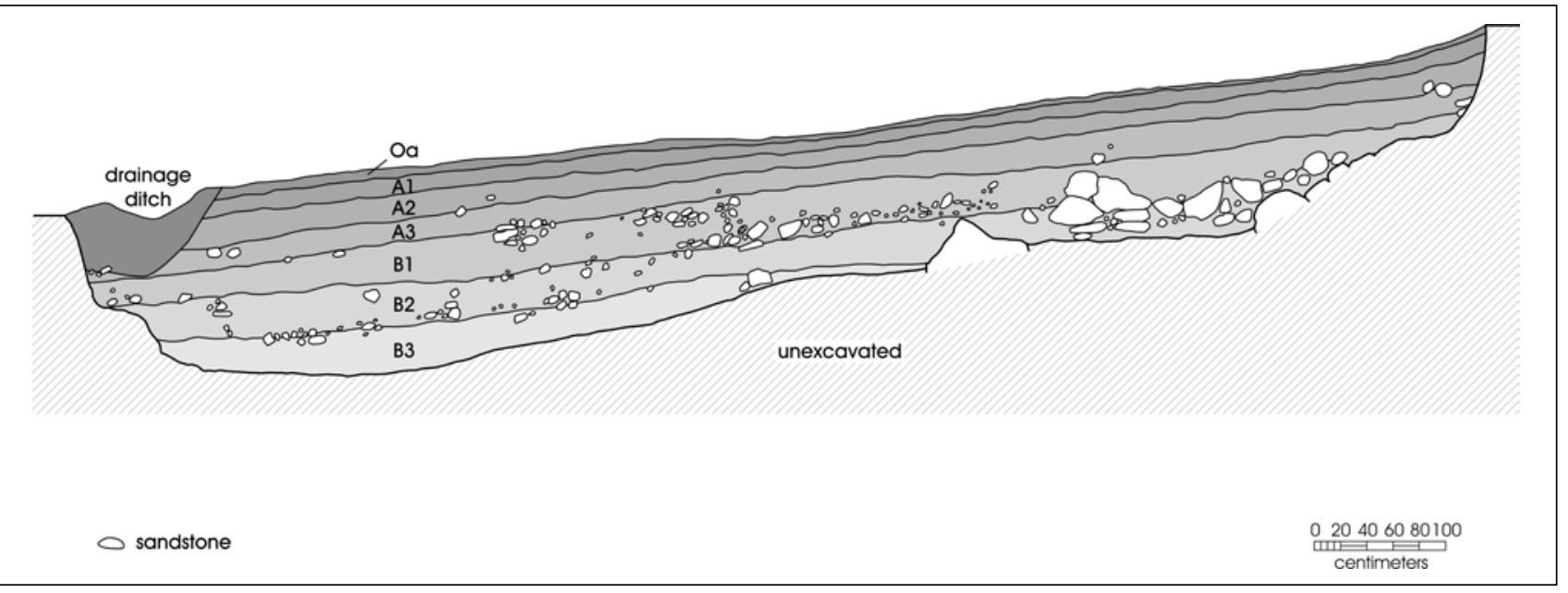

Figure 6-9. Backhoe Trench 3, south wall profile.

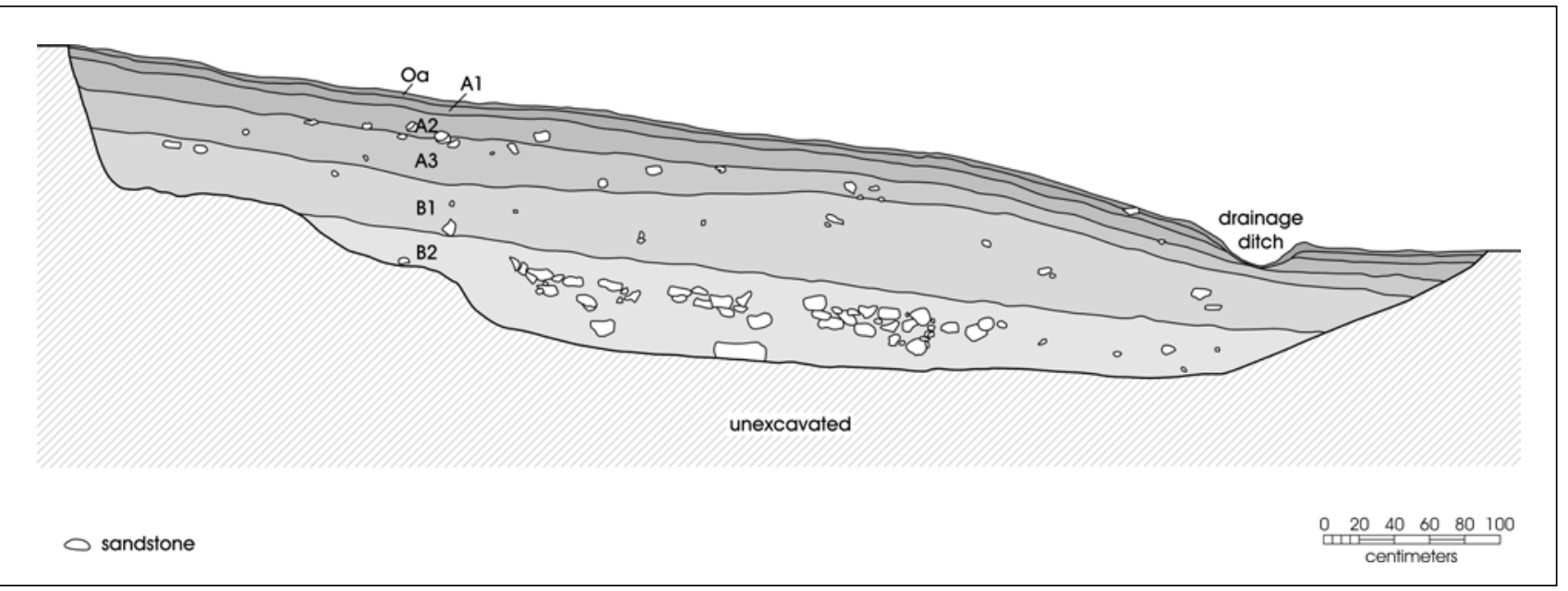

Figure 6-10. Backhoe Trench 4, north wall profile. 


\begin{tabular}{|c|c|c|c|c|c|c|c|}
\hline 产 & & & & 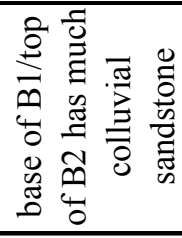 & & 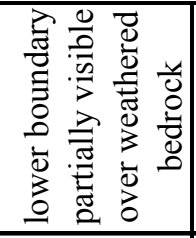 & 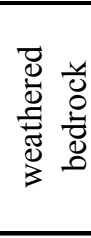 \\
\hline$\frac{\dot{\theta}}{\dot{\theta}}$ & 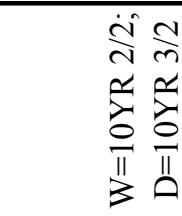 & 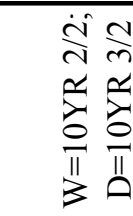 & 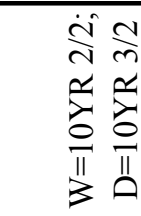 & 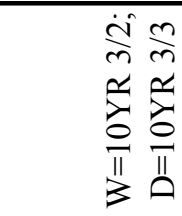 & 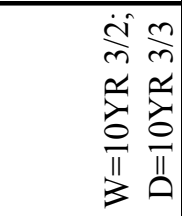 & 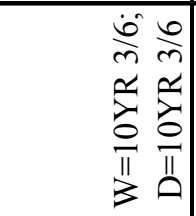 & \\
\hline ڤ્己 & 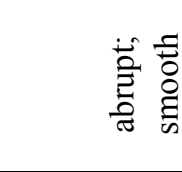 & 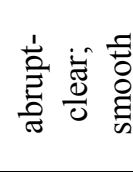 & 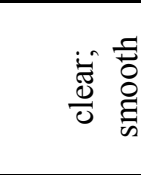 & 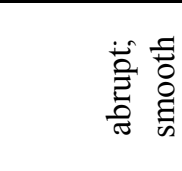 & 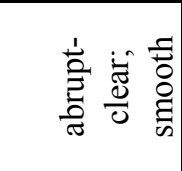 & 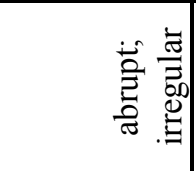 & \\
\hline 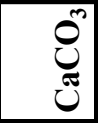 & 0 & 0 & 0 & 0 & 0 & 0 & \\
\hline$\stackrel{\bullet}{0}$ & 0 & 0 & 0 & 0 & 0 & 0 & \\
\hline$\stackrel{n}{8}$ & 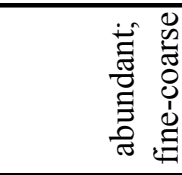 & 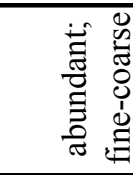 & 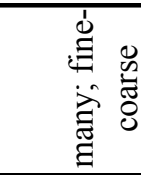 & 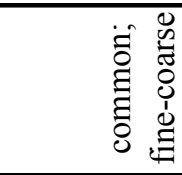 & 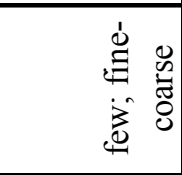 & 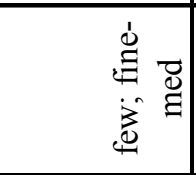 & \\
\hline 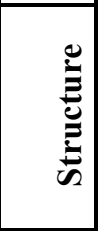 & 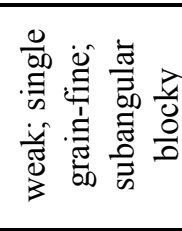 & 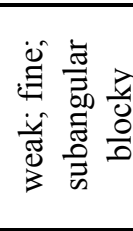 & 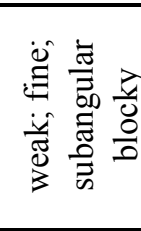 & 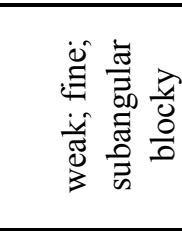 & 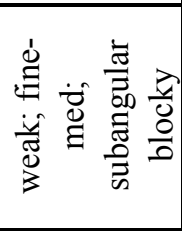 & 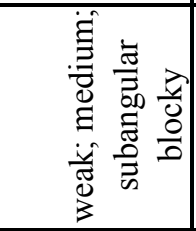 & \\
\hline טֶ. & 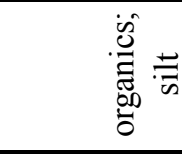 & 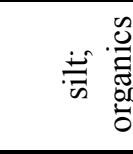 & 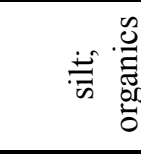 & 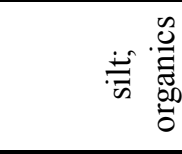 & $=\frac{\bar{n}}{\omega}$ & $\stackrel{ \pm}{\bar{n}}$ & \\
\hline 悹 & 0 & 0 & 0 & 0 & 0 & 0 & \\
\hline 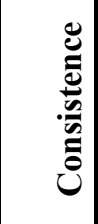 & 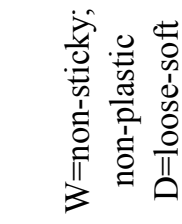 & 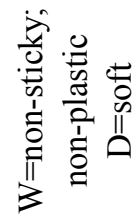 & 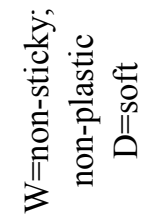 & 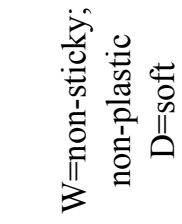 & 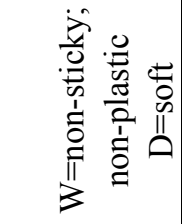 & 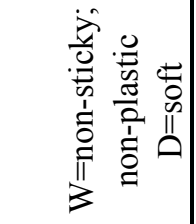 & \\
\hline 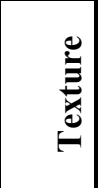 & 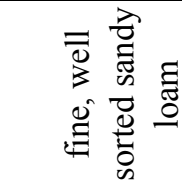 & 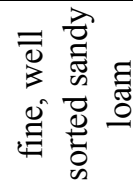 & 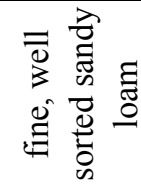 & 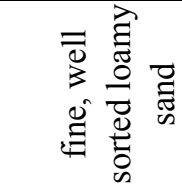 & 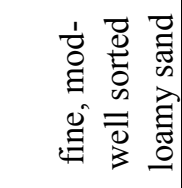 & 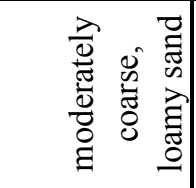 & \\
\hline 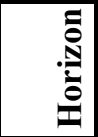 & « & $\mathbb{Z}$ & $\stackrel{2}{<}$ & $\bar{n}$ & $\tilde{n}$ & $u$ & $\simeq$ \\
\hline
\end{tabular}




\begin{tabular}{|c|c|c|c|c|c|c|c|c|}
\hline نُّ & 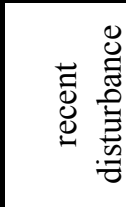 & & & & & & $\begin{array}{l}\pi \\
\pi \\
0 \\
0 \\
0 \\
0 \\
0 \\
3 \\
0 \\
0\end{array}$ & \\
\hline$\frac{\grave{\theta}}{\dot{\theta}}$ & & 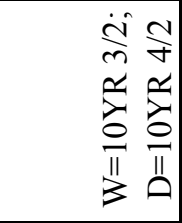 & 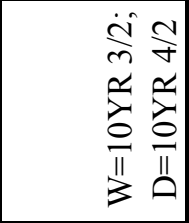 & 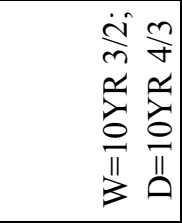 & 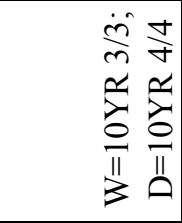 & 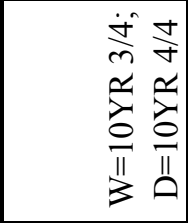 & 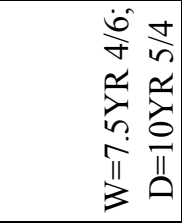 & 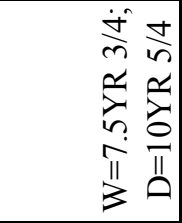 \\
\hline 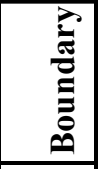 & 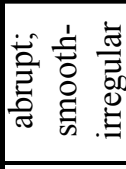 & 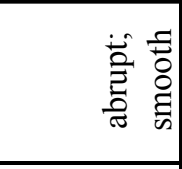 & 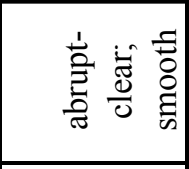 & 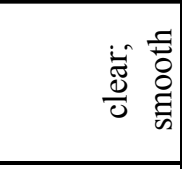 & 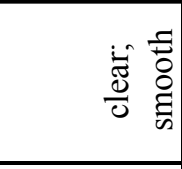 & 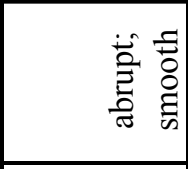 & 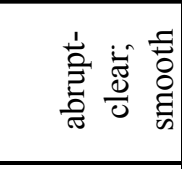 & 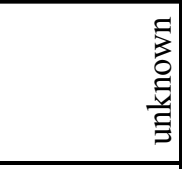 \\
\hline 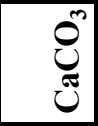 & 0 & 0 & 0 & 0 & 0 & 0 & 0 & 0 \\
\hline$\stackrel{0}{0}$ & & 0 & 0 & 0 & 总息 & 0 & 0 & 0 \\
\hline$\stackrel{n}{\mathscr{0}}$ & 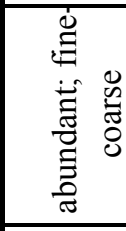 & 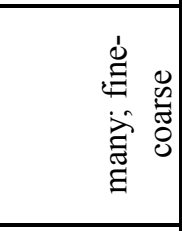 & 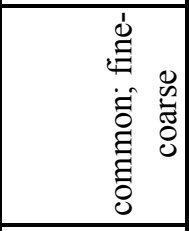 & 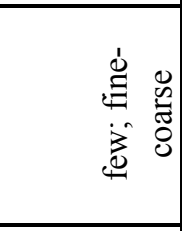 & 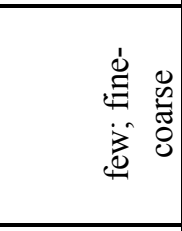 & 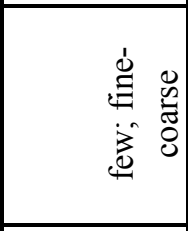 & 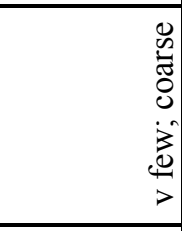 & 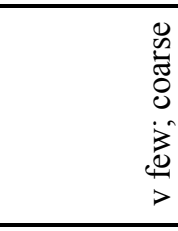 \\
\hline 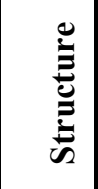 & & 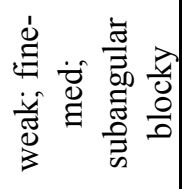 & 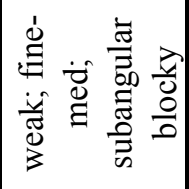 & 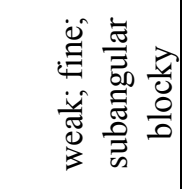 & 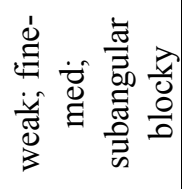 & 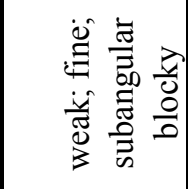 & 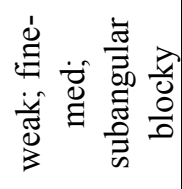 & 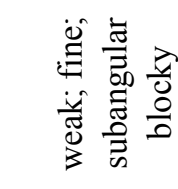 \\
\hline Uి & & $\vec{\omega}$ & $\frac{\overrightarrow{\mathrm{c}}}{\mathrm{m}}$ & $\vec{\omega}$ & $\stackrel{\vec{\omega}}{\vec{\omega}}$ & $=\frac{\vec{n}}{\omega}$ & $\frac{\vec{v}}{\vec{w}}$ & : \\
\hline$\frac{\mathrm{E}}{\mathrm{U}}$ & & 0 & 0 & 0 & 0 & 0 & 0 & 0 \\
\hline 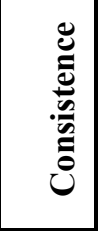 & & 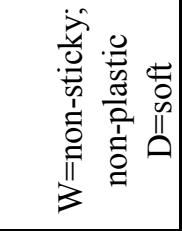 & 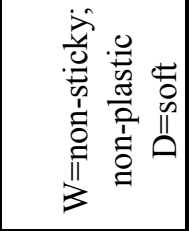 & 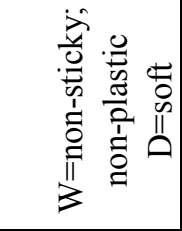 & 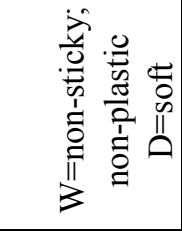 & 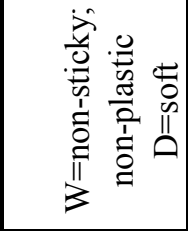 & 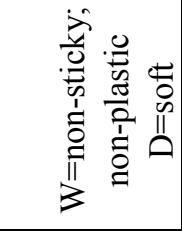 & 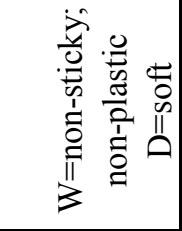 \\
\hline 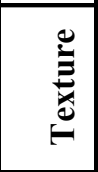 & & 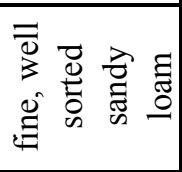 & 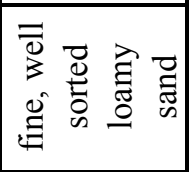 & 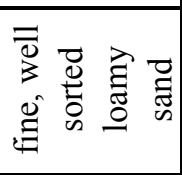 & 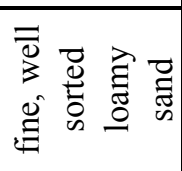 & 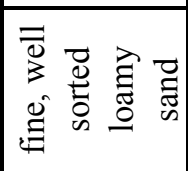 & 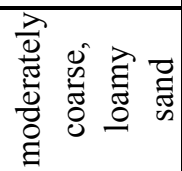 & 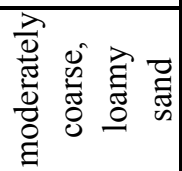 \\
\hline 产 & 0 & 《 & $\underset{2}{2}$ & $\vec{n}$ & $\tilde{n}$ & $\hat{\varphi}$ & $\vec{U}$ & $\widetilde{U}$ \\
\hline
\end{tabular}




\begin{tabular}{|c|c|c|c|c|c|c|c|c|}
\hline 这 & 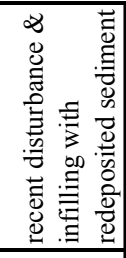 & 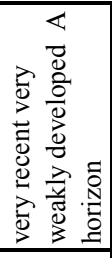 & & 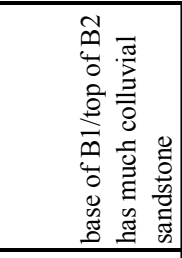 & & 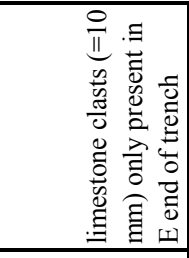 & 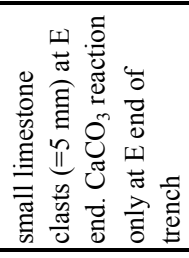 & 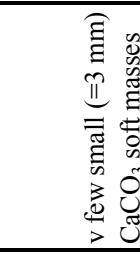 \\
\hline$\frac{\dot{\theta}}{\dot{\theta}}$ & 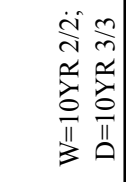 & 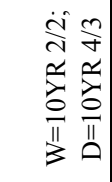 & 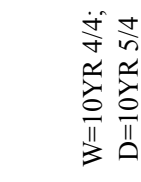 & 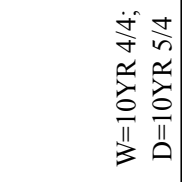 & 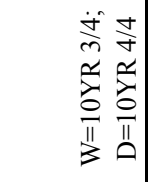 & 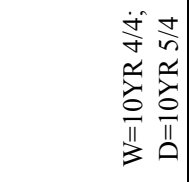 & 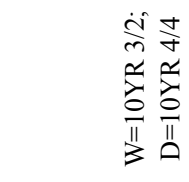 & 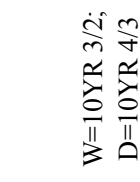 \\
\hline 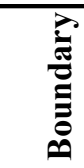 & 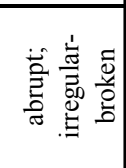 & 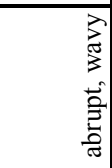 & 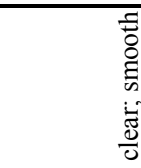 & 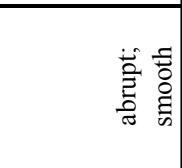 & 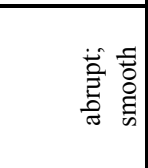 & 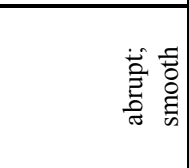 & 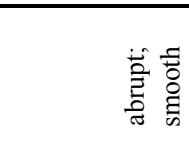 & 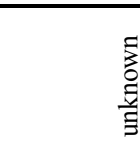 \\
\hline 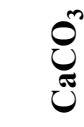 & 0 & 0 & 0 & 0 & 0 & 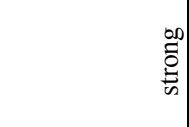 & $\begin{array}{l}\frac{0}{\pi} \\
\frac{\pi}{0} \\
0 \\
\Xi\end{array}$ & 해 \\
\hline$\stackrel{\mathscr{e}}{0}$ & 0 & 0 & 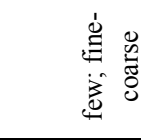 & 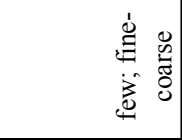 & 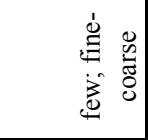 & 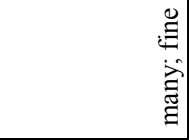 & 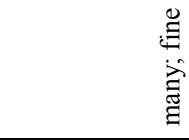 & 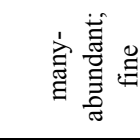 \\
\hline$\stackrel{n}{0}$ & 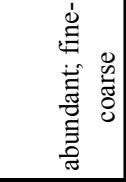 & 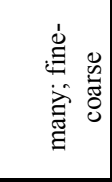 & 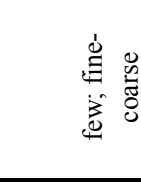 & 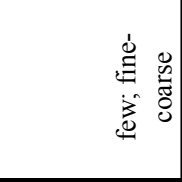 & 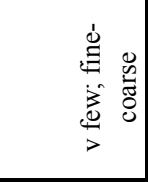 & 0 & 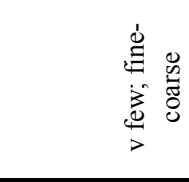 & 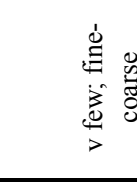 \\
\hline${ }_{0}^{0}$ & & 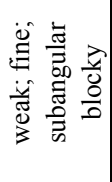 & 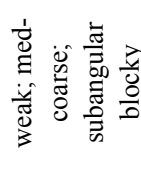 & 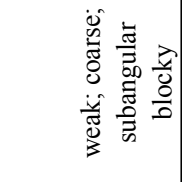 & 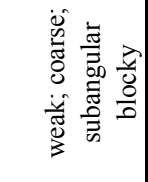 & 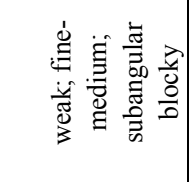 & 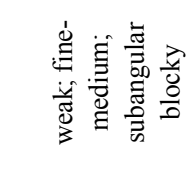 & 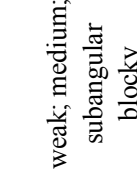 \\
\hline 施 & & & $\frac{\vec{n}}{\bar{\omega}}$ & 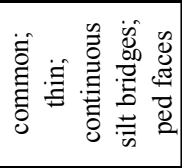 & 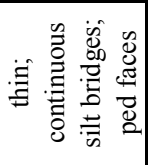 & 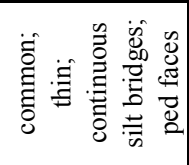 & 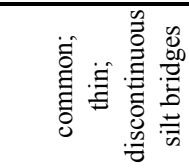 & \\
\hline 远 & & & 0 & 0 & 0 & 0 & 0 & 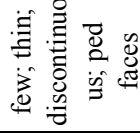 \\
\hline 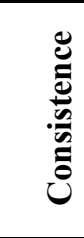 & & & 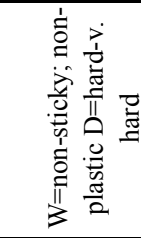 & 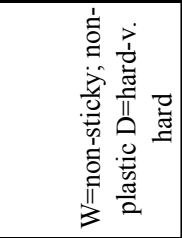 & 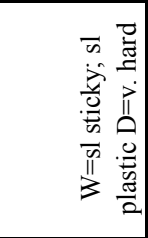 & 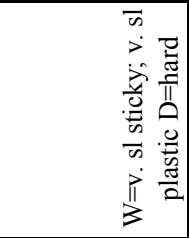 & 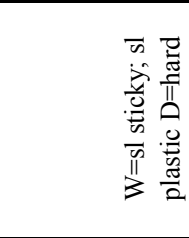 & 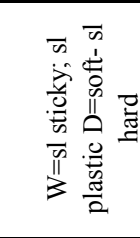 \\
\hline 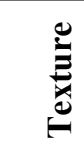 & 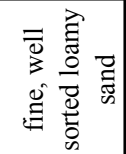 & 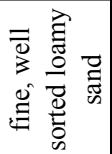 & 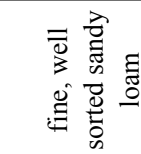 & 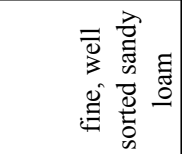 & 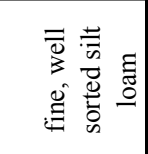 & 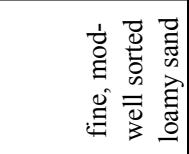 & 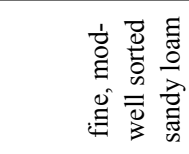 & 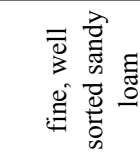 \\
\hline 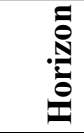 & ব & $\mathbb{Z}$ & $\vec{U}$ & రิ & $\overrightarrow{⿱ 乛 龰}$ & 酋 & $\frac{\widetilde{S}}{4}$ & $\stackrel{\Omega}{\&}$ \\
\hline
\end{tabular}




\begin{tabular}{|c|c|c|c|c|c|c|c|c|}
\hline 苞 & & & 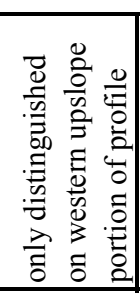 & 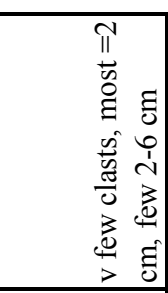 & 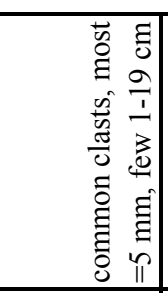 & 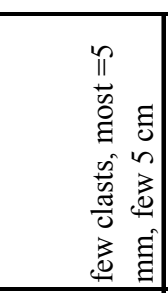 & 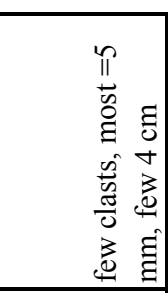 & 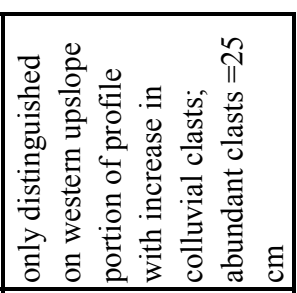 \\
\hline$\frac{\dot{\theta}}{\dot{\theta}}$ & 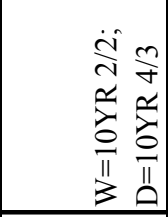 & 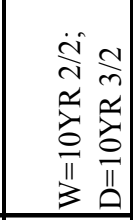 & 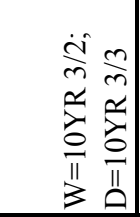 & 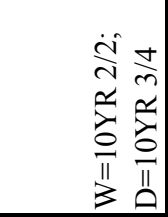 & 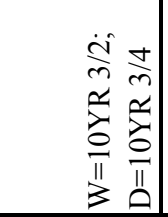 & 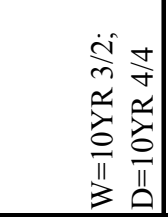 & 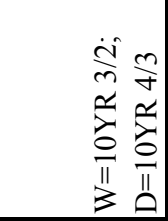 & 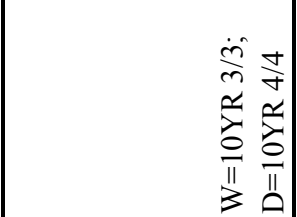 \\
\hline 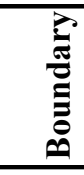 & 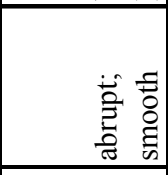 & 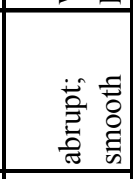 & 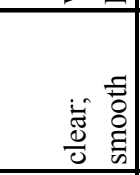 & 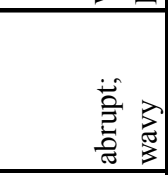 & 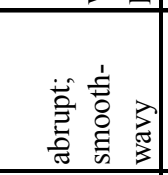 & 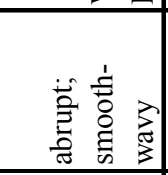 & 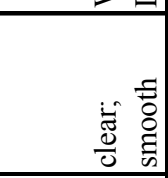 & $\begin{array}{l}\text { E⿱ } \\
0 \\
\vdots \\
\end{array}$ \\
\hline 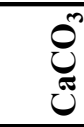 & 0 & 0 & 0 & 0 & 0 & 0 & 0 & 0 \\
\hline êt: & 0 & 0 & 0 & 0 & 0 & 0 & 0 & 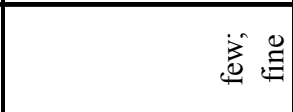 \\
\hline$\stackrel{\check{0}}{0}$ & 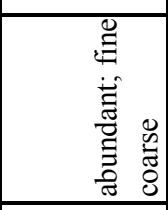 & 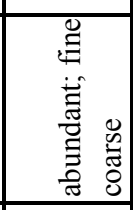 & 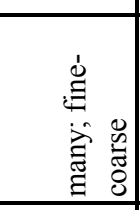 & 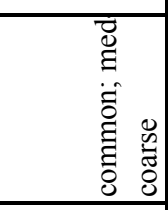 & 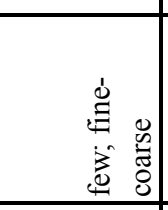 & 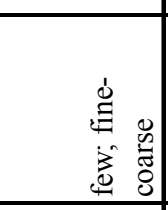 & 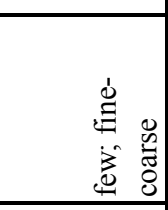 & 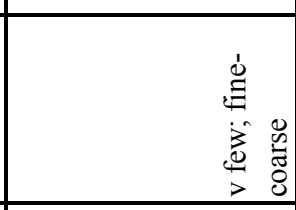 \\
\hline 总 & 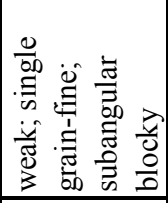 & 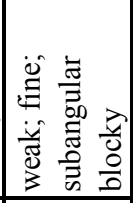 & 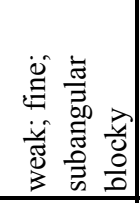 & 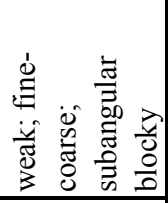 & 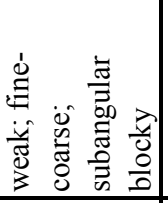 & 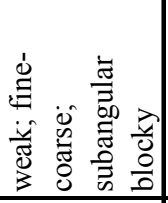 & 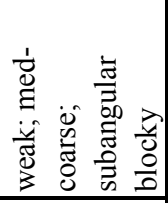 & 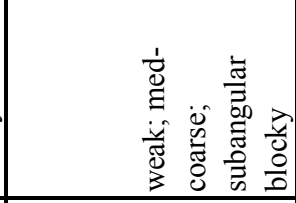 \\
\hline ن & $\frac{\vec{n}}{\bar{n}}$ & 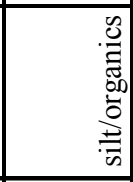 & $\stackrel{\bar{v}}{\bar{n}}$ & $\overrightarrow{\bar{n}}$ & $\stackrel{\bar{n}}{\bar{n}}$ & 莺 & : & $\bar{n}$ \\
\hline 远 & 0 & 0 & 0 & 0 & 0 & 0 & 0 & 0 \\
\hline 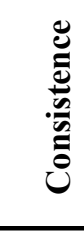 & 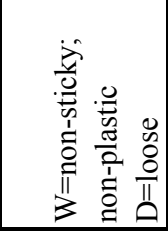 & 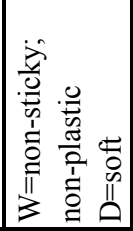 & 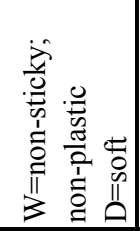 & 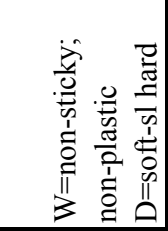 & 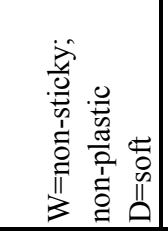 & 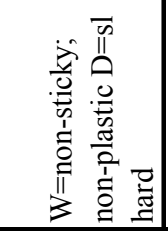 & 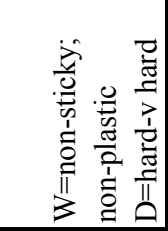 & 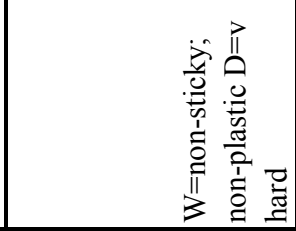 \\
\hline 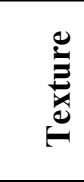 & 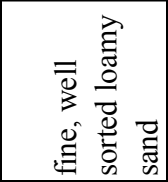 & 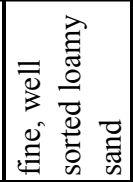 & 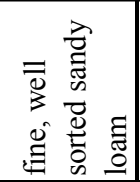 & 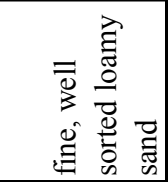 & 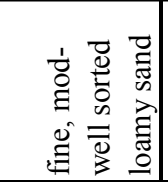 & 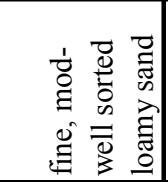 & 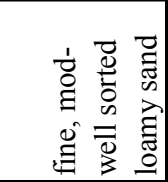 & 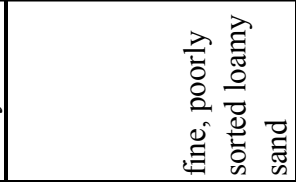 \\
\hline 苞 & రొ & 飞 & 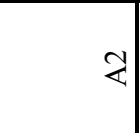 & 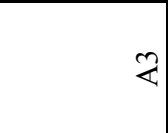 & $\vec{n}$ & $\tilde{\oplus}$ & $\tilde{\emptyset}$ & 0 \\
\hline
\end{tabular}




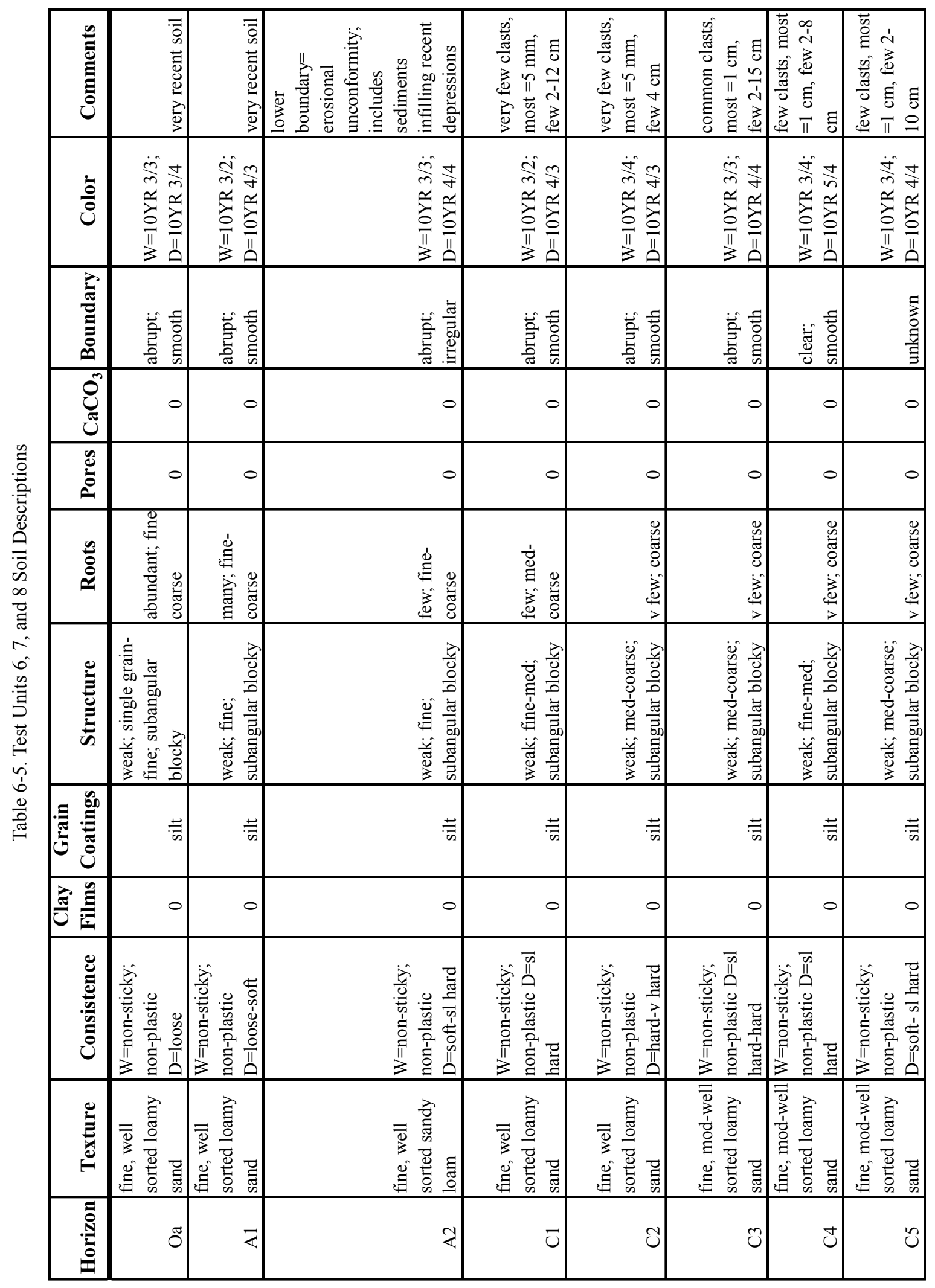


BHT 3 was situated just south of the central block (Area 3 ) excavation of TUs 9-12 (Figure 6-1). The soils and sediments exposed in this profile were entirely colluvial. BHT 3 was $10.7 \mathrm{~m}$ long and maximally $155 \mathrm{~cm}$ deep. The trench was much shallower at the western end where bedrock was encountered at approximately $75 \mathrm{cmbs}$. Both walls were examined and the southern wall of this trench was drawn (Figure 6-9). The soils and sediments in BHT 3 were analogous to the profile exposures of TUs 9 and 12, BHT 4, and TU 2. The A horizons were relatively free of clasts and the majority of the colluvial slope deposits were apparent within the B1 horizon and the boundary between the B2 and B3 soils. Weathered bedrock was present from approximately $6.45 \mathrm{~m}$ west of the eastern origin of BHT 3 to the western end of the trench. There was an interruption in the deposits at the eastern end of the trench that represented a drainage cut adjacent to the western margin of the roadway. All sediments and soils showed marked sloping indicating colluvial formation. No artifacts or charcoal were identified in the profile walls of this trench. The concentrations of sandstone were clearly colluvium and there was no evidence of archaeological features in this profile.

BHT 4 was excavated between BHT 3 and the location of the Area 2 block excavation of TUs 13-16, 22-25, 27-28 (Figure 6-1). The geomorphic setting was nearly identical to BHT 3 and to the exposure of TU 2. BHT 4 was $8 \mathrm{~m}$ long and maximally $135 \mathrm{~cm}$ deep. The northern profile wall of this trench was drawn (Figure 6-10). As noted for BHT 3, there was a drainage cut at the eastern end of the trench adjacent to the road. The soil sequence was identical to that in BHT 3. The Oa-A1-A2-A3 with few clasts was underlain by B1 and B2 soils. Sandstone was abundant throughout the middle of the $\mathrm{B} 2$ horizon. All of the deposits sloped from west to east, away from the sandstone ridge. As with BHT 3, TUs 9 and 12, and TU 2, the prehistoric surfaces also appeared to have been sloping accumulations of colluvial material. None of these rock accumulations were cultural features. As noted for the other profiles on this side of the roadway, the rock concentrations identify past surfaces or colluvial events but do not suggest that they indicate any thermal features or living surfaces.

\section{Discussion}

The research potential of 41PR44 was based, in part, on inferences that the site contained numerous thermal rock features. These were identified from the profile of an ephemeral drainage and two 1-x-1-m test units (Brownlow
2001:13-16). The discrete vertical distribution of rock was interpreted as evidence of a prehistoric living surface and the weathered bedrock was inferred to have been thermally altered. Geoarchaeological investigations by CAR do not support these preliminary interpretations. Site 41PR44 consists of floodplain sediments and colluvial and alluvial fan deposits. The abundant rock concentrations seen in the profiles of excavation units and backhoe trenches were naturally fractured and weathered sandstone bedrock.

Geoarchaeological investigations have documented that site formation at 41PR44 is a combination of alluvial sedimentation from Rock Creek and colluvial deposition from the adjacent sandstone ridge at the western margin of the site. This creates a complex archaeological record associated with these two geomorphic processes.

Geoarchaeological investigations suggest that the colluvial and alluvial fan deposits from the sandstone ridge are responsible for the rocky deposits initially identified as living surfaces and potential cultural features. The profiles of TUs 2, 9, and 12, and BHTs 3 and 4 are entirely within these slope deposits. No floodplain sediments are apparent within these profiles. In addition to the presence of abundant colluvial clasts, all the sediment units and soils dip to the east from the sandstone ridge along the western margin of 41PR44. The base of the western profile of TU 16 in the southern block excavation area encountered bedrock or colluvium. Interdigitation of alluvial fan deposits and floodplain sediments were apparent in BHT 1 (including TUs 6-8) and BHT 2. Both BHT 1 and BHT 2 contained evidence of slope wash sediments at their western ends. There was a pronounced deposit of weathered sandstone in the western 2-4 m of BHT 1 that was of colluvial origin. The concentration recorded in the profile was associated with a rock concentration that was excavated as a possible feature. An additional rock accumulation was identified in TUs 16 and 17 . These relatively horizontally discrete clusters may represent cultural features; however, the roughly ovoid or circular distribution is also consistent with lobes of terminal alluvial fan depositions. Localized visible organic enrichment was apparent only below these accumulations in profile. Such associations of higher organic content with these clasts can be due to erosional inclusion or greater localized plant growth because of the water retention around rocks. Profile information identified the presence of obviously sloping, colluvial deposits in these locations. None of the areas of rock concentration examined during the geoarchaeological investigations suggest high probabilities that these are prehistoric cultural features. 
Some limestone was present within these deposits (i.e., within the $\mathrm{C} 3$ and especially $\mathrm{C} 5$ sediments in BHT 1). It is unclear how the limestone has become mixed in with the sandstone. This may suggest redeposition of rock used by humans, or colluvial transportation of clasts from previous high-energy floodplain deposition. The associations of the limestone with robust slope deposits strongly suggest that they have been incorporated into the site as part of colluvium, whatever their origin. Only the presence of artifacts with demonstrable cultural spatial patterning, associated charcoal concentrations, or other compelling archaeological data would suggest these are anything other than natural accumulations of rock from periodic colluvial deposition.

Floodplain sediments observed in BHT 1, BHT 2, BHT 13, and the southern wall of the south excavation block represent fine, well-sorted loamy sands with no evidence of alluvial gravel deposits. Surface stability and soil formation were identified only in the lower portion of the profile of the southern block excavation area. All of the other floodplain deposits suggest frequent input of alluvial sediments accreting without significant periods of surface stability. Road construction and maintenance activities have truncated upper portions of the profile and initiated erosion of many portions of the site. The profile of TUs 6-8 and BHT 1 contained very recent A horizon soils that likely postdate road construction. No B horizons were identified, and the $\mathrm{A}$ units directly overlie a series of $\mathrm{C}$ horizon sediments. BHT 13 contained some weakly developed B horizons, but no archaeological materials were recovered in this portion of the site by CAR or the previous investigations (Brownlow 2001:13). Significant truncation of the alluvial deposits also was apparent in the profile of the southern excavation block. The existing A horizons were all very recent, weakly developed soils formed after road construction. The underlying Ab soils in this location were the only evidence of archeological deposits with potential for significant integrity. These appear to be soils formed on a level terrace setting and subsequently rapidly buried. Controlled excavation recovered relatively high artifact density from these soils and charcoal is also present. These same soils may be present in other portions of the site but are too deeply buried to have been encountered in the mitigation excavations. 


\section{Chapter 7: Chronology}

As discussed in Chapter 3, previous research at 41PR44 (Brownlow et al. 1999; Brownlow 2001) has demonstrated the presence of a Late Prehistoric occupation, as well as a possible Late Archaic occupation. The Late Prehistoric occupation is based on a radiocarbon date of $1110 \pm 40 \mathrm{BP}$ from near Feature 2 identified in TU 2, as well as the recovery of two arrow point fragments from this same test unit (Brownlow 2001:16-18). The Late Archaic occupation is inferred from a radiocarbon date $(3050 \pm 60 \mathrm{BP})$ associated with a buried soil and probable bison bone, though no associated artifacts (Brownlow et al. 1999). It was on the basis of these dates and artifacts, the suspected presence of numerous burned rock features, and an assessment of good integrity and preservation that 41PR44 was considered to be eligible for inclusion in the National Register of Historic Places (Brownlow 2001:18). CAR's subsequent investigation at the site produced a variety of projectile points that may reflect use of the site, at some level of intensity, from as early as the Early Archaic through the early portion of the Late Prehistoric. While no clearly Early Archaic projectile points have been unambiguously typed, several specimens compare favorably with Early Archaic or Early/Middle Archaic forms. No clearly Middle Archaic forms are present, but several Late Archaic forms were recovered. Several Late Prehistoric arrow points were also recovered. In addition, we have a radiocarbon date on an isolated piece of charcoal that returned an early Late Archaic age of around $3550 \mathrm{cal} \mathrm{BP}$.

Site 41PR44 has some level of occupation during the Late Prehistoric as well as the Late Archaic, and earlier occupations are probably also present. A variety of artifacts, burned rock clusters, and faunal material were generated by these occupations. However, Russell Greaves' assessment of the geomorphology of the site, presented in the previous chapter, presents a dire picture of the integrity of the deposits, as well as of the rock clusters identified as features. He suggests that only a single portion of the site, located near the bottom of excavation in Area 2, contains deposits with good integrity. In the current chapter, the distribution of temporally diagnostic projectile points, radiocarbon dates, and relative depth of material from 41PR44 are considered. As Greaves suggests, there does appear to be considerable mixing of deposits in some areas. However, isolated deposits with a high probability of dating between A.D. 750 and 1250 exist in Area 1, as well as earlier
Archaic deposits found in Areas 2 and 4. Much of Area 3, however, which contained a significant quantity of material, appears to be mixed, with a Late Prehistoric point located well below Archaic point types. Following a short discussion of the data types used, the chronological resolution of each of these hand-excavated areas is discussed.

\section{Chronological Data}

Two principal types of data, temporally diagnostic projectile points and radiocarbon dates, are used to identify when 41PR44 was occupied, as well as to isolate material for temporal comparison. Each data type is summarized below.

\section{Projectile Points}

The establishment of projectile point types, and their use as chronological indicators in Texas, flows from cultural history concerns that dominated archaeological investigations in the 1940s, 50s, and 60s (e.g., Suhm and Krieger 1954). The interest, in this period, was the establishment of cultural complexes across Texas. Cultural complexes, of which specific point types were designed to be one of several classes of material culture (e.g., houses, burials, other artifact types) that were associated at an assemblage level, were assumed to reflect "tribes" or other cultural entities present within a given spatial area and for a specific temporal span. Since the definition of many of these types in the 1950s, the theoretical interests of some in Texas have shifted from cultural history, but the use of projectile points as a temporal indicator has continued, and major temporal shifts (e.g., the shift from dart points to arrow points) have been refined by reference to stratigraphic relationships and radiocarbon dates.

Figure 7-1 presents six arrow points recovered from 41PR44 during the excavation conducted by CAR. Brownlow (2001:17-18) reported two arrow point fragments were also recovered at 41PR44 during testing of the site. The six points in Figure 7-1, typed by Steve Tomka of CAR (see also Turner and Hester 1999), appear to represent forms dated elsewhere to between about A.D. 700 or 750 and A.D. 1200. While the fragmentary nature of the points identified by Brownlow (2001:18) makes their temporal assignment 


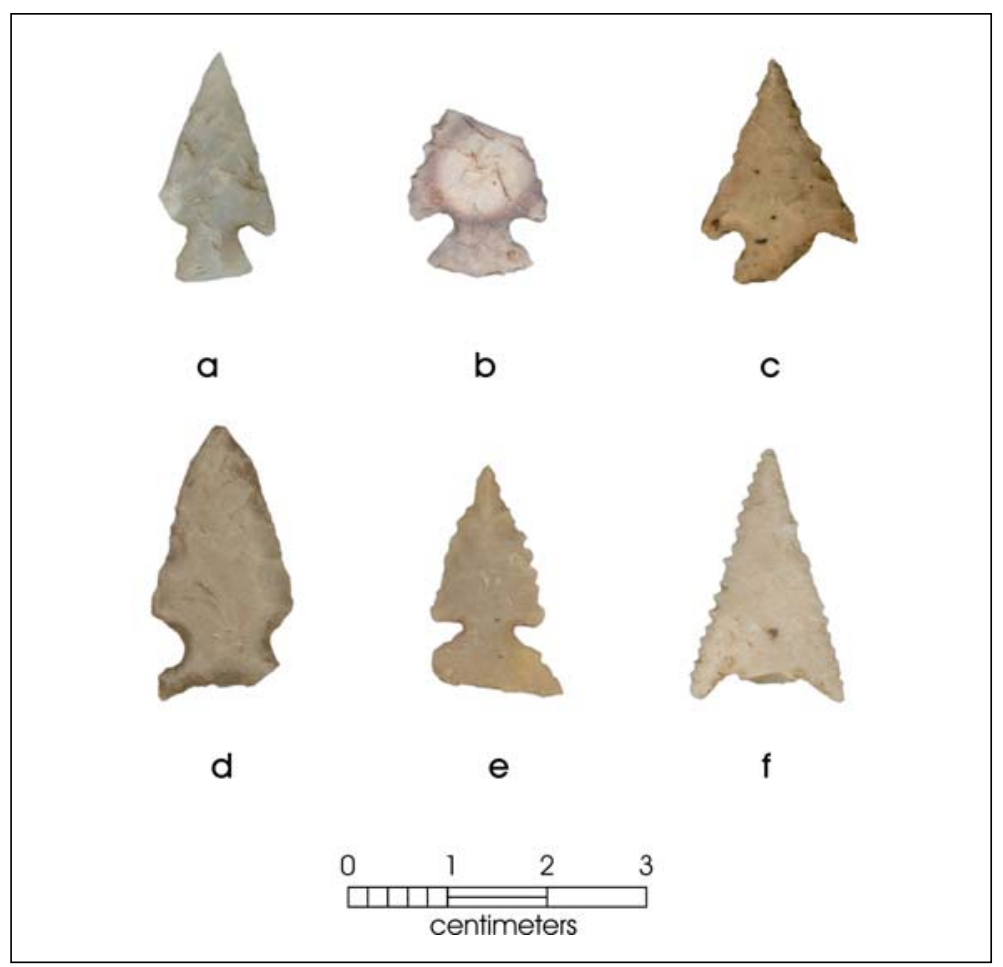

Figure 7-1. Late Prehistoric projectile points recovered from 41PR44: (a-c) Scallorn; (d-e) untyped arrow points; (f) untypable fragment.

impossible, both are consistent with this early Late Prehistoric temporal assignment.

Figure 7-2 presents ten dart points recovered from 41PR44 by CAR. No dart points were recovered during the survey or testing of the site (Brownlow et al. 1999; Brownlow 2001). Like the arrow points shown previously in Figure 7-1, Steve Tomka typed these forms. However, the fragmentary nature of many of these points made the firm establishment of the types difficult in some cases. Several fragments in Figure 7-2 (a, b, and possibly f) may reflect Late Archaic Marshall types that have been tentatively assigned dates in Central Texas from around 2000 to 3000 BP (see Collins 1995:376; Turner and Hester 1999:149). Other Late Archaic forms include a Bulverde (Figure 7$2[\mathrm{c}]$ ) and a possible Dawson (Figure 7-2[d]), though the temporal range of the latter type is not well established (Davis 1991; Turner and Hester 1999:102). Several points may reflect Early Archaic, or Early/Middle Archaic forms (see Davis 1991; Turner and Hester 1999), including a possible Hoxie (Figure 7-2[e]), Wells (Figure 7-2[h]), and Martindale (Figure 7-2[j]). Finally, several forms are untyped or untypable (Figure 7-2[g, i]).

\section{Radiocarbon Dates}

A second set of chronological information is provided by radiocarbon dates. CAR acquired a single date from an isolated piece of charcoal near the bottom of excavation in Area 3. Figure (top) presents the corrected, calibrated date using the OxCal Version 3.9 calibration program (Ramsey 2003). Additional information on this data is provided in Appendix A. The corrected date $(3310 \pm 40 \mathrm{BP})$ calibrates to a 1-sigma range of 1630 to $1520 \mathrm{BC}$. Two additional dates are available for the site. These were acquired during the survey (Brownlow et al. 1999) and testing (Brownlow 2001). The first date was acquired from a buried soil identified in Backhoe Trench 12. The soil is likely close to that dated by CAR. A corrected date of $3050 \pm 60 \mathrm{BP}$ (Brownlow et al. 1999) calibrates to a date of 1400 to 1210 $\mathrm{BC}$ (3350 to $3160 \mathrm{BP}$ ). The second sample was collected from Test Unit 2, a 1-x-1-m unit adjacent to CAR's Area 1 excavation. The sample returned a corrected date of $1110 \pm 40 \mathrm{BP}$, and appears to be from the same elevation as Feature 1 identified by TARL (Brownlow 2001). When calibrated using OxCAL (Ramsey 2003), a 1-sigma range of A.D. 890 to 985 is produced. These two dates, along 


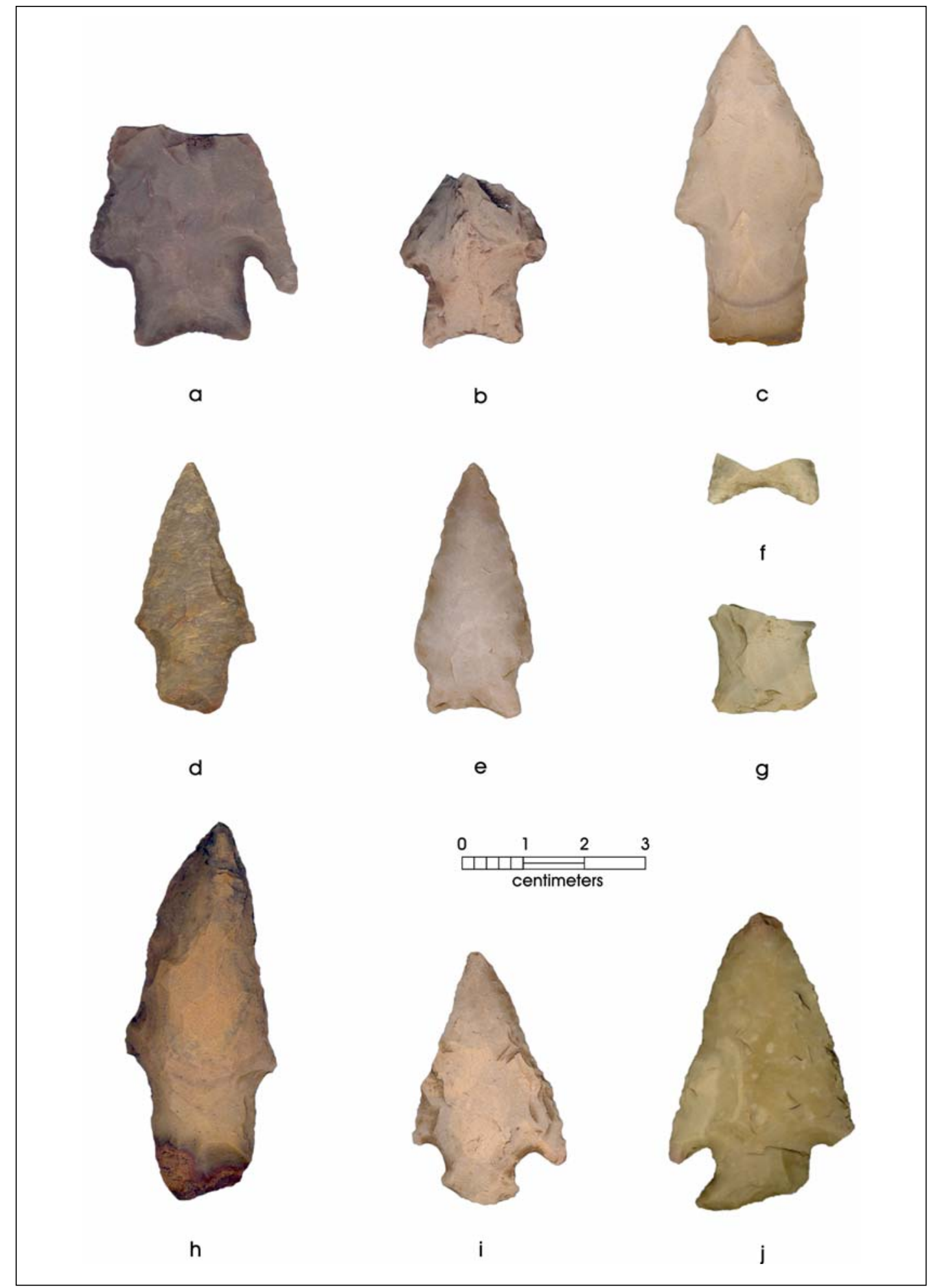

Figure 7-2. Dart points recovered from 41PR44: (a,b) consistent with Marshall; (c) Bulverde; (d) consistent with Dawson; (e) consistent with Hoxie; (f, g) untyped; (h) possible Wells; (i) possible Marshall; (j) Martindale. 
with the CAR sample date, are shown in Figure 7-3 (bottom). The dates again suggest use of the site during the early Late Prehistoric as well as the Late Archaic.

\section{Chronological Groupings}

While the projectile point dates, as well as the radiocarbon dates, clearly document use of the site during the early Late Prehistoric, the Late Archaic, and possibly earlier points in time in the Archaic, the distribution of the projectile points clearly confirms aspects of Greaves' position outlined in the previous chapter. That is, in several cases the point types represent surface finds or are not in the anticipated stratagraphic sequence. However, the data available does allow the identification of deposits that can form analytical groups in some areas of the site. While the chronological resolution is not always as fine as we would like, given the current state of knowledge regarding adaptations in this portion of Texas, an analysis of the deposits identified can make a significant contribution to our overall understanding. In this section, then, we discuss chronology for each of the four areas of the site where CAR conducted hand-excavations (Figure 7-4).

\section{Area 1}

As shown in Figure 7-4, Area 1 is located in the southwestern section of the site. TARL conducted excavations (TU 2) at this location (Brownlow 2001). CAR excavated three 1-x-1-m units adjacent to the TARL test unit, as well as several auger and shovel tests in the immediate area. The excavations in this portion of the site produced a variety of temporally diagnostic artifacts, as well as a single radiocarbon date. Chronometric data are summarized in Table 7-1 for each test unit, as well as for two nearby shovel tests (STs 2, 4; Figure 7-4).

The vertical distribution of chronometric data shown in Table 7-1 indicates that the upper levels of this area (Levels 1-7, blue in Table 7-1) are consistently associated with early Late Prehistoric projectile points, and a single radiocarbon date also falls into this same time period. Levels 8 through 12 , conversely, are associated with Archaic dart points. The untyped point recovered from TU 5 (Figure 7-2 [i]) is probably Late Archaic, and the TU 4 point form Level 9 is a Dawson (Figure 7-2[d]). Finally, what is probably an Early Archaic Martindale was recovered from near the bottom of TU 3. These lower deposits (red in Table 7-1) probably primarily reflect a Late Archaic age. However, given the ambiguity associated with the point identifications, and the fuzzy dates associated with the Dawson point, these lower levels are best simply considered Archaic in age. Note that while some of these deposits, especially those in the upper levels, may well have been redeposited as Greaves suggests, the data in Table 7-1 suggest that the deposits have not been mixed. It is possible to isolate a Late Prehistoric deposit and an Archaic deposit in this area.

\section{Area 2}

As discussed in Chapter 5, the deposits in Area 2 (see Figure 7-4) consist of several upper levels (2 through 7) that have moderate densities of cultural material, including chipped stone, rock and charcoal. One feature (Feature 10) was defined in this area. However, as Greaves suggests in the previous chapter, it is likely these upper deposits are not in situ. Some of the upper deposits, including Feature 10, are probably associated with a road maintenance ditch. No temporally diagnostic material was associated with these upper levels. Consequently, these materials cannot be assigned to any temporal period.

The middle levels $(8,9$, and 10) in this excavation area have few artifacts present, though densities increase starting in Level 11 and peak in Level 14 (ca. $130-140 \mathrm{cmbd}$ ). This lower peak is associated with the buried soils that Greaves, in the previous chapter, argued represent high integrity deposits. Diagnostic artifacts from this area include a Late Archaic Marshall point (Figure 7-2[a]) collected from the bottom of Level 13 of TU $22(130 \mathrm{cmbd})$, and a point fragment (Figure 7-2[f]) from Level 14 of TU 24 that is consistent with a Marshall form. In Central Texas, Marshall projectile point types are dated to between 2000 and 3000 BP, or earlier (see Collins 1995; Turner and Hester 1999). In addition to the points, one of TARL's radiocarbon dates (3350 to 3160 BP) was from Zone 4 in Backhoe Trench 12. The sample, associated with a buried soil, was from a depth of between 82 to $104 \mathrm{~cm}$ below ground surface, and BHT 12 had a terminal depth of $142 \mathrm{cmbd}$ (Brownlow et al. 1999; Brownlow 2001). This BHT was relocated in CAR's TU 23. In that TU, the terminal depth of BHT 12 was 148 $\mathrm{cmbd}$, suggesting that the radiocarbon date was probably collected from depths comparable to Levels 9 and 11 in the current excavations. Finally, a radiocarbon date of 3580 to 3470 BP was produced by a sample collected from TU 28 at a depth of $146 \mathrm{cmbd}$. Clearly, then, Levels 12 through 15 can be placed in the Late Archaic. In addition, Levels 9, 10 and 11 are probably also Late Archaic in age given the TARL date. Overall, then, these deposits appear to date from 


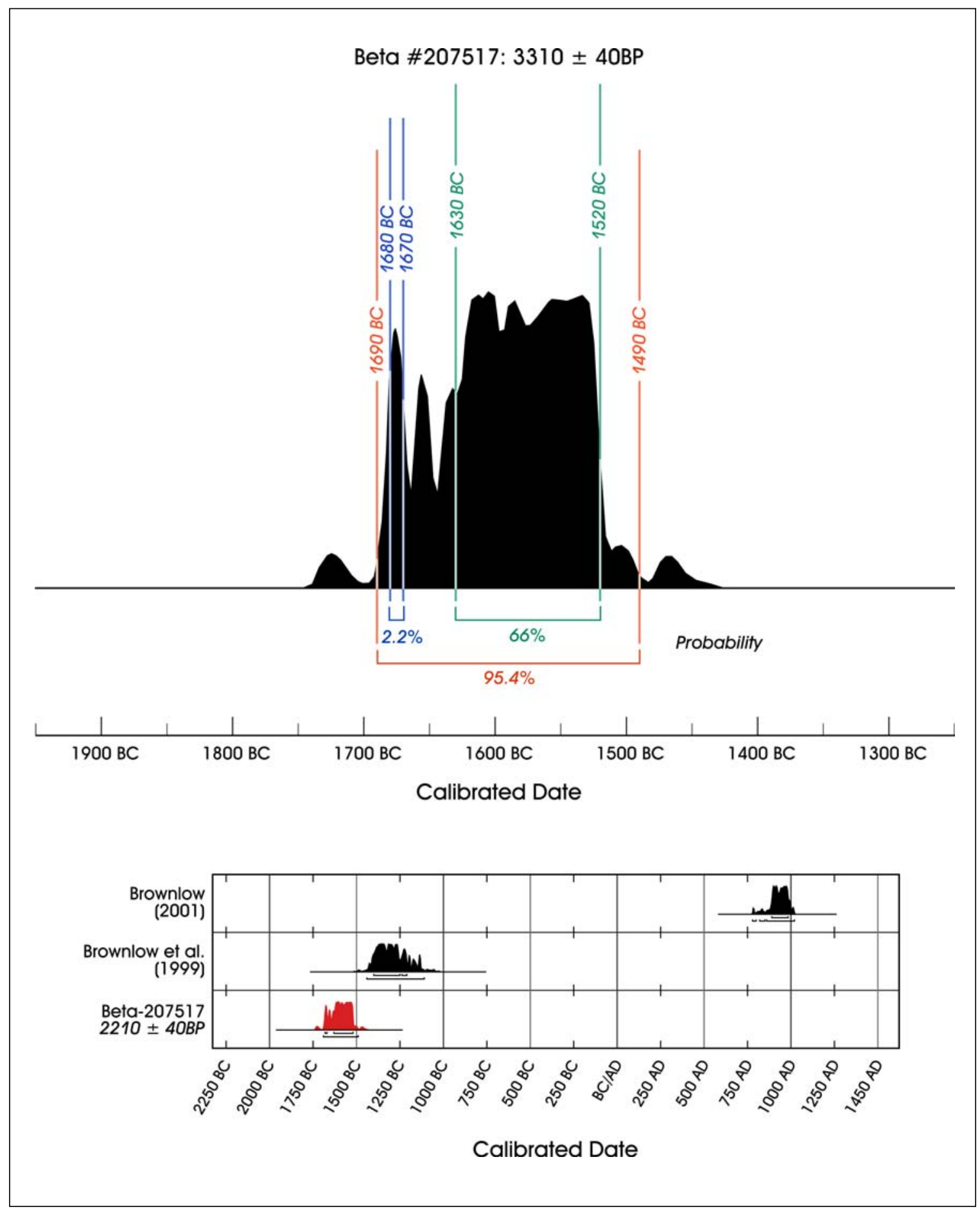

Figure 7-3. Calibrated radiocarbon dates from 41PR44. Top calibration is from Area 3, TU 28, at 1.46 meters below datum. Bottom shows all associated dates. 


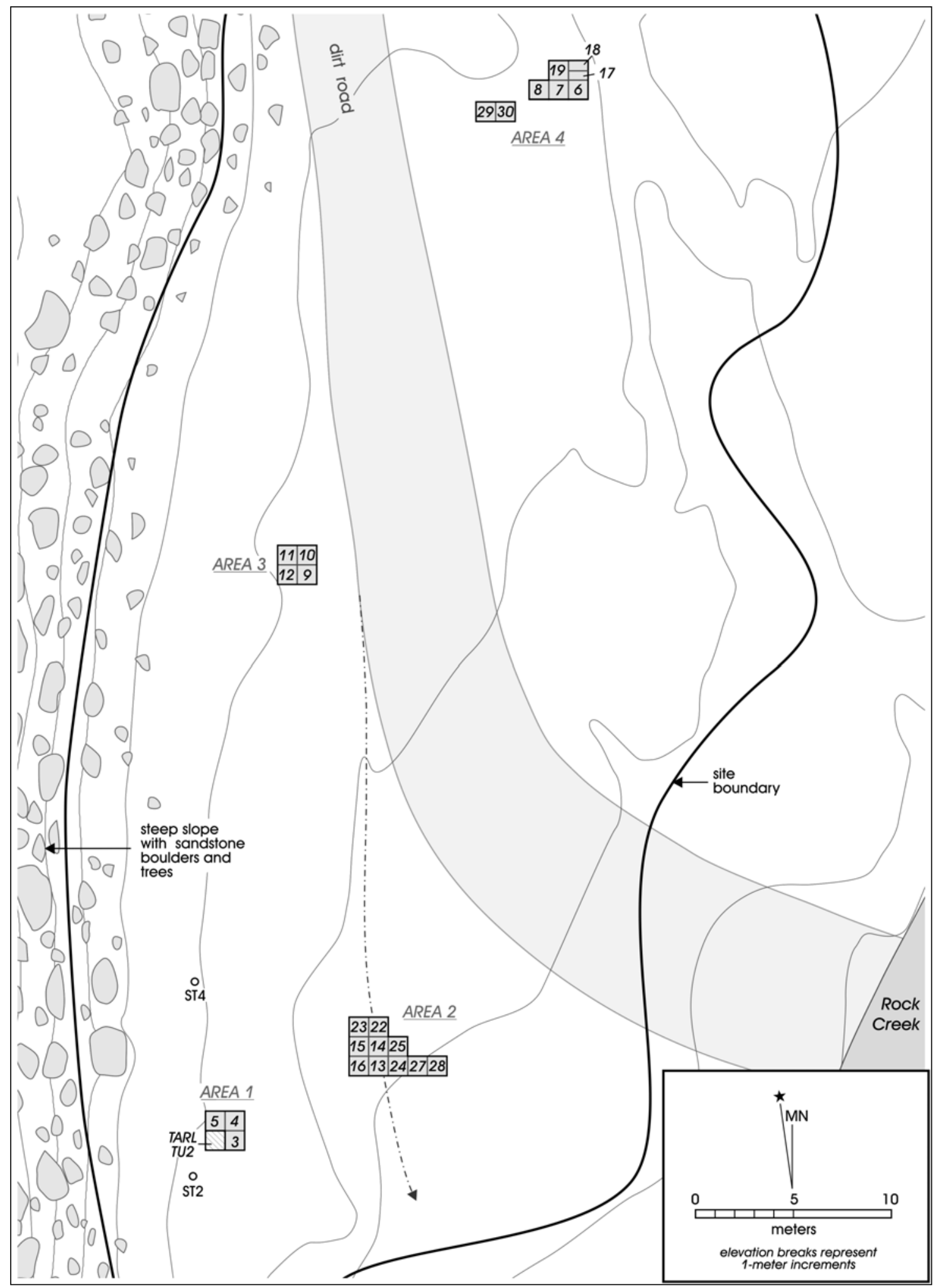

Figure 7-4. Excavation Units at 41PR44. 


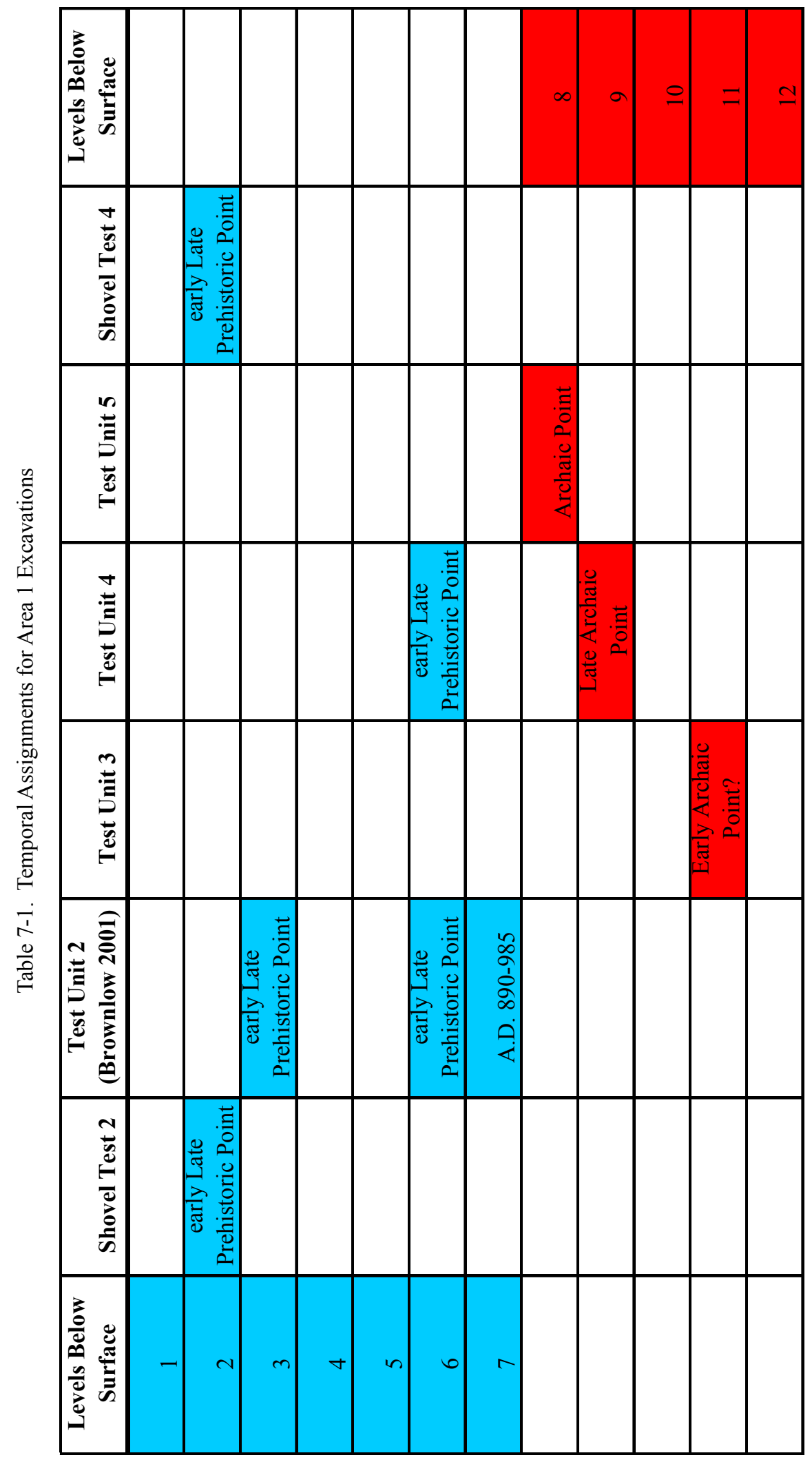


as early as around $3500 \mathrm{BP}$ to as late as $2000 \mathrm{BP}$. For analysis, we can further suggest, given the time frames of Levels 9 (ca. 2000 BP) and 15 (3500 BP), that Levels 8 and Levels 16 have a high probability of dating to the Late Archaic as well.

\section{Area 3}

Area 3 consisted of TU's 9 through 12 . This area contained a large quantity of material, including the bulk of the features identified in the field. Temporally diagnostic artifacts recovered from this area included the possible Middle to Early Archaic Wells point (Figure 7-2[h]), and an untypable Archaic base (Figure 7-2[g]). According to the analysis by Greaves in Chapter 6, these deposits appear to have little integrity. The stratigraphic distribution of these three projectile points is consistent with that suggestion, as is our analysis of the burned rock presented in Chapter 10 . The two Archaic points were recovered from TU 12, Levels 4 and 5, while the Late Prehistoric point was collected from Level 7 in TU 10. As we have no other diagnostic information on these units, and as all other analysis suggests that much of this material is in secondary context, the Area 3 material cannot be associated with any specific temporal period.

\section{Area 4}

The final area considered here is Area 4, located at the northern end of the site (Figure 7-4). As discussed in Chapter 5, this area initially consisted of four 1-x-1-m units (TUs 6, 7, 8 and 19), and two 50-cm-x-1-m units (TUs 17 and 18). The excavation was designed primarily to expose Feature 12, a burned rock cluster exposed in the cut bank (see Figure 5-6). Excavation revealed a low density of chipped stone material, most of which was associated with Levels 9 through 15 . No temporally diagnostic artifacts were recovered from these initial excavations. Subsequently, BHT 1 was cut to search for additional features. That trench was designed to explore a cluster of rock revealed in Auger Test 32. Subsequently, two 1-x-1-m units (TUs 29 and 30) were excavated to expose Feature 21. During the excavation of these two additional units, a Late Archaic Marshall point (Figure 7-2[b]) was uncovered in TU 29 in Level 5 (37-47 cmbd). The location of this point, being near the top of the excavation and in association with a feature that was originally defined at $27 \mathrm{cmbd}$, allows us to designate levels below this point as dating to the Archaic. While the upper deposits, as well as those associated with Feature 21, probably are Late Archaic in age, a fine-grained age assignment is not possible for the vast majority of the material. Consequently, we will simply consider this area as Archaic in age.

\section{Summary}

Based on CAR's work, as well as the survey and testing results, it is clear that site 41PR44 was occupied during the early Late Prehistoric, as well as the Late Archaic. Earlier occupations are probably also present as suggested by Early Archaic, or Early/Middle Archaic projectile types, such as Wells, Hoxie, and Martindale. Aspects of the distributional analysis conducted in this chapter support the arguments made by Greaves in Chapter 6 . Area 3, which contained a variety of material, as well as the upper levels of Area 2, appear to represent secondary deposits that either cannot be assigned to a specific period or are clearly mixed. We have, however, been able to identify early Late Prehistoric deposits, as well as deposits that date to the Archaic period. While the designation of deposits simply as "Archaic" limits their utility to some degree, given our current level of ignorance regarding hunters and gatherers in this portion of Texas, any analysis of deposits with some degree of temporal resolution has the potential to make a significant contribution to our overall understanding of adaptations. 


\section{Chapter 8: Subsistence}

Using both site level data, as well as the intra-site temporal divisions outlined in the previous chapter, this chapter explores subsistence activities reflected in the 41PR44 data. The acquisition of resources has significant implications for most other aspects of cultural systems, including how mobility and technology may be organized, as well as how aspects of these organizational components change through time. As outlined in Chapter 4, we approach this exploration from a theoretical position that involves a cost/benefit framework developed in evolutionary ecology (see Charnov et al. 1976; MacArther and Pianka 1966). Grouped under the rubric of average rate maximizing models, the position assumes that foragers will attempt to maximize average return rates in the context of different cost/benefit ratios for different prey (see Stephens and Krebs 1987). Benefits are broadly seen as energy obtained from food. Costs are broadly framed as the amount of time spent looking for game or resource patches (search costs), and handling costs, the amount of time required to pursue, capture, and process foods.

A critical element of these foraging based models involves ranking of prey alternatives. Potential prey items are ranked in terms of handling costs and benefits. For animals, this ranking often reflects body size, with larger-bodied animals such as bison having higher returns relative to their handling costs when compared to smaller-sized animals. Plants usually rank below animals, though there are exceptions (see Kelly 1995; Simms 1987). Search costs, though not taken into account in prey rankings, play an important role in determining the actual diet. As more resource types are added to the diet, search costs decline because resources are encountered more frequently. However, these new resources, being lower ranked, have higher handling costs and/or lower caloric benefits. That is, they have lower profitability. Foraging models predict a tradeoff, then, between handling cost, energy benefits, and search costs that will maximize the average return and produce an optimal diet. Under these models, foragers will continue to add lower-ranked resources to the diet so long as the overall profitability of the diet, seen in terms of total costs and benefits, is increased. Furthermore, resource types should be dropped from the diet when their exclusion would increase overall profitability.
Note that many assumptions of these foraging models are violated by human hunter-gatherers. In addition, specific parameters are often difficult or impossible to estimate in archeological situations. Nevertheless, we find the models appealing as they provide an explicit cost/benefit framework for analysis. Similar models have proven to be insightful elsewhere in the analysis of Texas archaeological material (see Figueroa and Mauldin 2005:88-92; Tomka and Mauldin 2003; Tomka et al. 2004).

Unfortunately, our investigation of 41PR44 produced little data with direct relevance to subsistence. Of the 12 features designated in the field, only three were determined to represent burned rock features with good context (see Chapter 10). Flotation samples from these three features failed to produce any significant quantity of carbonized material for analysis (see Appendix C). A low frequency of vertebrate faunal material was collected (see Appendix B for details), and the overall sample of lithic tools, including ground stone, projectile points and other bifaces, unifaces, and utilized/retouched flakes numbers only 46 items, with only a single bone tool (see Appendix B). Finally, some of the faunal material, as well as most of the lithic tools, are from questionable temporal contexts. Subsistence data are limited from this site, and conclusions reached are therefore tentative. However, the description of the available data is of interest given we currently know little about subsistence activities in this portion of Texas. The initial section of this chapter provides a description of the lithic tools recovered from the site, and makes some comparisons to other assemblages from North, East, South, and Central Texas. This is followed by a description of the faunal material at a site level. Finally, changes through time in faunal remains are documented and explored.

\section{Lithic Tools from 41PR44}

Forty-six lithic tools were recovered during CAR's excavation at 41PR44. Discounting the projectile points $(n=16)$, only eight items can be assigned to one of the two broad temporal periods, with six of these from deposits assigned to the Late Prehistoric period. Consequently, there is little use in concerning ourselves with temporal comparison of changes in forms. We can, however, provide some general descriptive data, as well as focus on impressions at a site level. 
The most frequent category of material collected during our data recovery efforts was projectile points $(\mathrm{n}=16)$, with 6 arrow points and 10 dart points recovered (see Figures 7-1 and 7-2). In addition to the projectile points, 15 other bifaces, three unifaces, and five edge-modified flakes were recovered. Figure 8-1 presents the bifacial tools recovered. Most are simply small to medium sized bifacial items, and 13 of the 15 (ca. 87\%) are broken. One item (Figure 8-1[a]) appears to be a point fragment that has been reworked into a graver spur or awl, while others (Figure $8-1[\mathrm{~h}, \mathrm{i}])$ are simply bifacial edges. In addition to the items shown in Figure 8-1, three unifacial retouched items (Figure 8-2[a-c]) and five edge-modified flakes (Figure 8-2[d-h]) are also present. All of these items are small and most are broken. Only Figure 8-2(e) has a well defined, intact working edge with small feather and step fractures, as well as rounding, present. When considered as a group, the items in Figure 8-1, as well as several shown in Figure 8-2, probably are consistent with reduction designed to produce projectile points, rather than other classes of formal tools (e.g., scrapers, knives). These site level data, then, at least hint at a subsistence focus on hunting.

In contrast to a possible hunting focus, however, is the recovery of several pieces of ground stone, most of which were on the surface of 41PR44. While none of the seven pieces of ground stone could be assigned to any temporal period, and while the overall tool assemblage is extremely small, ground stone is the third most frequently recovered tool, accounting for just over $15 \%$ of the combined lithic tool assemblage. Ground stone is more common than either unifaces or edge-modified flakes at 41PR44. Figure 8-3 shows two formal manos recovered from the site. Figures 8-4 and 8-5 present four of the five metate fragments collected. Note that all five are from different metates, and that several of the metate fragments (e.g., Figure 8-4, bottom; Figure 8-5, bottom) are large, formal items with extensive preparation and extensive use. The presence of a variety of different ground stone items, as well as their relatively formal nature and extensive use, suggests that plant resources requiring grinding may have been a focus of activities at 41PR44 at various points.

In order to explore the ground stone pattern at 41PR44, we developed a comparative database of 25 other site level assemblages from across the eastern, central, and southern portions of the state. Our interest is in developing ways to compare ground stone assemblages in light of variable reporting and drastically different levels of effort. Ideally, we would be able to compare ground stone densities between sites by taking into account the excavated volume. Unfortunately, volume is not always reported. In addition, ground stone is often collected from the surface of sites, rather than through excavation. While we could exclude these samples, and focus only on volume, the number of sites with ground stone present would be greatly reduced. Rather, we propose two different measures of ground stone that can be used to lessen the impact of different excavation and collection strategies. For purposes of this comparison, we include in our ground stone category only items that are classified as manos and metates as these items have a high probability of being associated with plant processing. The first measure used is a ratio of the number of manos and metates relative to the number of projectile points. The second is a similar ratio, but focuses on the number of ground stone tools relative to the number of other lithic tools. Here, other lithic tools are defined as unifaces, modified or edge damaged flakes, bifaces other than projectile points, and any other chipped stone tools. Other battered or ground stone tools, including abraders, hammer stones, and weights, are not included in these summaries unless there is evidence that they were also used as a mano or metate.

The 25 comparative sites were selected based on three criteria. First, only sites with a total tool sample size of more than 40 items were considered. This was done to minimize the impact of small samples on the patterns. Secondly, only sites with at least one piece of ground stone reflecting either a mano or metate in the collections were included. While including sites without ground stone would have greatly expanded the sample size, given the nature of the comparison these would consistently yield a ratio of zero on both measures. Thirdly, the sites had to have temporal periods present equivalent to either the Late Prehistoric or the Late Archaic, though earlier Archaic components could also be present. The 25 sites selected for comparison to 41PR44 certainly do not represent an exhaustive search, or a random sample, of excavated or tested sites with manos and metates present. Rather, they are simply assemblages that met the criteria listed above, had sufficient detail to allow for comparison with the 41PR44 data, and were readily available. Overall, the sites come from 22 different counties, with clusters in Northeast Texas, Central Texas, and a handful of sites in South Texas.

Table 8-1 presents the sites, along with the number of projectile points, the number of other chipped stone tools, the total tool sample size, and the reference for the report consulted. We used the data in Table 8-1 to construct 


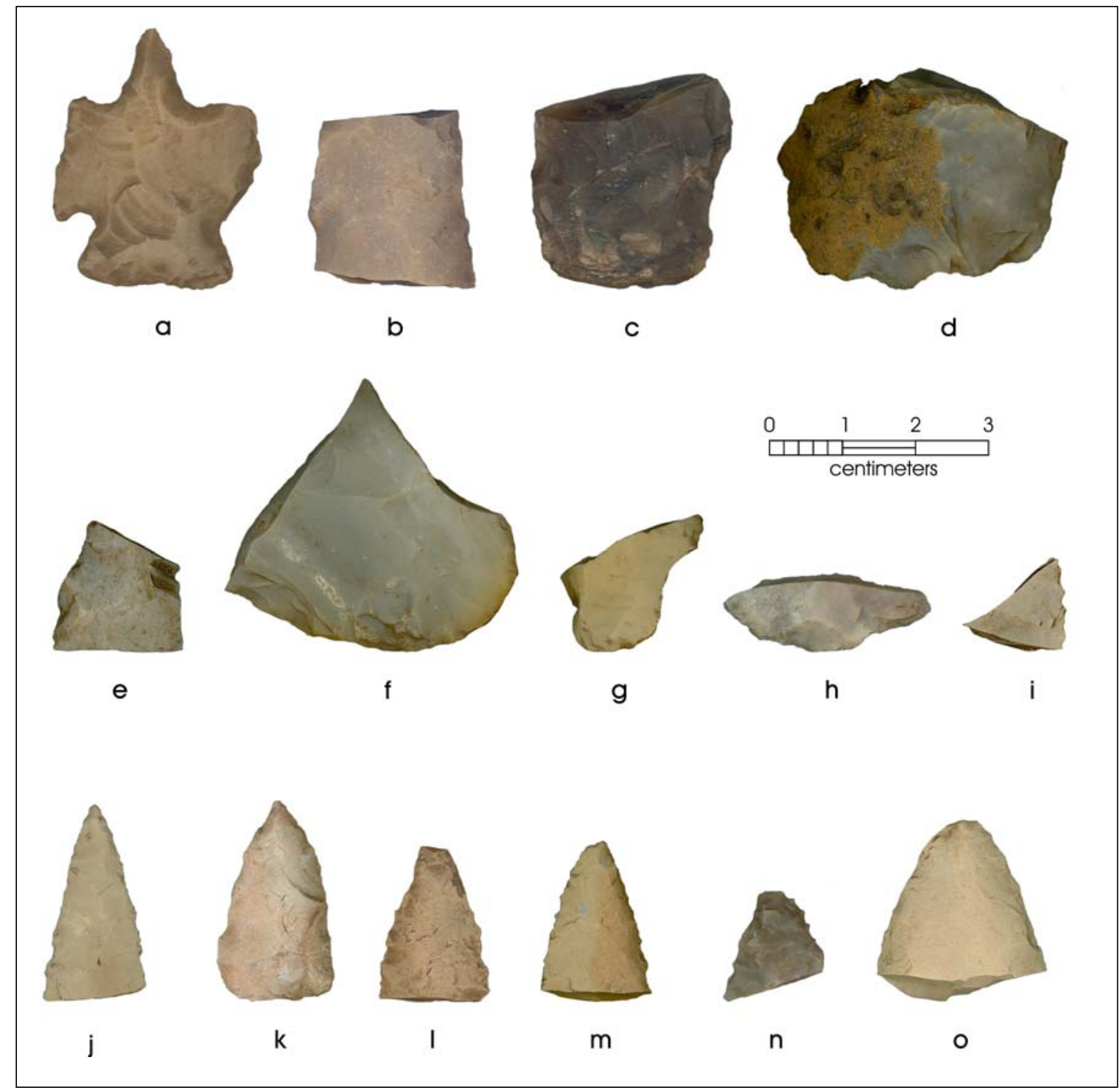

Figure 8-1. Bifaces recovered from 41PR44.

Figure 8-6 for the 26 sites. The Y-axis of the figure is the scores for the first variable, the number of manos and metates (ground stone) collected from a site divided by the number of projectile points recovered. The $\mathrm{X}$-axis is the number of ground stone collected from a site divided by the number of other stone tools. A variety of different elements are certainly involved in producing these ratios on any given site. These potentially include, but are not limited to, raw material access, group composition, patterns of reoccupation, length of occupation, use life of various tools, patterns of organization, and curation and caching behavior. In addition, note that as with any ratio, two variables are involved. That is, the frequency of ground stone can remain the same, but the overall value can rise or fall based on the frequency of other items. Nevertheless, we suggest that when a site has higher scores on both the $\mathrm{X}$ and $\mathrm{Y}$ axis, it is likely that a relatively high frequency of ground stone is present relative to those assemblages that fall near the origin. By implication, grinding associated with plant foods was potentially a major activity conducted at that location.

Focusing on Figure 8-6, most sites are clustered near the origin of the plot. While there are several sites that have 


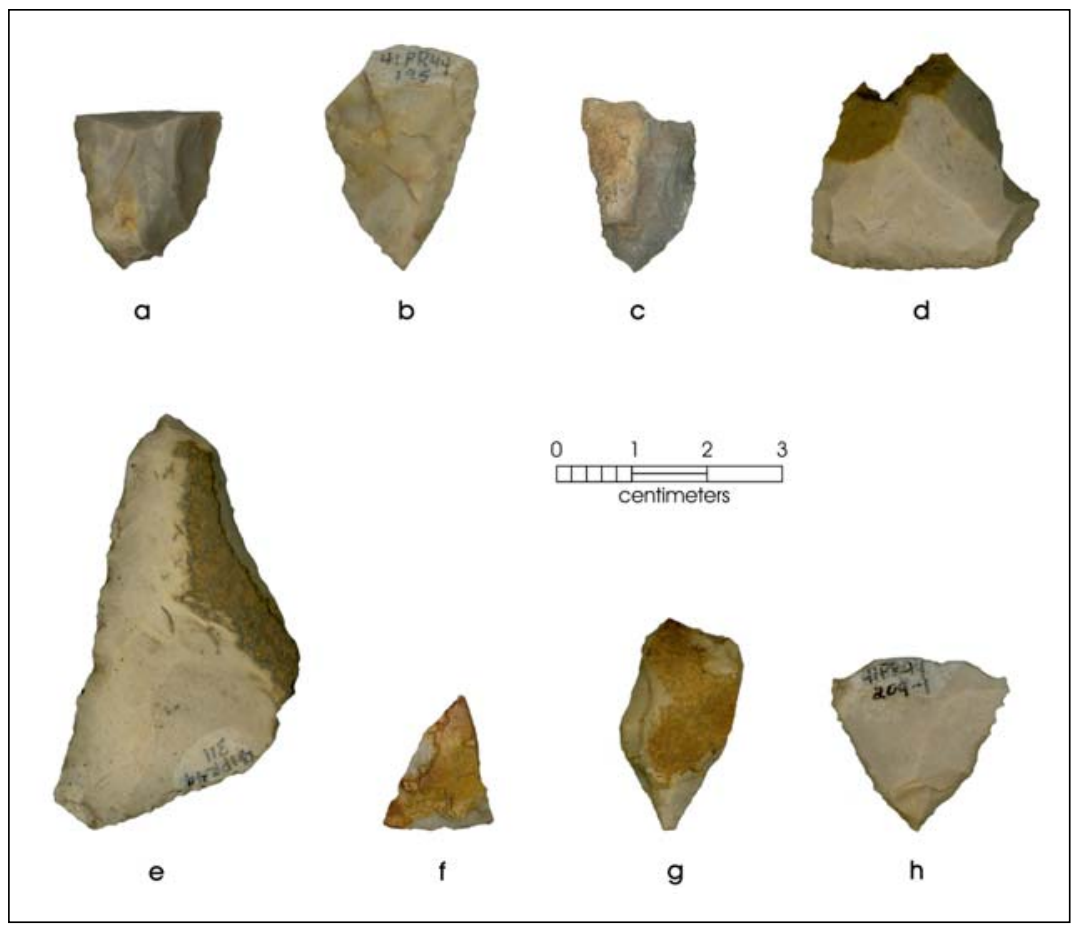

Figure 8-2. Edge-modified and unifacially retouched tools from 41PR44.

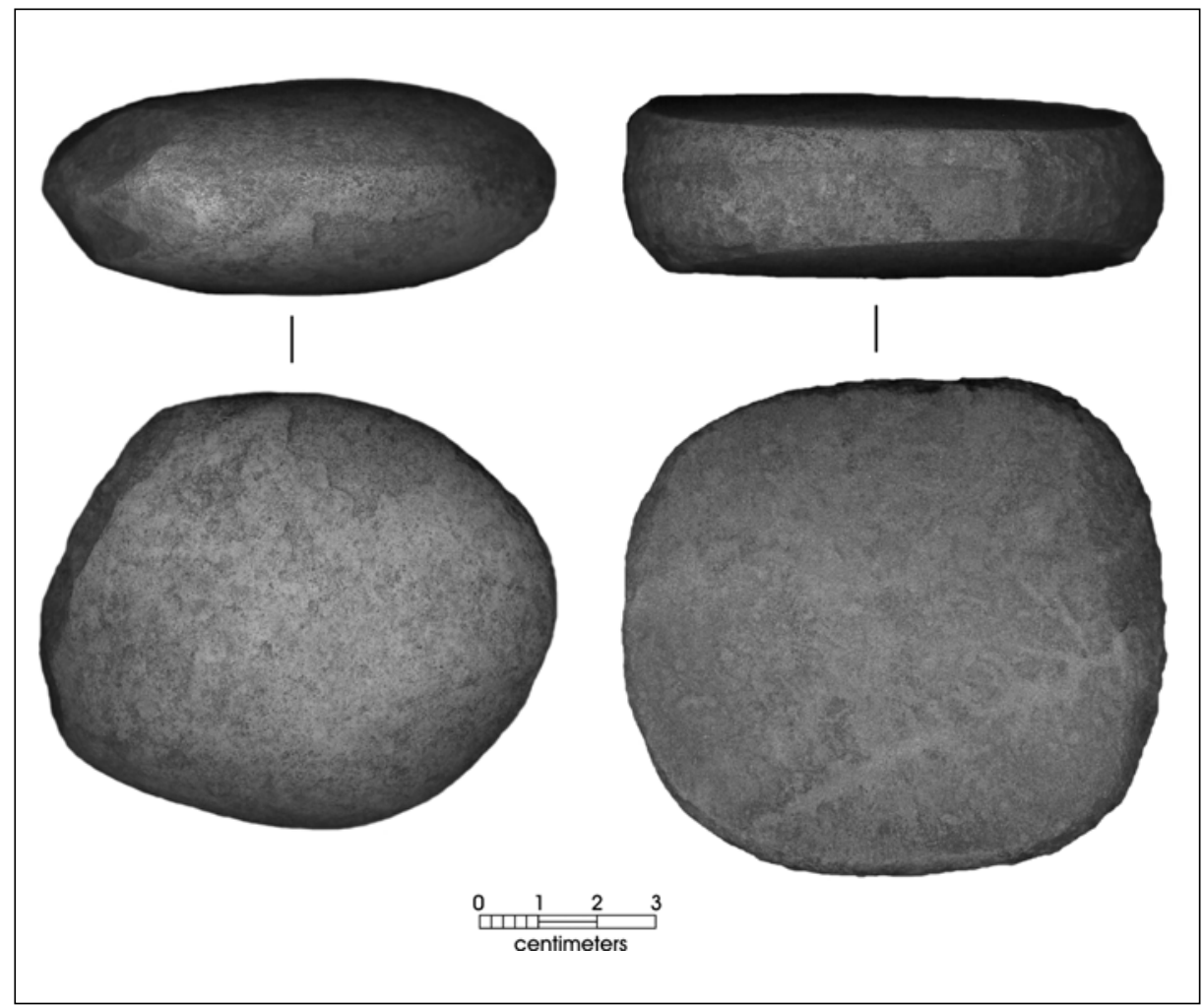

Figure 8-3. Manos recovered from 41PR44. 


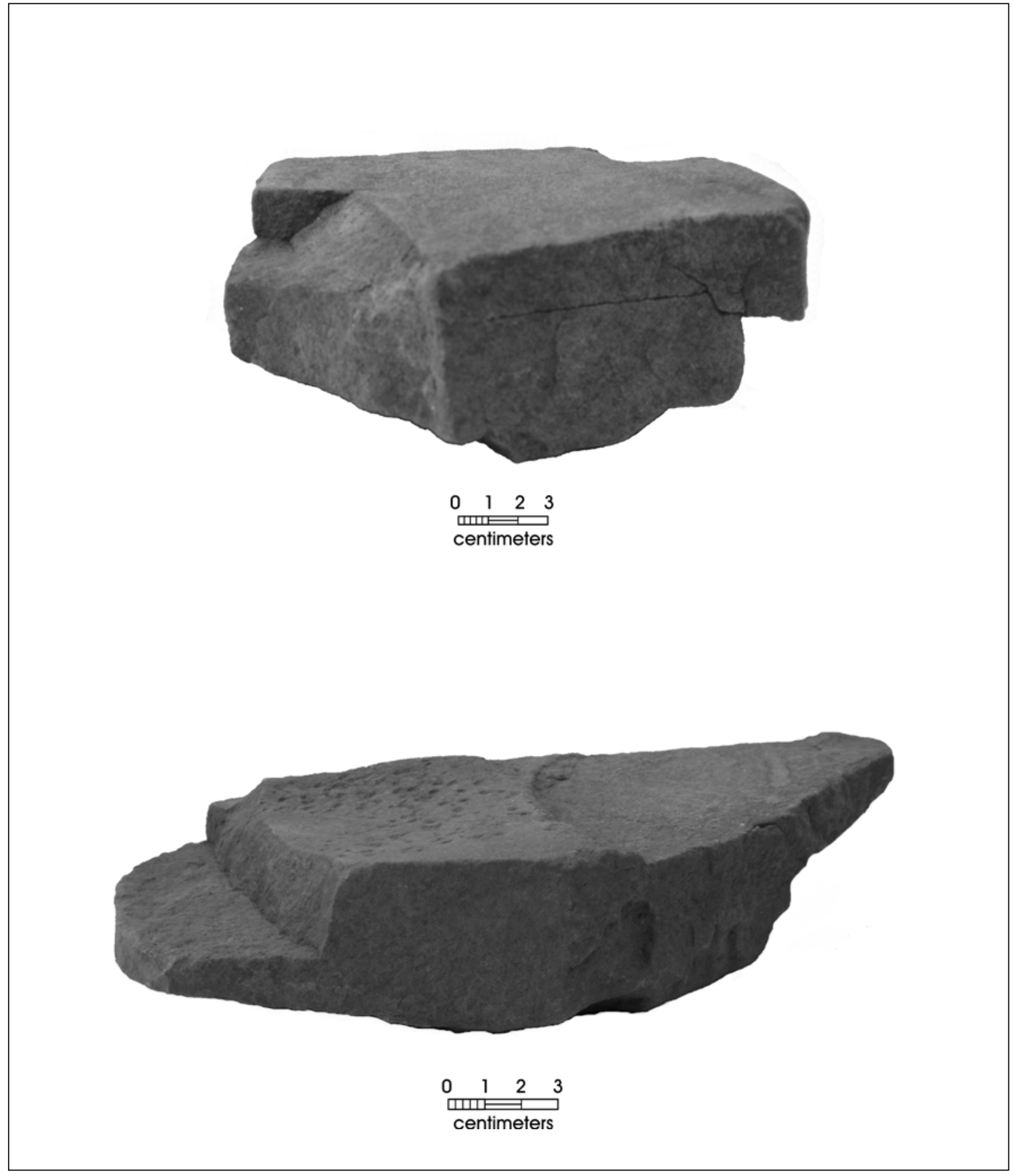

Figure 8-4. Sandstone metate fragments from 41PR44. 


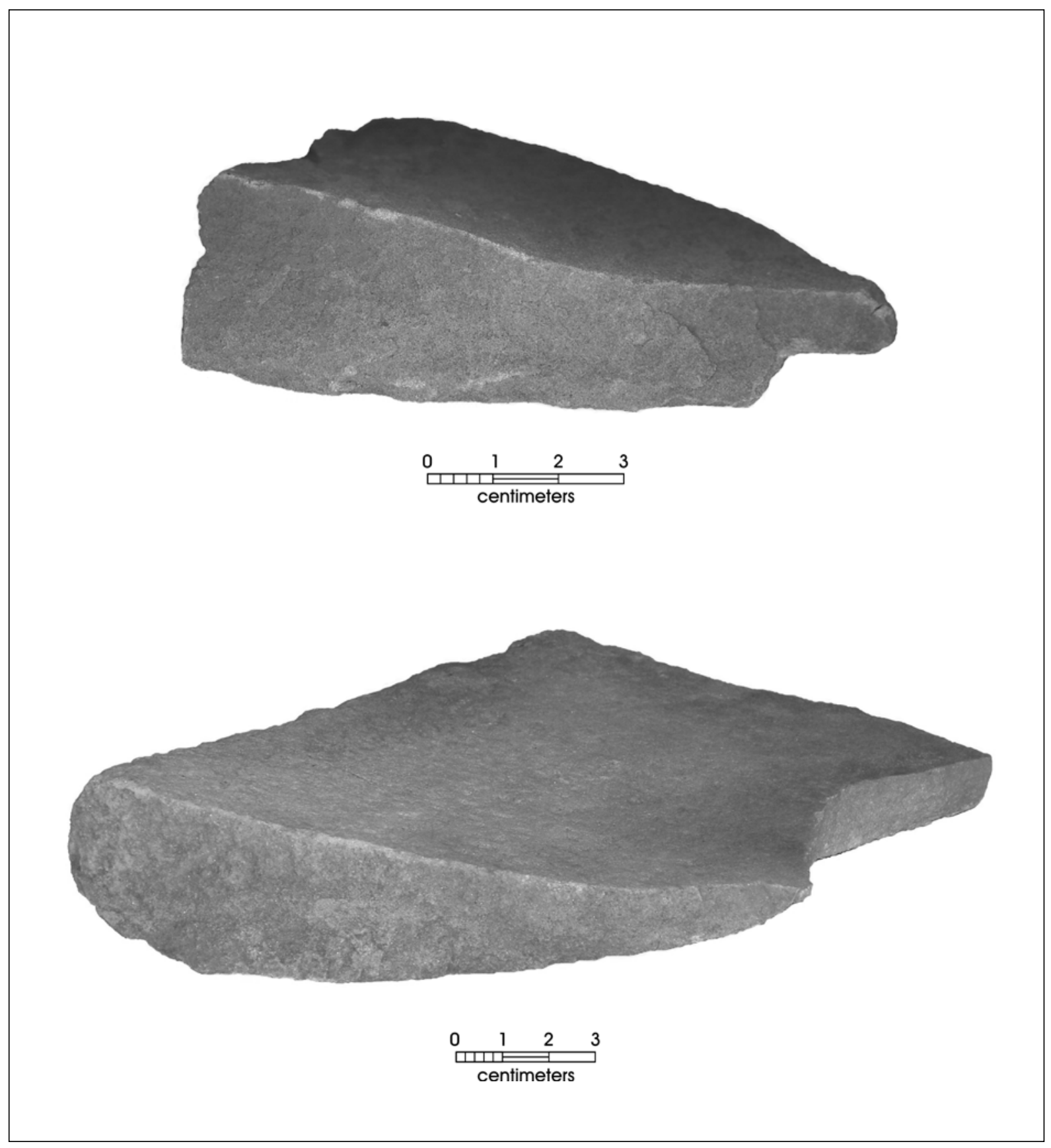

Figure 8-5. Sandstone metate fragments from 41PR44. 
Table 8-1. Regional Ground Stone, Projectile Point, and other Stone Tool Data

\begin{tabular}{|l|c|c|c|c|l|}
\hline Site No. & $\begin{array}{c}\text { Ground Stone } \\
\text { (manos + metates) }\end{array}$ & $\begin{array}{c}\text { Projectile } \\
\text { Points }\end{array}$ & $\begin{array}{c}\text { Other Chipped } \\
\text { Stone Tools* }\end{array}$ & $\begin{array}{c}\text { Sample } \\
\text { Size }\end{array}$ & \multicolumn{1}{|c|}{ Source } \\
\hline 41PR44 & 7 & 16 & 23 & 46 & This Report \\
\hline 41WD468 & 4 & 16 & 50 & 70 & Wormser and Strickland 2003 \\
\hline 41MV120 & 1 & 16 & 63 & 80 & Vierra 1998 \\
\hline 41WM13 & 2 & 81 & 11 & 94 & Johnson 2000 \\
\hline 41MX5 & 5 & 28 & 76 & 109 & Brewington et al. 1995 \\
\hline 41ZV83 & 10 & 47 & 91 & 148 & Montgomery 1978 \\
\hline 41HP159 & 10 & 37 & 101 & 148 & Gadus et al. 1992 \\
\hline 41BT6 & 7 & 57 & 98 & 162 & Young 1985 \\
\hline 41RN169 & 2 & 20 & 151 & 173 & Treece et al. 1993 \\
\hline 41MK27 & 3 & 33 & 149 & 185 & Irwin et al. 1999 \\
\hline 41TT108 & 8 & 160 & 81 & 249 & Young 1981 \\
\hline 41LE59 & 14 & 57 & 258 & 329 & Rogers and Kotter 1995 \\
\hline 41MM341 & 4 & 92 & 263 & 359 & Gadus et al. 2006 \\
\hline 41CC131 & 2 & 112 & 266 & 380 & Treece et al. 1993 \\
\hline 41LK201 & 40 & 190 & 209 & 439 & Highley 1986 \\
\hline 41HP175 & 4 & 130 & 360 & 494 & Klement et al. 1993 \\
\hline 41MM340 & 4 & 109 & 381 & 494 & Mahoney et al. 2003b \\
\hline 41UV60 & 5 & 260 & 453 & 718 & Goode 2002 \\
\hline 41BP19 & 12 & 84 & 645 & 741 & Bement 1989 \\
\hline 41BX52 & 1 & 187 & 573 & 761 & Collins et al. 2003 \\
\hline 41BR16 & 11 & 141 & 654 & 806 & Kalter and Nash 2002 \\
\hline 41BT105 & 65 & 321 & 568 & 954 & Johnson 1997 \\
\hline 41JW8 & 25 & 199 & 1085 & 1309 & Black 1986 \\
\hline 41TV163 & 19 & 431 & 1435 & 1885 & Mauldin et al. 2004 \\
\hline 41FY135 & 13 & 299 & 2539 & 2851 & Kalter et al. 2005 \\
\hline 41BX228 & 24 & 936 & 3557 & 4517 & Black and McGraw 1985 \\
\hline
\end{tabular}

* Includes all other non-projectile point chipped stone tools (e.g., bifaces, unifaces, utilized flakes).

high values on the $\mathrm{X}$-axis, and several that have high $\mathrm{Y}$ values, nine sites, identified by triangular symbols, have high scores on both X and Y. That group includes 41PR44, the values for which far exceed all other sites. While the distinct location of 41PR44 is probably a function of several factors, including the relatively small sample of comparative sites and the small overall size of the tool assemblage from the site $(n=46)$, the high values on both axes suggest that grinding was probably a major activity at this site. By implication, lower ranked plant foods (e.g., small seeds) requiring processing on manos and metates, may well have been a major component of the diet at 41PR44.

\section{Vertebrate Faunal Material from 41PR44}

The second data set used in documenting and investigating subsistence at 41PR44 is vertebrate faunal remains. While these data have a more direct link to subsistence questions, the problems of small sample size and ambiguous temporal affiliation that plagued the lithic tool data set are also present in the faunal data. Overall, 425 pieces of bone were recovered from the site, with temporal assignment to the early Late Prehistoric or the earlier Archaic occupation possible in 155 cases. Patterns at the site level in animal remains, as well as temporal patterns, are discussed below. Additional details on the faunal assemblage can be found in Appendix B. 


\section{Site Level Descriptive Data}

Previous research at the site (Brownlow et al. 1999; Brownlow 2001) had noted the presence of bison, deer, and rabbit, though no formal analysis of those remains was presented. Table 8-2 provides a summary of the 425 individual pieces of faunal material recovered from CAR's excavation at 41PR44. As can be seen in the table, mammalian fauna dominate the assemblage, both in terms of numbers of specimens $(\mathrm{n}=375 ; 88.2 \%)$ and in terms of overall bone weight (315.99 g.; 96.5\%). Reptiles, consisting of turtles and sliders, accounted for 35 specimens, while birds $(n=14)$ and fish $(n=1)$ were also recovered. The majority of the 375 mammal specimens could not be assigned to a more detailed taxonomic level. However, as shown in Table 8-2, within the small number of mammalian items that could be identified to lower taxonomic levels, both white-tail deer and cotton-tail rabbit were noted, as were three specimens of dog, coyote, or wolf (i.e., Canis sp.). In addition, a number of items consistent with or in the size range of deer $(\mathrm{n}=88)$ and bison $(\mathrm{n}=37)$ were noted, along with several smaller sized animals. Given the small overall sample size and the fragmentary nature of the assemblage, the range of animals noted for 41PR44 is not significantly different from those presented elsewhere in this region (see Brown 1989; Thoms 1994).

\section{Temporal Patterning}

As outlined in Chapter 4, and as reiterated at the beginning of this chapter, our approach to investigating the organization of and changes in subsistence is based in foraging theory. From this perspective, hunters and gatherers make subsistence decisions based on maximizing their average return rate. Those decisions are tied to prey profitability, and the actual diet is a function of interactions between profitability and search costs. As noted above, return rates for animal resources are generally higher than for most plant resources (see Kelly 1995; Simms 1987), and animal return rates are roughly correlated to body size.

Using the chronological divisions presented in Chapter 7 , we can assign only 151 of the 425 items collected from 41PR44 to either the early Late Prehistoric $(n=37)$ or the earlier Archaic $(\mathrm{n}=114)$ occupations. In addition, only 89 of the 155 items can be classified to a taxonomic level reflecting body size. These small samples preclude any detailed investigation except for broad patterns. For the purposes of comparing the Archaic and early Late Prehistoric faunal assemblages, the faunal material is divided into four body-size groups. The smallest body-size group consists of small and medium sized birds, reptiles, and fish. The second group includes large birds (e.g., turkey), and small and medium sized mammals. The third group consists of larger mammals, including deer and antelope. These animals generally weigh between $46.7 \mathrm{~kg}$ (pronghorn) and $275 \mathrm{~kg}$ (elk). Finally, the large body-size group consists of faunal material identified as bison, as well as remains classified as bison size (see Appendix B). These body-size classes should, at a broad scale, reflect profitability, as an average bison weighs around $835.5 \mathrm{~kg}$ (David and Schmidly 1997). That is, animals in the larger body-size group (i.e., bison) should have a higher return relative to handling costs than those in the smaller body-size groups. As such, these higher return, larger bodied animals should be pursued when they are encountered. Conversely, animals in the smaller body-sized groups should be ignored, provided that the search costs of more profitable resources are not such that to continue to search for them would lower the average profitability of the diet.

Figure 8-7 presents the results of this body-size grouping, arranged from low to high profitability, for the Archaic (top) and early Late Prehistoric (bottom) assemblages. While the sample sizes are small, rendering any conclusions tentative, several interesting elements are present in the figure. The first of these is the presence of bison in the early Late Prehistoric period deposits. The presence of bison during this time frame is contrary to the often referenced study by Dillehay (1974). In that study, Dillehay argued that these large bodied animals were absent from the state from the close of the Late Archaic through the end of the early Late Prehistoric. Mauldin and Kemp (2005) have recently reviewed 182 components from south, central and north-central Texas for the presence/absence of bison. Their review included most of the sites originally used by Dillehay (1974), as well as many more recent excavations. They conclude that bison are, in fact, present continuously from the beginning of the Late Archaic through European contact (see also Collins 1995; Huebner 1991; Wade 1998). The presence of bison during the early Late Prehistoric period at 41PR44 is consistent with the conclusions of that review.

The second element of interest in Figure 8-7 is the dramatic differences between the Archaic and early Late Prehistoric patterns. In the upper plot (Archaic) in Figure 8-7, high return bison elements account for just over $52 \%(n=24)$ of the categorized assemblage, while reptiles, small and medium sized birds, and fish account for only $4.3 \%$. While the overall sample available for classification is only 21 


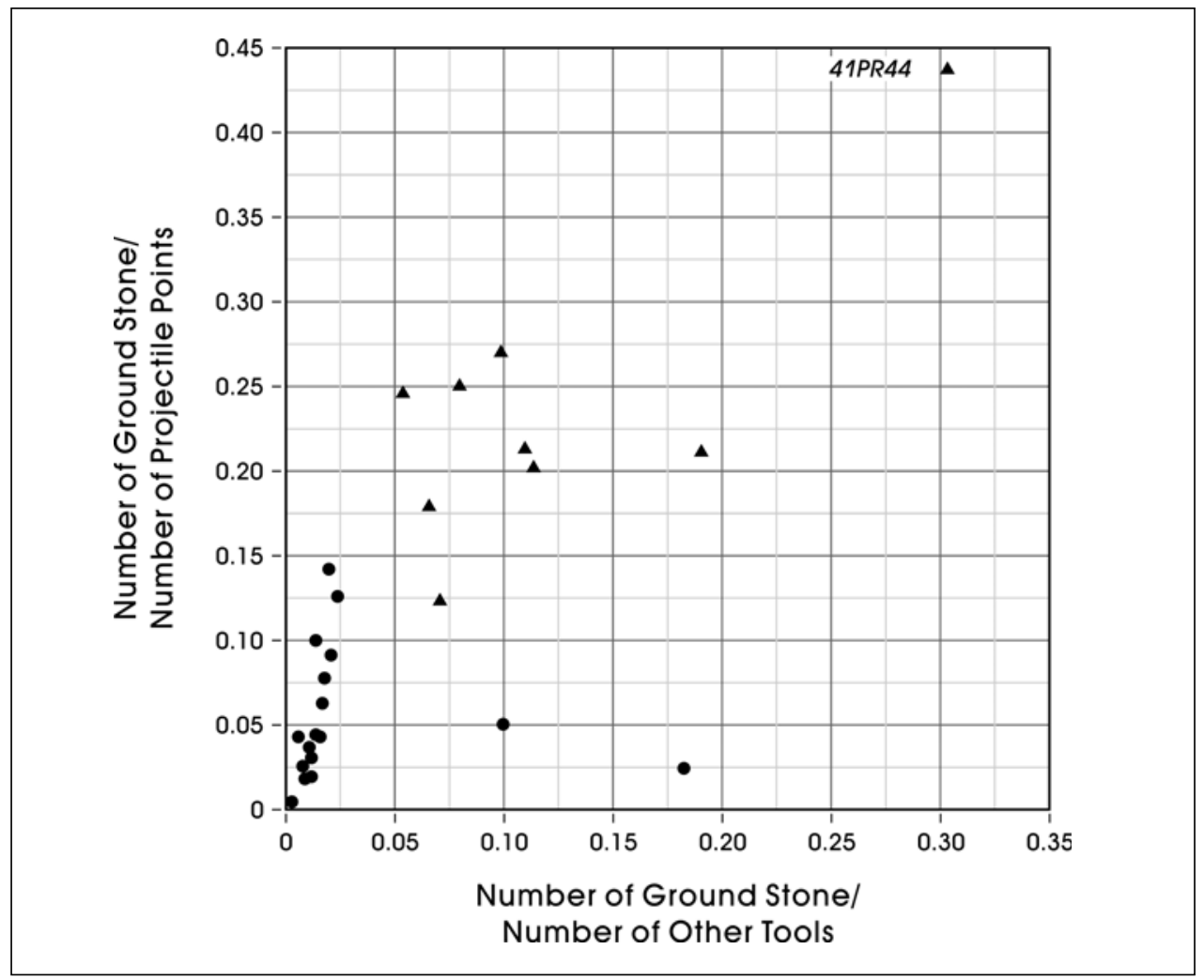

Figure 8-6. Comparsions of two ground stone indices from 26 sites (see Table 8-1). Triangles reflect sites with high scores on both $x$ and $y$ axis.

Table 8-2. Faunal Remains Recovered from 41PR44

\begin{tabular}{|c|c|c|c|}
\hline Scientific Name & Common Name & Count & Weight (g) \\
\hline \multicolumn{4}{|c|}{ Mammals } \\
\hline Artiodactyl & Deer, sheep, goat & 4 & 20.83 \\
\hline Bovinae & Cattle, Bison & 4 & 93.76 \\
\hline Canis sp. & Dog, coyote, wolf & 3 & 2.53 \\
\hline Odocoileus virginianus & White-tail Deer & 5 & 11.05 \\
\hline Sylvilagus sp. & Cotton-tail Rabbit & 2 & 0.27 \\
\hline Mammal--Rabbit-sized & & 3 & 0.48 \\
\hline Mammal--Deer-sized & & 83 & 71.90 \\
\hline Mammal--Bison-sized & & 33 & 72.16 \\
\hline Mammal--Indeterminate size & & 238 & 43.01 \\
\hline \multicolumn{4}{|c|}{ Birds } \\
\hline Aves--Quail-sized & & 8 & 0.98 \\
\hline Aves--Turkey-sized & & 1 & 1.28 \\
\hline Aves--Indeterminate size & & 5 & 0.57 \\
\hline \multicolumn{4}{|c|}{ Reptiles } \\
\hline Emydidae & Box turtles and pond sliders & 6 & 2.12 \\
\hline Testudines & Unidentified turtles & 29 & 6.46 \\
\hline \multicolumn{4}{|c|}{ Fish } \\
\hline Osteicthyes & Unidentified Fish & 1 & 0.02 \\
\hline & Total & 425 & 327.42 \\
\hline
\end{tabular}



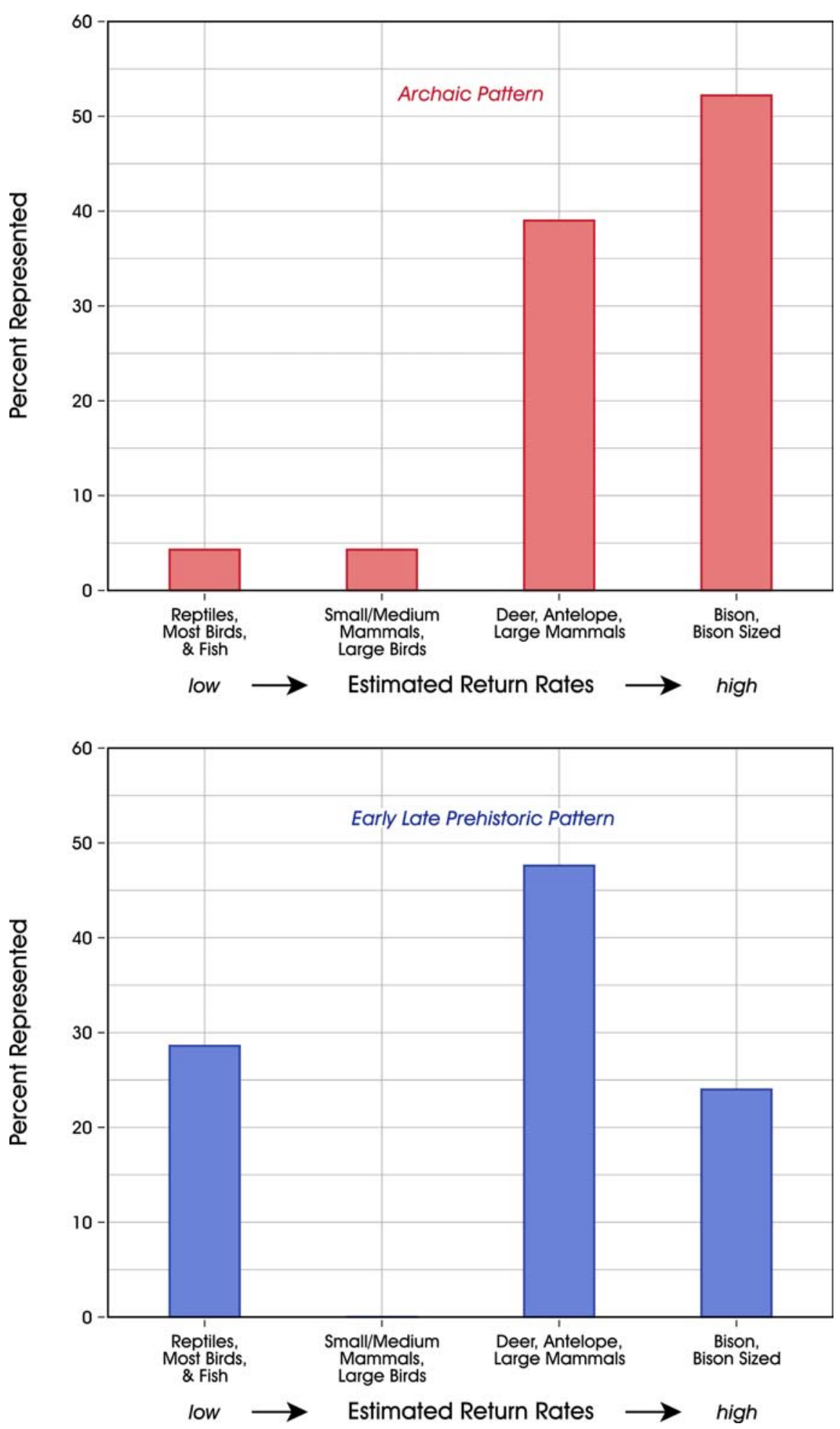

Figure 8-7. Body-size groups represented in Archaic (top) and Late Prehistoric (bottom) fauna from $41 P R 44$. 
items, the pattern for the early Late Prehistoric in Figure 8-7 (bottom) is substantially different, with bison accounting for only $24 \%$ and low return birds, reptiles, and fish making up over $28 \%$. The small sample size makes any conclusions tenuous, but the pattern is suggestive. From our perspective, the reduced dependence on high return resources in the Late Prehistoric, as well as the increased dependence on the smaller, lower return group, is consistent with increased diet breadth during the early Late Prehistoric. This should occur under conditions of increased costs associated with the pursuit of bison. That increased cost is probably associated with declining densities of these high ranked animals. Under conditions of declining densities, and by extension increased search costs, overall return rates would decline. Fewer bison would be encountered and killed, and the average return rate of the subsistence strategy would fall. Under these circumstances, lower ranked resources should be increasingly incorporated into the diet. While additional sites, especially sites with larger sample sizes will be necessary to explore this suggestion, the faunal data from 41PR44 hint at significant changes in subsistence during the Late Prehistoric in this region of Texas.

\section{Summary}

While the data available for the investigation of subsistence at 41PR44 have a number of limitations, this chapter has considered patterns in lithic tools and in vertebrate fauna in order to document, and begin to explore, aspects of subsistence. The ground stone assemblage from the site appears, when contrasted to other assemblages, to be consistent with a focus on lower return plant resources. While we cannot place the ground stone securely in a temporal framework, most of the assemblage (71\%) was recovered from the surface, a location that has a higher probability of dating to the Late Prehistoric period. We can place at least some of the faunal material in one of the two time periods identified in Chapter 7. Our focus on changes in the relative contribution of animals in different body-size groups suggests an increased dependence on lower return, but more ubiquitous, smaller animals is reflected by the early Late Prehistoric material. These faunal changes, along with the patterns in ground stone, may reflect a broadening of the diet during the early Late Prehistoric period relative to the Archaic occupations at 41PR44. 



\section{Chapter 9: Chipped Stone Technology}

This chapter investigates aspects of chipped stone technology at 41PR44. Our investigation is framed in terms of raw material availability. As noted in Chapter 2, high quality tool stone is limited in the area of 41PR44. Differential access to high quality raw material should have a significant impact on the organization of chipped stone technology. The 41PR44 chipped stone material provides an opportunity to better understand how raw material availability, quality, and size conditions reduction strategies and aspects of lithic tool organization. In this chapter we will first establish some general patterns of tool stone availability and consider the impacts of availability on the 41PR44 assemblage. We investigate changes through time in assemblages at $41 \mathrm{PR} 44$ by comparing different strategies of stone procurement reflected in Late Archaic and Late Prehistoric deposits. It is suggested that the Late Archaic occupation at the site focused on local materials, while the early Late Prehistoric occupants of 41PR44 were involved in a system that relied much more heavily on transporting previously reduced bifaces and finished tools to this location.

\section{Raw Material Availability}

Raw materials vary in terms of their quality, distribution, abundance, and size. Some portions of the state, such as many locations on the Edwards Plateau, have high quality cherts that occur in significant quantities and in large size ranges. Other areas, such as East Texas, lack any significant chert resources. Still other areas, such as South Texas, have secondary deposits associated with river systems, as well as chert gravel deposits. In Figure 9-1 we have attempted to define the spatial boundaries of raw material availability for the central, southern, and northern portions of the state. We define three zones of availability based initially on geological criteria, but will readily acknowledge that this tripartite partitioning, as well as exactly where the divisions are made, is a large scale, first approximation. That is to say, it represents a pretty good guess.

The zone designated as having high tool stone availability (red in Figure 9-1) corresponds, in rough detail, to the Edwards Limestone distribution presented by Frederick and Ringstaff (1994). The Edwards formation contains abundant, high quality chert nodules, often of significant size. While high quality chert exposure certainly varies across the large area depicted in red in Figure 9-1, it is likely that at any point on this landscape, hunters and gatherers are not a significant distance from good quality tool stone. The second zone, which is designated as having moderate availability of tool stone (yellow in Figure 9-1), is defined on the basis of proximity to the high availability zone, as well as drainage systems that flow through, or off of, the Edwards Plateau, and the presence of new stone sources in the Panhandle region. The definition of this zone, then, is certainly approximate. The definition is further complicated both by the presence of Alibates Chert sources in the Panhandle, as well as a variety of igneous stone and river gravels in far West Texas. The final zone shown in light blue in Figure 9-1 is one of low material availability. As with the designation of the moderate Zone, this designation is approximate. Certainly within this zone, there may be locations with good chert sources (e.g., river associations, Uvalde gravel clusters), but in general this portion of the state is impoverished with regard to tool stone, especially when compared to the stone availability reflected in the Edwards formation. Note that 41PR44 is within the low availability zone.

Assuming that the distribution mapped in Figure 9-1 does, in fact, capture the large scale patterns of raw material availability, what might assemblages from sites look like in these various areas? While a variety of different processes certainly impact assemblages, the most obvious of which is the goal of the reduction process, we can suggest some general patterns related primarily to differences in raw material size. In areas with high availability of quality stone, we would expect assemblages to have (1) large variation in flake size; (2) large average flake size, along with large tools and cores; (3) lower relative number of raw material sources for a given assemblage sample size; (4) low frequency of reworked or refurbished tools and exhausted cores in the tools and cores; and (5) high tertiary flake percentages. In contrast, areas with limited access should have (1) lower flake size variations; (2) smaller average flake size, smaller tools, and smaller cores; (3) higher relative number of raw material sources present; (4) higher frequency of reworked or refurbished tools and exhausted cores in the tools and cores; and (5) generally lower frequencies of tertiary flakes, a function of smaller nodule size (see Andrefsky 1998), with higher variability between sites. While considerable variability in these measures may 


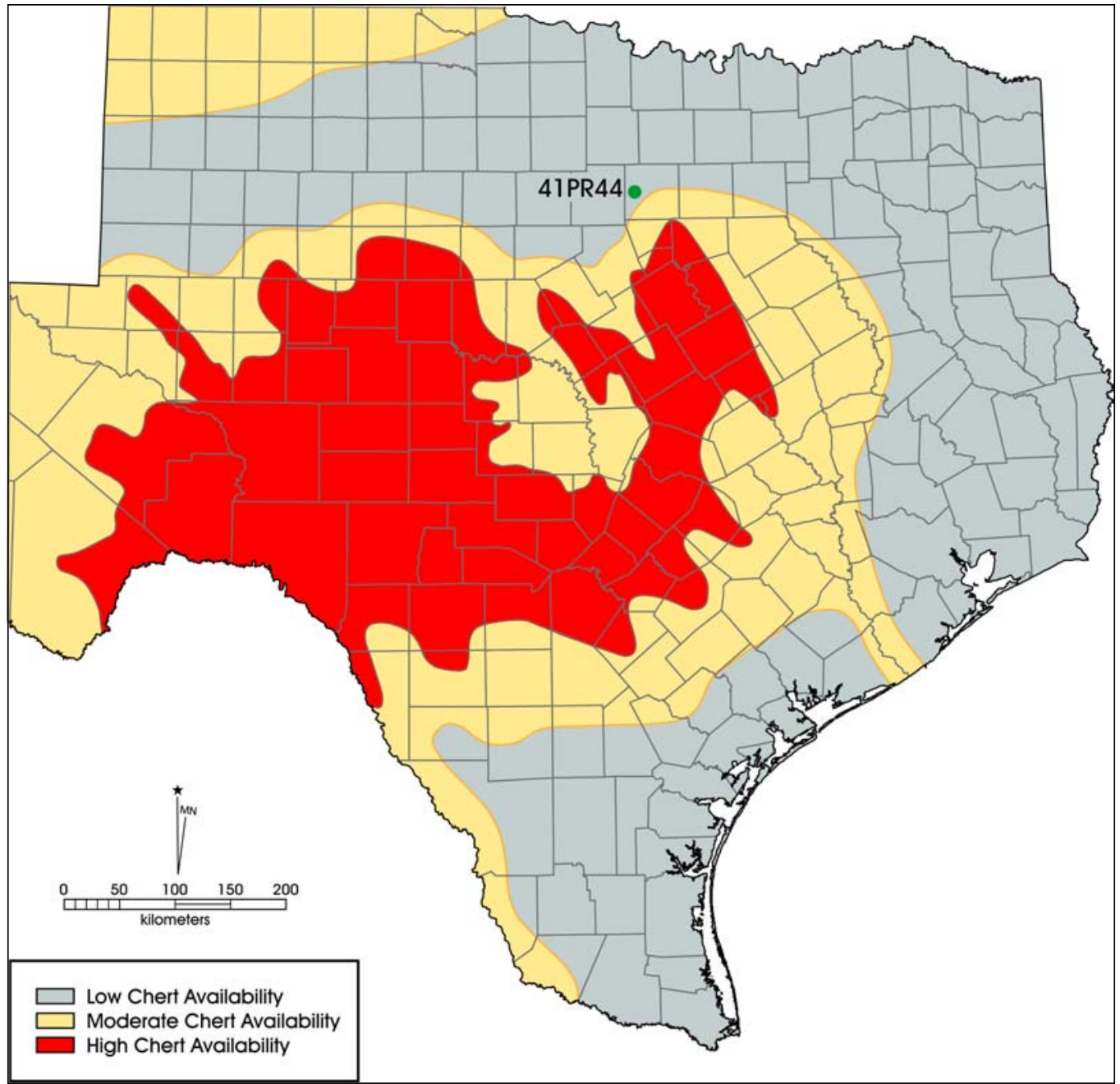

Figure 9-1. Estimated zones of chert availability.

be evidenced in any particular situation as a function of specific adaptive responses and reduction goals, when a number of assemblages are considered, patterns such as those outlined above can be anticipated.

Consistently reported data on flake size, or investigations of the number of stone sources, are simply not available for most sites in Texas. However, one attribute that seems to be consistently reported, either for the entire assemblage at a site, or for a sample of the debitage collected, is dorsal cortex coverage. While individual researchers differ as to the definition of what constitutes a "primary" or a "secondary" flake, most reports consistently define tertiary flakes as those without any cortex present. We can compare that percentage, then, with regard to raw material availability as an initial consideration of raw material impacts. Table 9-1 provides details on the comparative sample. Note that 41 different entries are summarized in the table, and that generally we are providing summaries at the level of a report rather than for individual sites. That is, in many cases, the individual summary is the result of multiple sites. For example, the Fort Hood entry is a summary of 94 sites discussed by Trierweiler (1994). The data in Table 9-1 are collected from 34 different counties, and represent nearly 200 individual site reports.

Figure 9-2 presents the percentage of non-cortical flakes present in these various reports in two different ways. The upper portion of the figure presents a histogram grouping assemblages at $5 \%$ intervals, with availability designated by different colors. The bottom portion presents a box plot of the data in the histogram, with the percentages grouped 
Table 9-1. Raw Material Availability, Cortical Data, and Reference Information for Selected Projects

\begin{tabular}{|c|c|c|c|c|c|c|}
\hline $\begin{array}{l}\text { Project, Area, or } \\
\text { Site Number(s) }\end{array}$ & County & $\begin{array}{c}\text { Raw } \\
\text { Material } \\
\text { Access }\end{array}$ & $\begin{array}{c}\text { Number of } \\
\text { Cortexed } \\
\text { Items }\end{array}$ & $\begin{array}{c}\text { Number of } \\
\text { Non-Cortexed } \\
\text { Items }\end{array}$ & $\begin{array}{c}\text { Percent } \\
\text { Tertiary } \\
\text { Debitage }\end{array}$ & Reference \\
\hline $41 \mathrm{WA} 47$ & Walker & Low & 1792 & \begin{tabular}{|l|}
1925 \\
\end{tabular} & 0.52 & Greaves et al. 2002a \\
\hline $41 \mathrm{MX} 5$ & Morris & Low & 255 & 282 & 0.53 & Brewington et al. 1995 \\
\hline 41DT59 & Delta & Low & 364 & 405 & 0.53 & Cliff et al. 1995 \\
\hline 41PK69 & Polk & Low & 745 & 871 & 0.54 & Ensor and Carlson 1988 \\
\hline Maxey 3 & Lamar & Low & 966 & 1132 & 0.54 & Mahoney 2001 \\
\hline Maxey 4 & Lamar & Low & 694 & 961 & 0.58 & Mahoney et al. 2002 \\
\hline 41PR44 & Parker & Low & 345 & 538 & 0.61 & This Repoft \\
\hline Garza & Garza & Low & 127 & 200 & 0.61 & Boyd et al. 1990 \\
\hline 41JW8 & Jim Wells & Low & 3986 & 8092 & 0.67 & Black 1987 \\
\hline 41GD113+114 & Goliad & Low & 295 & 636 & 0.68 & Greaves et al. $2002 b$ \\
\hline Chambers/ Liberty & Chambers/Liberty & Low & 623 & 1536 & 0.71 & Ensor 1995 \\
\hline 41HE14,139,343 & Henderson & Low & 143 & 462 & 0.76 & Cliff et al. 2002 \\
\hline $41 \mathrm{KT} 51$ & Kent & Low & 427 & 3049 & 0.88 & Boyd et al. 1993 \\
\hline $41 \mathrm{KT} 53$ & Kent & Low & 599 & 5427 & 0.9 & Boyd et al. 1993 \\
\hline 41LE177 & Lee & Moderate & 321 & 356 & 0.53 & Frederick et al. 2001 \\
\hline $41 Z V 83$ & Zavala & Moderate & 359 & 536 & 0.6 & Montgomery 1978 \\
\hline $41 \mathrm{WB} 557$ & Webb & Moderate & 265 & 577 & 0.69 & Quigg 2005 \\
\hline 41MM340 & Milam & Moderate & 1807 & 3993 & 0.69 & Mahoney et al. 2003b \\
\hline 41WB437 & Webb & Moderate & 1602 & 3818 & 0.7 & Quigg et al. 2000 \\
\hline $41 \mathrm{ZP} 39+176$ & Zapata & Moderate & 197 & 525 & 0.73 & Quigg and Cordova 1999 \\
\hline Camp Bowie & Brown & Moderate & 2334 & 7496 & 0.76 & Mauldin et al. 2003 \\
\hline 41FY135 & Fayette & Moderate & 1223 & 4053 & 0.77 & Kalters et al. 2005 \\
\hline Freestone/Leon & Freestone/Leon & Moderate & 3960 & 13203 & 0.77 & Fields et al. 1991 \\
\hline 41LN107 & Leon & Moderate & 694 & 2328 & 0.77 & Fields et al. 1988 \\
\hline Mclennan & Mclennan & High & 720 & 1008 & 0.58 & Scott et al. 2002 \\
\hline 41TG307+309 & Tom Green & High & 272 & 463 & 0.63 & Quigg et al. 1996 \\
\hline 41CW92 & Caldwell & High & 102 & 262 & 0.72 & Houk et al. 2005 \\
\hline $41 \mathrm{TG} 346$ & Tom Green & High & 958 & 2643 & 0.73 & Quigg and Peck 1995 \\
\hline $41 \mathrm{MK} 27$ & McCulloch & High & 3408 & 10342 & 0.75 & Irwin et al. 1999 \\
\hline 41BX377 & Bexas & High & 1479 & 5129 & 0.78 & Kibler et al. 2000 \\
\hline Grandberg-41BX17 & Bexar & High & 1603 & 6003 & 0.79 & Mauldin n.d. \\
\hline 41VV1882-1887 & Val Verde & High & 384 & 1469 & 0.79 & Cliff 2003 \\
\hline Ft Hood & Coryel & High & 7985 & 38961 & 0.83 & Trierweiler 1994 \\
\hline Uvalde sites & Uvalde & High & 7082 & 34677 & 0.83 & Lukoski 1989 \\
\hline $41 \mathrm{TV} 163$ & Travis & High & 1365 & 7291 & 0.84 & Mauldin et al. 2004 \\
\hline 41UV88 & Uvalde & High & 3298 & 18023 & 0.85 & Decker et al. 2000 \\
\hline $41 \mathrm{BX} 228$ & Bexar & High & 4505 & 24762 & 0.85 & Black and McGraw 1985 \\
\hline $41 \mathrm{MV} 120$ & Maverick & High & 663 & 3837 & 0.85 & Vierra 1998 \\
\hline $41 \mathrm{BX} 47$ & Bexar & High & 293 & 1701 & 0.85 & Tennis et al. 1996 \\
\hline 41BX1412 & Bexar & High & 498 & 3054 & 0.86 & Tomka and Robinson 2000 \\
\hline $41 \mathrm{CM} 111$ & Comal & High & 269 & 2862 & 0.91 & Mahoney et al. 2003a \\
\hline
\end{tabular}




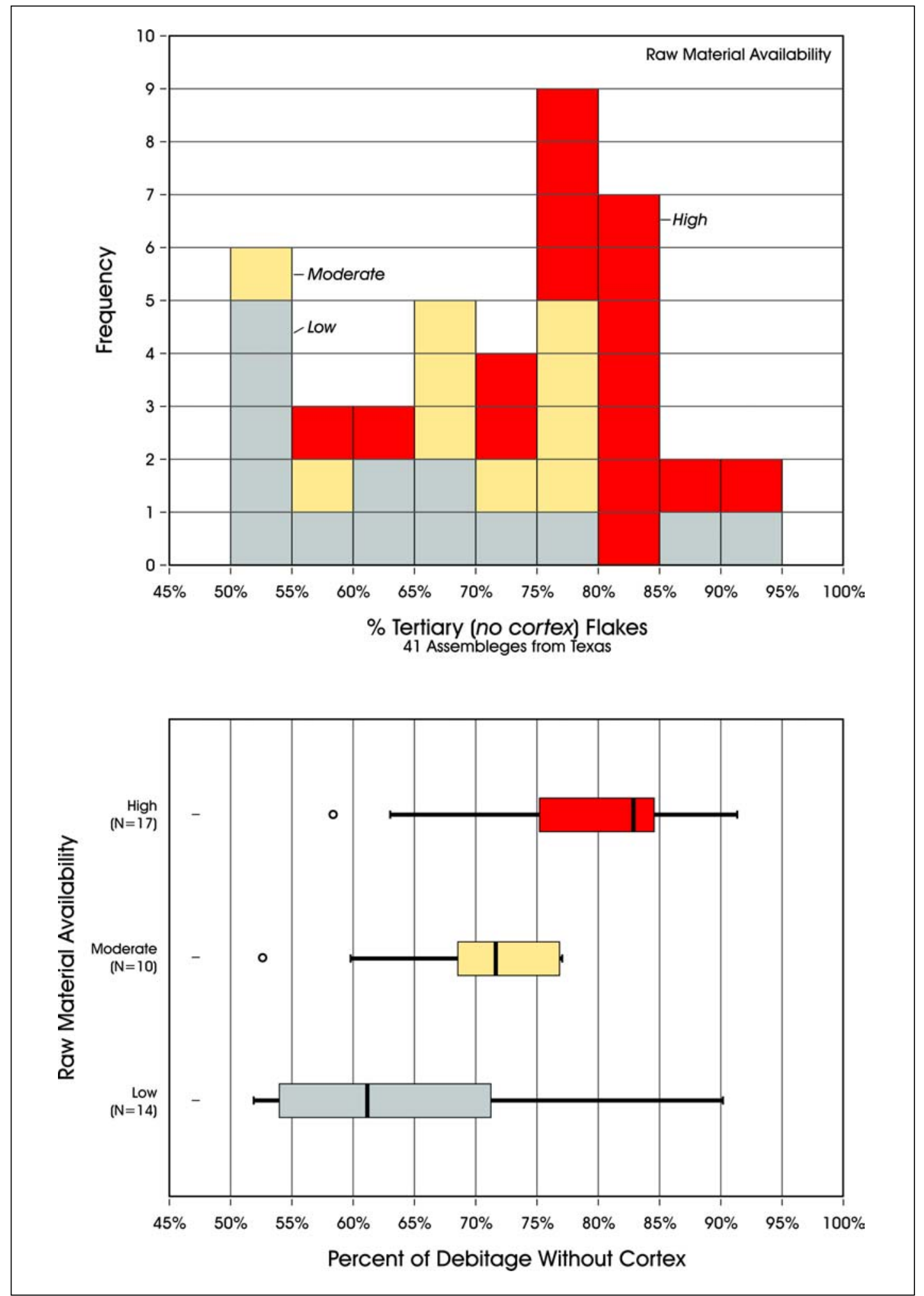

Figure 9-2. Histogram (upper) and box plots (lower) of tertiary flake percentages by raw material zone (see Figure 9-1; Table 9-1). 
by availability. Box plots provide a relatively simple method of summarizing and comparing distributions. Briefly, the upper and lower quartiles of a distribution form the upper and lower limits of the box. That is, $50 \%$ of the cases within a given distribution are within the box in the figure. The solid line in the box portrays the median value, so $50 \%$ of the cases in a distribution are to the right of the line, and $50 \%$ of the cases are to the left of that line. The lengths of the lines extending from the box, the "whiskers" in the box and whisker plot, are determined, in part, by the interquartile range (i.e., Q.75-Q.25, the length of the box). For the line extending to the right of the box, the lines terminate at the largest observation that is less than or equal to the upper quartile plus 1.5 times the interquartile range. For the line to the left of the box, the line terminates at the smallest value that is greater than or equal to the lower quartile minus 1.5 times the interquartile range. Values beyond the whiskers are termed outliers, and are identified by individual symbols (see Chambers et al. 1983). While the use of box plots with percentage data is somewhat inappropriate for statistical analysis as the variability is limited by the nature of the percentage comparison to between 0 and $100 \%$, the plots do provide a useful summary of the histogram data.

When seen together in Figure 9-2 (see also Table 9-1), these data clearly show that assemblages that were analyzed from areas classified as having high availability based on Figure 9-1 have significantly higher tertiary assemblages. Nine of the 11 cases in which tertiary flakes exceed $80 \%$ are from the high availability region, while only two of the 11 cases with less than $65 \%$ non-cortical debitage are in that region. The median percentage value for the high availability group is $83 \%$. Of the 197,371 pieces of debitage recorded from this zone (see Table 9-1), 82.3\% lacked cortex. In contrast, assemblages from locations in the low availability section are dominated by cortical assemblages, with five of the lowest six totals (50-55\%) being from this zone. While assemblages in this zone also have a high degree of variability, with a range of values from $52 \%$ to $90 \%$, the median value is $61 \%$, and of the 36,877 items from the low availability area (see Table 9-1), only $69.2 \%$ were non-cortical. Finally, note that the zones with moderate availability fall between the high and low extremes (median=71.5\%). The patterns in non-cortex shown in Figure 9-2 fit the suggestions made previously. It appears aspects of material availability, in this case probably material size, are conditioning assemblages. This further suggests that cortex percentages are responding as much to raw material size as to reduction stage.

\section{Raw Material Stress and Coping Strategies at 41PR44}

Site 41PR44 is located in an area of the state that has limited access to abundant, high quality stone (see Figure 9-1). As noted in Chapter 2 (see Figure 2-3), while sandstones, conglomerates, and shale are common in the immediate area, the limestone deposits in this section of the state lack high quality cherts. As shown is Table 9-1, the non-cortical component of the debitage at 41PR44 accounts for roughly $61 \%$, a figure comparable to the median value of assemblages from low availability regions. In addition, the tool and core assemblage collected by CAR from 41PR44 is certainly consistent with expectations of raw material stress. As shown previously in Figures 7-1, 7-2 (projectile points), 8-1 (bifaces), and 8-2 (unifaces, edge-modified items), the tool assemblage is generally small, and much of it is either broken or extensively reworked. Of the 16 projectile points, only three are complete (18.8\%). Two of the 15 bifaces (13.3\%) are not broken, and one of these two appears to be a projectile point base reworked into a graver (see Figure 8-1[a]). Of the eight edge-modified and unifacial tool fragments, one (Figure 8-2[e]) is potentially usable. The rest are partial edges or broken items. The average maximum size of the 23 non-projectile point tools is $2.86 \mathrm{~cm}$, and only one is over $4.2 \mathrm{~cm}$ in maximum length. The single core is $3.4 \mathrm{~cm}$ in maximum length. Overall, this tool assemblage is small, battered, and broken, a pattern consistent with raw material stress.

Given the location of 41PR44, it is likely that occupants of the site were faced with developing strategies to assure adequate stone for tool production. As discussed in Chapter 4 , we can envision two radically different coping strategies under conditions of raw material stress. In the first strategy, tool stone could be transported from areas of high availability into regions of low availability. These items would probably be in a partially reduced form such as bifaces or decorticated cores, though finished tools could also be present. These items could then be reduced, resharpened, or refurbished as needed. In the second strategy, hunters and gatherers would rely on lower quality/ smaller sized chert resources, as well as non-chert materials, to meet their tool stone needs.

Both strategies should produce small, broken, and refurbished tools and core assemblages, much like those at 41PR44. Both strategies should result in smaller sized debitage when compared to areas with high availability. While we might expect broken bifaces and projectile points 
to be dominated by non-local stone in the transport strategy when compared to a reliance on local materials, the major expected differences are in debitage. The transport strategy should produce debitage dominated by non-cortical debitage in the smaller size range, with the possibility of a few, larger decorticate flakes and, to the degree that partially decorticated cores were used, a few, larger flakes with some cortex. Conversely, non-cortical flakes should be less common if local raw materials are used. These differences may be further exaggerated where local materials are in the form of small nodules, as we suspect is characteristic of much of the resources in the low availability areas identified in Figure 9-1. As we noted earlier, small nodules should produce more cortical flakes relative to non-cortical flakes when compared to the reduction of larger cobbles. In addition, when local materials are used to alleviate raw material shortages, it is probable that some component of the chipped stone assemblage will be composed of non-chert materials. The presence of quartzite, petrified wood, and other coarser grained stone is, in many places within Texas, probably related to a reliance on local materials, at least to some degree.

In many, if not most cases where tool stone is limited, a combination of both strategies probably occurred. Consequently, in most cases it is likely that cherts from a variety of non-local and local sources, as well as non-chert materials (e.g., quartzite), were coming into a location. Some of these cherts may have been reduced to bifaces or finished tools elsewhere and some may reflect smaller, lower quality sources. Finally, note that there is a possibility that tool stone is scavenged from extant archaeological sites, which would further complicate interpretations. In order to document and begin to investigate such strategies for 41PR44, as well as to consider the relative contribution of each of the two major coping strategies (transported resources and local resources), we monitor a series of debitage attributes (e.g., maximum size, dorsal cortex percentages) for different raw material groups.

\section{Establishing Local and Non-Local Raw Material Sources}

In order to consider these suggestions, it is first necessary to identify groups of materials that have the possibility of coming from the same source, identifying which of these sources are local and non-local, and explore the mix of tool stone provisioning strategies present at 41PR44. Unfortunately, work on identifying and investigating the distribution of specific cherts in Texas is underdeveloped. While chemical sourcing and field investigation will ultimately be required to begin to make significant progress in this area, we can begin investigating sourcing by visually identifying groups of stone within the 41PR44 assemblage. The process of assigning individual pieces of debitage and tools to raw material groups involved sorting, and resorting, each piece of chipped stone based primarily on differences in color and the presence of inclusions in the stone. That process was done by a single individual over a short period of time. These original 19 groups were then reassessed by a second individual, and eventually combined into 15 different groups. Figure 9-3 presents examples of 14 of these 15 final groups. Group 19, which consists of a small number of items that could not be assigned to any other group, is not shown in the figure. Table 9-2 provides additional details on these raw material groups, including the number of cases present. The group designations (e.g., Group 2, 3, 4) shown in Figure 9-3 and Table 9-2 represents their original designations. Consequently, there is no group designated $1,13,14$, or 16 as these were absorbed into other groups during recombination.

Reference to Table 9-2 shows there are significant differences in the sizes of the samples. The most common materials represented at the site are in Groups 11 and 5. Together, these make up almost half (47.3\%) of the debitage from the site. Conversely, several groups have such small sample sizes that they have little analytical utility (e.g., Groups 3, 7, 8, 9, 15, 17, and 18). For the analysis conducted here, these samples will be combined into the miscellaneous group (Group19). Finally, note that Group 10 contains a variety of items, certainly representing several different chert types, all of which have been heated. In some cases, this heating is probably accidental.

Assuming that these different material groups do, in fact, reflect different sources, which of these reflect local sources, and which reflect non-local sources? To the degree that our initial characterization of the geology presented in Chapter 2 is correct, most of these sources could probably be characterized as "non-local" relative to the immediate site area. The caveat to this statement is the presence of extant archaeological deposits, so for Late Prehistoric populations at the site, earlier Archaic stone would, in fact, be a source of local stone. Nevertheless, what we are really concerned with here is the degree to which tool stone has arrived at the location of 41PR44 in a decorticate form, and by extension from areas with higher abundance of raw materials, relative to the use of stone that is from low 


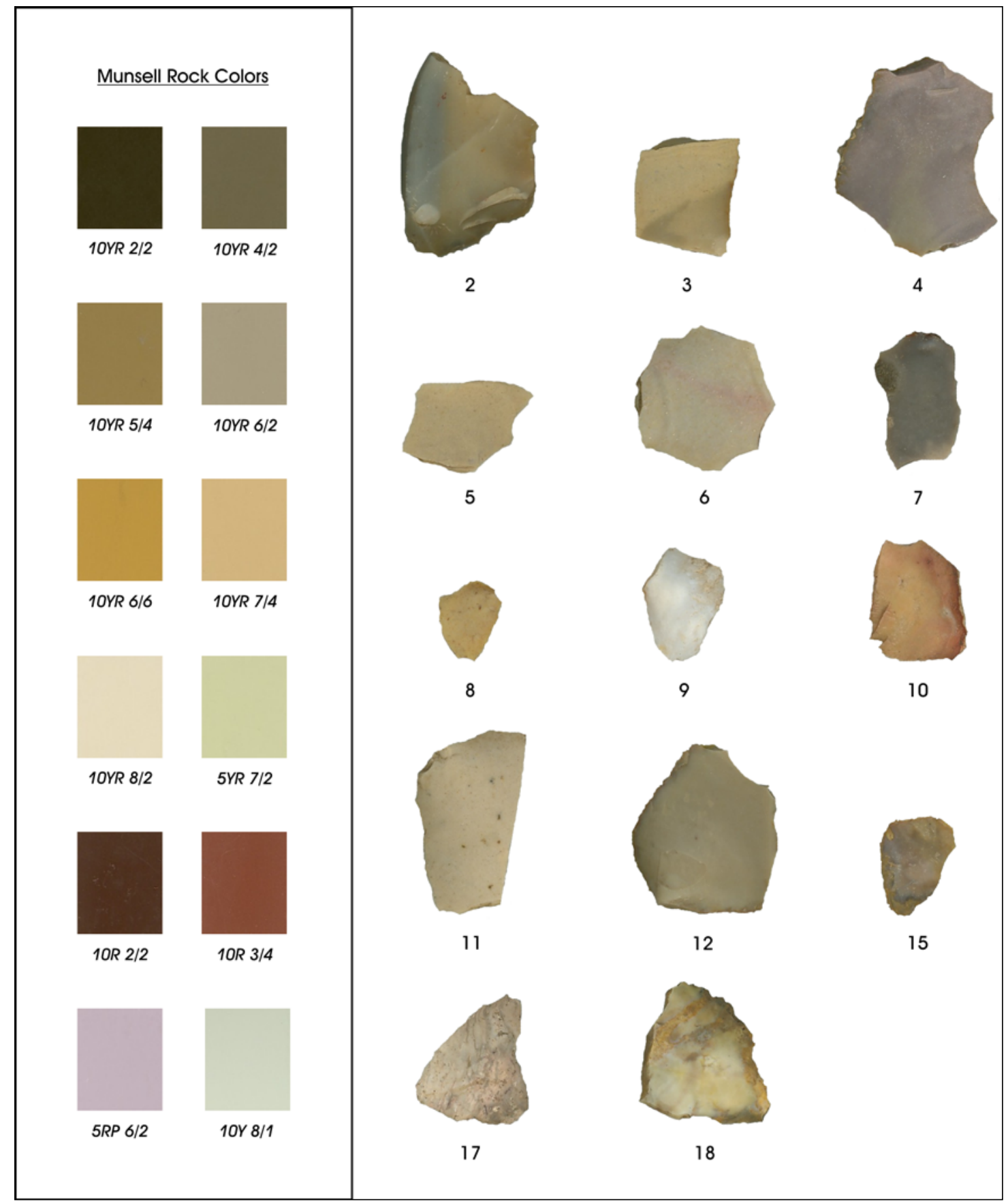

Figure 9-3. Examples of raw material groups identified on 41PR44. 
abundant areas, and by extension smaller in size, more variable in quality, and likely to be dominated by cortex when it enters 41PR44. As outlined above, the transport strategy, which implies a dependence on non-local stone, should produce debitage assemblages dominated by non-cortical debris in all size ranges, with the possibility of a small quantity of cortical remains present if the strategy involved partially decorticated cores. Conversely, a reliance on local materials should produce lower decorticate assemblages, with the presence of flakes with high cortex in all size ranges, and smaller overall size.

To consider these suggestions, we first focus on differences in debitage size. One of the attributes monitored on debitage was the maximum length of each piece. Table 9-3 presents summary statistics for each of the eight material groups, with all measurements in millimeters. Note that the interpretation of Group 10 is complicated by the fact that this group represents heated specimens. As such, the group represents a mishmash of material types that cannot, given their heating, be partitioned into their actual groups. Similarly, Group 19, by definition, contains a wide variety of stone. This group certainly contains local stone (e.g., quartzite) as well as non-local stone. Focusing then on the remaining six groups, the size data suggest that, as anticipated, the assemblage is extremely small for most groups, with four of the six having an average size of less than $20 \mathrm{~mm}$, and all six having median sizes below this value.

Figure 9-4 presents size and variability information on these six groups (Groups 2, 4, 5, 6, 11, and 12) from 41PR44 (see Table 9-3 for ranges, standard deviations, and group means). These groups are depicted by triangles and their associated group designations are provided next to the plotted point. Also present in the figure is comparative data for 14 material groups from 41TV163 (Mauldin et al. 2004), a site located within the high chert availability area as defined previously (Figure 9-1). A similar strategy of partitioning tool stone into groups based on color and inclusions was used at this site. The $\mathrm{X}$-axis for the plots in Figure 9-4 is the range (maximum size [mm]-minimum size $[\mathrm{mm}])$ of the raw material groups for both sites while on the Y-axis is the coefficient of variation (standard deviation/ mean) of that group. Both sites used $1 / 4$-in. screen, so the minimum size is probably limited by that recovery decision. What the range, then, is probably responding to is the maximum size of a flake in that particular group. The coefficient of variation $(\mathrm{CV})$ is preferred to the standard deviation as a measure of size variability. The $\mathrm{CV}$ is a measure of the size of the standard deviation relative to the mean, and corrects for the possibility that larger means should, simply as a function of being larger, have larger standard deviations (see Blalock 1979).

Focusing first on the upper plot in Figure 9-4, note that while there is some overlap between the two sites, the stone material groups in site 41TV163 are in general both substantially larger and more variable than the 41PR44 groups. The three groups in the lower corner of the graph, depicted by triangles (small size, low variation), are all from 41PR44. There is some overlap in the middle section of the plot, with four groups representing 41TV163 and two groups representing 41PR44 materials. Finally, in the upper quadrant of the graph, the area with largest size and variation (depicted by circles), 10 of the 11 material groups are from 41TV163. The single case from 41PR44 is group 12, which has a relatively small range but high variability (see Table 9-3). An examination of the distribution of maximum length of the 24 items in this group shows that a single case, with a maximum length of $54.81 \mathrm{~mm}$, is present. Twenty-three of the 24 cases are, in fact, below $33 \mathrm{~mm}$ in maximum length. The combination of the small group size $(n=24)$ and the extreme value of this single item substantially inflates both the range, as well as the mean and the standard deviation used in determining the coefficient of variation. The influence of this single case on the group location is clear in the bottom plot of Figure $9-4$, where this single case has been eliminated. The Group 12 plotting of the 23 remaining cases now is within the variation and range shown by the middle group. Overall, then, the 41PR44 data are clearly smaller, with lower variability when compared to a location from the Edwards Plateau. Finally, note that the bottom plot in Figure 9-4 presents the "local" and "non-local" groups as defined at 41TV163. That is, the middle, "non-local" group, at least from the perspective of 41TV163, overlaps with the upper end of the 41PR44 data set. That overlap, along with the general size and variability patterns seen for all 20 material groups, is consistent with suggestions made earlier regarding the impacts of raw material availability.

Debitage at 41PR44 are, then, generally much smaller and less variable in size when compared to 41TV163. We now consider a second variable, dorsal cortex cover, for the eight raw material groups. Dorsal cortex was recorded in one of six categories $(0 \%, 1-25 \%, 26-50 \%, 51-75 \%, 76-99 \%$, and $100 \%$ ) for each piece of debitage. Recall that the use of a material group in a transport strategy should produce debitage assemblages dominated by non-cortical debris, while a reliance on local stone should produce lower 
Table 9-2. Descriptions of Raw Material Types Observed in Debitage at 41PR44

\begin{tabular}{|c|c|}
\hline $\begin{array}{c}\text { Type/ } \\
\text { Group No. }\end{array}$ & Description \\
\hline 2 & $\begin{array}{l}\text { Chert; } 10 \text { YR } 4 / 2 \text { dark yellowish brown; } 10 \text { YR } 6 / 2 \text { pale yellowish brown; } 10 \text { YR } 5 / 4 \text { moderate yellowish } \\
\text { brown; a few slightly translucent a few opaque; inclusions are frequently present; } 51 \text { items. }\end{array}$ \\
\hline 3 & $\begin{array}{l}\text { Chert; } 10 \text { YR } 7 / 4 \text { grayish orange; } 10 \text { YR } 5 / 4 \text { moderate yellowish brown; } 10 \mathrm{YR} 6 / 2 \text { pale yellowish brown. } \\
\text { Gradient in color change, where one piece frequently has two or more colors. Opaque; few inclusions; } 14 \\
\text { items. }\end{array}$ \\
\hline 4 & $\begin{array}{l}\text { Chert; } 10 \text { YR } 7 / 4 \text { grayish orange; } 10 \text { YR } 6 / 2 \text { pale yellowish brown, } 5 \mathrm{RP} 6 / 2 \text { pale red purple; inclusions; a } \\
\text { gradient of color can be seen on a single piece; opaque; } 60 \text { pieces. }\end{array}$ \\
\hline 5 & $\begin{array}{l}\text { Chert; } 10 \text { YR } 8 / 2 \text { very pale orange; } 10 \text { YR / } 2 \text { pale yellowish brown; } 10 \text { YR } 5 / 4 \text { moderate yellowish brown; } \\
\text { inclusions; opaque; } 208 \text { items. }\end{array}$ \\
\hline 6 & $\begin{array}{l}\text { Chert; } 10 \text { YR } 6 / 2 \text { pale yellowish brown; } 10 \text { YR } 4 / 2 \text { dark yellowish brown; } 10 \text { YR } 6 / 6 \text { dark yellowish } \\
\text { orange; translucent; occasional inclusions; } 119 \text { pieces. }\end{array}$ \\
\hline 7 & $\begin{array}{l}\text { Chert; } 10 \text { YR } 4 / 2 \text { dark yellowish brown; } 10 \text { YR } 2 / 2 \text { dusky yellowish brown; N/ } 7 \text { medium dark gray; } \\
\text { minimal inclusions; opaque; } 12 \text { pieces. }\end{array}$ \\
\hline 8 & $\begin{array}{l}\text { Chert; } 10 \text { YR } 6 / 6 \text { dark yellowish orange; 10YR } 5 / 4 \text { moderate yellowish brown; inclusions; translucent; } 3 \\
\text { pieces. }\end{array}$ \\
\hline 9 & Quartzite; 5Y 8/1 yellowish gray, translucent; 10YR 5/4 moderate yellowish brown, opaque; 6 pieces. \\
\hline 10 & $\begin{array}{l}\text { Chert; burned material with wide range of colors; N7-light gray, opaque; } 5 \text { YR } 7 / 2 \text { grayish orange pink, } \\
\text { opaque; 10R } 2 / 2 \text { very dusky red, opaque; 10YR 5/5 yellowish brown, inclusions, opaque; } 10 \text { YR } 2 / 2 \text { dark } \\
\text { yellowish brown, opaque; 10R 3/4 dark reddish brown, opaque; } 119 \text { items. }\end{array}$ \\
\hline 11 & $\begin{array}{l}\text { Chert; 10YR 6/2 yellowish brown, inclusions, opaque; 10YR 6/6 dark yellowish brown, opaque; } 210 \\
\text { items. }\end{array}$ \\
\hline 12 & $\begin{array}{l}\text { Chert; } 10 \text { YR } 6 / 2 \text { pale yellowish brown, translucent; } 10 \text { YR } 5 / 4 \text { moderate yellowish brown, minimal } \\
\text { inclusions, opaque. } 5 \text { YR } 7 / 2 \text { grayish orange pink, opaque; } 24 \text { pieces. }\end{array}$ \\
\hline 15 & $\begin{array}{l}\text { Chert 10YR dark yellowish brown, opaque; 10YR moderate yellowish brown, translucent, no inclusions; } \\
5 \text { items. }\end{array}$ \\
\hline 17 & Chert mottled in color; 10 YR $8 / 2$ very pale orange; 10 YR pale yellowish brown, opaque; 3 pieces. \\
\hline 18 & $\begin{array}{l}\text { Chert, mottled in color; } 5 \mathrm{Y} \text { yellowish gray w/ 10YR 5/4 moderate yellowish brown, opaque. } 10 \mathrm{YR} 5 / 4 \\
\text { moderate yellowish brown w/ 10YR } 4 / 2 \text { dark yellowish brown, opaque; } 5 \text { pieces. }\end{array}$ \\
\hline 19 & $\begin{array}{l}\text { Chert, other. Consists of a variety of diverse types, usually represented by no more than two items, per } \\
\text { type. In most cases, each piece is unique; } 44 \text { pieces. }\end{array}$ \\
\hline
\end{tabular}

decorticate assemblages, with the presence of flakes with high cortex in all size ranges. Table 9-4 presents the counts for the cortex classes by material type. A chi-square test suggests that there is a significant relationship between cortex coverage and raw material groups $\left(\mathrm{X}^{2}=156.08\right.$; $\mathrm{df}=35 ; \mathrm{p}>.0001)$.
Of much more interest than the overall chi-square results, however, are the adjusted standardized residuals included just below the observed counts for each cell in Table 9-4. As discussed by several authors (see Everitt 1977; Haberman 1973) adjusted standardized residuals provide information on the contribution of each cell to the overall significance of a chi-square test. Adjusted residuals are 
Table 9-3. Maximum Size Data for Chipped Stone Raw Material Groups at 41PR44

\begin{tabular}{|c|c|c|c|c|c|}
\hline Material Group & $\begin{array}{c}\text { Number of } \\
\text { Items }\end{array}$ & $\begin{array}{c}\text { Mean Size } \\
\mathbf{( m m})\end{array}$ & $\begin{array}{c}\text { Median } \\
\text { Value }(\mathbf{m m})\end{array}$ & $\begin{array}{c}\text { Standard } \\
\text { Deviation }\end{array}$ & Range (mm) \\
\hline 2 & 51 & 21.39 & 19.31 & 8.86 & 34.56 \\
\hline 4 & 60 & 20.55 & 19.57 & 6.77 & 24.43 \\
\hline 5 & 208 & 18.72 & 17.16 & 7.61 & 41.27 \\
\hline 6 & 119 & 13.64 & 12.45 & 4.23 & 22 \\
\hline 10 & 119 & 15.92 & 14.3 & 5.79 & 29.89 \\
\hline 11 & 210 & 16.17 & 14.81 & 5.66 & 32.1 \\
\hline 12 & 24 & 18.4 & 15.93 & 10.49 & 48.24 \\
\hline 19 & 92 & 17.2 & 14.96 & 9 & 58.5 \\
\hline Total & $\mathbf{8 8 3}$ & $\mathbf{1 7 . 1 6}$ & $\mathbf{1 5 . 3 4}$ & $\mathbf{7 . 1 7}$ & $\mathbf{5 9 . 7}$ \\
\hline
\end{tabular}

analogous to $\mathrm{Z}$ scores in that adjusted residual values exceeding an absolute value of 1.96 suggest that the individual cell is significant at a probability beyond the .05 level, while values exceeding \pm 1.65 are significant at or beyond the .10 level. Adjusted residual values in 23 cells are significant at the .10 probability level, and 19 of these (highlighted in bold text) continue to be significant at .05. Those adjusted residuals that are bold and negative, then, have significantly fewer than expected items present in that cell at the .05 level. Those that are positive and bold have significantly more than expected items present.

Examination of Table 9-4 will show that raw material Groups 2, 4, and 5 all have significantly fewer flakes lacking cortex than expected with adjusted residual values ranging from -2.88 to -5.63 . For the combined totals in these three groups, only $44.2 \%(n=141)$ of the 319 items lack cortex. In contrast, the overall percentage of non-cortical debitage at a site level is $60.9 \%$. All also have a significant overrepresentation in several cortex classes, with counts in seven of the 15 cortex cells being significantly overrepresented at the .10 level, and four of these seven being significant at the .05 level. Groups 2, 4, and 5, then, seem to fit the expected pattern for the use of local materials. In contrast to these three groups, adjusted residuals in Table 9-4 for Groups 6 and 11 have significantly more than expected tertiary flakes. Together, $79 \%(n=260)$ of the 329 items in these two groups lack cortex. In addition, both groups are significantly underrepresented in cortical flakes in several cortex classes, with Group 6 having only nine cortical flakes in the assemblage, and having no flakes with more than 50\% cortex. Groups 6 and 11 are consistent with the expectation for debitage created from transported, previously decorticated blanks or cores.
As with the size data, interpretations of the patterns of cortex shown in Table 9-4 for Group 10 and Group 19 are complicated by the nature of these groups. Recall that Group 10 reflects heated specimens with an associated color change that rendered real group assignments impossible. Only one of the cells in this group, cortex flakes in the $1-25 \%$ range, is significantly overrepresented. Similarly, Group 19, which probably contains both local and non-local debitage, is difficult to interpret. Two cells are significant at the .05 level, with less than expected counts in the $1-25 \%$ cortex coverage cell, and more than expected counts in the $100 \%$ cortex coverage cell. Interestingly, three of the 8 items (ca. 38\%) in the latter category are quartzite, a material that is probably local. Finally, note that Group 12 material lacks any significant cells. No interpretation of this particular material group, then, is possible.

Considering both size attributes and dorsal cortex coverage, we can suggest that roughly $36 \%$ of the debitage recovered from 41 PR44 reflects the use of local stone. About 37\% can be assigned to non-local stone. Groups 10, 12, and 19, representing about $27 \%$ of the debitage could not be assigned to either strategy, though Group 19 certainly contains some items (e.g., quartzite) that are probably associated with local acquisition.

Additional data on the use of local and non-local materials at 41PR44 is reflected in the tools. To the degree that a transport strategy is used, we might expect that within the non-local material groups, bifaces and projectile points will be overrepresented relative to the use of these stone types in edge-modified or utilized flakes. This suggestion is primarily related to the expectation that when transported, items will often arrive at a location in forms that are finished 


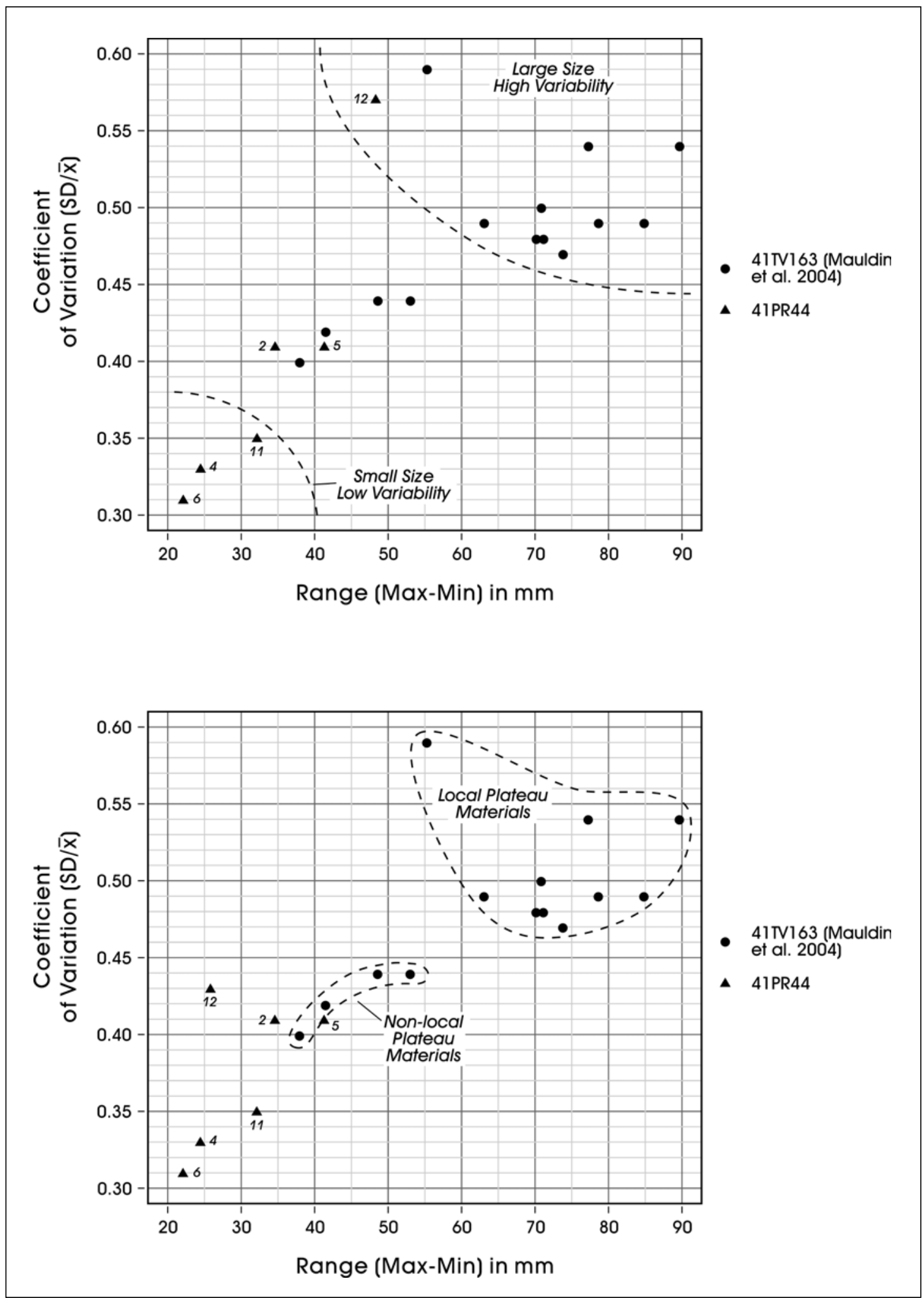

Figure 9-4. Comparison of size variation and range for material groups at $41 P R 44$ and $41 T V 163$. 
Table 9-4. Observed Counts for Material Groups and Dorsal Cortex Coverage at 41PR44

\begin{tabular}{|c|c|c|c|c|c|c|c|c|c|}
\hline \multirow{2}{*}{$\begin{array}{c}\text { Group } \\
\text { No. }\end{array}$} & & \multicolumn{6}{|c|}{ Cortex Grouping } & \multirow[b]{2}{*}{ Total } & \multirow[b]{2}{*}{$\%$} \\
\hline & & $\mathbf{0}$ & 12 & 36 & 62 & 87 & 100 & & \\
\hline \multirow[t]{2}{*}{2} & Count & 16 & 13 & 9 & 2 & 4 & 7 & 51 & 5.8 \\
\hline & Adjusted Residual & -4.46 & 1.83 & 1.78 & 0.54 & 0.78 & 3.42 & & \\
\hline \multirow[t]{2}{*}{4} & Count & 16 & 19 & 10 & 3 & 10 & 2 & 60 & 6.8 \\
\hline & Adjusted Residual & -5.63 & 3.34 & 1.68 & 1.13 & 3.97 & -0.38 & & \\
\hline \multirow[t]{2}{*}{5} & Count & 109 & 37 & 33 & 6 & 12 & 11 & 208 & 23.6 \\
\hline & Adjusted Residual & -2.88 & 0.66 & 3.02 & 0.17 & 0.24 & 0.80 & & \\
\hline \multirow{2}{*}{6} & Count & 110 & 7 & 2 & 0 & 0 & 0 & 119 & 13.5 \\
\hline & Adjusted Residual & 7.57 & -3.31 & -3.33 & -1.96 & -2.81 & -2.49 & & \\
\hline \multirow[t]{2}{*}{10} & Count & 65 & 27 & 9 & 3 & 10 & 5 & 119 & 13.5 \\
\hline & Adjusted Residual & -1.52 & 2.03 & -1.06 & -0.14 & 1.53 & -0.06 & & \\
\hline \multirow[t]{2}{*}{11} & Count & 150 & 31 & 15 & 7 & 3 & 4 & 210 & 23.8 \\
\hline & Adjusted Residual & 3.57 & -0.69 & -1.73 & 0.63 & -2.93 & -1.96 & & \\
\hline \multirow[t]{2}{*}{12} & Count & 16 & 2 & 4 & 0 & 1 & 1 & 24 & 2.7 \\
\hline & Adjusted Residual & 0.58 & -1.07 & 1.04 & -0.83 & -0.28 & -0.03 & & \\
\hline \multirow[t]{4}{*}{19} & Count & 56 & 8 & 9 & 3 & 8 & 8 & 92 & 8.8 \\
\hline & Adjusted Residual & -0.01 & -2.09 & -0.17 & 0.34 & 1.46 & 2.19 & & \\
\hline & Count & 538 & 144 & 91 & 24 & 48 & 38 & 883 & \\
\hline & $\%$ of Total & 60.9 & 16.3 & 10.3 & 2.7 & 5.4 & 4.3 & & 100 \\
\hline
\end{tabular}

$X^{2}=156.08 ; d f=35 ; p>.0001$

tools or bifaces rather than utilized flakes. The more formal tools (projectile points, bifaces, unifaces) are likely to be curated given that they are more expensive in terms of both material acquisition and labor involved in production. While broken bifaces, points, and unifaces can certainly be recycled into informal tools (e.g., edge-modified, utilized flakes), fewer of these recycled items are likely to be produced if those non-local forms are already in a finished or partially finished state. These suggestions are partially supported by the 41PR44 tools, but the sample sizes are small. Twelve of the 13 tools made on non-local materials are formal $(92.3 \%)$. However, this tool group also dominates in local materials as 13 of the 16 tools made from local stone $(81.25 \%)$ are formal. While this difference of $10 \%$ is in the anticipated direction, the small sample size renders any conclusions regarding tools, tentative.

Despite the ambiguity in the tool data noted previously, the pattern in cortex percentages and debitage variability and size clearly suggests that both local stone, as well as transported raw materials, are present at 41PR44. That is, both strategies outlined previously in Chapter 4 were used to solve raw material shortfalls. While, at a site level, we are unable to classify about $27 \%$ of the 833 items as representing either a local or non-local source, the debitage that can be classified into one of these two groups $(n=648)$ is evenly split with 319 items (49.2\%) reflecting local stone, and 329 items $(50.8 \%)$ probably coming from non-local sources.

\section{The Late Archaic and Early Late Prehistoric Patterns at 4IPR44}

In the previous section, we established that the occupants of 41PR44 relied on both local raw materials as well as non-local materials transported, probably in a finished or reduced form, to address tool stone needs. The previous discussion has been based simply on spatial differences, 
defined by differences in access to quality stone for tool production. In this section, however, we explore changes in stone procurement strategies through time at 41PR44.

In Chapter 7, we argued that deposits dating to the early portion of the Late Prehistoric period can be isolated at the site. In addition, we presented data that suggested a primarily Late Archaic occupation was present, though given small faunal samples, the temporally ambiguous point types in some locations of the site, the presence of several earlier point forms, and the questionable geomorphic context in other locations, we chose to group faunal material as simply "Archaic" in age (see Chapters 7 and 8). When considering debitage, however, we can refine the long "Archaic" designation to some extent, as we have a large sample of chipped stone for one area that we can confidently assign to the Late Archaic. We focus, then, on comparisons of the tool stone composition of the early Late Prehistoric deposits from Area 1 (see Chapter 7; also Figure 7-4 and Table 7-1) with the Late Archaic material from the lower levels of Area 2 (see Chapters 6 and 7; Figure 7-4). Both areas have small, but adequate sample sizes, with 137 pieces of debitage coming form the Late Prehistoric deposits, and 253 items associated with the Late Archaic deposits in Area 2. Both areas are also reasonably well dated. The upper portions of Area 1 has several Scallorn points and a radiocarbon date that place these deposits between about 700 and 1100 BP. The Late Archaic age of the middle and lower levels in Area 2 are supported by two radiocarbon dates and two projectile point fragments, one of which is a Late Archaic Marshal point and one of which is a base consistent with a Marshal form. We suggested in Chapter 7 that these Area 2 deposits span a period from sometime between 3500 and $2000 \mathrm{BP}$.
Table 9-5 presents the number of debitage, by material group, for the Late Prehistoric and Late Archaic deposits defined above. While the overall chi-square value for the table is significant $\left(\mathrm{X}^{2}=126.83, \mathrm{df}=7, \mathrm{p}>.0001\right)$, standardized adjusted residuals, provided below the observed count in each cell, are our main focus. As with Table 9-4, adjusted residuals that are significant are identified in bold text. Note that the residuals in a given column in Table 9-5 are mirror images. This reflective property is simply a function of the two row table. While this limits the interpretive power of the residuals, note that all three local materials (Groups 2, 4, 5) are significantly underrepresented (or significantly overrepresented in the Late Archaic). Conversely, in the non-local materials, Group 11 is significantly overrepresented in the Late Prehistoric (or underrepresented in the Late Archaic). Within the unknown material groups (10,12 and 19), two $(10,19)$ are significantly different from expectations, though the patterns cannot be easily interpreted given the mixed character of these groups.

Figure 9-5 presents the Table 9-5 data in a slightly different way, focusing on the relative contributions for local, non-local, and unknown materials in the assemblages of the Area 2 Late Archaic (red) deposits, and the early Late Prehistoric (blue) material. Clearly, the Late Archaic debitage is dominated by the use of local stone, with almost $80 \%$ of the chipped stone being from these sources. At least for this one Late Archaic area at 41PR44, there is little evidence of the transportation of previously reduced bifaces or finished tools. The Late Prehistoric material has a dramatically different pattern, with more non-local than local stone present in the debitage. To the degree that the frequency of debitage recovery from local and non-local

Table 9-5. Observed Counts of Local, Unknown, and Non-local Materials by Temporal Period

\begin{tabular}{|c|c|c|c|c|c|c|c|c|c|c|}
\hline \multirow[b]{2}{*}{ Period } & \multirow[b]{2}{*}{ Group No. } & \multicolumn{3}{|c|}{ Local Material } & \multicolumn{3}{|c|}{ Unknown Material } & \multicolumn{2}{|c|}{ Non-Local Material } & \multirow[b]{2}{*}{ Total } \\
\hline & & 2 & 4 & 5 & 10 & 12 & 19 & 6 & 11 & \\
\hline \multirow{2}{*}{$\begin{array}{c}\text { Late } \\
\text { Prehistoric }\end{array}$} & Count & 3 & 2 & 36 & 21 & 5 & 16 & 12 & 42 & 137 \\
\hline & $\begin{array}{l}\text { Adjusted } \\
\text { Residual }\end{array}$ & -3.94 & -5.14 & -3.35 & 4.37 & -0.33 & 4.32 & 0.16 & 7.41 & \\
\hline \multirow{2}{*}{$\begin{array}{l}\text { Late } \\
\text { Archaic }\end{array}$} & Count & 38 & 51 & 110 & 8 & 11 & 4 & 21 & 10 & 253 \\
\hline & $\begin{array}{l}\text { Adjusted } \\
\text { Residual }\end{array}$ & 3.94 & 5.14 & 3.35 & -4.37 & 0.33 & -4.32 & -0.16 & -7.41 & \\
\hline Total & Count & 41 & 53 & 146 & 29 & 16 & 20 & 33 & 52 & 390 \\
\hline
\end{tabular}

$\mathrm{X}^{2}=126.83, \mathrm{df}=7, \mathrm{p}>.0001$ 
stone resources is reflecting the frequency of different acquisition strategies, a reliance on previously reduced bifaces, tools, and decorticate cores is much more common during the early Late Prehistoric at 41PR44.

The degree to which such changes are characteristic of other Late Archaic deposits at 41PR44, let alone other Late Prehistoric and Late Archaic deposits from other sites in the region, clearly requires investigation. Given the sample sizes available at the site, the patterns shown could simply reflect short term, tactical responses to immediate, unanticipated needs rather than any strategic change in the way that stone was procured or the way that mobility was organized. Nevertheless, the shift in raw material sources, and by implication the shift in the contribution of different procurement strategies seen at 41PR44, may also be reflecting different strategic responses. While any such suggestion would have to be documented at other sites in the region, a strategic shift in organization, such as an increased reliance on task-specific groups during the early
Late Prehistoric relative to a more generalized Late Archaic pattern, is also consistent with these data.

\section{Summary}

This chapter has investigated the impact of differential access to high quality raw materials on chipped stone assemblages at 41PR44. The site is located in a section of the state with impoverished stone resources. The small size of the debitage, a high frequency of cortex, and a tool assemblage that is small and fragmentary at this site clearly reflects limited access to high quality stone resources. Occupants of 41PR44 were faced with developing coping strategies for reducing the impact of stone shortage. We suggested that at a site level, a combination of a reliance on local, lower quality stone as well as the transportation of finished tools, bifaces, and partially decorticate cores to the site, were used. Focusing on temporal differences within the site, we further suggested that, at least for these particular

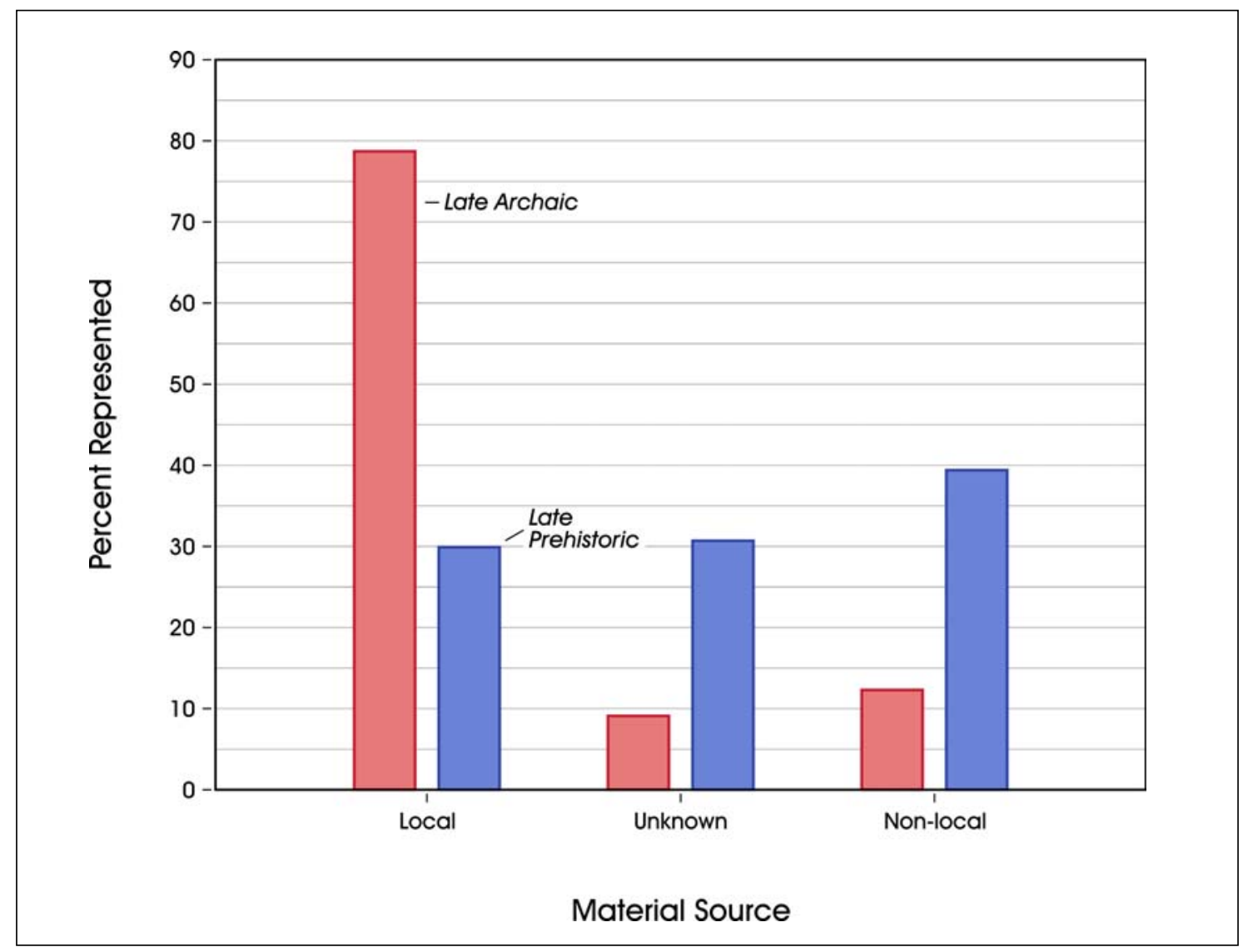

Figure 9-5. Raw material sources for Late Archaic (red) and Late Prehistoric (blue) assemblages at 41PR44. 
deposits, early Late Prehistoric occupants relied more heavily on a transport strategy, while the Late Archaic populations at 41PR44 were using local stone. While these differences may simply reflect short term tactical responses, they may also reflect a larger scale, adaptive change.

Finally, note that regardless of the degree to which the documented shift reflects short term tactical responses, or long term strategic shifts, the focus on raw material size has a number of implications for interpretation of chipped stone assemblages. For example, tertiary (i.e., non-cortical) flakes in the Late Archaic deposits in Area 2 of the site make up $41.9 \%$ of the debitage, while flakes with cortex covering more than $50 \%$ of their dorsal surface account for $21.7 \%$. In contrast, in the Late Archaic deposits at 41TV163, tertiary flakes account for $85.5 \%$ of the assemblage, with only $2.8 \%$ of the Late Archaic material having more than $50 \%$ of their dorsal surface covered by cortex (see Mauldin et al. 2004:85). The extremely low tertiary percentage in the 41PR44 deposits, as well as the high percentage of flakes with more than $50 \%$ cortex, would commonly be interpreted as reflecting an extremely high frequency of early stage reduction. In contrast, the percentages from 41TV163 would be seen as clearly reflecting late stage reduction, with little emphasis on initial reduction activities. The patterns documented previously in this chapter suggest that both of these reductions could conceivably reflect the same reduction trajectory, one relying on small cobbles and a second relying on much larger stone. Said in a slightly different way, we are suggesting that a frequency of $75 \%$ tertiary flakes in South or East Texas may mean something radically different than that same percentage in Central Texas. 



\section{Chapter 10: Burned Rock Features}

This chapter investigates burned rock features at 41PR44. Research into the use of rock features has seen considerable development over the last decades (e.g., Black et al. 1998; Black 2003; Dering 1999; Ellis 1997; Wandsnider 1977). We anticipated such features would be common at 41PR44. As outlined in Chapter 3, testing on the site had been limited, with a reliance on backhoe trenching and shovel testing. While only two 1-x-1-m units had been hand-excavated, both produced burned rock features (see Brownlow 2001). The probability of discovering and excavating numerous features, each with the potential to provide chronologically grounded information on technology and subsistence, was a primary research interest when CAR began work. During our fieldwork it became apparent that reddened, angular sandstone and, to a lesser degree, limestone rocks were common in the site deposits. These rocks often appeared in clusters, and were frequently associated with artifacts and, in several cases, had burned bone and darkened sediment present. During our field work, CAR archaeologists defined 12 burned rock features at 41PR44.

However, our project geoarchaeologist, Dr. Russell Greaves, suggested that in all cases, the rock clusters identified as cultural features by CAR, as well as those identified previously by TARL, had a high probability of representing natural accumulations of unburned rock as well as re-deposited burned rock and artifacts. We were initially skeptical of these suggestions. However, Greaves makes a convincing case in Chapter 6 of this report that at least some of these features are in less than ideal geomorphic context. When combined with our observations in the field, it became apparent we needed to develop an independent method to assess burning. We needed to know when rocks had been heated and what clusters of burned rock were the results of cultural rather than natural processes. The initial portion of this chapter is specifically concerned with that identification method which relies on changes in magnetic susceptibility of crushed sandstone rock and sediment that occur when heated. The procedure is time consuming, and therefore could only be done on a small number of rocks. However, in several cases, at least some of the rock assumed to be in a feature had not been previously heated. In these particular cases, this is strong evidence the clusters were not hearths. When combined with the arguments presented previously in Chapter 6, the magnetic susceptibility testing allowed elimination of nine of the 12 features identified by CAR during fieldwork. In addition, when we excavated adjoining units we found no evidence of Feature 2, a burned rock cluster previously identified by TARL (Brownlow 2001:16-19).

Having developed procedures to identify thermal features on 41PR44, the second section of this chapter explores what these features may represent. Four burned rock features, designated Features 1 (Brownlow 2001), 12, 20, and 21 remain, and we have little information regarding Feature 1, excavated previously by TARL. While we lack absolute dates for these features, all three excavated by CAR probably date prior to the early Late Prehistoric period. In addition, while flotation samples were collected and processed from Features 12, 20, and 21, recovery was minimal (see Appendix C). Our investigation into the nature of the features at 41PR44 is limited by the small sample size and virtually no recovery of carbonized material. Nevertheless, this research can begin to form a baseline that can be expanded by future investigations in this region. Our analysis, which focuses on the total rock weight of features, the distribution of rock size within features, and the stone makeup of features at 41PR44, is designed to provide clues to different types of features that were used by the prehistoric inhabitants of the region.

\section{Identifying Burned Rock and Thermal Features with Magnetic Susceptibility}

In Chapter 6 of this report, Greaves argued that colluvial and alluvial fan deposits from the sandstone ridge on the western side of 41PR44, as well as deposits from Rock Creek, combined to produce the pattern of rock clusters initially identified as cultural features by both TARL and CAR archaeologists. He further argued that sandstone rocks, thought to be burned, were naturally fractured and weathered bedrock. While we were in the field, CAR personnel compared sandstone collected off-site with examples collected from site and feature contexts. In many cases, the off-site sandstone samples were angular and were similar in color to those from site and feature contexts, supporting Greaves' position. Of course, if none of the features were intact cultural entities, then we could dispense with any detailed analysis of materials directly associated with those "features." We needed to develop methods to 
identify which of these accumulations were likely to represent cultural features rather than redeposited cultural material or natural accumulations of weathered sandstone. As several researchers (e.g., Bellomo 1993; Crowther 2003; Dearing 1999; Farwig et al. 2004) had noted that heating of sediment to certain temperature ranges resulted in modifications in magnetic susceptibility values, we turned initially to exploring the potential of documenting magnetic changes as a way to identify contexts that had been heated.

\section{Magnetic Soil Susceptibility Analysis}

Magnetic soil susceptibility (MSS) has been used in a variety of contexts. In archaeological research, it has primarily been used on sediment as a discovery method on survey projects (e.g., Clark 1996), a method to help identify buried soils that may be associated with occupation (e.g., Takac and Gose 1998), and as an aid in identifying heated sediment (Bellomo 1993; Dalan and Banerjee 1998). The magnetic susceptibility of a given sample can be thought of as a measure of how easily that sample can be magnetized (Dearing 1999; Gose and Nickels 2001). While the measure of susceptibility is initially dependent on the mineralogy of a particular sample, that is the concentration and grain size of ferro- and ferrimagnetic minerals, a number of processes can result in an increase in MSS values in a sediment sample. These processes include an increase in the organic constitutes of the sediment and changes in the mineralogy of sediments in a given sample (see Collins et al. 1994; McClean and Kean 1993; Singer and Fine 1989). Sediments with higher organic content tend to have higher magnetic susceptibility values, probably as a result of the production of maghemite, an iron oxide, during organic decay (Reynolds and King 1995). Pedogenic processes, such as soil formation and weathering, can result in the concentration of organic material, as well as alterations in the mineralogy of a given zone. These processes can significantly increase susceptibility readings. Cultural processes, such as the concentration of ash, charcoal, and organic refuse, would also produce higher MSS readings.

Of specific concern here are modifications in magnetic susceptibility values related primarily to changes in mineralogy of sediments as a function of heating (see Bellomo 1993; Crowther 2003; Dearing 1999; Farwig et al. 2004). Magnetic alteration seems to be related to both modification in grain size and to mineralogical changes in iron rich minerals that occur with increasing temperatures
(Crowther 2003). The temperature at which transformation occurs is variable depending on specific minerals comprising the sample, as well as the duration and conditions of heating, the amount of organic matter in the sample, and the water content of the sample (Dearing 1999). Transformation may occur as low as $200^{\circ} \mathrm{C}$ and may continue up to temperatures over $900^{\circ} \mathrm{C}$ in some sediment (Farwig et al. 2004). While heated samples will frequently show an enhancement, note that heating may, depending on the makeup of the sample, also result in a decrease in susceptibility. This process is usually associated with the changes in maghemite to hematite at temperatures of around $300^{\circ} \mathrm{C}$ (Dearing 1999). While the specific changes are somewhat unpredictable, it is the case that alterations in magnetic parameters of sediment produced by heating have been used by several archaeological researchers to identify and investigate differences in natural and cultural fire events (e.g., Bellomo 1993). Here, we explore the potential of alterations in the magnetic susceptibility values of both sediment and sandstone from features at 41PR44 as an independent method for identifying cultural relative to natural features.

\section{Procedures}

All samples discussed in this chapter were processed in the CAR laboratory. Sediment samples were air dried on a non-metal surface. After drying, sediment samples were ground to a uniform grain size using a ceramic mortar and pestle. For sandstone specimens, rocks were initially broken using a hard rubber hammer and a wooden block. These broken specimens were then crushed using the ceramic mortar and pestle. In the case of both sediment and rock, this was done to standardize particle size and make the material both easier to handle and pack into sample containers. After each sample was prepared, the mortar and pestle were washed with tap water and wiped dry with a paper towel to avoid cross-sample contamination. The ground samples were then poured into sample containers consisting of plastic cubes with external dimensions of $2.54-\mathrm{x}-2.54-\mathrm{x}-1.94 \mathrm{~cm}$. The cubes have an average weight of $4.85 \mathrm{~g}$. The sediment or crushed rock filled cube was then weighed, and the weight of the sample calculated by subtracting the empty cube weight. This was done to correct for differences in mass. Assuming that sample volume and material is constant, larger samples should have higher susceptibility values simply as a function of greater mass. 
The cube was then placed into a MS2B Dual Frequency Sensor that, in conjunction with a MS2 Magnetic Susceptibility Meter, provided a measure of the magnetic susceptibility of the sample (see Dearing 1999). For each cube, two readings were taken using the SI (standard international) scale, and the values were averaged. The resulting average value, referred to as volume specific susceptibility and noted with the symbol K (Kappa), was recorded on a scale of $10^{-5}$, though there are no units associated with the value. That is, the value is dimensionless (Dearing 1999).

In order to correct for differences in sample weight, and provide units to the value $K$, the mass-specific susceptibility value $(\mathrm{X})$ was calculated using the formula

$$
\mathrm{x}=(\mathrm{K} / \mathrm{p})
$$

where $\mathrm{p}$ is the sample bulk density expressed in $\mathrm{kg} \mathrm{m}^{-3}$. The bulk density is determined by dividing the sample mass by volume. However, as all samples were measured in identical cubes, and all cubes were full, the sample volume is assumed to be constant. Only the mass of the sample varied. Mass-specific susceptibility can be determined by

\section{$\mathbf{x}=\mathrm{K}^{*}$ calibrated mass/sample mass}

where sample mass is determined by subtracting the cube weight from the total sample weight (Dearing 1999). Calibrated mass is assumed to be $10 \mathrm{~g}$.

While the resulting values now have both a scale and associated units, the critical element for the current discussion is related to relative differences between sample values as a result of exposure to heat. That is, the principal interest here is in changes in the mass-specific susceptibility values when either sediment or crushed sandstone is heated to a given temperature.

\section{Experimental Samples}

In order to investigate the impacts of heating on sediments, a series of controlled heating experiments were undertaken at CAR. Initially, the magnetic susceptibility values of four unheated sediment samples, collected from a single source in the San Antonio area, were determined using the measurement procedures outlined above. Each sample was then heated at a temperature of $400^{\circ} \mathrm{C}$ for one hour in a
Therolyne FB1300 furnace. Sediment was removed from the furnace and allowed to cool for a minimum of two hours. After cooling, the magnetic susceptibility of the sample was again measured. This procedure was repeated at temperatures of $500^{\circ} \mathrm{C}$ and $600^{\circ} \mathrm{C}$. The temperature ranges are derived, in part, from readings on modern small hearths that suggest post-firing temperatures average between $500^{\circ} \mathrm{C}$ and $300^{\circ} \mathrm{C}$ for as much as six hours after firing (see Mauldin et al. 1998:128-130). In addition, changes in magnetism of sediment are expected, based on mineralogy, to occur most commonly between temperatures of $300^{\circ} \mathrm{C}$ and $600^{\circ} \mathrm{C}$ (see Crowther 2003; Dearing 1999).

Figure 10-1 (top) presents the results of these initial heating experiments. Heating the sediment to $400^{\circ} \mathrm{C}$ produced an average enhancement of $24.25 \%$ over the original, unheated values. At $500^{\circ} \mathrm{C}$, that enhancement was $33.09 \%$, and by $600^{\circ} \mathrm{C}$, the average was $31.77 \%$. Note, however, that not all sediment will necessarily respond in this same way. The degree of increase should be dependent on the initial mineralogy of the sample, as well as the heating conditions. This can be seen in the bottom plot in Figure 10-1. Here, we plot the results of a second heating experiment using a different sediment source from the San Antonio area. Heating was conducted in 50 -degree increments from $300^{\circ} \mathrm{C}$ to $550^{\circ} \mathrm{C}$. The percentage increase over the unheated sample at $400^{\circ} \mathrm{C}$ is $16.3 \%$, slightly lower than that seen in the top portion of Figure $10-1$. However, above $400^{\circ} \mathrm{C}$ the increase in magnetic enhancement is substantially greater than that shown previously, with an increase of over $100 \%$ at $500^{\circ} \mathrm{C}$, and an increase of over $300 \%$ at $550^{\circ} \mathrm{C}$.

Figure 10-2 presents a final example of changes in sediment as a function of heating. Here, we measured, and then heated, sediment collected from 41PR44. The particular sample was from about $2.5 \mathrm{~m}$ west of Feature 12, a burned rock feature recorded by CAR (see Chapter 5). The sample was collected from a similar depth as the feature. The sample was heated to $400^{\circ} \mathrm{C}$, then allowed to cool. The sample was then heated to $500^{\circ} \mathrm{C}$, allowed to cool, and magnetic susceptibility was again recorded. As can be seen in the Figure 10-2 plot, each heating resulted in an increase in susceptibility values, though the relative increase in the 41PR44 sample was less than those seen in either of the Figure 10-1 plots at similar temperatures. The differences in the magnetic enhancements in the two Figure 10-1 samples, as well as the sample from 41PR44 (Figure 10-2), are probably related to different characteristics of the sediment, including different minerals that react at varying temperatures (see Dering 1999). 


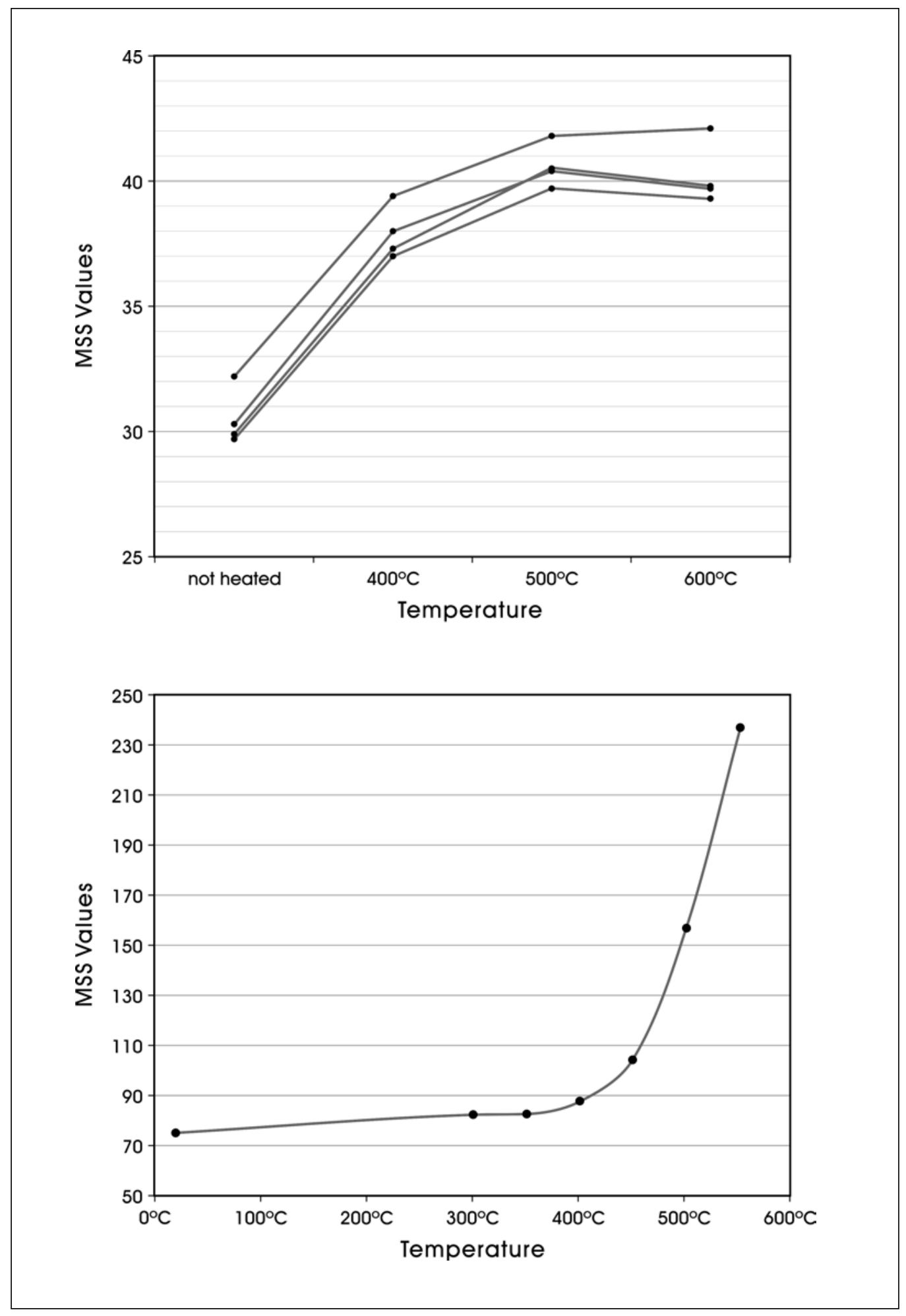

Figure 10-1. Mass-specific magnetic soil susceptibility values from various sources. 


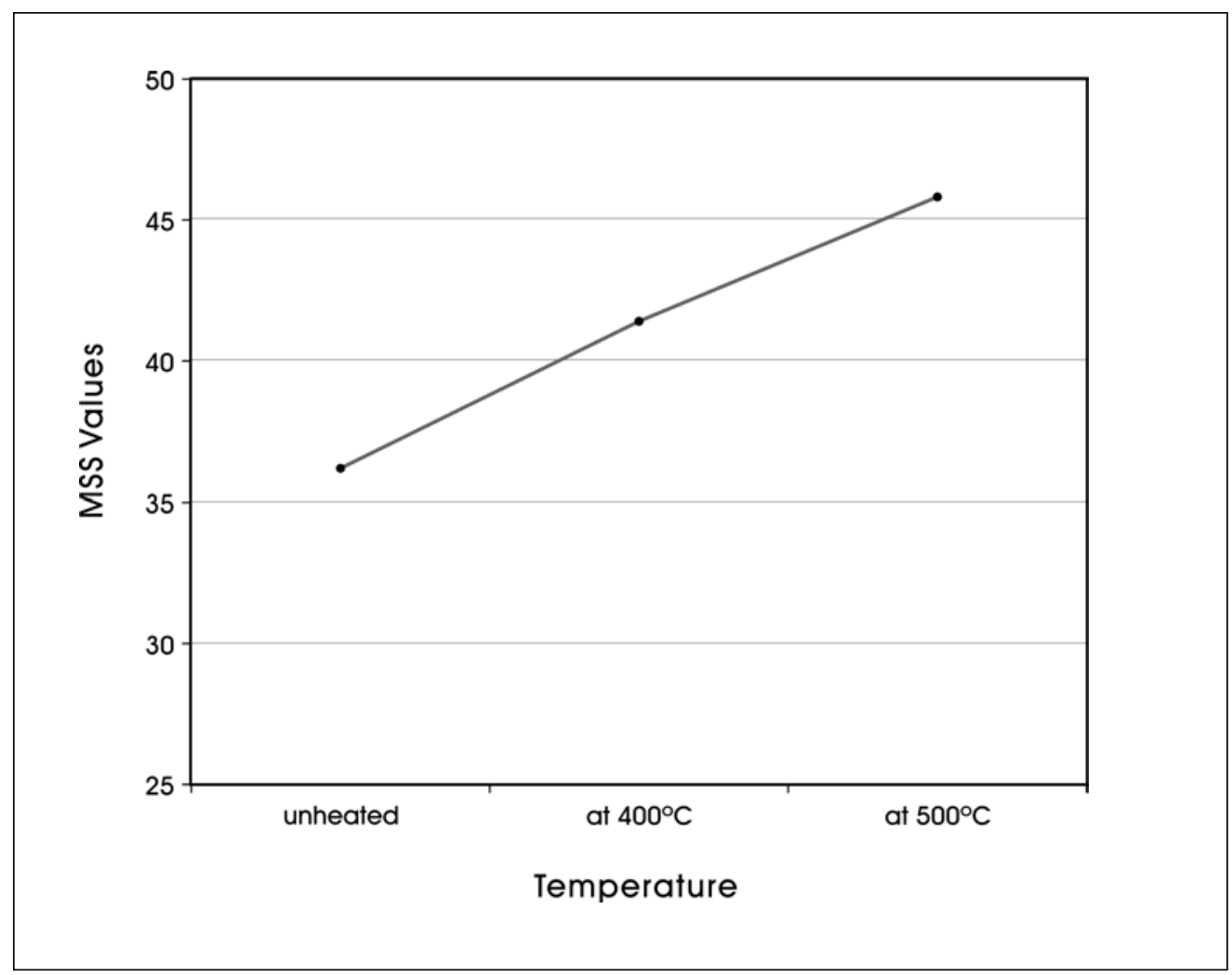

Figure 10-2. Mass-specific magnetic susceptibility values for sediment collected from near Feature 12, 41 PR44.

The initial experiments on magnetic enhancement in sediment were encouraging. Heating at temperatures above $300^{\circ} \mathrm{C}$ seemed to consistently result in some level of enhancement. These results were consistent with early work on alterations in magnetic susceptibility in sediment as a result of heating (see Bellomo 1993; Crowther 2003; Farwig et al. 2004). Experiments to assess the impact of heating on the magnetic susceptibility of sandstone were also conducted. Several off-site samples of sandstone, including samples from the ridge located to the west of the site, were collected. Following the procedures outlined above, eight samples from various locations around 41PR44 were crushed, and the magnetic susceptibility measured. Values ranged from between 1.23 and 5.24, with a median value of 2.015 and a mean value of 2.49. These samples were then heated following the procedures summarized previously for sediments. Samples were heated in 100-degree increments between $300^{\circ} \mathrm{C}$ and $500^{\circ} \mathrm{C}$, with magnetic susceptibility values calculated after each heating event. Figure 10-3 presents the resulting curves for the eight samples.
Examination of the plots will document that while in each case heating resulted in an enhancement in the magnetic susceptibility of the sandstone, there is considerable variability in both the starting MSS value as well as the rate of increase. For example, the percentage increases at $400^{\circ} \mathrm{C}$, which is provided as an insert on the lower left of each of the sample plots in Figure 10-3, shows a range of enhancement from as low as $67 \%$ (Sample 6) to as high as $7,906 \%$ (Sample 3). Similar variation is present at both $300^{\circ} \mathrm{C}$ and at $500^{\circ} \mathrm{C}$. Essentially three different heating curves are present in the figure, with Samples 1, 2, 3, 4, and 8 having rapid increased in MSS values at $300^{\circ} \mathrm{C}$. Enhancements to original values are all in excess of $700 \%$ between the unheated and heated values. After $300^{\circ} \mathrm{C}$, enhancements continue but at a lower rate, with a general leveling off, or even a decline (e.g., Figure 10-3:Samples 1,2 , and 8) in MSS values, after $400^{\circ} \mathrm{C}$. A second group, reflected by Samples 5 and 6 (Figure 10-2), show a pattern of slower, but consistent increase throughout the heating events. By $400^{\circ} \mathrm{C}$, the minimum increase over the initial value is $67 \%$ (Sample 6), and both samples exhibit a 
continued, steady rise up to $500^{\circ} \mathrm{C}$ where heating was terminated. Finally, Sample 7 in Figure 10-3 shows a third pattern that may, in fact, be intermediate between the two noted above.

We suspect that, as in sediment, the different levels of enhancements, as well as different patterns of change with increasing temperatures seen in the sandstone samples are a result of different amounts and different mixtures of trace minerals that will react at different temperature thresholds (see Crowther 2003; Dearing 1999). Whatever the cause, the data clearly suggest that when pieces of off-site sandstone rocks, which we presume to have not been heated in direct fires, are exposed to hearth-like temperatures, enhancements of MSS values consistently occur. To the degree that the eight samples reflect the overall range of sandstone in the immediate site area, these enhancements may be as low as $67 \%$ at $400^{\circ} \mathrm{C}$. These data can provide some general expectations for magnetic susceptibility values in unheated sandstone specimens at 41PR44 when they are exposed to high temperatures.

Figure 10-4 presents an example of the impacts of reheating on a previously heated specimen. The graph shows the original results for off-site sandstone Sample 1 (solid line), presented previously in Figure 10-3 (top, left), along with the magnetic susceptibility values for this same sample (dotted line) when it was reheated to $300^{\circ} \mathrm{C}, 400^{\circ} \mathrm{C}$, and $500^{\circ} \mathrm{C}$. Notice that upon reheating, there is minimal change in the initial value. This graph suggests that once a rock has undergone the mineralogical changes as a result of heating to a given temperature, in this case $500^{\circ} \mathrm{C}$, reheating the sample to temperatures below $500^{\circ} \mathrm{C}$ should have no substantial impact on the susceptibility value. Only temperatures above the maximum temperature of exposure should have an impact on the magnetic susceptibility value. While this observation clearly has the potential to provide information on prehistoric hearth temperatures, our current concern is with the more basic question of identifying what samples have, and have not, been heated. If, when heated to temperatures of $400^{\circ} \mathrm{C}$ or above, samples do not show any substantial change in susceptibility value, then it is likely that the sample has been exposed to that temperature previously. Conversely, if changes occur, especially enhancements on the order of more than $67 \%$, it is likely that the particular sandstone item has not been previously exposed to those temperature ranges for a significant period of time.

\section{Summary}

The results of the experimental heating of sediment from 41PR44, a well as the heating of crushed sandstone samples collected from the immediate site area, suggests that there are recognizable changes in the magnetic susceptibility values as a function of heating. While the level of enhancement, especially in sandstone samples, appears to be highly variable, the experimental results suggest that increases in values for sandstone surrounding 41PR44 can be expected to be at least on the order of $67 \%$ over the initial, pre-heated values. In addition, reheating previously heated samples of sandstone demonstrate that once a sample has been exposed to a given temperature, and mineralogical changes have occurred, additional exposure up to that particular temperature will have no significant impact on magnetic susceptibility values.

These experimental results should prove useful in distinguishing cultural features from natural accumulations of sandstone at 41PR44. Sediment samples from feature contexts where that sediment has been heated should have higher magnetic susceptibility values relative to samples from outside that feature setting. When heated sandstone rocks shows a significant change in magnetic susceptibility, possibly on the order of at least $67 \%$ enhancement over an original measurement, it is probable they have not been previously exposed to higher temperatures characteristic of a hearth. In addition, when heated rock samples show no substantial change in magnetic susceptibility values, it is highly likely to have been previously heated.

While we use each of these procedures to various degrees to investigate sandstone and sediment from 41PR44 in the following section, a number of caveats are necessary. First, as noted in the brief discussion of magnetic susceptibility at the beginning of this chapter, sediment values can be increased by a number of different processes, including an increase in organic matter. Changes in sediment values may, then, be seen in feature contexts that are not necessarily the result of heating.

Second, while the off-site sandstone samples were collected from several different contexts surrounding 41PR44, how representative they are of variability in the environment is not known. It is certainly conceivable that other sources of sandstone, sources that have substantially different susceptibility values, are present in the immediate environment and that these were used at 41PR44. 


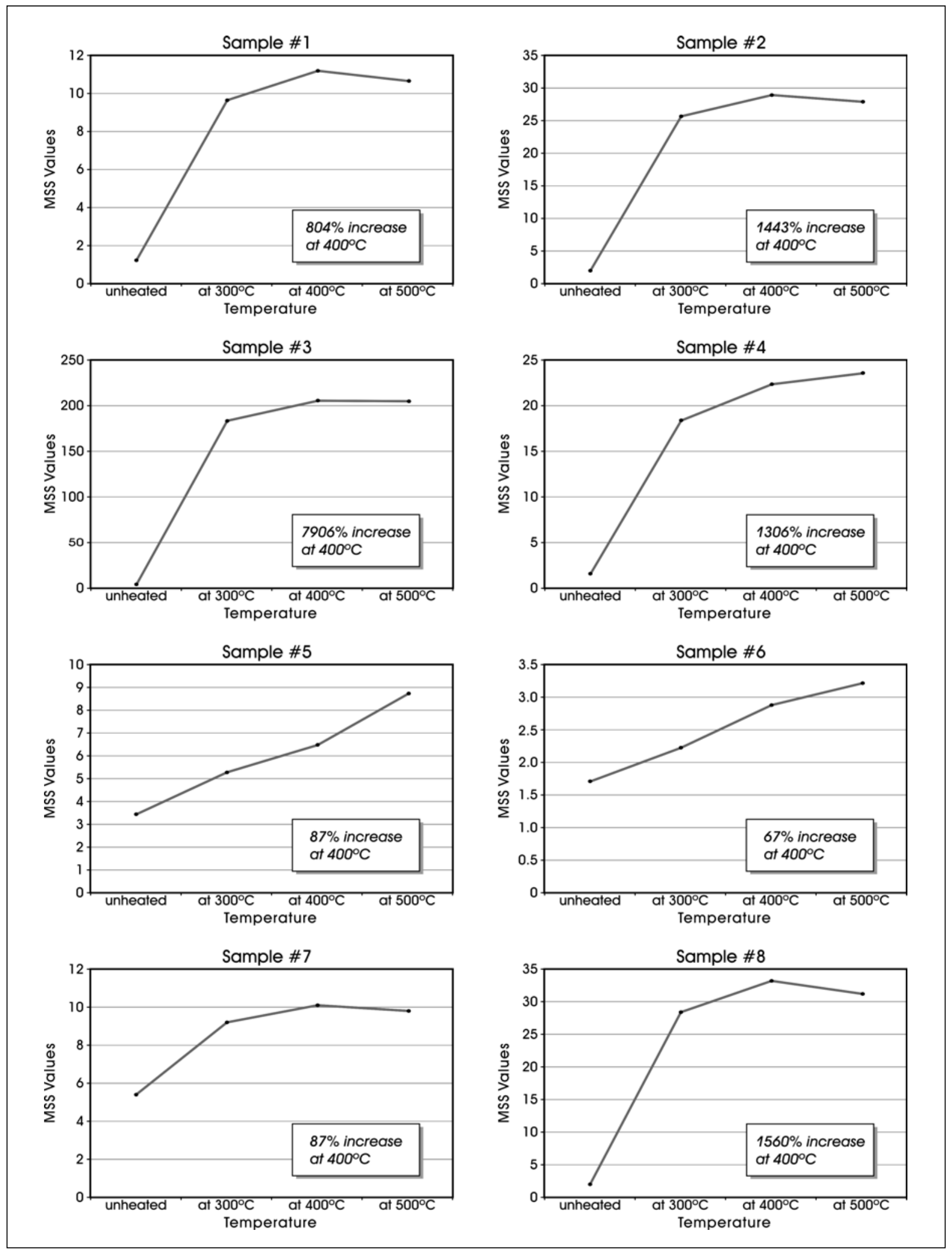

Figure 10-3. Mass-specific magnetic susceptibility values of off-site sandstone samples at various temperatures. 


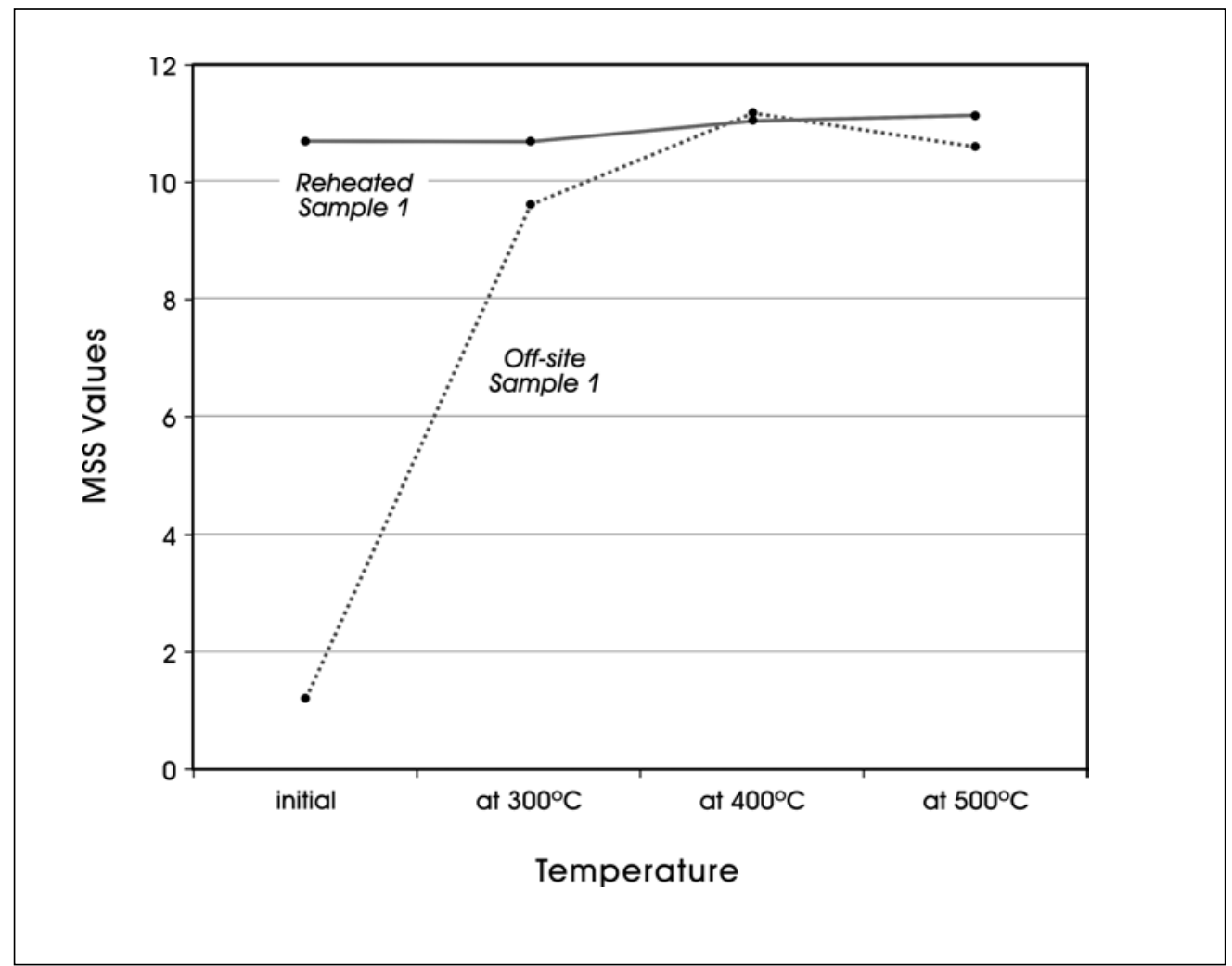

Figure 10-4. Mass-specific magnetic susceptibility values of sandstone Sample 1, original (see Figure 10-3) and reheated specimen.

Third, the patterns seen in the experimental heating occurred in a controlled setting in which all rock samples were thoroughly heated at a constant temperature for a substantial length of time. In an actual rock hearth, this would not be the case. Temperatures would certainly fluctuate widely, several different burning events may occur of variable duration, and depending on the location of a given stone relative to the heat source, only partial heating of a specimen would occur. It is not clear, then, if the pattern seen in the reheating of Sample 1 shown in Figure 10-4 would be precisely replicated in rock collected from an actual hearth, as a given rock may have experienced incomplete heating.

Finally, note that there is the possibility that some of the off-site sandstone has been exposed to heating through natural fires. The history of exposure of a given specimen is not known. We would guess that these often quick-moving natural fires are not of sufficient duration to significantly alter the natural magnetic susceptibility of a stone. However, that really is a guess. While research on this topic is ongoing, we have no results at the present time to support or refute that assertion.

\section{Identifying Burning in Sediment and Rock at 4IPR44}

In spite of these potential problems, however, the results of the experimental work summarized in the previous section clearly suggest that heating sediment and sandstone rock when neither was previously heated will result in an increase in magnetic susceptibility values. The increases are variable, even under the same temperature regimes. This variability is probably related to the presence of different quantities and mixtures of trace elements in particular samples. We can also conclude, at least for sandstone, that once a rock has undergone mineralogical changes as a result of heating to a given temperature (e.g., $400^{\circ} \mathrm{C}$ ), reheating the sample to temperatures below that point are unlikely to have any additional impact on the susceptibility value. Assuming complete heating, only temperatures above the maximum temperature of previous exposure should have the potential to impact the magnetic susceptibility value. These experimental results are consistent with literature on changes in magnetic susceptibility as a result of heating (see Bellomo 1993; Crowther 2003). Shifts in magnetic 
susceptibility values should provide a method for assessing burning in sediment and sandstone within site 41PR44.

\section{Sediment Samples for Feature 12}

As we have shown in Figure 10-1, sediment from 41PR44 show increased magnetic susceptibility values when they are heated. Consequently, when thermal features are in use at the site, we should see higher susceptibility values as a function of heating. Detailed sediment samples collected for magnetic susceptibility are, unfortunately, only available for a single feature, Feature 12 in Area 4. In this particular case, 21 samples were collected that cross-cut the feature boundary. These were collected after much of the rock had been removed. Figure 10-5 (top) shows the collection vials, along with the Feature 12 outline defined both by slightly darkened soil as well as the areas of rock concentration in the upper levels. Susceptibility samples were collected at 5 -cm intervals with 11 samples being outside of the feature boundary, and 10 samples falling within the boundary. These samples were processed following the procedures outlined previously. Table 10-1 presents information on the provenience, sample weights, the values of two independent susceptibility readings, the average of those two readings, and the mass-specific magnetic susceptibility value. The magnetic susceptibility values are also presented in the bottom portion of Figure 10-5, along with the susceptibility values for a sample of unheated sediment (bottom horizontal green line) and the values of that same sediment (horizontal red lines) after heating to $400^{\circ} \mathrm{C}$ and $500^{\circ} \mathrm{C}$. These samples were discussed previously (see Figure 10-2).

While the results show considerable variation, especially outside of the Feature 12 boundary, the overall pattern is relatively clear (see Figure 10-5). Of the 11 samples collected from outside of the Feature 12 boundary, three have high susceptibility values. These values are in the range that would be expected as a result of heating. The remaining eight samples are consistent with the signature of unheated sediment in this area, the value evidenced by the green horizontal line near the bottom of the figure. One of these three anomalous samples, the sample located $30 \mathrm{~cm}$ east of the TU 17 boundary is at the border of the feature, and certainly should have been exposed to heating. In that regard, this sample is analogous to those on the inside of the feature collected at $35 \mathrm{~cm}$ east of the TU 17 line. While the high signatures of the other two samples are not consistent with our expectations, it is certainly possible that selected areas around a hearth would be exposed to high temperatures. Overall, the 11 samples from outside the feature have an average value of 39.08 , and a median value of 37.41. In contrast, the magnetic susceptibility signatures of the 10 samples within the feature average 45.32, with a median value of 44.71 (see Table 10-1).

Perhaps more interesting than the absolute difference between the outside and inside groups, however, is the overall pattern of values within the feature itself. Samples closer to the western edge of the feature have consistently lower values, values that are in the range of that produced by native soil exposed to $400^{\circ} \mathrm{C}$ temperatures (middle red line, Figure 10-5, bottom). Magnetic susceptibility values increase in the center of the feature, and are generally above the signature produced by sediment which we had heated to $500^{\circ} \mathrm{C}$. Finally, note that the far eastern edge of the feature was not sampled as that edge had been removed by erosion associated with an abandoned road cut. Nevertheless, the values of the samples are declining as that feature edge is approached. While it is possible that the sediment analysis of Feature 12 presented previously is simply tracking on an increase in organics associated with a natural accumulation of sandstone, the close correspondence between the feature susceptibility scores and those of the heated sediments in our experimental undertaking (see Figures 10-2 and 10-5, bottom), as well as the overall pattern of increasing values towards the center of the feature and declining values as the edges are approached, is clearly consistent with expectations associated with a thermal feature.

\section{Sandstone Samples from 41PR44}

While we lack any additional sediment for susceptibility measures in this, or other features at the site, we do have sandstone samples that can be tested for changes in susceptibility. Fifty-nine individual pieces of sandstone were selected from various locations within 41PR44 for analysis. Most of these $(n=42)$ were selected from feature contexts and their analysis was done in an effort to either support or refute the notion that rocks associated with these clusters were burned. In addition to sampling at a feature level, we also wanted to get samples from a wide area of the site. Consequently, larger features, or features that had greater depth, were sampled more heavily. The feature rocks were supplemented by 16 sandstone pieces from non-feature contexts. Some of these $(n=9)$ were selected to explore the levels and test units adjacent to Feature 2 (Area 1), the burned rock cluster defined in TU 2 by TARL (Brownlow 2001). While we found no additional evidence of this feature 


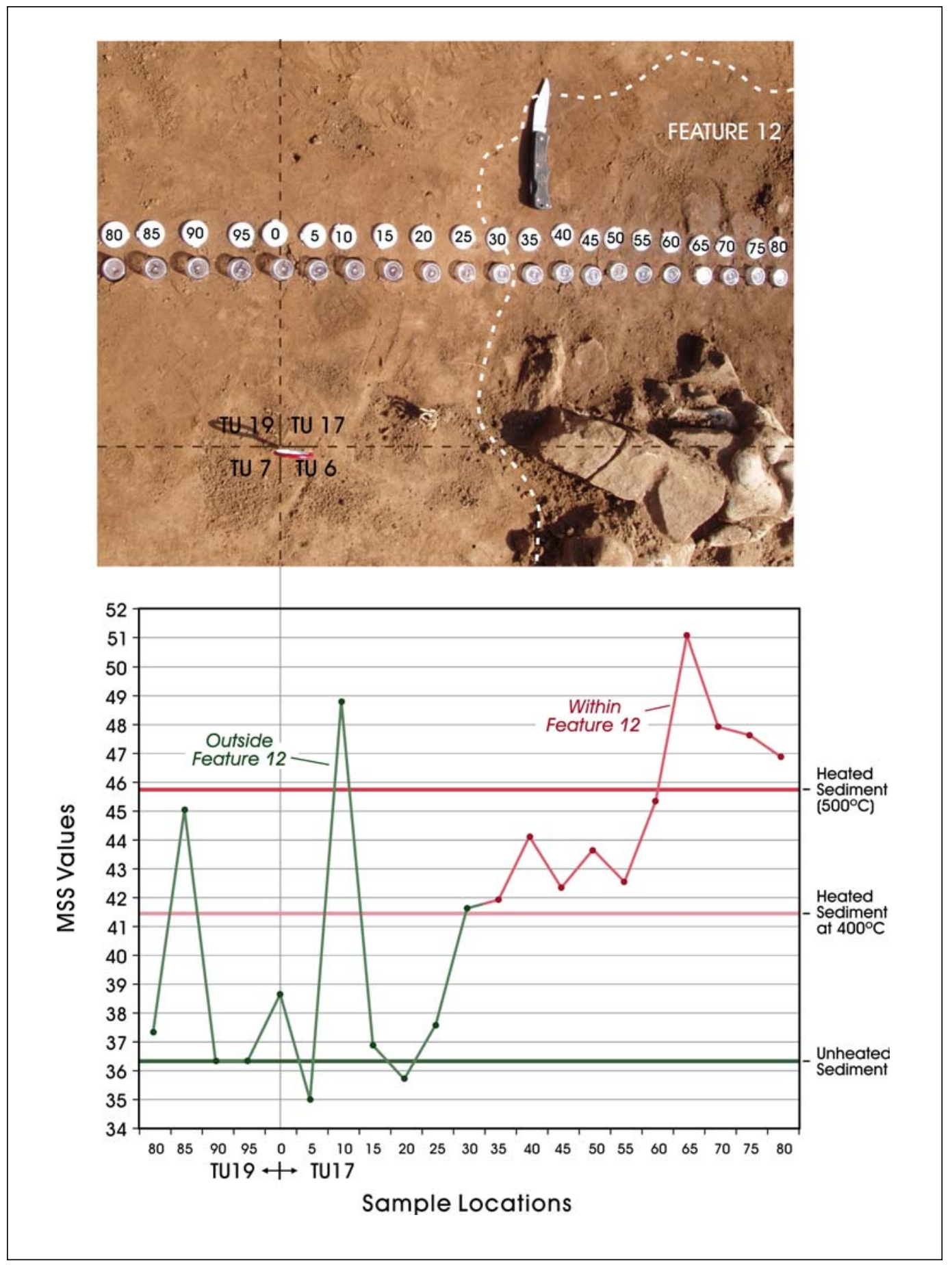

Figure 10-5. Mass-specific magnetic soil susceptibility values through Feature 12. 
Table 10-1. Magnetic Sediment Susceptibility Data, Feature 12 (see Figure 10-5)

\begin{tabular}{|c|c|c|c|c|c|c|}
\hline $\begin{array}{c}\text { Northing } \\
\text { Provenience }\end{array}$ & $\begin{array}{c}\text { Easting } \\
\text { Proveninece }\end{array}$ & $\begin{array}{c}\text { Total } \\
\text { Weight (g) }\end{array}$ & $\begin{array}{c}\text { First } \\
\text { Reading }\end{array}$ & $\begin{array}{c}\text { Second } \\
\text { Reading }\end{array}$ & $\begin{array}{c}\text { Average } \\
\text { Value (K) }\end{array}$ & MSS Value \\
\hline TU19@.20 & TU19@.80 & 14.5 & 36.1 & 36.1 & 36.1 & 37.41 \\
\hline TU 19@.20 & TU 19@.85 & 12.9 & 36.2 & 36.4 & 36.3 & 45.09 \\
\hline TU19@.20 & TU19@.90 & 13.8 & 32.6 & 32.6 & 32.6 & 36.42 \\
\hline TU19@.20 & TU 19@.95 & 14.5 & 35 & 35.3 & 35.15 & 36.42 \\
\hline TU $17 @ .20$ & TU 17@.00 & 14.6 & 37.7 & 37.8 & 37.75 & 38.72 \\
\hline TU17@.20 & TU 17@.05 & 14 & 32 & 32.2 & 32.1 & 35.08 \\
\hline TU $17 @ .20$ & TU 17@.10 & 14.2 & 45.6 & 45.7 & 45.65 & 48.82 \\
\hline TU17@.20 & TU 17@.15 & 14.6 & 36 & 36 & 36 & 36.92 \\
\hline TU17@.20 & TU17@.20 & 14.1 & 33 & 33.2 & 33.1 & 35.78 \\
\hline TU17@.20 & TU17@.25 & 13.9 & 34 & 34.1 & 34.05 & 37.62 \\
\hline TU17@.20 & TU17@.30 & 14.2 & 38.9 & 39 & 38.95 & 41.66 \\
\hline TU17@.20 & TU $17 @ .35$ & 13.6 & 36.6 & 36.8 & 36.7 & 41.94 \\
\hline TU17@.20 & TU 17@.40 & 13.6 & 38.5 & 38.7 & 38.6 & 44.11 \\
\hline TU 17@.20 & TU 17@.45 & 14.4 & 40.4 & 40.5 & 40.45 & 42.36 \\
\hline TU17@.20 & TU $17 @ .50$ & 14.6 & 42.5 & 42.6 & 42.55 & 43.64 \\
\hline TU $17 @ .20$ & TU 17@.55 & 12.4 & 32.1 & 32.1 & 32.1 & 42.52 \\
\hline TU 17@.20 & TU $17 @ .60$ & 13.6 & 39.6 & 39.7 & 39.65 & 45.31 \\
\hline TU17@.20 & TU17@.65 & 13.3 & 43.1 & 43.1 & 43.1 & 51.01 \\
\hline TU17@.20 & TU17@.70 & 14.2 & 44.8 & 44.7 & 44.75 & 47.86 \\
\hline TU17@.20 & TU17@.75 & 14.1 & 44 & 44 & 44 & 47.57 \\
\hline TU17@.20 & TU $17 @ .80$ & 13.7 & 41.4 & 41.5 & 41.45 & 46.84 \\
\hline
\end{tabular}

in our excavation, rocks from the middle levels of the adjacent units were selected for analysis. Additional material was selected from Area 1, as this portion of the site had a high density of rock but was not represented by a defined feature. Finally, one rock from Area 3, TU 10, Level 5, was included by mistake.

All 59 sandstone rocks were broken with non-metallic implements, ground with a ceramic mortar and pestle, and the crushed stone placed in plastic bags. The pulverized stone was then placed into plastic cubes, and measurement procedures outlined previously were followed for the analysis. While ideally each measured sample would have been systematically heated to various temperatures (i.e., $300^{\circ} \mathrm{C}, 400^{\circ} \mathrm{C}$, and $500^{\circ} \mathrm{C}$ ) to monitor if, and when, a change occurred, the time requirements associated with heating, cooling, measuring, and then repeating these three steps would have significantly limited the number of samples we were able to run. Consequently, we sacrificed some detailed information in order to increase the number of samples processed. The 59 samples discussed here, then, were heated only once to $400^{\circ} \mathrm{C}$. In addition, note that different samples were measured for the unheated and heated measurements reported here. That is, the sample that was heated, while selected from the same bag and thus representing the same rock, was not the same sample measured initially. This may introduce some additional variation in the results.

Table 10-2 presents provenience information, the initial weight, the average reading, and the mass-specific susceptibility scores for these 59 sandstone samples. These columns are followed by information associated with the rock after heating to $400^{\circ} \mathrm{C}$. The final column in Table 10-2 presents the relative change between the unheated and heated samples for that piece of sandstone. If there is no significant change in the value shown in this final column, then it is probable that the rock has been exposed to temperatures at or exceeding $400^{\circ} \mathrm{C}$. If a significant change in this column is present, then the rock had not been previously heated to that temperature range, and it is unlikely that the rock is associated with a thermal feature. 
What degree of change is "significant?" In our experimental analysis of the eight samples collected from off-site that we presumed to be unheated (see Figure 10-3), the minimum change at $400^{\circ} \mathrm{C}$ was an enhancement of about $67 \%$, with five of the eight samples having increases in excess of $800 \%$. To the degree that this small off-site sample captures the variability in magnetic signatures in sandstone, and assuming that the on-site sandstone is collected, or deposited, on site in similar ratios, we might expect unheated rock to respond in a similar way. Examination of the range of values in the final column of Table 10-2 will show that while we have one value in excess of $800 \%$, and while we have seven samples that exceed the $67 \%$ value and one value at $66.5 \%$, most of the percentages are well below $66 \%$ value. This suggest either that most of the stone tested has been previously heated, or that the $67 \%$ value is not a useful cutoff point for making that decision. That is, it may be the case that the eight samples are not a good representation of the variation in magnetic properties of sandstone in the area. Certainly, if that was the case, it would not be surprising.

Note also that in a small number of cases in Table 10-2, negative values are present, though in only one case is the negative shift in excess of 10 percentage points. No negative values were observed in any of the eight experimental analyses. Some of this variability may be related to the fact that different samples were used for the initial and the heated measurements (see also Dearing 1999).

Examination of the rates of change in Table 10-2 suggests several different gaps in the percentage values. These gaps are apparent in Figure 10-6, a histogram of the percentage change after heating for the 59 samples. The primary mode in the histogram (red, Figure 10-6) contains 46 cases. The distribution of that mode approximates a normal curve, and the 46 cases have a mean value of $4.1 \%$, and a median value of $2.7 \%$. The highest value of change within that mode is $23.3 \%$. A second series of 13 cases are present to the right of the initial mode. Ten of these 13 are shown in Figure 10-6 in blue; three extreme values are not plotted. The lowest value in blue in Figure 10-6 is 51.2\%. Given the normal distribution of the initial mode, and the break shown in Figure 10-6 (see also Table 10-2), we will use 50\% as a cut-point for these data. That is, only those cases that shown enhancement in excess of $50 \%$ of their original value will be classified as previously unheated.

Table 10-3 provides summary information for the Table 10-2 data by feature number. The feature designation, number of rocks tested on that feature, the number of rocks that showed enhancement greater than $50 \%$, the highest percentage change noted for the feature rock, and the determination of the thermal nature of the feature, are all provided. In eight of the 12 features, we found at least one rock that, when heated to $400^{\circ} \mathrm{C}$, had enhancement of magnetic susceptibility values in excess of $50 \%$ (Table 10-3). It is unlikely that these rocks, and by extension their associated clusters, were heated to that temperature previously. These clusters are highly unlikely to represent thermal features. In four clusters (Features 12, 17, 20, and 21 ), from which we tested a minimum of three rocks from each, we did not encounter any stone that showed enhancement. We classify these as possible thermal features (bold text, Table 10-3). That is, while the presence of unheated rock in a cluster is sufficient to strongly suggest that the cluster does not reflect a thermal feature, the presence of heated rock is not, by itself, sufficient to allow us to confirm the cluster as a thermal feature. This is especially the case where only a small number of samples were tested from a cluster, and in a context where only $22 \%$ of all rock tested (13 of 59) had not been previously heated. That is, we can eliminate clusters as thermal features if they lack heated rock, but we can't confirm them as features if they have heated rock. This is especially the case given the conclusions presented in Chapter 6. Features 12, 17, 20, and 21 , then, are likely candidates, but may still simply reflect secondary deposition.

For Feature 12, there are additional data, including the sediment results presented previously, that suggest that this cluster does reflect a thermal feature. As shown in Figure 10-7 (see also Figure 10-5 top, and Figure 5-6), the cluster is composed of various sized sandstone and limestone rock, some of which appears to be cracked in place. The cluster of rock is isolated and forms two circular patterns, with larger rock surrounding central areas that have lower rock density. The cluster may, in fact, reflect two smaller hearths. The rock in the feature is associated with darkened sediment (Figure 10-5, top) that has a basin shaped cross-section (Figure 10-7). Both the sediment (Figure 10-5, bottom) and the rock (Tables 10-2 and 10-3) have been heated. Given these various lines of evidence, we are confident that the rock cluster defined as Feature 12 at 41PR44 does, in fact, reflect an intact, thermal feature.

Figure 10-8 presents a plan view of Area 3 (TUs 9, 10, 11, and 12) showing rock distributions for Levels 8 though 10 (100-130 cmbd). Included in the figure are Features 17 and 20 , two of the four features that we were unable to 
Table 10-2. Magnetic Susceptibility Data on Crushed Sandstone from 41PR44 Before and After Heating

\begin{tabular}{|c|c|c|c|c|c|c|c|c|c|c|}
\hline Area & $\begin{array}{l}\text { Test } \\
\text { Unit }\end{array}$ & Level & Feature & $\begin{array}{c}\text { Weight } \\
\text { (g) }\end{array}$ & $\begin{array}{c}\text { Initial } \\
\text { Reading } \\
\text { (K) }\end{array}$ & $\begin{array}{c}\text { MSS } \\
\text { Value }\end{array}$ & $\begin{array}{l}\text { Weight } \\
\text { (g) at } \\
400^{\circ} \mathrm{C}\end{array}$ & $\begin{array}{c}\text { Reading } \\
\text { After } \\
\text { Heating (K) }\end{array}$ & $\begin{array}{c}\text { MSS } \\
\text { Value at } \\
400^{\circ} \mathrm{C}\end{array}$ & $\begin{array}{l}\text { Percent } \\
\text { Change }\end{array}$ \\
\hline 3 & 12 & 7 & 16 & 14.9 & 185 & 184.1 & 14.8 & 157.9 & 158.7 & -13.8 \\
\hline 1 & 5 & 3 & 0 & 15 & 10 & 9.9 & 15.3 & 9.4 & 9 & -9.1 \\
\hline 3 & 10 & 10 & 20 & 14.9 & 195.2 & 194.2 & 14.4 & 169.3 & 177.3 & -8.7 \\
\hline 3 & 12 & 6 & 13 & 14.5 & 335.9 & 348.1 & 14 & 295.3 & 322.7 & -7.3 \\
\hline 3 & 11 & 10 & 20 & 14.4 & 400.2 & 419.1 & 14.3 & 367.5 & 388.9 & -7.2 \\
\hline 3 & 10 & 10 & 20 & 13.7 & 754.9 & 853 & 15.1 & 814.1 & 794.2 & -6.9 \\
\hline 3 & 10 & 10 & 20 & 14.2 & 3.5 & 3.7 & 14.1 & 3.2 & 3.5 & -5.4 \\
\hline 3 & 11 & 10 & 20 & 14 & 65.9 & 72 & 15 & 69.9 & 68.9 & -4.3 \\
\hline 3 & 12 & 7 & 16 & 13.9 & 202.2 & 223.4 & 14.5 & 206.5 & 214 & -4.2 \\
\hline 1 & 5 & 8 & 0 & 14.1 & 77.1 & 83.4 & 13.9 & 73.2 & 80.9 & -3.0 \\
\hline 2 & 16 & 5 & 10 & 14.8 & 97.8 & 98.3 & 14.6 & 93.2 & 95.6 & -2.7 \\
\hline 3 & 9 & 8 & 17 & 14.6 & 12.8 & 13.1 & 14.5 & 12.4 & 12.8 & -2.3 \\
\hline 1 & 4 & 9 & 0 & 14.2 & 58.4 & 62.5 & 14.1 & 56.6 & 61.2 & -2.1 \\
\hline 1 & 5 & 5 & 0 & 14.1 & 253 & 273.5 & 14.6 & 262.6 & 269.3 & -1.5 \\
\hline 3 & 9 & $7 / 8$ & 11 & 15.2 & 7.5 & 7.2 & 14.2 & 6.6 & 7.1 & -1.4 \\
\hline 1 & 3 & 10 & 0 & 14.2 & 11.2 & 12 & 14.4 & 11.4 & 11.9 & -0.8 \\
\hline 3 & 9 & 7 & 15 & 14.8 & 104.6 & 105.1 & 14.8 & 105.2 & 105.7 & 0.6 \\
\hline 3 & 9 & 9 & 18 & 13.1 & 182.5 & 221.2 & 13.1 & 183.6 & 222.5 & 0.6 \\
\hline 4 & $6 / 17$ & $11 / 13$ & 12 & 14.3 & 11.55 & 12.2 & 13.6 & 10.85 & 12.4 & 1.6 \\
\hline 3 & 9 & 8 & 17 & 13.9 & 80.4 & 88.8 & 13.8 & 80.7 & 90.2 & 1.6 \\
\hline 1 & 5 & 8 & 0 & 14.4 & 164.7 & 172.5 & 14.7 & 173.2 & 175.8 & 1.9 \\
\hline 3 & 10 & 9 & 19 & 14.4 & 39 & 40.8 & 14.2 & 39 & 41.7 & 2.2 \\
\hline 1 & 5 & 5 & 0 & 14.5 & 12.6 & 13.1 & 14.7 & 13.2 & 13.4 & 2.3 \\
\hline 4 & 29 & 4 & 21 & 15.4 & 21.1 & 20 & 15.1 & 21.1 & 20.6 & 3.0 \\
\hline 3 & 11 & 8 & 14 & 14.2 & 5.2 & 5.6 & 14.9 & 5.8 & 5.8 & 3.6 \\
\hline 3 & 12 & 6 & 13 & 15 & 156.1 & 153.8 & 15.5 & 171 & 160.6 & 4.4 \\
\hline 2 & 16 & 5 & 10 & 15.1 & 7.6 & 7.4 & 15.1 & 8 & 7.8 & 5.4 \\
\hline 3 & 11 & 7 & 14 & 14.8 & 12.5 & 12.6 & 14.5 & 12.8 & 13.3 & 5.6 \\
\hline 3 & $11 / 12$ & 8 & 16 & 14.6 & 7.5 & 7.7 & 14.4 & 7.8 & 8.2 & 6.5 \\
\hline 1 & 5 & 12 & 0 & 14.7 & 7.5 & 7.6 & 14.5 & 7.8 & 8.1 & 6.6 \\
\hline 3 & 9 & 9 & 18 & 14.8 & 52.3 & 52.6 & 14.6 & 54.7 & 56.1 & 6.7 \\
\hline 3 & 9 & 8 & 17 & 14 & 499.5 & 545.9 & 13.9 & 528.3 & 583.8 & 6.9 \\
\hline 4 & $6 / 17$ & $11 / 13$ & 12 & 14.5 & 949.9 & 984.4 & 14.3 & 994.3 & 1052.2 & 6.9 \\
\hline 3 & 9 & 9 & 18 & 14.5 & 25.6 & 26.5 & 14.5 & 27.4 & 28.4 & 7.2 \\
\hline 1 & 3 & 7 & 0 & 14.1 & 23.6 & 25.5 & 14.6 & 27.2 & 27.9 & 9.4 \\
\hline 3 & 9 & 10 & 16 & 14.3 & 3.9 & 4.1 & 15.2 & 4.8 & 4.6 & 12.2 \\
\hline 1 & 5 & 3 & 0 & 14.2 & 57 & 61 & 14.3 & 64.9 & 68.7 & 12.6 \\
\hline 1 & 4 & 9 & 0 & 14.2 & 25.9 & 27.7 & 14.5 & 30.5 & 31.6 & 14.1 \\
\hline 4 & $6 / 17$ & $11 / 13$ & 12 & 13.7 & 564.5 & 637.9 & 13.6 & 640.4 & 731.9 & 14.7 \\
\hline 1 & 3 & 10 & 0 & 14.8 & 61.2 & 61.5 & 14.4 & 67.4 & 70.6 & 14.8 \\
\hline 4 & 29 & 4 & 21 & 14.6 & 45.1 & 46.3 & 14.4 & 51.85 & 54.3 & 17.3 \\
\hline 3 & 11 & 9 & 15 & 14.4 & 52.2 & 54.7 & 14.8 & 64.3 & 64.6 & 18.1 \\
\hline 3 & 10 & 9 & 19 & 13.3 & 3.9 & 4.6 & 13.2 & 4.6 & 5.5 & 19.6 \\
\hline 4 & 29 & 4 & 21 & 15 & 16.4 & 16.2 & 14.9 & 19.6 & 19.5 & 20.4 \\
\hline 1 & 3 & 7 & 0 & 14.2 & 279.3 & 298.7 & 14.4 & 343.8 & 360 & 20.5 \\
\hline 3 & 12 & 10 & 16 & 14 & 17.7 & 19.3 & 14.6 & 23.2 & 23.8 & 23.3 \\
\hline 3 & 9 & $7 / 8$ & 11 & 14.8 & 205.8 & 206.8 & 13.9 & 283 & 312.7 & 51.2 \\
\hline
\end{tabular}


Table 10-2, contd. Magnetic Susceptibility Data on Crushed Sandstone from 41PR44 Before and After Heating

\begin{tabular}{|c|c|c|c|c|c|c|c|c|c|c|}
\hline Area & $\begin{array}{c}\text { Test } \\
\text { Unit }\end{array}$ & Level & Feature & $\begin{array}{c}\text { Weight } \\
(\mathbf{g})\end{array}$ & $\begin{array}{c}\text { Initial } \\
\text { Reading } \\
(\mathbf{K})\end{array}$ & $\begin{array}{c}\text { MSS } \\
\text { Value }\end{array}$ & $\begin{array}{c}\text { Weight } \\
\mathbf{( g )} \text { at } \\
\mathbf{4 0 0}{ }^{\circ} \mathbf{C}\end{array}$ & $\begin{array}{c}\text { Reading } \\
\text { After } \\
\text { Heating (K) }\end{array}$ & $\begin{array}{c}\text { MSS } \\
\text { Value at } \\
\mathbf{4 0 0}{ }^{\circ} \mathbf{C}\end{array}$ & $\begin{array}{c}\text { Percent } \\
\text { Change }\end{array}$ \\
\hline 1 & 4 & 6 & 0 & 14 & 13.6 & 14.9 & 13.6 & 19.8 & 22.6 & 51.7 \\
\hline 1 & 5 & 12 & 0 & 14.4 & 58.6 & 61.4 & 14.3 & 88.3 & 93.4 & 52.1 \\
\hline 2 & 16 & 5 & 10 & 14.6 & 11.1 & 11.4 & 14.4 & 16.9 & 17.7 & 55.3 \\
\hline 3 & 10 & 9 & 19 & 15 & 7 & 6.9 & 14.8 & 10.9 & 11 & 59.4 \\
\hline 3 & 11 & 10 & 16 & 14.7 & 43.8 & 44.5 & 14.9 & 74.5 & 74.1 & 66.5 \\
\hline 3 & 11 & 7 & 14 & 14.6 & 7.2 & 7.4 & 14.6 & 13.2 & 13.5 & 82.4 \\
\hline 3 & 11 & 9 & 15 & 14.8 & 8.2 & 8.2 & 15 & 15.5 & 15.3 & 86.6 \\
\hline 3 & 10 & 5 & 0 & 13.9 & 107.8 & 119.1 & 13.8 & 206.6 & 230.8 & 93.8 \\
\hline 3 & 9 & 9 & 18 & 14.1 & 8.3 & 9 & 14 & 16.2 & 17.7 & 96.7 \\
\hline 3 & 12 & 6 & 13 & 14.7 & 49.1 & 49.8 & 14.9 & 190.8 & 189.9 & 281.3 \\
\hline 3 & $11 / 12$ & 8 & 16 & 15.1 & 8.1 & 7.9 & 15.4 & 62.5 & 59.2 & 649.4 \\
\hline 3 & 11 & 10 & 16 & 14.2 & 4.5 & 4.8 & 14.5 & 51.4 & 53.3 & 1010.4 \\
\hline
\end{tabular}

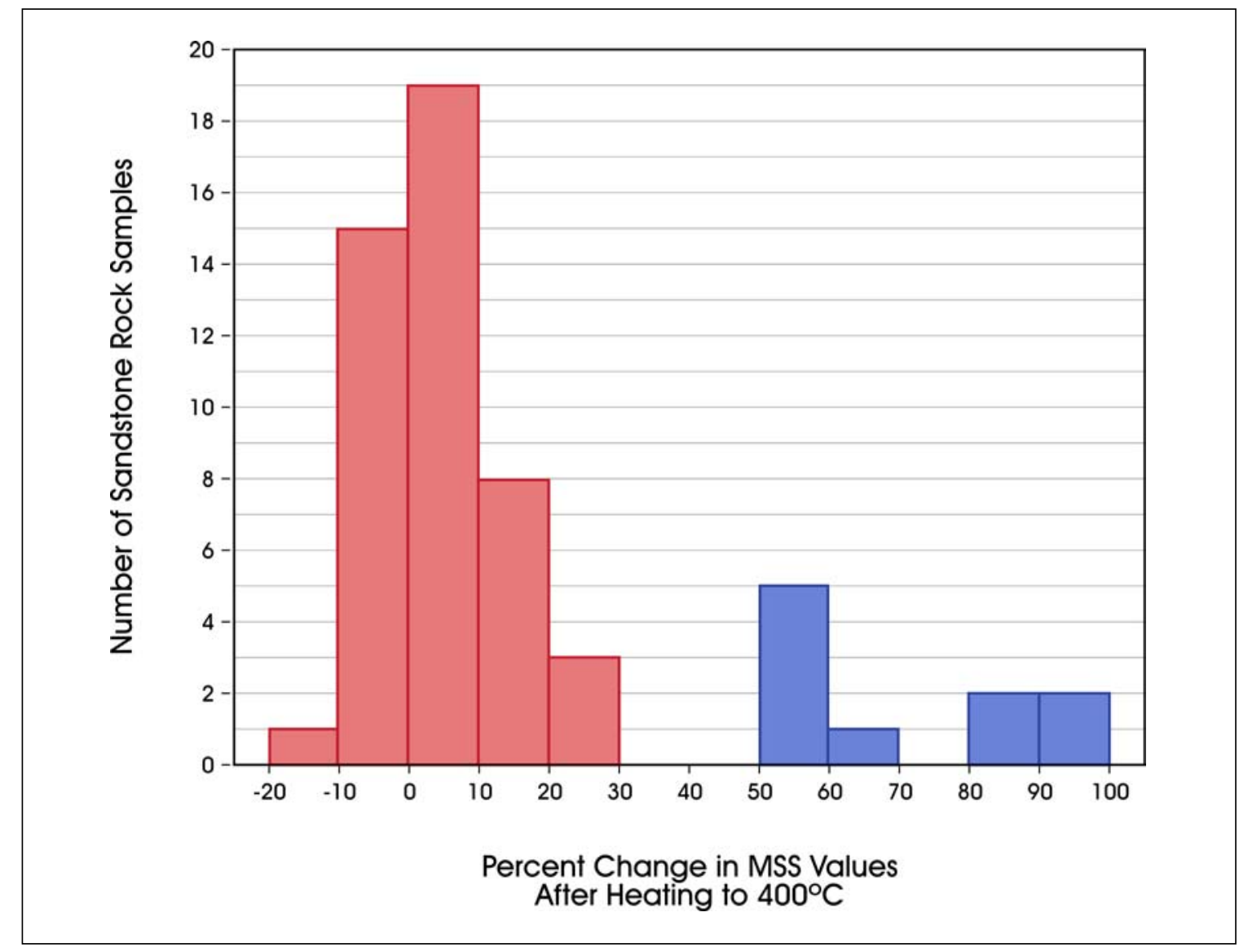

Figure 10-6. Relative changes in mass-specific magnetic susceptibility values in sandstone rock after heating to $400^{\circ} \mathrm{C}$ (see Table 10-2). Three extreme values are not shown. 
eliminate on the basis of the rock analysis presented in Table 10-2. Also outlined in Figure 10-8 are the boundaries of rock clusters defined as Features 14, 16, 18, and 19 as they are manifested at these depths. Recall that all of these features contained previously unheated stone and, therefore, do not reflect intact thermal features (see Table 10-3). Note that with the exception of Feature 20, all of the other clusters, including Feature 17, seem to be associated with a northeast to southwest trending distribution of stone (Figure 10-8). The current ground surface slope decidedly to the east and it appears that a large quantity of sandstone is probably being moved down slope (see Chapter 6). In contrast to Feature 17, Feature 20 is an isolated cluster of stone in a tight circular pattern not associated with any obvious slope distributions (see Figure 10-8). The five stones tested from this cluster, which represents $4.5 \%$ of the 111 stones associated with this feature, all were previously exposed to temperatures of at least $400^{\circ} \mathrm{C}$ (see Table 10-3). Given these data, we feel that Feature 20 has a high probability of representing an intact, thermal feature. Reference to Table 10-2 will show that, overall, 20 of the 28 rocks tested from Area 3, Levels 8 through 10, were previously heated. Removing the 5 previously heated items from Feature 20, unheated stone made up about $35 \%(n=8)$ of the remaining 23 rocks tested. These are primarily associated with the northeast to southwest trending distributions in the Figure $10-8$. Given these patterns, we suggest that Feature 17 is unlikely to represent an intact feature. While certainly containing previously heated sandstone, the overall distribution of stone shown in Figure 10-8, and the relatively high frequency of unheated stone, is consistent with the assessment of Greaves presented in Chapter 6 .

Figure 10-9 presents a plan view of the final rock cluster considered here, Feature 21. As noted in Chapter 5, the feature was originally suspected based on auger testing. It was subsequently cut by Backhoe Trench 1, and explored through the excavation of TUs 29 and 30 . Reference to Table 10-2 and 10-3 will show that three stones were tested from this cluster, all of which were previously heated. Though substantially larger than either Feature 12 or 20, the rock cluster identified as Feature 21 is isolated and associated with slightly darker sediments (see Figure 5-8). It is roughly circular in outline, and was roughly basin shaped in cross-section. While, as Greaves contends in Chapter 6, it may represent a secondary deposit of stone, some of which has been heated, the isolated nature and circular outline is consistent with an intact, thermal feature. Therefore, we will consider Feature 21 as an intact, thermal feature, though we admit that this particular case is the weakest example among the three features (i.e., Features 12, 20, and 21) that we ultimately identified.

Note that the rocks tested in association with the TARLdefined Feature 2 in Area 1 produced magnetic susceptibility patterns that were consistent with previous heating. However, as shown in Table 10-2, one (TU 4, Level 6) of the nine rocks tested that were near the level of this feature

Table 10-3. Feature Level Summary Data (see Table 10-2)

\begin{tabular}{|c|c|c|c|c|}
\hline $\begin{array}{c}\text { Feature } \\
\text { Number }\end{array}$ & $\begin{array}{c}\text { Rock Samples } \\
\text { Tested }\end{array}$ & $\begin{array}{c}\text { Number Not } \\
\text { Previously Heated }\end{array}$ & $\begin{array}{c}\text { Highest \% } \\
\text { Change }\end{array}$ & Thermal Feature Status \\
\hline 10 & 3 & 1 & 55.3 & Not a Feature \\
\hline 11 & 2 & 1 & 51.2 & Not a Feature \\
\hline 12 & 3 & 0 & 14.7 & Possible Feature \\
\hline 13 & 3 & 1 & 281.3 & Not a Feature \\
\hline 14 & 3 & 1 & 82.4 & Not a Feature \\
\hline 15 & 3 & 1 & 86.6 & Not a Feature \\
\hline 16 & 8 & 3 & 1010.4 & Not a Feature \\
\hline 17 & 3 & 0 & 6.9 & Possible Feature \\
\hline 18 & 4 & 1 & 96.7 & Not a Feature \\
\hline 19 & 3 & 1 & 59.4 & Not a Feature \\
\hline 20 & 5 & 0 & -4.3 & Possible Feature \\
\hline 21 & 3 & 0 & 20.4 & Possible Feature \\
\hline
\end{tabular}




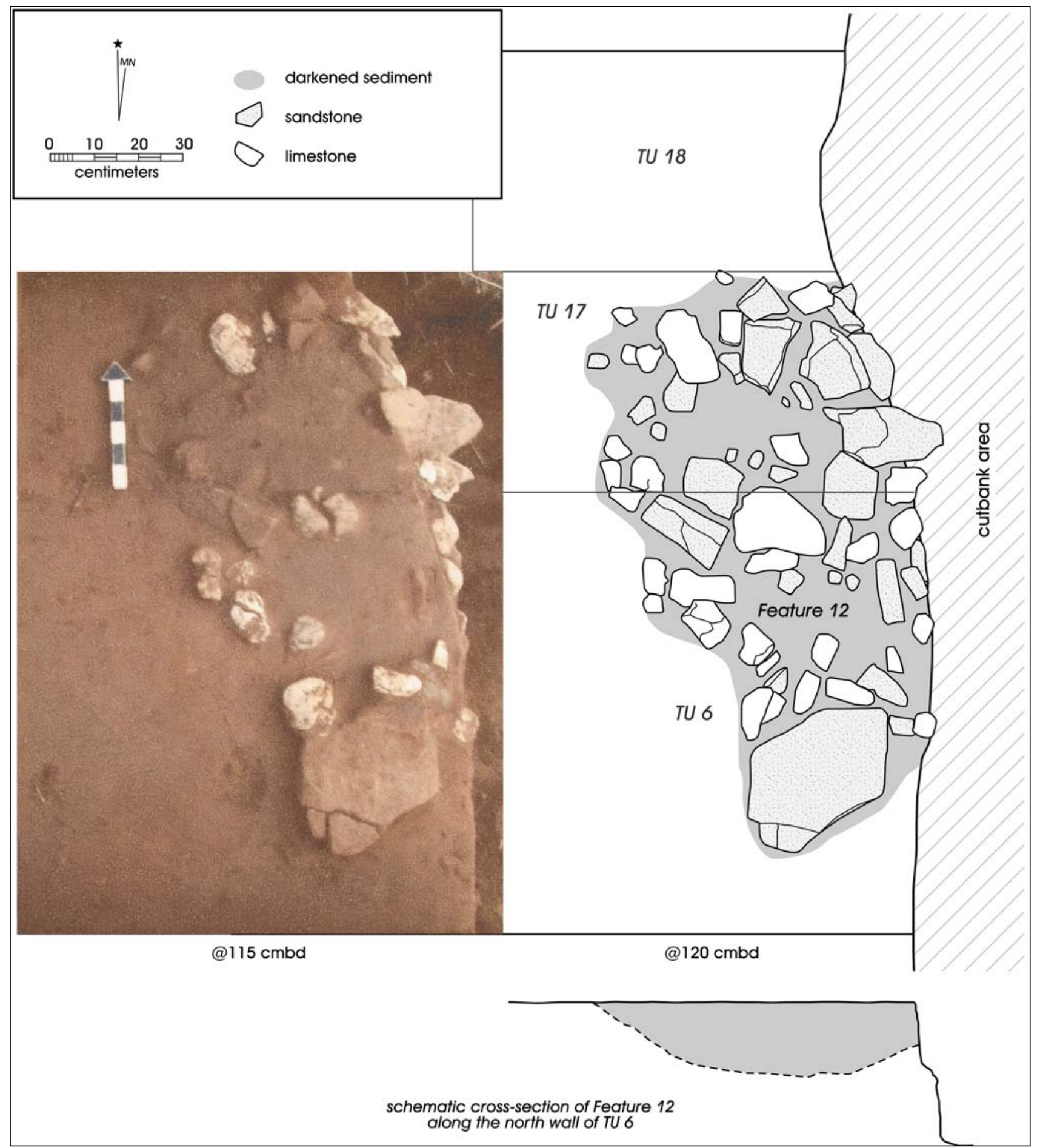

Figure 10-7. Feature 12 plan view and schematic cross-section. 


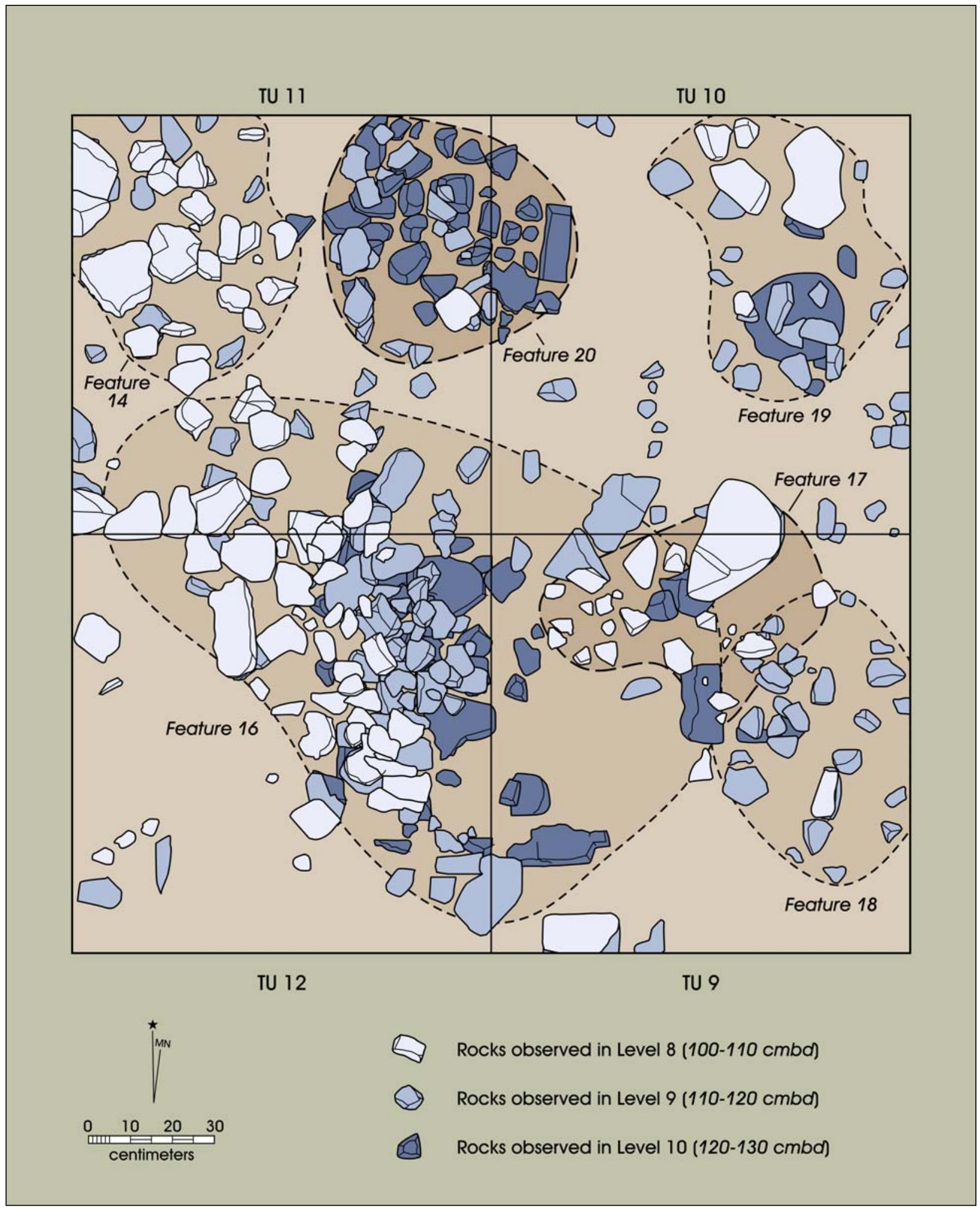

Figure 10-8. Plan view of Area 3 showing Features 14, 16, 17, 18, 19, and 20 and rock distributions in Levels 8-10. 


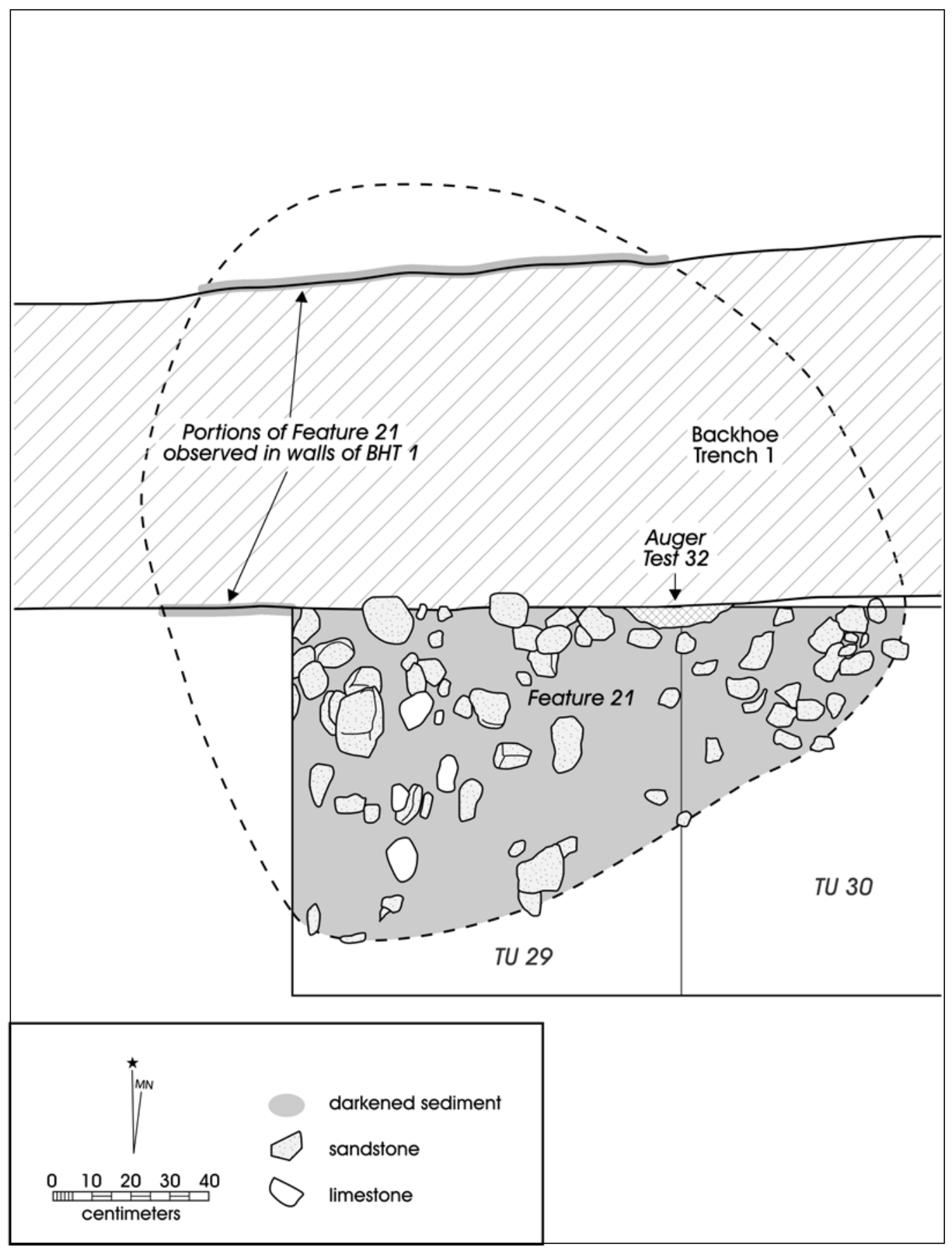

Figure 10-9. Plan view of Feature $21 \mathrm{ca} .28 \mathrm{cmbd}$ (top of feature). 
was not previously heated to $400^{\circ} \mathrm{C}$. Given this, and the lack of any additional evidence for this feature found in adjacent units excavated by CAR, it seems unlikely the concentration identified as Feature 2 represents a thermal feature.

Finally, we have no information on Feature 1, defined by TARL in TU 1 (Brownlow 2001). We will assume, then, that this does represent a thermal feature, though we have no additional information on this sandstone and limestone cluster beyond that provided by Brownlow (2001).

\section{Summary}

The analysis of changes in magnetic susceptibility of sandstone rock as a result of heating provided a method for assessing features defined by CAR at 41PR44. The method proved successful in clearly eliminating some $(n=8)$ of the original 12 clusters that CAR had identified as thermal features. At least some of the tested rocks in each of those clusters had not been previously heated. This is strong evidence that the cluster was not used as a hearth. In a second group of rock clusters $(n=4)$, all the rocks that we tested proved to have been previously heated and therefore we could not eliminate those clusters based the presence of unheated stone. Patterning in sediment changes in Feature 12 , coupled with the overall appearance of the cluster, suggested that this feature, along with Feature 20, were strong candidates for intact hearths. In the case of Feature 17 , the cluster was identified in a context that, based on the distribution of sandstone in a 2-x-2 m block, as well as the assessment of our geoarchaeologist, was secondary. That is, the feature contained burned rock, but the clustering identified as a feature was almost certainly a result of natural rather than cultural processes. The evidence for the intact nature of Feature 21 is more ambiguous, but given the isolated nature and overall appearance, we assume that it, like Features 12 and 20, does reflect an intact thermal feature. In addition to these CAR-excavated clusters, we have some information on Feature 2, defined during testing at the site (Brownlow 2001). We had previously, in excavations in Area 1, failed to find any additional evidence associated with this feature which was defined in TU 2. An analysis of rock collected from our excavations and reflecting roughly similar levels as Feature 2 suggests that at least in one case, the rock was not previously heated. Given the earlier excavations in this area, it is, then, unlikely that Feature 2 is an intact, thermal feature.

\section{Attributes and Patterning in Burned Rock Features at 41PR44}

Given the results in the previous section and the lack of information on Feature 1 at 41PR44, we are left with Features 12, 20, and 21 with which to consider more general questions centered on feature use. On Feature 12, we excavated roughly $89 \%$ of the cluster as the eastern edge was previously removed by erosion (see Figure 10-7). We excavated $100 \%$ of Feature 20 (Figure 10-8). On Feature 21 , we excavated roughly $35 \%$ of the cluster, as much of that feature was previously removed by BHT 1 (see Figure 10-9) and, in addition, the cluster was exposed at the end of the field project. For each feature, we have the number of rock recovered, the stone material (i.e., limestone, sandstone), and the weight of individual rocks. Table 10-4 uses this data, in conjunction with the percentage of excavation conducted on a feature, to provide some summary data for these features, including an estimate of the original feature area, the number of rock, total estimated weight, weight of limestone, and a temporal assignment. While we lack any direct dates on these features, it is probable that at least two of the three are Archaic in age. A Late Archaic Marshall point was recovered in direct association with Feature 21. Feature 21 was located significantly higher than, but in close proximity to, Feature 12 (see Chapter 5). This suggests that Feature 12 predates Feature 21. Finally, the dating of Feature 20 is more problematic and is listed as "Unknown" in Table 10-4. Above this feature are mixtures of Late Prehistoric and Late Archaic point forms that are associated with slope deposits (see Chapters 6,7). We did not conduct excavation below this feature level. Given the depth of the feature, however, it is probable that it is Archaic in age.

As outlined in Chapter 4, recent research on burned rock features has primarily focused on investigating the thermal storage capacity of rock in the context of long-term cooking requirements of certain plant foods that require extended cooking times (see Black et al. 1998; Black 2003; Dering 1999; Ellis 1997; Wandsnider 1997). Thermal features without rock are adequate in preparing foods that require short cooking times (e.g., meats) and/or when food is cooked in ceramic pots. However, several classes of food, including geophytes (e.g., bulbs), and some nut resources, require lengthier cooking times if they are to be efficiently digested by humans. When lengthier cooking times are necessary, the use of rocks to increase heat storage and lengthen the time of heat dissipation is commonly employed. In this 
Table 10-4. Selected Attributes of Thermal Features, 41PR44

\begin{tabular}{|c|c|c|c|}
\hline Attributes & Feature 12 & Feature 20 & Feature 21 \\
\hline Feature Area $\left(\mathrm{m}^{2}\right)$ & 0.803 & 0.289 & 2.84 \\
\hline Estimated Number of Rocks & 432 & 115 & 3,746 \\
\hline Percent Limestone Rock & $52.8 \%$ & $19.1 \%$ & $24.9 \%$ \\
\hline Estimated Feature Weight & $45.52 \mathrm{~kg}$ & $9.62 \mathrm{~kg}$ & $335.92 \mathrm{~kg}$ \\
\hline Estimated Limestone Weight & $19.78 \mathrm{~kg}$ & $.86 \mathrm{~kg}$ & $63.52 \mathrm{~kg}$ \\
\hline Probable Temporal Period & Archiac & Unknown & Late Archaic \\
\hline
\end{tabular}

section, we consider several attributes of burned rock features from 41PR44, including rock size, rock composition, and total rock weight. Our goal is to begin to develop baseline data that may provide clues to different types of features used by the prehistoric inhabitants of the region. While conclusions are limited by the small number of rock features available for consideration, the 41PR44 feature data can serve as a starting point for an investigation of feature technology at a regional level.

\section{Rock Size in Features}

The idea that the amount of rock in a feature is reflecting the thermal storage capacity of that feature (e.g., Black 2003) assumes that a given rock cluster is representative of the location of cooking activities. This assumption is probably warranted for most rock features. However, several concentrations of burned rock may result from other activities. In Texas, several researchers had argued that some burned rock concentrations represent dumps associated with indirect cooking methods, such as stone boiling (see Quigg 1997; Quigg et al. 2002). Refuse associated with stone boiling (see Driver and Massy 1957; Ellis 1997) should be dominated by accumulations of small, badly fractured rock, all of which are within the same general size range. However, if rock features primarily represent cooking locations, where rock is used as a direct cooking method, we might expect larger rocks to be consistently present in the feature, though smaller rocks might dominate as a result of thermal shattering or fatigue during feature use.

We begin the investigation of rock size within features by focusing on rock weight as a proxy for rock size. We then consider the distribution of rock weights within the three features on 41PR44. In addition, we developed a comparative data set consisting of rocks from non-feature contexts. While over 25,000 individual pieces of what was thought to be burned rock were collected from the site, the vast majority of this was under one-half inch in size. Here, we focus on burned rocks that were a minimum of one-half inch in size from contexts that we have determined do not represent features. At the site level, 6,568 rocks were in the greater than one-half inch size range, with sandstone representing 5,832 items and the remaining 736 items being limestone. From non-feature locations at the site, we selected a $10 \%$ random sample of provenience level data using SPSS Version 14.0. Table 10-5 lists the associated field sack (fs) numbers, along with counts of limestone, weights of limestone, counts of sandstone, and weights of sandstone, found in the $10 \%$ sample of non-feature locations. The 821 items in Table 10-5 actually comprise roughly $12.4 \%$ of all non-feature rock at the site.

Table 10-6 presents weight divisions and associated percentages for each of the three features, as well as the non-feature random sample data set in Table 10-5. Below the weight groups we list the average stone weight for that column. The three feature data sets vary, but in general stone weighing $100 \mathrm{~g}$ or less comprise about 74 to $79 \%$ of rock in an individual feature, and while the smaller size ranges dominate, stones greater than $500 \mathrm{~g}$ in weight are present, accounting for between $2.4 \%$ and $3.5 \%$ of feature rock (Table 10-6). The non-feature sample, however, is dominated by smaller stone, with just over $88 \%$ being in the smallest category. While stones greater than $500 \mathrm{~g}$ are present in the non-feature category, the overall percentage of $2.3 \%$ is the lowest in the table. The mean rock weight at the bottom of the table is consistent with this distributional data, as the non-feature sample has the lowest average weight. The average of $67.4 \mathrm{~g}$ for this non-feature sample is more than $16 \mathrm{~g}$ less than the lowest feature average, and roughly $38 \mathrm{~g}$ below the $105.37 \mathrm{~g}$ average for rock in Feature 12 (Table 10-6). 
The Table 10-6 data clearly suggest that, relative to the non-feature contexts at 41PR44, features have larger rocks and more rocks in the larger weight category. The comparative sample in Table 10-5, however, does not represent a non-cultural assemblage. In fact, if the data presented in Table 10-3 is any indication, the vast majority of non-feature rocks probably have experienced some heating. The sample likely represents a combination of previously burned rock that has been displaced, discarded, as well as unburned, naturally deposited rock. The comparisons in Table 10-6 suggest that the three features on the site have roughly similar size distribution, implying

Table 10-5. Counts and Weights by Rock Material Type, for Selected Non-feature Locations

\begin{tabular}{|c|c|c|c|c|c|}
\hline FS No. & $\begin{array}{c}\text { Limestone } \\
\text { Count }\end{array}$ & $\begin{array}{c}\text { Limestone } \\
\text { Weight (g) }\end{array}$ & $\begin{array}{c}\text { Sandstone } \\
\text { Count }\end{array}$ & $\begin{array}{c}\text { Sandstone } \\
\text { Weight (g) }\end{array}$ & Total \\
\hline 31 & 5 & 226 & 55 & 2555 & 60 \\
\hline 89 & 0 & 0 & 6 & 67 & 6 \\
\hline 91 & 0 & 0 & 1 & 340 & 1 \\
\hline 135 & 1 & 101 & 5 & 48 & 6 \\
\hline 150 & 0 & 0 & 13 & 173 & 13 \\
\hline 155 & 2 & 73 & 10 & 257 & 12 \\
\hline 157 & 19 & 395 & 53 & 1063 & 72 \\
\hline 160 & 21 & 728 & 36 & 2015 & 57 \\
\hline 171 & 15 & 1500 & 90 & 5080 & 105 \\
\hline 176 & 4 & 1720 & 92 & 18504 & 96 \\
\hline 191 & 0 & 0 & 64 & 3608 & 64 \\
\hline 215 & 2 & 218 & 48 & 1970 & 50 \\
\hline 221 & 20 & 1144 & 39 & 1479 & 59 \\
\hline 229 & 0 & 0 & 30 & 2672 & 30 \\
\hline 233 & 0 & 0 & 4 & 24 & 4 \\
\hline 250 & 5 & 95 & 3 & 19 & 8 \\
\hline 259 & 0 & 0 & 4 & 948 & 4 \\
\hline 261 & 0 & 0 & 19 & 115 & 19 \\
\hline 274 & 0 & 0 & 2 & 205 & 2 \\
\hline 280 & 0 & 0 & 12 & 1519 & 12 \\
\hline 306 & 11 & 325 & 63 & 1762 & 74 \\
\hline 315 & 7 & 363 & 60 & 4027 & 67 \\
\hline Total & $\mathbf{1 1 2}$ & $\mathbf{6 8 8 8}$ & $\mathbf{7 0 9}$ & $\mathbf{4 8 4 5 0}$ & $\mathbf{8 2 1}$ \\
\hline & & & & & \\
\hline
\end{tabular}

Table 10-6. Feature and Non-feature Rock Weight Data, 41PR44

\begin{tabular}{|c|c|c|c|c|}
\hline Weight Groups & Feature 12 & Feature 20 & Feature 21 & $\begin{array}{c}\text { Non-Feature } \\
\text { Random Sample }\end{array}$ \\
\hline$<101 \mathrm{~g}$ & $74.5 \%$ & $77.2 \%$ & $78.7 \%$ & $88.2 \%$ \\
\hline $101-200 \mathrm{~g}$ & $10.9 \%$ & $12.3 \%$ & $10.3 \%$ & $4.9 \%$ \\
\hline $201-300 \mathrm{~g}$ & $5.7 \%$ & $4.4 \%$ & $4.9 \%$ & $2.6 \%$ \\
\hline $301-400 \mathrm{~g}$ & $3.9 \%$ & $1.8 \%$ & $2.7 \%$ & $1.0 \%$ \\
\hline $401-500 \mathrm{~g}$ & $1.8 \%$ & $0.8 \%$ & $1.1 \%$ & $1.1 \%$ \\
\hline $501-1000 \mathrm{~g}$ & $1.8 \%$ & $3.5 \%$ & $1.9 \%$ & $1.6 \%$ \\
\hline$>1000 \mathrm{~g}$ & $1.8 \%$ & $0.0 \%$ & $0.5 \%$ & $0.7 \%$ \\
\hline Mean Rock Weight & $105.37 \mathrm{~g}$ & $83.64 \mathrm{~g}$ & $85.41 \mathrm{~g}$ & $67.4 \mathrm{~g}$ \\
\hline
\end{tabular}


that at a broad level (e.g., thermal features vs. stone boiling dump) they are probably being used in a roughly similar manner. The comparison further implies some differences in the feature and non-feature assemblages. The comparison does not clarify what that broad pattern may be, though the presence of rock in the larger size ranges would tend to negate the stone boiling dump scenario.

Data with more direct impact on this question is provided by Quigg and Cordova (2000:85-91, 165-168). They convincingly argue, based on both rock size and residue analysis, that four sandstone dominated features from 41ZP364, located in south Texas in Zapata County, are the result of stone boiling dumps. All four of these features have small quantities of sandstone, with average number of rock being just over 18 items. Average weight for stones recovered from these features is about $76.5 \mathrm{~kg}$, and, like the three feature from 41PR44, the vast majority of rock $(79.5 \%)$ are less than $101 \mathrm{~g}$ in weight. However, the weight distributions of the 41ZP364 features differ significantly from the 41PR44 features in the larger weight classes. This can be seen in Figure 10-10. Here, we have combined the four 41ZP364 features into a single "stone boiling" curve and compared the relative number of items in each weight class to the curves for the 41PR44 features. Note that the initial weight class $(<101 \mathrm{~g})$ is not plotted in the figure. The percentages are roughly similar in this smallest weight group, ranging from $74.5 \%$ to $79.5 \%$ for all features, and if plotted, these percentages tend to obscure differences in the heavier weight classes. Focusing on the Figure 10-10, the differences in the curves are clear. The pattern that Quigg and Cordova (2000) suggest is a result of stone boiling lacks any stones greater than $300 \mathrm{~g}$, while the three 41PR44 features all have roughly similar curves, but curves that are quite different from the stone boiling dump expectations. Given these results, it is unlikely that the 41PR44 features reflect stone boiling dumps. They appear, rather, to be consistent with a suggestion of direct heating, with the stone being used primarily to store and then dissipate heat.

\section{Rock Type in Features}

To the degree that heat retention was, in fact, a relevant element in feature construction, we would expect that denser limestone rock would be differentially used in feature construction. As demonstrated in Chapter 2, sandstone dominates the immediate site environment, but limestone is present, being exposed in Rock Creek. Limestone and sandstone probably have different characteristics when it comes to heating and heat dissipation. While a similar weight of limestone and sandstone may retain and dissipate heat in a similar pattern, the higher density of limestone means that fewer rocks will be necessary to obtain a given weight. Perhaps more critical than any density differences, however, is the potential that limestone is more resistance to thermal fatigue and thermal shock, and thus would not require replacement as often as sandstone. Studies of Edwards Limestone suggest that from four to eight cycles of heating and cooling will result in disintegration of the stone (see Lucas and Frederick 1998). While we know of no comparable studies on materials in the Parker County area, the limestone located near the site is a much denser material than the sandstone, and may be more resistant to thermally induced failure. However, Jackson (1998) argues that because sandstone is more porous and course grained, it would be more likely to withstand stresses. At the present time, we do not know if, in fact, replacement rates are substantially different for these two materials. While controlled studies are clearly needed, it may well be the case that limestone frequencies in features vary as a function of both replacement rates and different heating requirements.

Reference to Table 10-4, presented previously, shows that the percentage of limestone varies considerably between the three features, with this denser material accounting for more than $50 \%$ of the stone in Feature 12, almost $25 \%$ in Feature 21, and $19 \%$ in Feature 20. These limestone percentages are substantially higher than those for non-feature contexts. In the non-feature material greater than one-half inch in size, limestone accounted for only $11.2 \%$ of the 6,568 items collected from 41PR44.

A more critical element than the number of items of a given material within a feature, however, may be the overall weight of those items. The weight of limestone in the 41PR44 features is consistently less than that of sandstone. Limestone accounts for roughly $43 \%$ of the total weight in Feature 12, and about 19\% in Feature 21 (Table 10-4). Reference to the weight totals in Table 10-5 will show that weight totals in these two features far exceed that for non-feature contexts where limestone accounts for about $12.4 \%$ of the $55.4 \mathrm{~kg}$ of rock. The totals for Feature 20, however, are quite different. For Feature 20, while limestone accounts for $19.1 \%$ of the total feature rock, the weight contribution is only $.86 \mathrm{~kg}$, roughly $8.9 \%$ of the overall feature weight (see Table 10-4). The limestone rocks in this feature, then, are quite small, with the 22 items having an average weight of only 39 g. In contrast, Feature 12 limestone averages 86.8 g, and those in Feature 21 average $68.1 \mathrm{~g}$. 


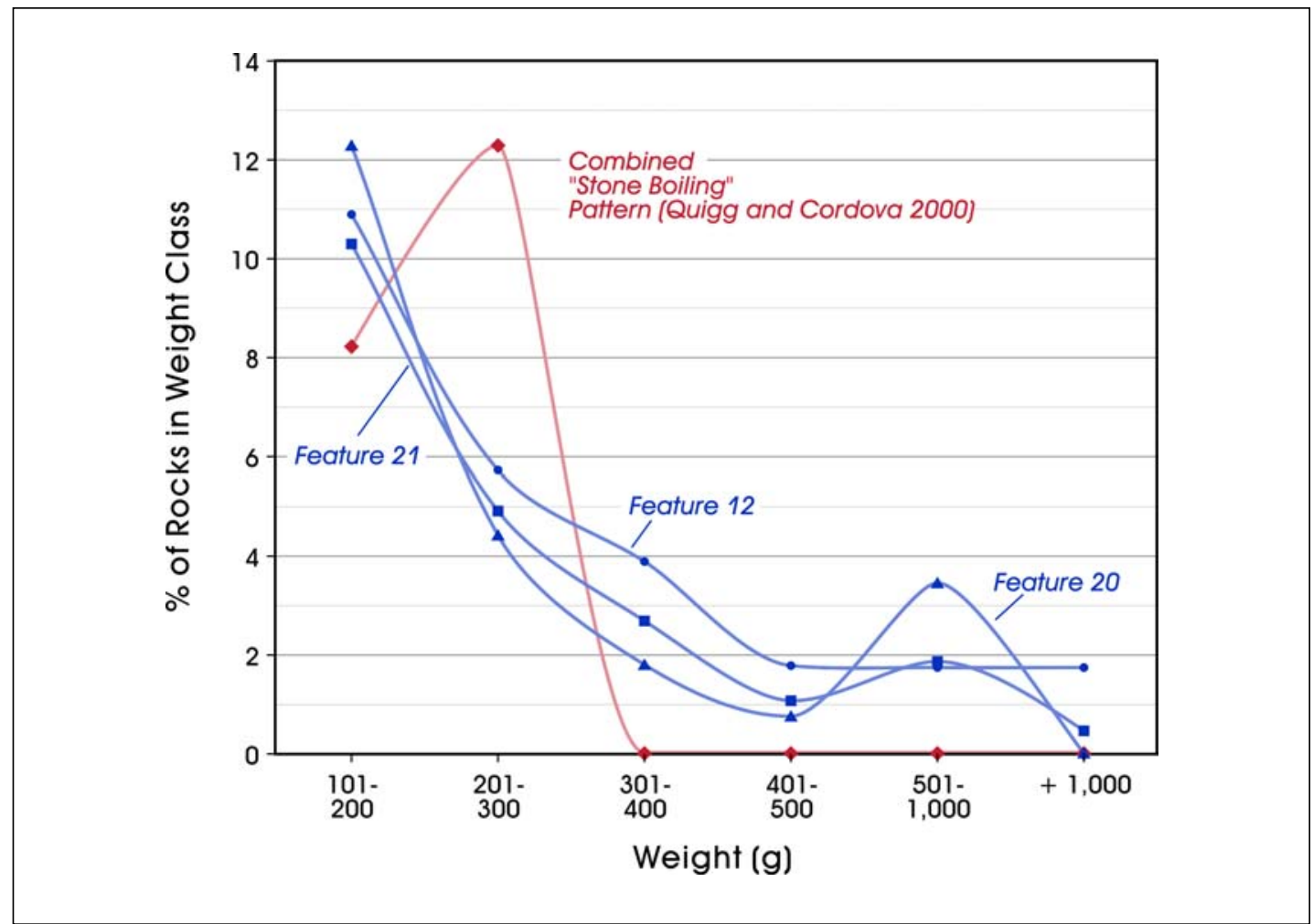

Figure 10-10. Percentage of rock in various weight classes for 41PR44 features (blue) and features previously classified as resulting from "stone boiling” (red). Note that the 0-100 g weight class is not shown.

While we do not know the reasons for the substantially smaller limestone in Feature 20, it is clear that at least for Features 12 and 21, limestone weights at a feature level account for a higher contribution than expected based on site totals. There appears to be a preference for this denser stone in these two features. That preference may be related to aspects of heat retention/dissipation patterns and differences in thermal fatigue and associated replacement rates in the denser limestone when compared to sandstone. The lack of a significant weight contribution from limestone in Feature 20 hints that this feature may have had different heating requirements, or that replacement of fractured stone was not a primary concern.

\section{Total Rock Weight in Features}

The final feature attribute considered here is the total weight of rocks that make up an individual feature. As several researchers have argued (e.g., Black 2003; Mauldin et al. 1998), there should be a relationship between the total weight of a feature and the capacity of that feature to store and transmit heat. By focusing on weight as a measure of the thermal capacity of features, we might be able to empirically define different feature types, and begin to develop an understanding of the range of resources that were processed in those features. While any strict interpretation will be complicated by patterns of feature reuse, as well as feature definition, total rock weight for a feature may provide our best measure, albeit at a general level, of feature function. Any patterns identified here are, of course, tentative being based on only three features, all of which lack any additional data (e.g., ethnobotanical information, residue analysis) that might be used to support different feature types. Additional features from throughout the region will be necessary to explore the potential of weight as a defining characteristic for rock features.

Nevertheless, for the three features defined at 41PR44, total weights varied considerably. As shown in Table 10-4, weights ranged from as low as $9.62 \mathrm{~kg}$ for Feature 20, to over $335 \mathrm{~kg}$ for Feature 21. While it may be the case that the $45.52 \mathrm{~kg}$ weight for Feature 12 reflects two features (see Figure 10-7), this was not recognized in the field, and, 
as a consequence, the material was not excavated separately. Even if the Feature 12 weight was split, however, each individual lobe of Feature 12 would still be substantially heavier than Feature 20. Given these substantial weight differences, it is possible that each of the features at 41PR44 were used for different activities.

The suggestion that each of these three features may represent different types is supported by the pattern in Figure 10-11. Here, we plot the number of rocks and the rock feature weight for the three features at 41PR44, along with 10 features from 41MU55 reported by Clabaugh (1994: 81-102). 41MU55 is located roughly $120 \mathrm{~km}$ north of 41PR44, and is within the Cross-Timbers area (see Thoms 1994). The upper portion of Figure 10-11 presents all 13 features, while the lower plot omits the extreme case of Feature 21 at 41PR44. Focusing initially on the upper plot, the extreme case of Feature 21 relative to the other 12 features is clear. With a weight of in excess of $335 \mathrm{~kg}$, the weight of this feature is comparable to the weights suggested for single use burned rock midden features in Central Texas (see Black 1997; Mauldin et al. 2003; Thoms 1989). When the extreme counts and weights associated with Feature 21 are eliminated (Figure 10-11, bottom), a cluster of smaller features, identified in the figure by a dashed line, are clearly present near the origin of the plot. These features have low weights and low numbers of rock. While they may represent a specialized type, it may also be the case that this group represents general domestic hearths. Finally, Feature 12, which may represent two distinct features, falls in the upper quadrant of Figure 10-11. If it was, in fact, two distinct features, then the number and weights presented in the figure should be roughly halved, and the feature would be closer to that identified by the dashed line. Conversely, if the feature is a single hearth, then it is comparable in weight to one recorded at $41 \mathrm{MU} 55$, and may define a different type relative to other groups.

\section{Summary}

At 41PR44, CAR initially defined 12 burned rock features. These 12 were added to a list that included two burned rock features identified by Brownlow (2001) during testing. As presented in Chapter 6, our project geoarchaeologist suggested that in all 12 cases, the rock clusters were probably natural accumulations of unburned rock as well as re-deposited burned rock, rather than representing intact thermal features. A similar assessment was presented for the two features previously identified by TARL. During our fieldwork, we had the opportunity to examine a series of off-site deposits that were dominated by reddened, angular sandstone. These deposits appeared quite similar to the material we had identified as features on 41PR44. Much of the current chapter, then has been concerned with identifying what was, and was not, a burned rock feature. In attempting to answer this basic question, we have employed experimental data to identify patterns in magnetic alterations in rock and sediment as a function of heating, and then applied that experimentally supported data to the archaeological record. Changes in magnetic susceptibility of archaeological material allowed us to eliminate a number of clusters that we had previously identified as features. Greave's assessment of these clusters, presented in Chapter 6, was generally supported. However, in three cases, there is evidence to indicate that clusters of sandstone and limestone were intact, thermal features. In addition, we have no information on Feature 1 (Brownlow 2001), and so we will assume that it, too, represents an intact feature at this site.

Focusing on a variety of attributes of the three features excavated by CAR, and using other archaeological cases from the region, as well as outside the study area, we suggested that none of the cases at 41PR44 matched expectations for stone boiling dumps. Rather, they appear to represent thermal features probably used to process food resources. Comparison of the weights of features suggests that Feature 21 may represent a different type of feature when compared to Features 12 and 20. That is, relative to other features, Feature 21 may have been used to process either a different range of foods that require longer cooking times, or greater quantities of food at one time. In fact, the weights of this feature are comparable to the weights suspected for single-use burned rock midden features in Central Texas. The weight and number of rock in Feature 20 , conversely, is similar to other features defined in the region. These may represent general domestic hearths, rather than a more specialized feature type, though this suggestion is nothing more than that. Finally, Feature 12 may define a more specialized feature.

Clearly, additional feature weights from other locations, both within and outside of the region, will be necessary to being to document the extant variability in feature weights, rock size, and composition. The patterns presented here are simply a first step in that direction. Once established, features within a given cluster or type (e.g., domestic hearths, burned rock midden) should be further investigated through macrobotanical analysis of sediment or residue analysis on rocks to identify the types and range of resources processed. 


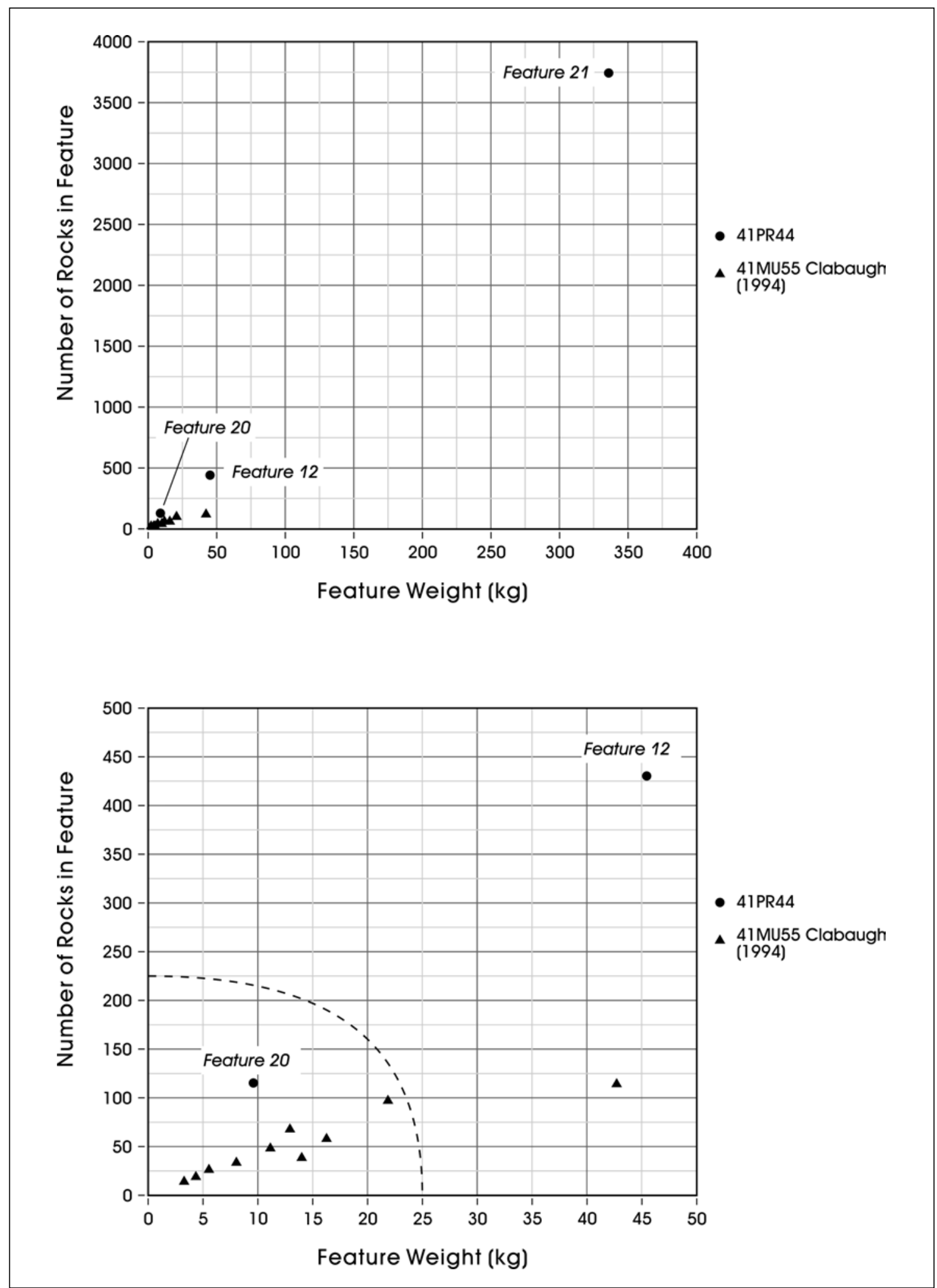

Figure 10-11. Number of rocks and total weight for features at sites 41PR44 and 41MU55. Feature 21 (41PR44) is included in top plot and excluded in bottom plot. 



\section{Chapter 11: Summary and Conclusions}

During the late spring of 2004, the Center for Archaeological Research (CAR) of The University of Texas at San Antonio conducted data recovery excavations at site 41PR44, located on Fort Wolters in Parker County, Texas. Previous survey and testing of the site, conducted by TARL (Brownlow 2001; Brownlow et al. 1999), had identified Late Prehistoric, and possibly Late Archaic, materials. The presence of what was thought to be a high density of burned rock features, along with faunal material, chipped stone debitage and tools, and ground stone was used to recommend the site as eligible for listing on the National Register of Historic Places (Brownlow 2001:18). A frequently used dirt road cuts through the center of the site, and maintenance of the road was damaging the archaeological deposits. As avoidance of this site area was not possible, CAR was contracted by the Adjutant General's Office of the Texas Military Forces to develop and execute a data recovery plan that was designed to target critical data from the Late Prehistoric, and potentially earlier, occupations at 41PR44.

Field work at site 41PR44 occurred during March and April of 2004. The work was conducted under a memorandum of agreement between the Texas Army National Guard and the Texas Historical Commission. Consistent with the data recovery plan (Mauldin 2004), CAR personnel initially excavated a series of shovel tests and hand-auger tests to better document the vertical and horizontal distributions of cultural material. The results of these shovel tests, along with the results from the previous work at 41PR44, were then used to locate hand-excavated units. CAR personnel excavated $241-\mathrm{x}-1-\mathrm{m}$ units, and screened roughly $18.8 \mathrm{~m}^{3}$ of sediment from these units. Following the completion of the hand-excavated units, four backhoe trenches were cut. The excavations at 41PR44 produced a variety of data sets, including large quantities of what was thought to be burned sandstone and limestone rock, 46 lithic tools, 883 pieces of chipped stone debitage, sediment samples from burned rock clusters identified in the field, and small quantities of bone, charcoal, and mussel shell.

However, the picture of 41PR44 that emerges from the analysis of the data recovery material is different in several important aspects from the one developed by TARL based on the limited testing. While the site does have clear evidence of early Late Prehistoric, Late Archaic, and earlier occupations, the data potential of these occupations are significantly less than suggested by earlier research. It appears that many of the clusters of sandstone and limestone that were thought to reflect intact, cultural features are probably a combination of natural accumulations of unburned sandstone and redeposited cultural materials. While we were able to isolate and excavate several cultural features that were intact, our shovel and hand auger testing, as well as our backhoe trenching, failed to produce any unexplored clusters that have a reasonable probability of reflecting intact thermal features. In addition, while we were able to identify pockets that have some level of integrity, our excavation results suggest that much of the western portion of 41PR44 has deposits that are substantially mixed. This conclusion is based both on the geoarchaeological analysis, as well as the analysis of temporally sensitive artifacts. Any deposits that remain in this area of the site are unlikely to have sufficient integrity to address any research questions requiring fine-grained temporal resolution. Our systematic shovel and auger testing did reveal chipped stone deposits in the southeastern section of the site (Area 2) that had high integrity, as well as good temporal resolution. Data present in these deposits have been recovered through excavation. The work conducted by CAR at 41PR44 in combination with the results of earlier survey and testing efforts completed by TARL (Brownlow et al. 1999; Brownlow 2001) has effectively sampled or completely recovered known significant data types from this site.

While the data collected from 41PR44 were, in several cases, less than ideal, we were able to use these data to explore a number of different interpretive and methodological issues, as well as address limited aspects of prehistoric adaptations in north-central Texas. In terms of interpretive considerations, the first issue relates to raw material availability and the potential impacts of differential access on an assemblage. Traditionally, variations in cortex percentages have been interpreted as reflecting different levels of reduction. Assemblages characterized by low frequencies of tertiary flakes and high frequencies of flakes with large amounts of cortex, were thought to unambiguously reflect early reduction activities. Their counterparts, assemblages with high percentages of tertiary flakes and low percentages of primary flakes, were interpreted as reflecting late reduction activities. An outgrowth of the work presented in Chapter 8 is that both 
of these cortical patterns could reflect the same level of reduction, with one relying on small cobbles and the second relying on much larger tool stone. That is, a focus on cortex percentage, as such, is of little use in tracking different levels of reduction. Cortical percentages are an outgrowth of the interaction between reduction trajectories and raw material sizes. While additional efforts in defining availability of raw materials across the state are certainly necessary, as well as experimental efforts to better define the relationship between raw material size and cortical patterns, the simplistic equation of varying cortical percentages reflecting reduction levels is no longer warranted.

Much of the discussion in Chapter 10 was concerned with identifying what was, and was not, a burned rock feature. In attempting to answer that basic question, we used experimental and archaeological data to identify alterations in patterns in magnetic susceptibility of rock and sediment as a function of heating. The changes in magnetic susceptibility shown in both the experimental and archaeological sediment samples as a function of temperature for Feature 12 at 41PR44, as well as the shifts in the experimental samples of sandstone rock with incremental heating, suggests not only that magnetic susceptibility may provide keys to what samples were, and were not heated, but also suggests the possibility that we may be able to isolate specific temperature ranges for features. A variety of problems must be solved before we are able to directly monitor temperature ranges in prehistoric features. The impacts of natural fires on sandstone need to be quantified. We need to develop ways to document what mineralogical changes are taking place in a specific sample as a function of increased temperatures. Nevertheless, the possibility that we may be able to directly monitor temperature ranges in prehistoric features opens up a more direct method for isolating different feature types. This, in turn, has implications both for increasing our understanding of feature technology as well as the organization of subsistence.

Beyond these potential developments in the interpretive and methodological areas, we also gained some insights into aspects of the Late Prehistoric and Archaic adaptations at 41PR44. Chapter 8 considered patterns in lithic tools and in vertebrate fauna in order to explore aspects of subsistence. The ground stone assemblage from 41PR44, when contrasted to other assemblages, seems to reflect a focus on lower return plant resources. While we cannot place the ground stone securely in a temporal framework, most of the assemblage was recovered from locations that have a higher probability of dating to the Late Prehistoric period.
The relative contribution of animals in different body-size groups suggests that an increased dependence on lower return, but more ubiquitous, smaller animals is reflected by the early Late Prehistoric material. These faunal changes, along with the patterns in ground stone, may reflect a broadening of the diet during the early Late Prehistoric period relative to the earlier Archaic occupations at 41PR44. If this is supported by additional investigations, the patterns can be interpreted as an outgrowth of falling return rates for higher ranked resources, such as bison, and an increased intensification during the early Late Prehistoric time frame.

Chapter 9 investigated the impact of differential access to raw materials on chipped stone assemblages at 41PR44. We suggested that early Late Prehistoric occupants relied more heavily on non-local resources while the Late Archaic populations at 41PR44 were using primarily local stone. The pattern of reliance on local tool stone in the Late Archaic is consistent with the suggestions of Prikryl (1990) for this region. The shift to non-local stone in the early Late Prehistoric, however, if verified in other sites, clearly hints at the development of different levels of mobility, and perhaps different ways of organizing that mobility, relative to the Late Archaic.

Finally, in Chapter 10, we explored the utility of investigating different types of features. This preliminary attempt to define different types of features based primarily on weights, while limited by the small number of intact burned rock clusters, is of interest in that it highlights the unique nature of Feature 21 at 41PR44. That is, Feature 21 may have been used to process either a different range of foods that require longer cooking times, or greater quantities of food at one time. In fact, the weights of this feature are comparable to the weights suspected for single-use burned rock midden features in Central Texas. Features of this size range have not been documented in this region previously.

\section{Summary}

Data recovery excavation at 41PR44 was conducted by CAR for the Texas Military Forces. The work was conducted in accordance with a Memorandum of Agreement between Texas Military Forces and the Texas Historical Commission (Appendix D). Analysis of the data recovered from excavation revealed that most of the deposits in the western portion of 41PR44 are substantially mixed and have little data potential. Chipped stone deposits in the southeastern section of the site (Area 2) that had high integrity and good 
temporal resolution were recovered through excavation. The work conducted by CAR at 41PR44, in combination with the results of earlier survey and testing efforts completed by TARL (Brownlow et al. 1999; Brownlow 2001), has effectively sampled or completely recovered known significant data types from this site. Deposits remaining at 41PR44 are unlikely to have sufficient integrity to address any research questions requiring fine-grained temporal resolution. In accordance with the MOA, mission critical military training activities should be allowed to proceed without any further restrictions. 



\section{References Cited}

Andrefsky, W.

1998 Lithics: Macroscopic Approaches to Analysis. University Press, Cambridge.

Anthony, D., and D. O. Brown

1991 Archeological Survey of a Proposed Electrical Transmission Line between Dicey and Aledo Substations, Parker County, Texas. Hicks \& Company, Austin.

Barnes, V. E.

1972 Geologic Atlas of Texas: Abilene Sheet. Bureau of Economic Geology, The University of Texas at Austin.

1988 Geologic Atlas of Texas: Dallas Sheet. Bureau of Economic Geology, The University of Texas at Austin.

Bellomo, R. V.

1983 A Methodological Approach to Identifying Archaeological Evidence of Fire Resulting from Human Activities. Journal of Archaeological Science 20:523-553.

Bement, L.C.

1989 Excavations at 41BP19 the Kennedy Bluffs Site, Bastrop County, Texas. Contract Reports in Archaeology, Report Number 5. Texas State Department of Highways and Public Transportation Highway Design Division, Austin.

Birkeland, P. W.

1984 Soils and Geomorphology. Oxford University Press, New York.

Black, S. L.

1986 The Clemente and Herminia Hinojosa Site, 41JW8: A Toyah Horizon Campsite in Southern Texas. Special Report, No. 18. Center for Archaeological Research, The University of Texas at San Antonio.

2003 Studying the Hearths of the Greater Edwards Plateau. In Pavo Real (41BX52): A Paleoindian and Archaic Camp and Work-shop on the Balcones Escarpment, South-Central Texas, by M. B. Collins, D. B. Hudler, and S. L. Black, pp. 375-405. Studies in Archeology 41, Texas Archeological Research Laboratory, The University of Texas at Austin. Archeological Studies Program, Report 50, Environmental Affairs Division, Texas Department of Transportation, Austin.

Black, S. L., L. W. Ellis, D. G. Creel, and G. T. Goode

1997 Hot Rock Cooking on the Greater Edwards Plateau: Four Burned Rock Midden Sites in West Central Texas. Studies in Archeology 22, Texas Archeological Research Laboratory, The University of Texas at Austin. Archeology Studies Program, Report 2, Environmental Affairs Division, Texas Department of Transportation, Austin.

Black, S. L, K. Jolly, C. D. Frederick, J. R. Lucas, J. W. Karbula, P. R. Takac, and D. R. Potter.

1998 Archeology along the Wurzbach Parkway Module 3: Investigation and Experimentation at the Higgins Site (41BX184). Volume 1. Studies in Archeology 27. Texas Archeological Research Laboratory, The University of Texas at Austin. 
Black, S. L. and A. J. McGraw

1985 The Panther Springs Creek Site: Cultural Change and Continuity within the Upper Salado Creek Watershed, South-Central Texas. Archaeological Survey Report, No. 100. Center for Archaeological Research, University of Texas at San Antonio.

Blalock, H. M.

1979 Social Statistics. 2d ed. McGraw Hill, Inc. New York.

Bomar, G. W.

1999 Texas Weather. 3d ed. University of Texas Press, Austin.

Bousman, C. B.

1998 Paleoenvironmental Change in Central Texas: The Palynological Evidence. Plains Anthropologist 43(164): 201-219.

Boyd, D. K., J. T. Abbot, W. A. Bryan, C. M. Garvey, S. Tomka and R. C. Fields

1990 Phase II Investigations at Prehistoric and Rock Art Sites, Justiceburg Reservoir, Garza and Kent Counties, Texas. Reports of Investigations, No. 71. Prewitt and Associates, Inc., Austin.

Boyd, D. K., J. Peck, S. A. Tomka, and K. W. Kibler

1993 Recovery at Justiceberg Reservoir (Lake Alan Henry), Garza and Kent Counties, Texas: Phase III, Season 2. Reports of Investigations, No. 88. Prewitt and Associates, Inc. Austin, Texas.

Brewington, R. L., J. E. Dockall, and H. J. Shafer

1995 Archaeology of 41MX5: A Late Prehistoric Caddoan Hamlet in Morris County, Texas. Reports of Investigations No. 1. Center for Environmental Archaeology, Texas A\&M University, College Station.

Brown, D.

1986 Summary Report: Cultural Resource Surveys, Agnes Electrical Transmission Line and Substation, Parker County, Texas. Document No. 861301. Espey, Huston and Associates, Inc., Austin.

1989 Prehistoric Subsistence Strategies in Northeastern Central Texas. Bulletin of the Texas Archeological Society 59:201-244.

1998 Late Holocene Climates of North-Central Texas. Plains Anthropologist 43:157-172.

Brownlow, R. K.

2001 The Testing of Four Sites at the Texas Army National Guard's Fort Wolters Facility, Parker County, Texas. Studies in Archeology 37, Texas Archeological Research Laboratory, The University of Texas at Austin. Environmental Report 2, Texas Army National Guard, Austin.

1999 Appendix A: Site and Locality Descriptions. In An Intensive Cultural Resources Survey of the Texas Army National Guard's Fort Wolters Facility, Parker and Palo Pinto Counties, Texas, by R. K. Brownlow, D. J. Prikryl, T. Gustavson, J. Garner, and M. B. Collins, pp. 67-93. Studies in Archaeology 32, Texas Archeological Research Laboratory, The University of Texas at Austin. Environmental Report 1, Texas Army National Guard, Austin. 
Brownlow, R. K., D. J. Prikryl, T. Gustavson, J. Garner, and M. B. Collins

1999 An Intensive Cultural Resources Survey of the Texas Army National Guard's Fort Wolters Facility, Parker and Palo Pinto Counties, Texas. Studies in Archaeology 32, Texas Archeological Research Laboratory, The University of Texas at Austin. Environmental Report 1, Texas Army National Guard, Austin.

Bryant, V. M., Jr., and R. Holloway

1985 A Late-Quaternary Paleoenvrionmental Record of Texas: An overview of the Pollen Evidence. In Pollen Records of Late-Quaternary Sediments, edited by Vaughan Bryant and Richard Holloway pp. 39-70. American Association of Stratigraphic Palynologists Foundation. Hart Graphics, Austin.

Camper, H. A.

1991 Pollen Analysis of Patschke Bog. Unpublished Master's thesis, Department of Botany, Texas A\&M University, College Station. Data archived at the World Data Center System, http://www.ncdc.noaa.gov/paleo/datalist.html, accessed January, 2006. North American Pollen Database, made available by the NOAA Paleoclimatology Program, National Climatic Data Center (NCDC), Boulder. Contributor of data to site is V. M. Bryant, Jr.

Chambers, J. M., W. S. Cleveland, B. Kleiner, and P. A. Tukey

1983 Graphical Methods for Data Analysis. Bell Laboratories, Duxbury Press, Boston.

Charnov, E. L., G. H. Orians, and K. Hyatt

1976 The Ecological Implications of Resource Depression. American Naturalist 110:247-259.

Clabaugh, P. A.

1994 The Nature and Distribution of Features at 41MU55. In The Valley Branch Archaeological Project: Excavations at an Archaic Site (41MU55) in the Cross Timbers Uplands, North Central Texas, edited by A. V. Thoms, pp. 81110. Reports of Investigations No. 15, Archaeological Resources Laboratory, Texas A\&M University, College Station.

Clark, A. J.

1996 Seeing Beneath the Soil. 2d ed. Batsford Press, London.

Cliff, M.

2003 Archeological Data Recovery Investigations of Four Burned Rock Midden Sites (41VV1892, 41VV1893, 41VV1895, 41VV1897), Val Verde County, Texas. Document No. 010102, PBS\&J. Environmental Affairs Division, Texas Department of Transportation, Austin.

Cliff, M. B., M. M. Green, S. M. Hunt, D. Shanabrook

1995 Archeological Test Excavations at Two Prehistoric Sites (41DT59 and 41DT247) at Cooper Lake, Delta County, Texas, 1994. Miscellaneous Report of Investigations No. 90, Geo-Marine, Inc., Plano, Texas.

Cliff, M. B, E. C. Sills, T. K. Perttula and P. Dering

2002 National Register Testing of Sites 41HE14, 41HE139, and 41HE343 Within Proposed FM 3506 Right of Way, Henderson County, Texas. Document No. 030373, PBS\&J. Archeological Studies Program, Report 60, Environmental Affairs Division, Texas Department of Transportation, Austin.

Collins, M. B.

1995 Forty Years of Archaeology in Central Texas. Bulletin of the Texas Archeological Society 66:361-400. 
Collins, M. B., D. B. Hudler, and S. Black

2003 Pavo Real (41BX52): A Paleoindian and Archaic Camp and Workshop on the Balcones Escarpment, SouthCentral Texas. Studies in Archeology 41, Texas Archeological Research Laboratory, The University of Texas at Austin.

Collins, M. B., W. A. Gose, and S. Shaw

1994 Preliminary Geomorphological Findings at Dust and Nearby Caves. Journal of Alabama Archaeology 40:35-56.

Crowther, J.

2003 Potential Magnetic Susceptibility and Fractional Conversion Studies of Archaeological Soils and Sediments. Archaeometry 45:685-701.

Dalan, R. A., and S. K. Banerjee

1998 Solving Archaeological Problems Using Techniques of Soil Magnetism. Geoarchaeology 13:3-36.

Davis, D. R., Jr.

1991 Prehistoric Artifacts of the Texas Indians. Pecos Publishing Company, San Antonio, Texas.

Davis, W. B. and D. J. Schmidly

1997 The Mammals of Texas- Online Edition. Electronic database, http://www.nsrl.ttu.edu/ tmot1/Default.htm, accessed January, 2006. Texas Tech University and Texas Parks and Wildlife Department, Nongame and Urban Program, Austin.

Dearing, J.

1999 Environmental Magnetic Susceptibility. Chi Publishing, Kenilworth, England.

Decker, S., S. L. Black, and T. Gustavson

2000 The Woodrow Heard Site, 41UV88: A Holocene Terrace Site in the Western Balcones Canyonlands of Southwestern Texas. Studies in Archeology 33, Texas Archeological Research Laboratory, The University of Texas at Austin. Archeology Studies Program, Report 14. Environmental Affairs Division, Texas Department of Transportation, Austin.

Dering, J. P.

1999 Earth Oven Processing in Archaic Period Economics: An Example from a Semi-Arid Savannah in South-Central North America. American Antiquity 64:659-674.

Diamond, D. D., D. H. Riskind, and S. L. Orzell

1987 A Framework for Plant Community Classification and Conservation in Texas. The Texas Journal of Science 39(3):203-221.

Dillehay, $\mathrm{T}$.

1974 Late Quaternary Bison Population Changes on the Southern Plains. Plains Anthropologist 19(64):180-196.

Driver, H. E. and W. C. Massey

1957 Comparative Studies of North American Indians. Transactions of the American Philosophical Society. Vol. 47. Philadelphia, Pennsylvania. 
Dyksterhuis, E. J.

1948 Vegetation of the Western Cross Timbers. Ecological Monographs 18:325-376.

Elias, S. A.

2001 Paleoenvironmental Significance of Late Glacial Insect Fossil Assemblages from the Aubrey Site, North Central Texas. In The Archaeology and Paleoecology of the Aubrey Clovis Site (41DN479) Denton County, Texas. Center for Environmental Archaeology, Department of Geography, University of North Texas, Denton.

Ellis, L. W.

1997 Hot Rock Technology. In Hot Rock Cooking on the Greater Edwards Plateau: Four Burned Rock Midden Sites in West Texas, Volume 1, by S. L. Black, L. W. Ellis, D. G. Creel, and G. T. Goode, pp. 43-81. Studies in Archeology 22, Texas Archeological Research Laboratory, The University of Texas at Austin. Archeology Studies Program Report 2, Environmental Affairs Division, Texas Department of Transportation, Austin.

Ensor, B. E.

1995 Archaeological Test Excavations at Four Shell Midden Sites in the Wallisville Lake Project Area, Chambers and Liberty Counties, Texas. Wallisville Lake Project Technical Series Reports of Investigations, No. 2. Geo-Marine, Inc., Plano, Texas.

Ensor, B. H. and D. L. Carlson

1988 The Crawford Site, 41PK69, Central Trinity River Uplands Polk County, Texas. Contracts in Archaeology, Report 4. Texas State Department of Highways and Public Transportation, Highway Design Division, Austin.

Epstein, H. E., W. K. Lauenroth, I. C. Burke, and D. P. Coffin

1997 Productivity Patterns of $\mathrm{C}_{3}$ and $\mathrm{C}_{4}$ Functional Types in the U.S. Great Plains. Ecology 78:722-731.

Everitt, B. S.

1977 The Analysis of Contingency Tables. Chapman and Hall, London.

Farwig, V. J., S. H. Doerr, W. B. Blake, and R. A. Shakesby

2004 The Effects of Heating on Mineral Magnetic Enhancement of Soils: A Case Study Using Australian Soils. Geophysical Research Abstracts Vol. 6, No. 04912. European Geosciences Union, Strasbourg, France.

Fenneman, N.

1938 Physiography of the Eastern United States. McGraw-Hill, New York.

Ferring, C.R.

1989 The Aubrey Clovis Site: A Paleoindian Locality in the Upper Trinity River Basin, Texas. Current Reasearch in the Pleistocene 6:9-11.

2001 The Archaeology and Paleoecology of the Aubrey Clovis Site (41DN479) Denton County, Texas. Center for Environmental Archaeology. Department of Geography, University of North Texas, Denton.

Ferring, C. R. and B. C. Yates

1997 Holocene Geoarchaeology and Prehistory of the Ray Roberts Lake Area, North Central Texas. Institute of Applied Sciences, University of North Texas, Denton.

1998 Archaeological Investigations at Five Prehistoric Sites at Lewisville Lake, Denton County, Texas. Center of Environmental Archaeology, Department of Geography, University of North Texas, Denton. 
Fields, R. C., C. B. Bousman, and S. J. Kooren

1988 National Register Assessments of Six Prehistoric Sites at the Jewitt Mine, Leon County, Texas. Reports of Investigations, No. 67. Prewitt and Associates, Inc. Consulting Archeologists. Austin, Texas.

Fields, R.C., L. W. Klement, C. B. Bousman, S. A. Tomka, E. F. Gadus, and M. A. Howard

1991 Excavations at the Bottoms, Rena Branch, and Moccasin Springs Sites, Jewitt Mine Project, Freestone and Leon Counties. Reports of Investigations, No. 82. Prewitt and Associates, Inc. Consulting Archaeologists. Austin, Texas.

Figueroa, A. L. and R. P. Mauldin

2005 Test Excavations and Monitoring at 41BX1598, A Multicomponent Site in San Antonio, Bexar County, Texas. Archaeological Report, No. 360. Center for Archaeological Research, The University of Texas at San Antonio.

Frederick, C. D. and C. Ringstaff

1994 Lithic Resources at Fort Hood: Further Investigations. In Archeological Investigations on 571 Prehistoric Sites at Fort Hood, Bell and Coryell Counties, Texas, edited by W. Nicholas Trierweiler, pp.125-181. Fort Hood Archeological Resource Management Series No. 31, TRC Mariah Associates Inc., Austin.

Frederick, C. D., M. D. Bateman, and P. Lehman

2001 National Register Eligibility Testing at 41LE177, Alcoa Sandow Mine, Lee County, Texas: Archaeological, Geoarchaeological and Paleoenvironmental Assessment of an Upland Sandy Mantle Site. Coastal Archaeological Research, Inc., Corpus Christi, Texas.

Gadus, E. F., Ross C. Fields, C. B. Bousman, S. A. Tomka and M. A. Howard.

1992 Excavations at the Finley Fan Site (41HP159) Cooper Lake Project, Hopkins County, Texas. Reports of Investigations, No. 78. Prewitt and Associates, Inc., Austin.

Gadus, F. E., R. C. Fields, and K. W. Kibler

2006 Data Recovery Excavations at the J.B. White Site (41MM341), Milam County, Texas. Reports of Investigations, No. 145. Prewitt and Associates, Inc., Austin.

Goode, G. T.

2002 The Anthon Site: A Prehistoric Encampment in Southern Uvalde County, Texas. Archaeological Studies Program, Report 38. Environmental Affairs Division, Texas Department of Transportation, Austin.

Gose, W. A., and D. L. Nickels

2001 Archaeomagnetic and Magnetic Susceptibility Analyses. In Test Excavations at the Culebra Creek Site, 41BX126, Bexar County, Texas, by D. L. Nickels, C. B. Bousman, J. D. Leach, and D. A. Cargill, pp. 204-214. Archaeological Survey Report, No. 265, Center for Archaeological Research, The University of Texas at San Antonio. Archeology Studies Program, Report 3, Environmental Affairs Division, Texas Department of Transportation, Austin.

Gould, F. W.

1969 Texas Plants: A Checklist and Ecological Summary. Texas Agricultural Experiment Station. Publication MP-585. Texas A\&M University, College Station.

Gould, F. W., G. O. Hoffman, and C. A. Rechenthin

1960 Vegetation Areas of Texas. Texas Agricultural Experimental Station Leaflet No. 492. Texas A\&M University, College Station. 
Greaves, R. D.

2002a Archaeological Survey of Huntsville State Park and Excavations in 41WA47, Walker County, Texas. Archaeological Survey Report, No. 327. Center for Archaeological Research, The University of Texas at San Antonio.

2002b Archaeological Testing of Sites 41 GD113 and 41 GD114 in Goliad County, Texas. Archaeological Survey Report, No. 344. Center for Archaeological Research, The University of Texas at San Antonio.

Greenwade, J. M., J. D. Kelley, and H. W. Hyde.

1977 Soil Survey of Parker County, Texas. United States Department of Agriculture, Soil Conservation Service. Washington, D. C.

Haberman, S. J.

1973 The Analysis of Residuals in Cross-classified Tables. Biometrics 29:205-220.

Hall, S. A.

2001 Pollen Analysis of Late-Glacial Pond and Spring Deposits, Aubrey Clovis Site, Denton Co., Texas. In The Archaeology and Paleoecology of the Aubrey Clovis Site (41DN479) Denton County, Texas. Center for Environmental Archaeology, Department of Geography, University of North Texas, Denton.

Hatch, S. L., K. N. Gandhi, and L. E. Brown

1990 Checklist of the Vascular Plants of Texas. MP-1655. The Texas Agricultural Experiment Station, Texas A\&M University, College Station.

Hendricks, L.

1957 Geology of Parker County. Bureau of Economic Geology, Publication No. 5724. Austin, Texas.

Highley, C. L.

1986 Archaeological Investigations at 41LK201, Choke Canyon Reservoir, Southern Texas. Choke Canyon Series: Volume 11. Center for Archaeological Research. The University of Texas at San Antonio.

Houk, B. A. W. Boone Law, and K. A. Miller

2005 Significance Testing at the Troll Site, 41CW92, Caldwell County, Texas. SWCA Cultural Resource Report No. 2005-137. SWCA, Inc. Environmental Consultants, Austin. Archeology Studies Program, Report 77. Environmental Affairs Division, Texas Department of Transportation, Austin.

Hubbard, R. A.

1994 An Archeological Survey of the Walnut Creek Special Utility District Proposed Water Distribution Pipeline Extensions, Parker and Wise Counties, Texas. Water Supply Project \#1247W. Texas Water Development Board, Austin.

Huebner, J. A.

1991 Late Prehistoric Bison Populations in Central and Southern Texas. Plains Anthropologist 36(137):343-358.

Humprey, J. and C. R. Ferring

2001 Stable Isotopic Evidence from Late Pleistocene to Holocene Climatic Change, North-Central Texas. Quaternary Research 41:200-213. 
Irwin, A. M., B. Houk, and D. Drake

1999 Excavations at the Bluff Creek Sites: 41 MK10 and 41MK27, McCulloch County, Texas. SWCACultural Resource Report No. 99-61. SWCA, Inc. Environmental Consultants., Austin. Archeology Studies Program, Report 16. Environmental Affairs Division, Texas Department of Transportation, Austin.

Jackson, M. A.

1998 Ethnoarcheological Experiments and New Insights on the Nature of Fire-Cracked Rock. Paper presented at the $4^{\text {th }}$ Headwaters Experimental Workshop, Dripping Springs, Texas.

Jochim, M.

1975 Hunter-gatherer subsistence and settlement: A predictive model. Academic Press, New York.

Johnson, L.

1997 The Lion Creek Site (41BT105): Aboriginal Houses and other remains at a prehistoric Rancheria in the Texas Hill Country (Burnet County). Archeology Studies Program, Report 1. Office of the State Archeologist, Report 41. Texas Department of Transportation, Austin.

2000 Life and Death as Seen at the Bessie Kruze Site (41WN13) on the Blackland Prairie of Williamson County, Texas. Archeology Studies Program, Report 22. Environmental Affairs Division, Texas Department of Transportation, Austin.

Johnson, L., and G. T. Goode

1994 A New Try at Dating and Characterizing Holocene Climates, as Well as Archeological Periods, on the Eastern Edwards Plateau. Bulletin of the Texas Archeological Society 65:1-51.

Kalter, A. and M. A. Nash

2002 Analysis of Materials from Data Recovery Investigations at Site 41BR16, Brown County, Texas. Archeological Studies Program, Report 40. Environmental Affairs Division, Texas Department of Transportation, Austin. PBS\&J, Austin.

Kalters, A. J., R. M. Rogers and M. N. Smith

2005 Analysis and Reporting of 41FY135, the Sandbur Site, Fayette County, Texas. PBS\&J, Document No. 020388. Archeological Studies Program, Report 73. Environmental Affairs Division, Texas Department of Transportation, Austin.

Kaplan, K. H., and K. Hill

1992 The Evolutionary Ecology of Food Acquisition. In Evolutionary Ecology and Human Behavior, edited by E. A. Smith and B. Winterhalder, pp. 167-201. Aldine de Gruyter, New York.

Kelly, R. L.

1995 The Foraging Spectrum. Smithsonian Institution Press, Washington, D.C.

Kibler, K. W. and A. M. Scott

2000 Archaic Hunters and Gatherers of the Balcones Canyonlands: Data Recovery at the Cibolo Crossing Site (41BX377), Camp Bullis Military Reservation, Bexar County, Texas. Reports of Investigations, No. 126. Prewitt and Associates, Inc., Austin. 
Klement, W., R. C. Fields, E. F. Gadus, J. B. McLerran, and C. B. Bousman

1993 The Peerless Bottoms Site, 41HP175. In Excavations at the Tick, Spike, Johns Creek, and Peerless Bottoms Sites, Cooper Lake Project, Delta and Hopkins Counties, Texas, by R. C. Fields, E. F. Gadus, L. W. Klement, C. B. Bousman, and J. B. McLerran, pp. 165-226. Reports of Investigations, No. 91. Prewitt and Associates, Inc., Austin.

Koch, P. L., N. D. Diffenbaugh, and K. A. Hoppe

2004 The Effects of Late Quaternary climate and $\mathrm{CO}_{2}$ Change on $\mathrm{C}_{4}$ Plant Abundance in the South-Central United States. Palaeogeography, Palaeoclimatology, Palaeoecology 207:331-357.

Lucas, J. R. and C. D. Fredrick

1998 Burned Rock as Artifact. In Archeology along the Wurzbach Parkway, Module 3. Investigation and Experimentation at the Higgins Site (41BX184), Vol. I and II, by S. L. Black, K. Jolly, C. D. Frederick, J. R. Lucas, J. W. Karbula, P. R. Takac, and D. R. Potter, pp. 163-188. Studies in Archeology 27. Texas Archeological Research Laboratory, The University of Texas at Austin. Environmental Affairs Division, Texas Department of Transportation, Austin.

Lukowski, P. D.

1989 Archaeological Investigations Along the Leona River Watershed, Uvalde County, Texas. Archaeological Survey Report, No. 132. Center for Archaeological Research, The University of Texas at San Antonio.

MacArther, R. H., and E. R. Pianka

1966 On Optimal Use of a Patchy Environment. American Naturalist 100:603-609.

Mahoney, R. B

2001 Camp Maxey III: Archaeological Testing of 23 Prehistoric Sites, Lamar County, Texas. Archaeological Survey Report, No. 314. Center for Archaeological Research, The University of Texas at San Antonio.

Mahoney, R. B., H. J. Shafer, S. A. Tomka, L.C. Nordt, and R. P. Mauldin

2003a Royal Coachman (41CM111) An Early Middle Archaic Site along Cordova Creek in Comal County, Texas. Archaeological Survey Report, No. 332. Center for Archaeological Research, The University of Texas at San Antonio.

Mahoney, R. B., S. A. Tomka, R. P. Mauldin, H. J. Shafer, L. C. Nordt, R. D. Greaves, and R. R. Galdeano,

2003b Data Recovery Excavations at 41MM340, A Late Archaic Site Along Little River in Milam County, Texas. Archaeological Survey Report, No. 340. Center for Archaeological Research, The University of Texas at San Antonio.

Mahoney, R. B., S. A. Tomka, J. D. Weston, and R. P. Mauldin

2002 Camp Maxey IV: Archaeological Testing of Six Sites, Lamar County, Texas. Archaeological Survey Report, No. 326. Center for Archaeological Research, The University of Texas at San Antonio.

Mauldin, R.

n.d. Analysis of Lithic Material from 41BX271 (Granberg Site). Manuscript on file, Center for Archaeological Research, The University of Texas at San Antonio.

2004 A Proposal for Data Recovery at Site 41PR44, Fort Wolters, Texas. Manuscript on file, Center for Archaeological Research, The University of Texas at San Antonio. 
Mauldin, R. P., T. Graves, and M. Bentley

1998 Small sites in the Central Hueco Bolson: A Final Report on Project 90-11. Conservation Division, Directorate of Environment, United States Army Air Defense Artillery Center, Fort Bliss, Texas.

Mauldin, R. P. and L. Kemp

2005 An Initial Summary of Bison Presence/Absence associated with Data Recovery at 41ZV202. Manuscript on file, Center for Archaeological Research, The University of Texas at San Antonio.

Mauldin, R. P., and D. L. Nickels

2001 An Archaeological Survey of Twin Buttes Reservoir, Tom Green County, Texas. Archaeological Survey Report, No. 300. Center for Archaeological Research, The University of Texas at San Antonio.

Mauldin, R. P., D. L. Nickels, and C. J. Broehm

2003 Archaeological Testing to Determine the National Register Eligibility Status of 18 Prehistoric Sites on Camp Bowie, Brown County, Texas. Vol I and II. Archaeological Survey Report, No. 334. Center for Archaeological Research, The University of Texas at San Antonio.

Mauldin, R. P., J. L. Thompson, and S. A. Tomka

2006 Theoretical Overview. In Data Recovery at 41KM69, Flatrock Road Site in Junction, Kimble County, Texas, by Jennifer L. Thompson. Manuscript on file, Center for Archaeological Research, The University of Texas at San Antonio.

Mauldin, R. P., S. A. Tomka, and H. J. Shafer

2004 Millican Bench (41TV163): A Multicomponent Site in Travis County, Texas. Archaeological Survey Report, No. 351. Center for Archaeological Research, The University of Texas at San Antonio.

McClean, R. G., and W. F. Kean

1993 Contributions of Wood Ash Magnetism to Archeomagnetic Properties of Fire Pits and Hearths. Earth and Planetary Science Letters 119:387-394.

McDonald, J. N.

1981 North American Bison, Their Classification and Evolution. University of California Press, Berkeley.

Moerman, D.

2005 North American Ethnobotany: A Database of Foods, Drugs, Dyes and Fibers of Native American Peoples, Derived from Plants. Electronic database, http://herb.umd.umich.edu/, accessed January 2006. Dearborn College of Arts and Sciences, University of Michigan.

Montgomery, J.

1978 The Mariposa Site: A Late Prehistoric Site on the Rio Grande Plain of Texas. Volume 2: Studies in the Archaeology of Chaparossa Ranch. Special Report No. 6, Center for Archaeological Research, The University of Texas at San Antonio.

National Climate Data Center (NCDC)

2003 Precipitation Data, Weatherford, Texas. Global Historical Climatology Network (GNCN). Electronic database, $<$ http:// climvis.ncdc.noaa.gov/cgi-bin/ghcn/precip.ghencgi>, accessed July 2003. 
Nickels, D.L., C. B. Bousman, J. D. Leech, and D. A. Cargill,

1997 Test Excavations at the Culebra Creek Site, 41BX126, Bexar County, Texas. Archaeological Survey Report, No. 265. Center for Archaeological Research, The University of Texas at San Antonio.

Nickels, D. and R. Mauldin

2001 The Project Environment. In An Archaeological Survey of Twin Buttes Reservoir, Tom Green County, Texas, edited by Raymond Mauldin and David L. Nickels, pp. 25-38. Archaeological Survey Report, No. 300, Center for Archaeological Research, The University of Texas at San Antonio.

Owen, J. G.

1988 On Productivity as a Predictor of Rodent and Carnivore Diversity. Ecology 69(4):1161-1165.

1990 An Analysis of the Spatial Structure of Mammalian Distribution Patterns in Texas. Ecology 71(5):1823-1832.

Owen, J. G. and D. J. Schmidly

1986 Environmental Variables of Biological Importance in Texas. The Texas Journal of Science 38:99-117.

Paruelo, J. M. and W. K. Lauenrooth

1996 Relative Abundance of Plant Functional Types in Grasslands and Shrublands of North America. Ecological Applications 6(4):1212-1224.

Perttula, T. K.

1995 The Archeology of the Pineywoods and Post Oak Savanna of Northeast Texas. Bulletin of the Texas Archeological Society 66:331-359.

2004 An Introduction to Texas Prehistoric Archaeology. In The Prehistory of Texas, edited by Timothy K. Perttula, pp. 5-13. Texas A\&M Press, College Station.

Prikryl, D. J.

1990 Lower Elm Fork Prehistory: A Redefinition of Cultural Concepts and Chronologies along the Trinity, North Central Texas. Report No. 37. Office of the State Archeologist, Texas Historical Commission, Austin.

Quigg, M. J.

1997 The Sanders Site (41HF128) A Single Event Late Archaic Camp/Bison Processing Site Hansford County, Texas. Technical Report No. 19751. TRC Mariah Associates Inc., Austin.

Quigg, J. M. and C. Cordova

1999 Archaeological Investigations at Upland Sites 41ZP39 and 41ZP176 for TransTexas Gas Well Site USA \#3 Falcon Reservoir, Zapata County, Texas. Technical Report No. 22347. TRC Mariah Associates Inc., Austin.

Quigg, M. J., C. Lintz, G. Smith and S.Wilcox

2000 The Lino Site: A Stratified Late Archaic Campsite in a Terrace of the San Idelfonzo Creek, Webb County, Southern Texas. Technical Report No. 23756. TRC Mariah Associates Inc., Austin.

Quigg, M. J. and J. Peck

1995 The Rush Site (41TG346) A Stratified Late Prehistoric Locale in Tom Green County, Texas. Technical Report No. 816C. TRC Mariah Associates Inc., Austin. 
Quigg, J. M., J. Peck, C. Lintz, A. C. Treece, C. D. Frederick, R. Clem, G. Lain Ellis, P. Schuchert and J. T. Abbott 1996 Early Archaic Use of the Concho River Terraces: Cultural Resources Investigations at 31 TG307 and $41 T G 309$ Tom Green County, San Angelo, Texas. Texas Department of Antiquities Technical Report No. 11058. TRC Mariah Associates Inc., Austin.

Quigg, J. M., S. Pritchard, and G. Smith

2002 The Boiler Site (41WB557): Utilization of an Upland Setting Over the Last 4200 Years, Webb County, Texas. Technical Report No. 27277. TRC Mariah Associates Inc., Austin. Archeological Studies Program, Report 45. Environmental Affairs Division, Texas Department of Transportation, Austin.

Ramsey, C. B.

2003 OxCAL Radiocarbon Calibration Program. Version 3.9 Radiocarbon Accelerator Unit, University of Oxford. Oxford, England.

Reynolds, R. L., and J. W. King

1995 Magnetic Records of Climate Change. U.S. National Report to I.U.G.G., 1991-1994. American Geophysical Union. Electronic document, <http://www.agu.ong/revgeophys/reyno100/reyno100.html>, accessed April 2001.

Rogers, R. and S. Kotter

1995 Archaeological Investigations at the Chesser Site (41LE59) Lee County, Texas. Document No. 950209. PBS\&J, Austin.

Scott, A. M., K. W. Kibler, and M. E. Blake

2002 National Register Testing of Nine Archeological Sites at Waco Lake, McLennan County, Texas. Reports of Investigations, No. 132. Prewitt and Associates, Inc., Austin.

Simms, S.

1987 Behavioral Ecology and Hunter-Gatherer Foraging: An Example from the Great Basin. British Archaeological Reports, International Series 381. Oxford, England.

Singer, M. J., and P. Fine

1989 Pedogenic Factors Affecting Magnetic Susceptibility of Northern California Soils. Soil Science of America Journal 53:1119-1127.

Skinner, S. A.

1981 Cultural Resource Survey of Fort Wolters. Report 82-7. Environmental Conservation, Inc., Dallas.

Soil Survey Staff

1993 Soil Survey Manual. U.S. Department of Agriculture Handbook No. 18. U.S. Department of Agriculture. U.S. Government Printing Office, Washington, D.C.

Southern Regional Climate Center (SRCC)

2003a Normal Monthly Precipitation. Electronic document, $<$ http://www.srcc.lsu.edu/7100/prcp/TX.html $>$, accessed July 2003.

2003b Normal Daily Minimum Temperature. Electronic document, <http://www.srcc.lsu.edu/7100/tmin/USMap. html>, accessed February 2003. 
2003c Normal Daily Maximum Temperature. Electronic document, <http://www.srcc.lsu.edu/7100/tmax/TX.html>, accessed July 2003.

Speth, J. D., and K. A. Spielmann

1983 Energy source, protein metabolism and hunter-gatherer subsistence strategies. Journal of Anthropological Archaeology 2:1-31.

\section{SSURGO}

2006 SSURGO Soils Database, Parker County. Texas Strategic Mapping Program. Texas Natural Resources Information System, Texas Water Development Board, Austin.

Stephens, D. W., and J. R. Krebs

1987 Foraging Theory. Princeton University Press, Princeton, New Jersey.

Suhm, D. A. and E. B. Jelks

1954 An Introductory Handbook of Texas Archeology. Bulletin of the Texas Archeological Society 25.

Takac, P. R., and W. A. Gose

1998 Magnetic Susceptibility of Sediments. In Wilson-Leonard. An 11,000-year Archeological Record of Hunter-Gatherers in Central Texas. Volume IV: Archeological Features and Technical Analyses, assembled and edited by M. B. Collins, pp.1329-1341. Studies in Archeology 31. Texas Archeological Research Laboratory, University of Texas at Austin. Archeology Studies Program, Report 10. Environmental Affairs Division, Texas Department of Transportation, Austin.

Teeri, J. A., and L. G. Stowe

1976 Climatic Pattern and the Distribution of $\mathrm{C}_{4}$ Grasses in North America. Oecologia 23:1-12.

Tennis, C. L., with contributions by R. J. Hard, C. B. Bousman, L. C. Nordt, and W. Gose

1996 Archaic Land Use of Upper Leon Creek Terraces: Archaeological Testing in Northern Bexar County, Texas. Archaeological Survey Report, No. 234. Center for Archaeological Research, The University of Texas at San Antonio.

Texas Army National Guard

2002 Integrated Cultural Resources Management Plan. Manuscript on file, Environmental Branch, Camp Mabry, Austin.

Thoms, A. V.

1994 The Valley Branch Archaeological Project: Excavations at an Archaic Site (41MU55) in the Cross Timbers Uplands, North Central Texas. Reports of Investigations No. 15. Archaeological Resources Laboratory, Texas A\&M University, College Station.

Tomka, S. A., and R. C. Fields

1990 Chipped Stone Artifacts, 41LN29A and 41LN106. Chapter 9 in Excavations at the Charles Cox, Lambs Creek Knoll, and Buffalo Branch Sites, Jewett Mine Project, Leon and Freestone Counties, Texas, Vol. I, edited by R. C. Fields, pp. 141-287. Report of Investigations, No. 70. Prewitt and Associates, Inc., Austin.

Tomka, S. A. and R. C. Robinson

2000 The McAllister Park Roadway System Extension Project, San Antonio, Texas. Archaeological Survey Report, No. 301. Center for Archaeological Research, The University of Texas at San Antonio. 
Tomka, S. A. and R. P. Mauldin

2003 Subsistence Strategies. In Data Recovery Excavations at 41MM340, A Late Archaic Site Along Little River in Milam County, Texas, by R. B. Mahoney, S. A. Tomka, R. P. Mauldin, H. J. Shafer, L. C. Nordt, R. D. Greaves, and R.R. Galdeano, pp. 109-118. Archaeological Survey Report, No. 340. Center for Archaeological Research, The University of Texas at San Antonio.

Tomka, S. A., R. P. Mauldin, and R. D. Greaves

2004b Late Prehistoric and Late Archaic Subsistence Practices: A Comparative Analysis. Chapter 7 in Millican Bench (41TV163) A Multicomponent Site in Travis County, Texas. Archaeological Survey Report, No. 351, Center for Archaeological Research, The University of Texas at San Antonio. Archeological Studies Program, Report 66, Environmental Affairs Division, Texas Department of Transportation, Austin.

Treece, A. C., C. Lintz, W. N. Trierweiler, J. M. Quigg, and K. A. Miller

1993 Cultural Resource Investigations in the O. H. Ivie Reservoir, Concho, Coleman, and Runnels Counties, Texas: Volume IV: Data Recovery from Ceramic Sites. Technical Report, No. 346-IV. TRC Mariah Associates Inc., Austin.

Trierweiler, W. N.

1994 Archeological Investigations on 571 Prehistoric Sites at Fort Hood, Bell and Coryell Counties, Texas. United States Army Fort Hood Archeological Resource Management Series Research Report No. 31. TRC Mariah Associates Inc., Austin.

Turner, S. E., and T. R. Hester

1999 A Field Guide to Stone Artifacts of Texas Indians. 3d ed. Gulf Publishing Co., Houston, Texas.

\section{USGS}

2006 Annual Mean Stramflow in $\mathrm{Ft}^{3} / \mathrm{s}$ for Brazos River near Dennis, Texas. Electronic document, $<$ http://nwis.waterdata.usgs.gov/tx/nwis/inventory/?site_no=08090800>, accessed July 2006.

Vierra, B. J.,

1998 41MV120: A Stratified Late Archaic Site in Maverick County, Texas. Archaeological Survey Report, No. 251. Center for Archaeological Research, The University of Texas at San Antonio.

Wade, M.

1998 The Native Americans of the Texas Edwards Plateau and Related Areas, 1582-1799. Unpublished Ph.D. dissertation, The University of Texas at Austin.

Wandsnider, L.

1997 Roasted and the Boiled: Food Composition and Heat Treatment with Special Emphasis on Pit-Hearth Cooking. Journal of Anthropological Archaeology 16:1-48.

Winterhalder, B.

1981 Optimal Foraging Strategies and Hunter-Gatherer Research in Anthropology: Theory a Models. In Hunter-Gatherer Foraging Strategies: Ethnographic and Archaeological Analyses, edited by B. Winterhalder and E. A. Smith, pp. 13-35. The University of Chicago Press, Chicago.

Wormser, A. J. and S. S. Strickland

2003 Archeological Investigations at Site 41WD468/41WD469 Along SH182 at Lake Fork Creek, Wood County, Texas. Archeological Studies Program, Report 47. Environmental Affairs Division, Texas Department of Transportation, Austin. 
Young, W. C.

1981 The Tankersley Creek Site, Titus County, Texas. Publications in Archaeology Report No. 22. Texas State Department of Highways and Public Transportation Highway Design Division, Austin.

1985 Archaeological Excavations at Site 41BT6 Burnet County, Texas. Publications in Archaeology Report No. 28. Texas State Department of Highways and Public Transportation Highway Design Division, Austin. 

Appendix A

\section{Radiocarbon Results}


FROM: Darden Hood, Director (mailto:mailto:dhood@radiocarbon.com)

(This is a copy of the letter being mailed. Invoices/receipts follow only by mail.)

September 12, 2005

Dr. Raymond Mauldin

University of Texas at San Antonio

Center for Archaeological Research

6900 North Loop 1604 West

San Antonio, TX 78249

USA

RE: Radiocarbon Dating Result For Sample 41PR44-294-1

Dear Ray:

Enclosed is the radiocarbon dating result for one sample recently sent to us. It provided plenty of carbon for an accurate measurement and the analysis went normally. As usual, the method of analysis is listed on the report sheet and calibration data is provided where applicable.

As always, no students or intern researchers who would necessarily be distracted with other obligations and priorities were used in the analysis. It was analyzed with the combined attention of our entire professional staff.

If you have specific questions about the analyses, please contact us. We are alway s available to answer your questions.

Our invoice has been sent separately. Our copy is enclosed. Thank you for your prior efforts in arranging payment. As always, if you have any questions or would like to discuss the results, don't hesitate to contact me.

incerely,

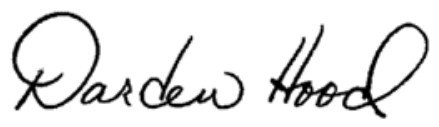


Dr. Raymond Mauldin

Report Date: 9/12/2005

University of Texas at San An tonio

Material Received: 8/9/2005

\begin{tabular}{|c|c|c|c|}
\hline Sample Data & $\begin{array}{c}\text { Measured } \\
\text { Radiocarbon Age }\end{array}$ & $\begin{array}{c}13 \mathrm{C} / 12 \mathrm{C} \\
\text { Ratio }\end{array}$ & $\begin{array}{c}\text { Conventional } \\
\text { Radiocarbon Age }\left(^{*}\right)\end{array}$ \\
\hline $\begin{array}{l}\text { Beta - } 207517 \\
\text { SAMPLE : 41PR44-294-1 } \\
\text { ANALYSIS : AMS-Standard c } \\
\text { MATERIAL/PRETREATMEI } \\
2 \text { SIGMA CALIBRATION : }\end{array}$ & $\begin{array}{l}3340+/-40 \text { BP } \\
\text { material): acid/alkali/a } \\
1690 \text { to } 1500 \text { (Cal BP } 3\end{array}$ & $-26.7 \mathrm{o} / \mathrm{oo}$ & $3310+/-40 \mathrm{BP}$ \\
\hline
\end{tabular}




\section{CALIBRATION OF RADIOCARBON AGE TO CALENDAR YEARS}

(Variables: $\mathrm{C} 13 / \mathrm{C} 12=-26.7: 1 \mathrm{ab}$. mult $=1$ )

Laboratory number: Beta-207517

Conventional radiocarbon age: $3310 \pm 40 \mathrm{BP}$

2 Sigma calibrated result: Cal BC 1690 to 1500 (C al BP 3640 to 3460) (95\% probability)

In tercept data

Intercept of radiocarbon age

with calibration curve: Cal BC 1600 (Cal BP 3550)

1 Sigma calibrated result: Cal BC 1630 to 1520 (Cal BP 3580 to 3470 )

(68\% probability)

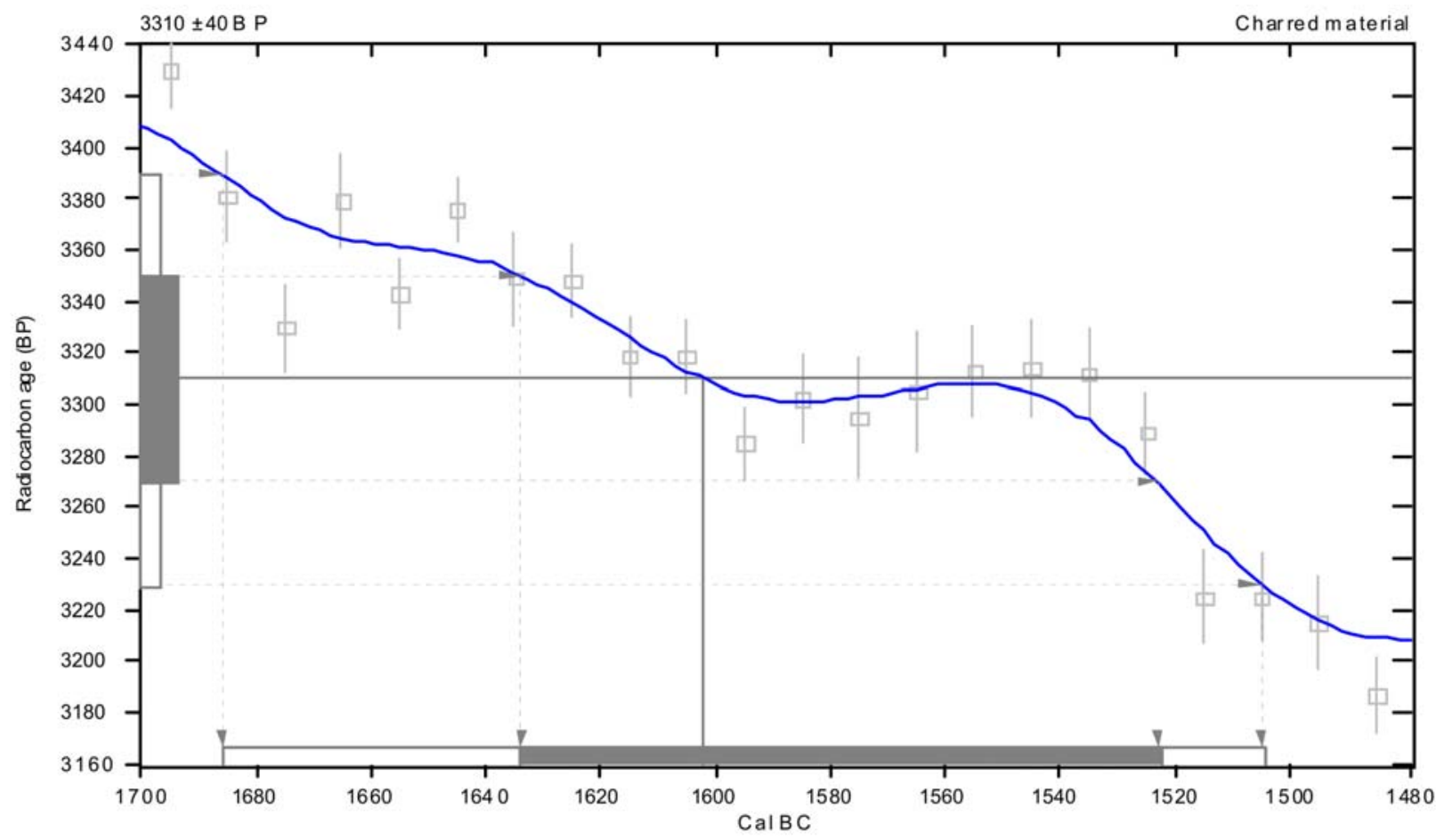

References:

Database used

INTC AL 98

Calibration Database

Editorial Com m ent

Stui ver, M., van de $r$ Plicht, $H_{,}, 1998$, Radi oc ar bon 40( 3), pxii-xi ii

INTCAL 98 Radiocarbon Age Cal ibration

Stuiver, M., et. al., 1998, Radiocarbon 40(3), p1041-1083

Mathe matics

A Sim pl ified Approach to Calibrating C14 Dates

Talma, A. S., Vogel, J. C., 1993, Radiocarbon 35(2), p317-322

Beta Analytic Radiocarbon Dating Laboratory

4985 S.W.74th Court, Miami, Florida33155.Tel: (305)667-5167·Fax: (305)663-0964・E-Mail: beta@radiocarbon.com 


\title{
Appendix B
}

\section{Vertebrate Faunal Remains}

\author{
by Barbara A. Meissner
}




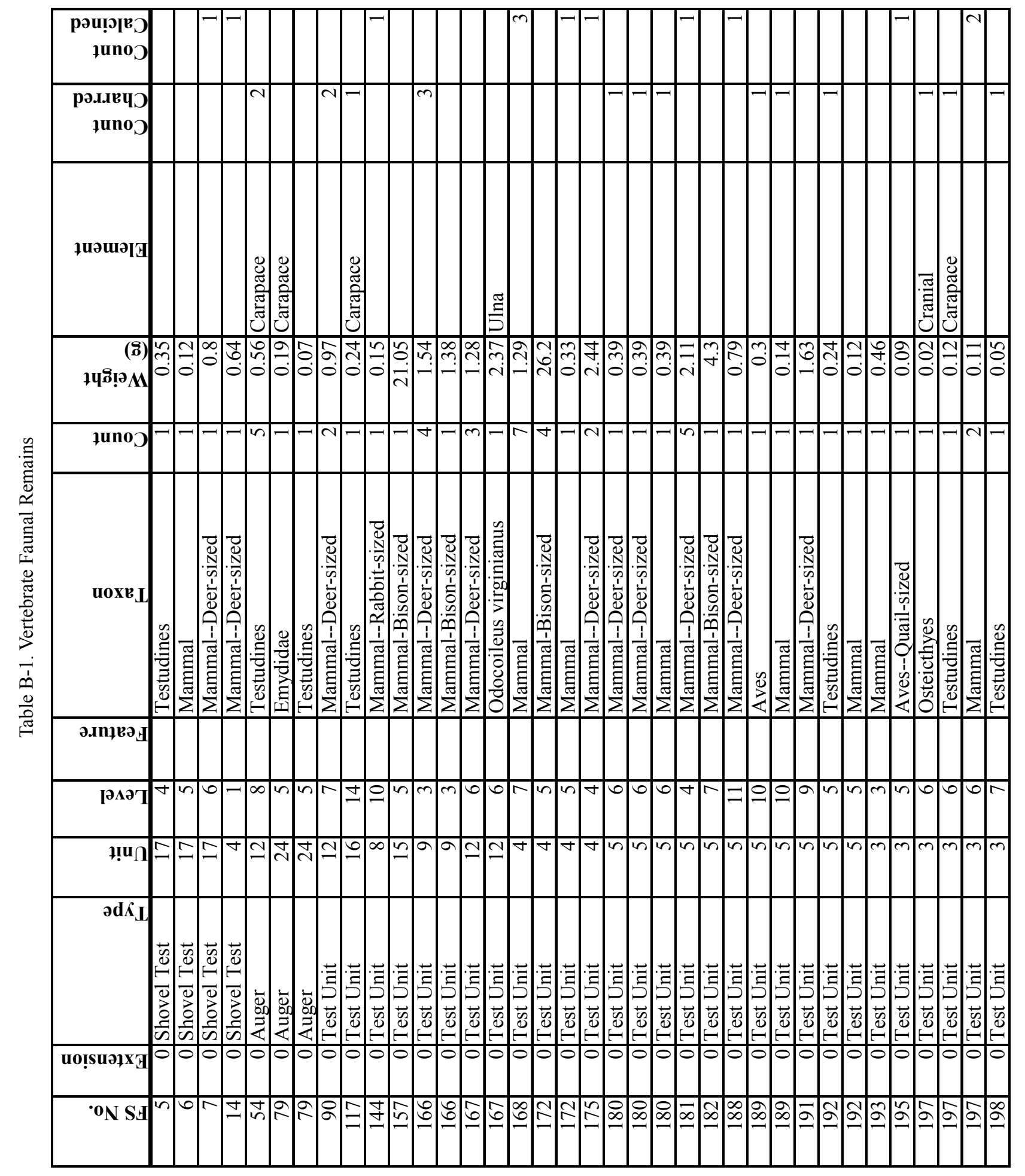




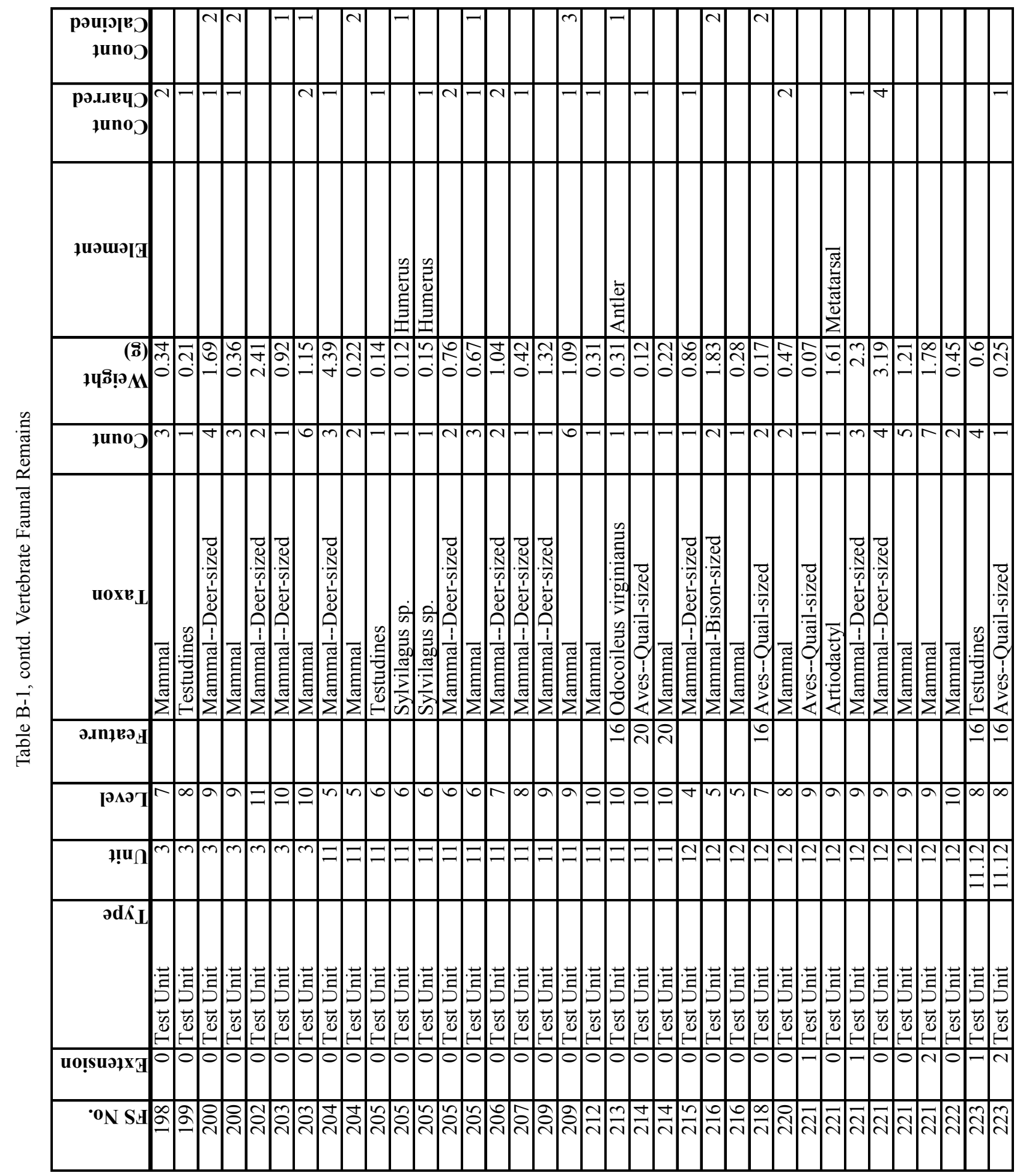




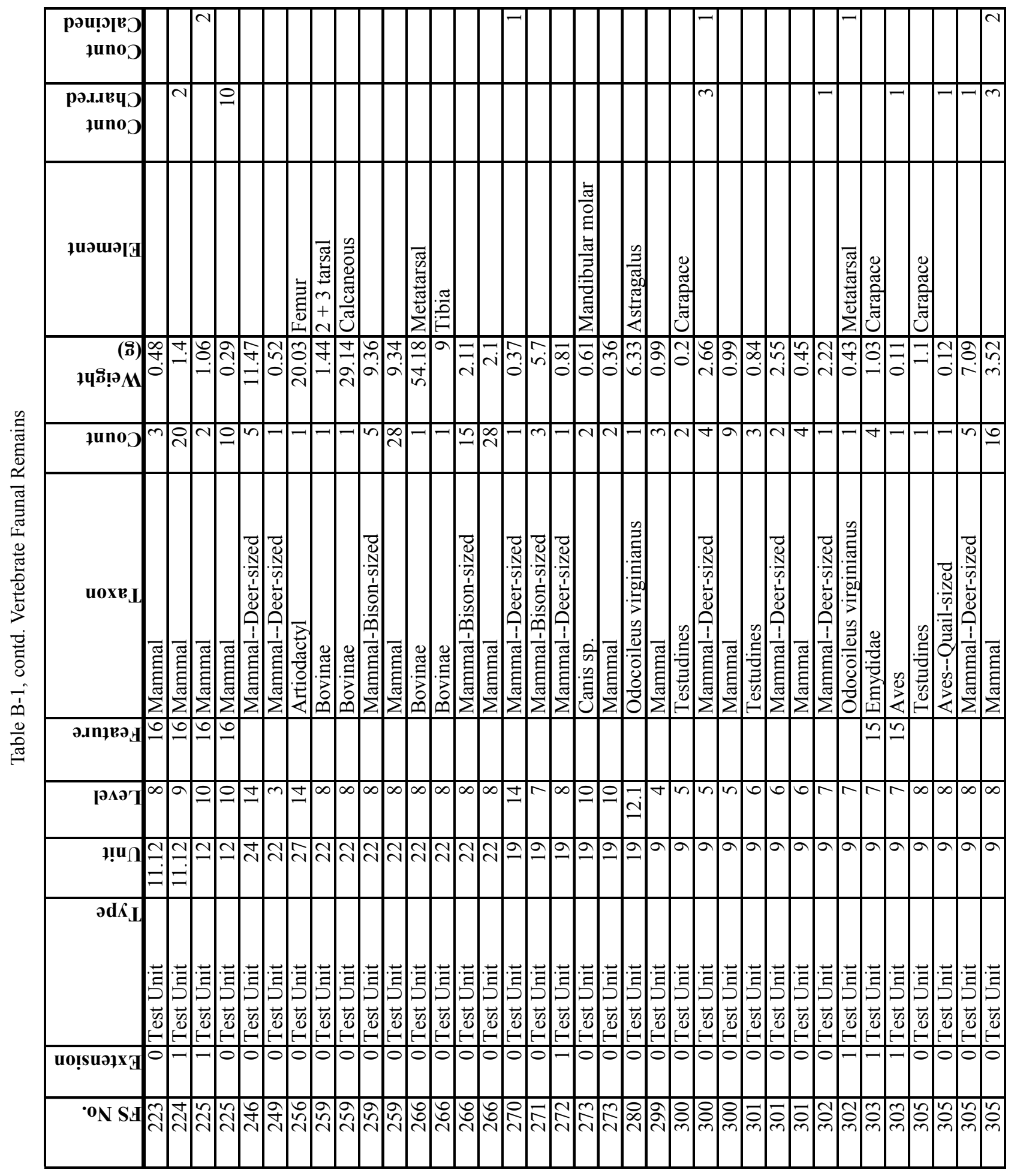




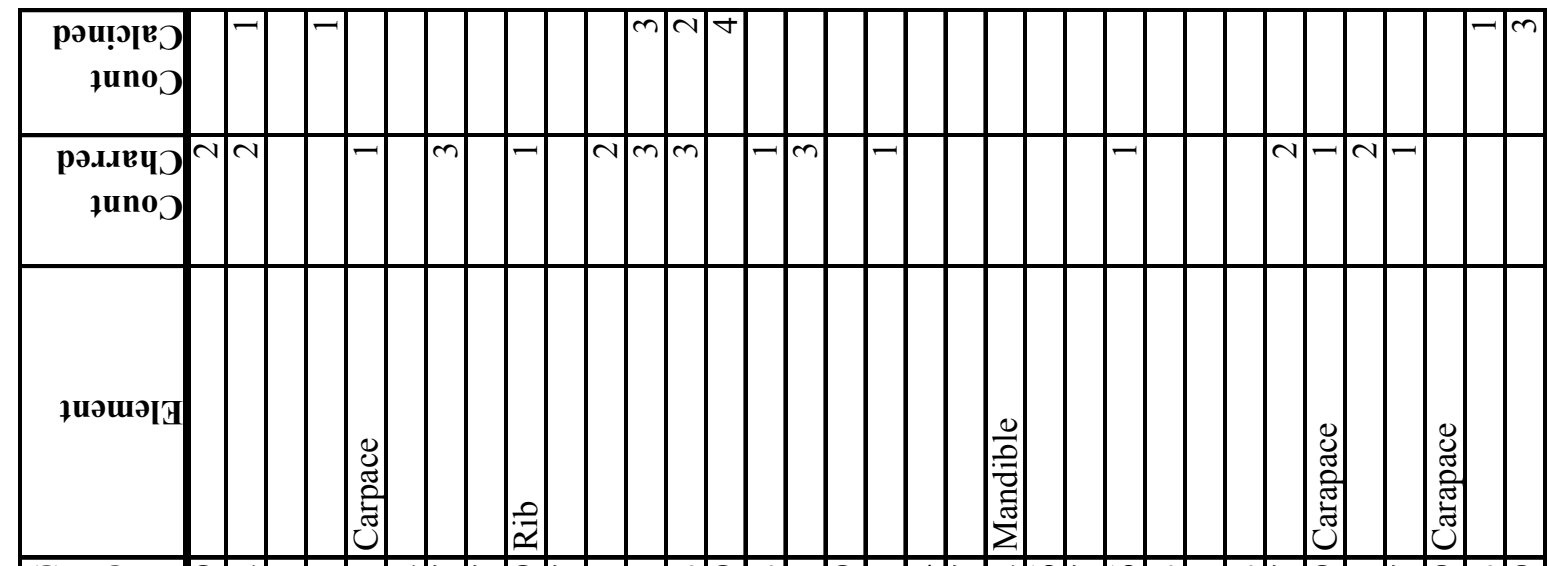

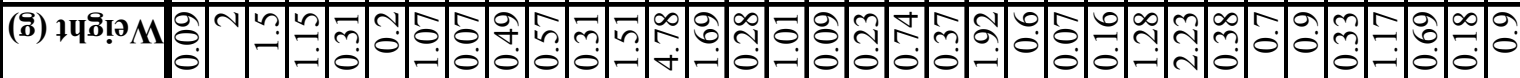

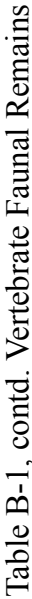

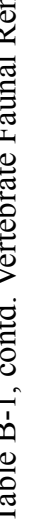

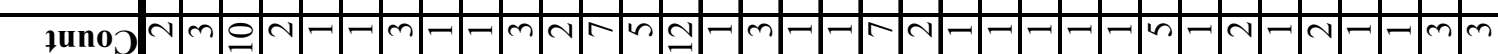
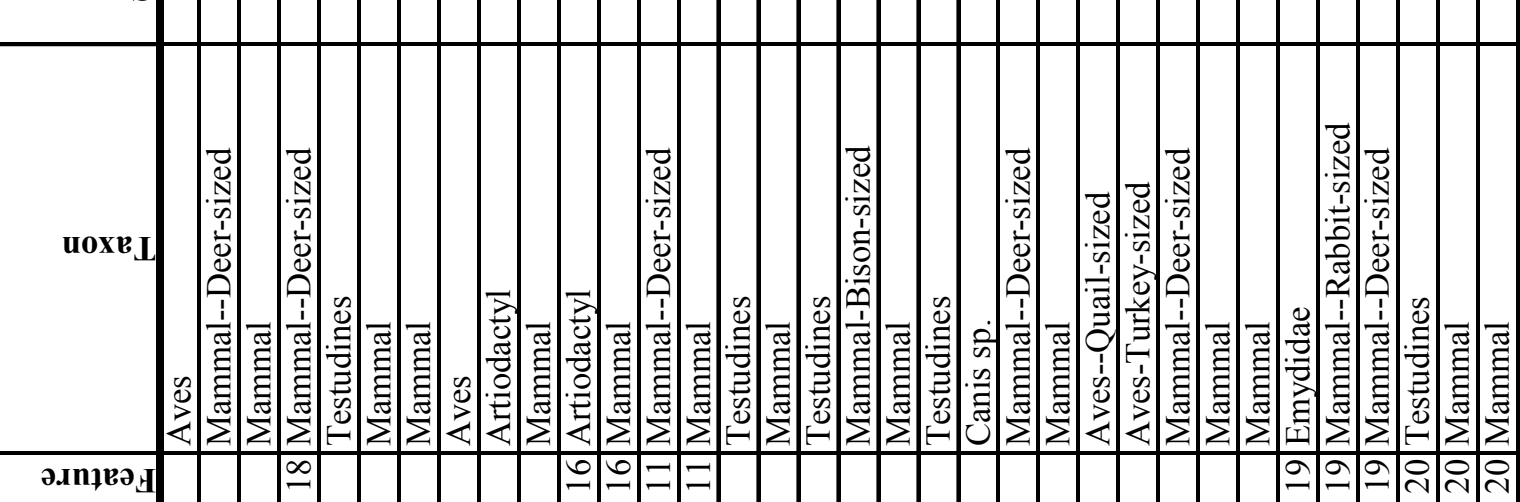

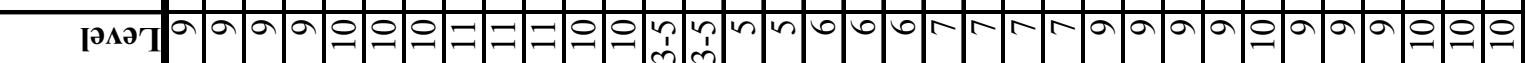

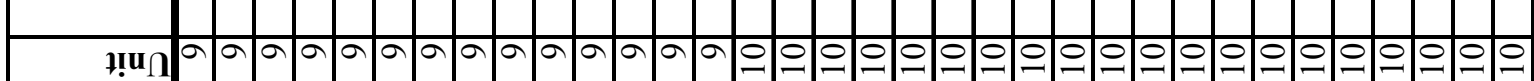

$\operatorname{\partial d} \hat{K}_{\mathbf{I}}$

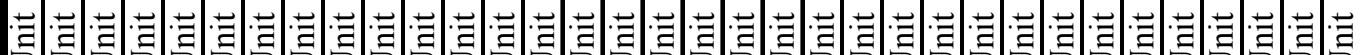

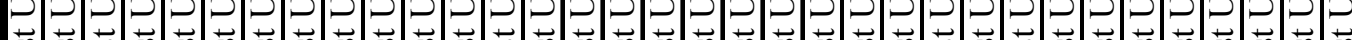

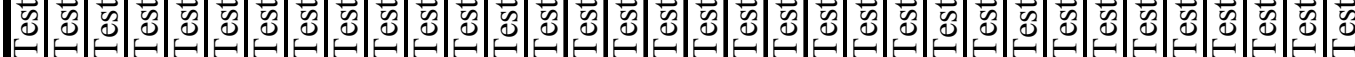
иoIsuдx

'ON SU 

Appendix C

\section{Flotation Summaries}


Soils samples were collected from the three features identified as thermal, burned rock features in Chapter 10. Each sample was then processed at the Center for Archaeological Research using the following procedures. For each sample, the volume of soil measured was recorded. The flotation procedure used relied on forced water, with the sample suspended by a fine-meshed screen inside a 55 gallon drum. Continuous water inflow from the bottom of the drum, below the sample, is then used to float any lighter material, including any carbonized matter, off into a tightly woven cheese cloth. Once the sediment sample is dissolved in the water (ca.. 1 to 5 minutes depending on the nature and size of the sample), the water inlet is turned off, and the screen insert is removed from the drum. The light fraction, collected in the cheese cloth, allowed to dry for a minimum of 24 hours, and eventually transferred to a plastic bag. The heavy fraction, collected in the screen insert, is transferred to cloth and also allowed to dry. The dried heavy fraction was also placed into a plastic bag. The procedure has been tested on known quantities of carbonized material, including burned poppy seeds and larger items of wood charcoal. Wood charcoal recovery was excellent, with only minor breakage of material and, as far as could be determined, all material recovered. Burned poppy seeds were recovered at rates exceeding $90 \%$.

Seven different samples were processed from features at 41PR44 using the previously described methods. Following those procedures, the heavy fraction from each sample was examined and any chipped stone, bone, or shell collected. Sandstone and limestone rock less than $1 / 2$ in. in maximum size was present in all heavy fraction samples but not collected. The light fraction from each sample was examined under low power magnification for any charred material. As shown in Table C-1, recovery from both the light and heavy fractions was minimal. Given the low recovery rates, no additional analysis was undertaken.

Table C-1. Light and Heavy Fraction Recovery from Water-Screening

\begin{tabular}{|c|c|c|c|c|c|c|c|c|c|c|}
\hline \multirow[b]{2}{*}{$\begin{array}{l}\text { FS } \\
\text { No. }\end{array}$} & \multirow[b]{2}{*}{$\begin{array}{c}\text { Feature } \\
\text { No. }\end{array}$} & \multirow[b]{2}{*}{$\begin{array}{c}\text { Sample } \\
\text { Size }\end{array}$} & \multicolumn{4}{|c|}{ Light Fraction Recovery } & \multicolumn{4}{|c|}{ Heavy Fraction Recovery } \\
\hline & & & $\begin{array}{c}\text { Carbonized } \\
\text { Material }\end{array}$ & $\begin{array}{l}\text { Shell/ } \\
\text { Bone }\end{array}$ & $\begin{array}{c}\text { Chipped } \\
\text { Stone }\end{array}$ & Other & $\begin{array}{c}\text { Carbonized } \\
\text { Material }\end{array}$ & $\begin{array}{l}\text { Shell/ } \\
\text { Bone }\end{array}$ & $\begin{array}{c}\text { Chipped } \\
\text { Stone }\end{array}$ & Other \\
\hline 321 & 12 & $1.9 \mathrm{~L}$ & 0 & 0 & 0 & 0 & 0 & 0 & 1 & 0 \\
\hline 322 & 12 & $1.8 \mathrm{~L}$ & 0 & 0 & 0 & 0 & 0 & 0 & 1 & 0 \\
\hline 323 & 12 & $5.8 \mathrm{~L}$ & 1 & 0 & 0 & 0 & 0 & 0 & 0 & 0 \\
\hline 324 & 20 & $2.0 \mathrm{~L}$ & 0 & 0 & 0 & 0 & 0 & 2 & 0 & 0 \\
\hline 325 & 21 & $2.0 \mathrm{~L}$ & 0 & 0 & 0 & 0 & 0 & 3 & 0 & 0 \\
\hline 326 & 21 & $2.0 \mathrm{~L}$ & 0 & 0 & 0 & 0 & 0 & 1 & 0 & 0 \\
\hline 327 & 21 & 3.7 & 0 & 0 & 0 & 0 & 0 & 0 & 0 & 0 \\
\hline
\end{tabular}




\section{Appendix D}

Memorandum of Agreement for Recovery of Significant Information from Archeological Site 41PR44, Ft. Wolters, Mineral Wells, Parker County, Texas 


\title{
MEMORANDUM OF AGREEMENT FOR RECOVERY OF SIGNIFICANT INFORMATION FROM ARCHEOLOGICAL SITE 41PR44, FT. WOLTERS, MINERAL WELLS, PARKER COUNTY, TEXAS
}

\author{
among the \\ Texas Military Forces (Texas National Guard) \\ National Guard Bureau/Army Directorate, and the \\ Texas State Historic Preservation Office
}

\author{
UNDERTAKING: Archeological Data Recovery for 41PR44 \\ STATE: $\quad$ Texas (Parker County) \\ AGENCY: $\quad$ Texas Military Forces (Texas National Guard)
}

WHEREAS, the National Guard Bureau (NGB) is the federal agency that provides funding and assists the Texas Military Forces (TXMF), a state agency, in fulfilling its federal mission; and

WHEREAS, mission critical military training activities may adversely affect prehistoric archaeological site 41PR44 at Fort Wolters; and

WHEREAS, the TXMF in consultation with the State Historic Preservation Officer (TXSHPO) determined in March 2001 that site 41 PR44, is eligible for inclusion in the National Register of Historic Places by virtue of the significant information they may yield about Texas prehistory and history.

WHEREAS, the consulting parties agree that it is in the public interest to expend funds to mitigate the adverse effects of military training at site 41PR44, through the recovery of significant information from archaeological sites; and

WHEREAS, the consulting parties agree that federally recognized Indian Tribes that may attach traditional religious or cultural importance to the affected properties have been consulted and have raised no objection to the work proposed (see attachment l); and

WHEREAS, the Advisory Council of Historic Preservation (ACHP) was notified of this undertaking and declined to participate in the consultation; and

WHEREAS, to the best of our knowledge and belief, no human remains, associated or unassociated funerary objects or sacred objects or objects of cultural patrimony as defined in the Native American Graves Protection and Repatriation Act (25) U.S.C. 3001), are expected to be encountered in the archaeological work proposed for site 41PRDY;

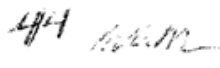


NOW, THEREFORE, the NGB and TXMF shall ensure that the following stipulations, for data recovery at Site 41PR44 will be implemented in a timely manner and with adequate resources in compliance with the National Historic Preservation Act of 1966 (16 U.S.C. 470$)$.

\section{STIPULATIONS:}

\section{Site 41PR44 Data Recovery Plan}

Because it has been determined by the TXMF and the TXSHPO that Site 41PR44 will be adversely affected by tank training, TXMF shall implement the attached Data Recovery Plan (Attachment II) developed in consultation with the TXSHPO, to mitigate the adverse effects of training on this historic property.

\section{Site Protection and Monitoring}

During the data recovery effort, the Fort Wolters Facility Manager shall take measures to ensure the protection of site 41PR44. The Facility Manager shall follow the guidance set forth and approved by the TXMF Facilities and Engineering Directorate (Attachment III).

\section{Professional Supervision}

TXMF shall ensure that all activities regarding archeology carried out pursuant to this Agreement are carried out by, or under the direct supervision of a person or persons meeting, at minimum, the Secretary of Interior's Professional Qualification Standards for Archeology (48 FR 44739).

\section{On site Visits by the TXSHPO}

In coordination with TXMF, the TXSHPO or his representative may visit the data recovery work in progress. The TXSHPO shall be notified in writing by TXMF of the proposed work schedule and any subsequent changes in work schedule for the data recovery investigations conducted at site 41PR44.

\section{Public Involvement}

Through consultation with the TXSHPO, it has been determined that local archeological societies (Tarrant County Archeological Society, Texas Archeological Society, e.g.) will be afforded the opportunity to comment on the investigations at site 41PR44. Information and documentation of this site will be available for their review and any concerns that may arise from this investigation will be taken into consideration by TXMF. 


\section{Involvement by Federally Recognized Indian Tribes}

In coordination with TXMF, representatives of the federally recognized Indian Tribes may visit the data recovery work in progress at site 41PR44.

\section{Recovery and Treatment of Human Remains and Associated Funerary Objects}

A. The federally recognized Indian Tribes, TXSHPO and TXMF (consulting parties) agree that the proper methods and treatments for handling human remains and funerary objects that may be found at site 41PR44, and for recording related information, are set forth in the Advisory Council on Historic Preservation's Recommended Approach for Consultation on the Recovery of Significant Information from Archaeological Sites, published in the Federal Register on May 18, 1999; and

B. The consulting parties agree that if an inadvertent discovery of human remains or cultural items should occur then TXMF would initiate NAGPRA consultations in accordance with 43 CFR 10.

C. Upon the discovery of human remains, excavation of the site shall cease and the remains left in situ. If the remains are discovered eroding from the site, the site shall be stabilized to prevent further erosion. TXMF representatives will contact the federally recognized Indian Tribes within three days of receiving written notification of the discovery of human remains from the TXMF's contractor. Excavation at the site shall not resume until the TXMF has developed a plan of action in consultation with the federally recognized Indian Tribes and provided the tribes with a copy of the plan of action.

\section{Curation of Artifacts and Records}

Following the analysis of all recovered artifacts and materials (i.e. notes, photographs, negatives, processed data, maps) from the data recovery excavations atsite 41PR44 by a qualified professional archeologist, TXMF will curate these materials at the Texas Archeological Research Laboratory (TARL) in accordance with 36 CFR 79.

\section{Draft Reports}

TXMF shall provide 1 (one) copy of the draft report of the data recovery investigations to the TXSHPO, 1 (one) copy each to the federally recognized Indian Tribes. The Draft report shall meet, in content and in form, the documentation standards in the Secretary of the Interior's Standards and Guidelines for Archeology and Historic Preservation.

\section{Final Reports}

TXMF shall provide 20 (twenty) copies of the final report of the data recovery investigations to the TXSHPO, 1 (one) copy each to the federally recognized Indian 
Tribes, 1 (one) copy to National Guard Bureau. All final reports shall meet, in content and in form, the documentation standards in the Secretary of the Interior's Standards and Guidelines for Archeology and Historic Preservation.

\section{Review of Draft and Final Reports}

Whenever a party to this Agreement is given the opportunity to review documents prepared pursuant to the terms of this Agreement, that party shall have 30 (thirty) days to conduct such review. Failure of the reviewing party to provide comments in accordance to this stipulation will be taken to indicate that the reviewing party has no comments on the pertinent document.

\section{OTHER TERMS AND CONDITIONS}

\section{Dispute Resolution}

A. Should any of the signatories object to any plans or documents provided by the TXMF or others for review pursuant to this agreement, or to any actions proposed or initiated by the TXMF pursuant to this agreement, the TXMF shall consult with the objecting party to resolve the objection. If the TXMF determines that the objection cannot be resolved, the TXMF shall forward all documentation relevant to the dispute to the NGB and Advisory Council.

Within thirty (30) days after receipt of all pertinent documentation, the Advisory Council will either:

(1) Provide the TXMF with recommendations, which the TXMF will take into account in reaching a final decision regarding the dispute; or

(2) Notify the TXMF that it will comment pursuant to 36 CFR $800.6(\mathrm{~b})$, and proceed to comment.

Any Advisory Council comment will be taken into account by the TXMF in accordance with 36 CFR 800.6(c)(2) with reference to the subject of the dispute.

B. Any recommendations or comment provided by the Advisory Council will pertain only to the subject of the dispute; the TXMF's responsibility to carry out all other actions under this agreement that are not the subjects of the dispute will remain unchanged.

C. At any time during implementation of the measures stipulated in this agreement by the TXMF, if an objection to any such measure or its manner of implementation is raised by interested persons, then the TXMF shall consider the objection and consult, as appropriate, with the objecting party, the SHPO, and the Advisory Council to attempt to resolve the objection. 


\section{Anti-Deficiency Act}

All requirements set forth in this MOA requiring expenditure of federal funds are expressly subject to the availability of appropriations and the requirements of the AntiDeficiency Act (31 USC Section 1341). No obligation undertaken by the TXMF under the terms of this MOA shall require or be interpreted to require a commitment to expend funds not appropriated for a particular purpose. If compliance with the Anti-Deficiency Act alters or impairs the TXMF's ability to implement the stipulations of this MOA, the TXMF will consult according to the amendment and termination procedures found a Stipulation I of this section.

\section{Termination of Memorandum of Agreement}

A. If the TXMF determines that it cannot implement the terms of this MOA, or if the SHPO or Council determines that the MOA is not being properly implemented, the TXMF, the SHPO, or NGB may propose to the other parties to this MOA that it be terminated.

B. The party proposing to terminate this MOA shall so notify all parties to this MOA, explaining the reasons for termination and affording them at least thirty days to consult and seek alternatives to termination.

C. Should such consultation fail and the MOA be terminated, the TXMF and NGB shall consult in accordance with 36 CFR Section 800.6 (c) (7) to develop a new MOA.

\section{Amendments to this Agreement}

Modification, amendment, or termination of this agreement as necessary shall be accomplished by the signatories in the same manner as the original agreement.

\section{Time Limit}

This agreement shall be null and void if its terms are not carried out within 5 (five) years from the date of its execution, unless the signatories agree in writing to an extension for carrying out its terms.

TXMF Official:

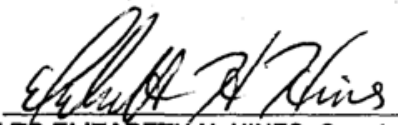

3hArgust 2004

LTC ELIZABETH H. HINES, Construction and Facilities Management Officer Date

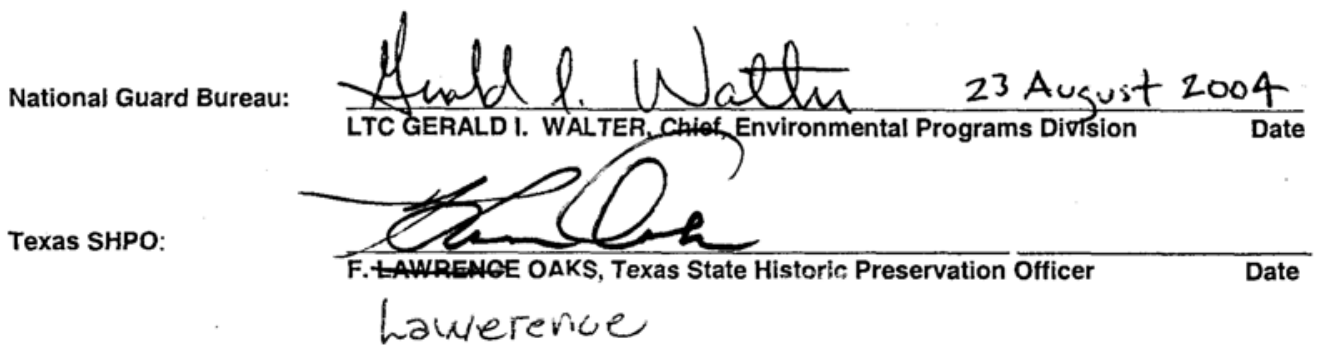

